

\section{Measurement Methods to Assess \\ Methane Production of Individual \\ Dairy Cows in a Barn}

Liansun $\mathrm{Wu}$ 


\section{Thesis committee}

\section{Promotor}

Prof. Dr P.W.G. Groot Koerkamp

Professor of Farm Technology

Wageningen University

\section{Co-promotor}

Dr N.W.M. Ogink

Researcher, Animal Sciences Group

Wageningen UR Livestock Research

\section{Other members}

Prof. Dr W.H. Hendriks, Wageningen University

Dr N. Peiren, Institute for Agricultural and Fisheries Research (ILVO), Melle, Belgium

Dr J. Lassen, Aarhus University, Tjele, Denmark

Dr R. van der Tol, Lely Industries N.V., Maassluis

This research was conducted under the auspices of the Graduate School of Wageningen Institute of Animal Science (WIAS) 


\title{
Measurement Methods to Assess Methane Production of Individual Dairy Cows in a Barn
}

\section{Liansun Wu}

\author{
Thesis \\ submitted in fulfilment of the requirements for the degree of doctor \\ at Wageningen University \\ by the authority of the Rector Magnificus \\ Prof. Dr A.P.J. Mol, \\ in the presence of the \\ Thesis Committee appointed by the Academic Board \\ to be defended in public \\ on Wednesday $11^{\text {th }}$ of May 2016 \\ at 4 p.m. in the Aula.
}


Liansun $\mathrm{Wu}$

Measurement methods to assess methane production of individual dairy cows in a barn, 190 pages.

$\mathrm{PhD}$ thesis, Wageningen University, Wageningen, NL (2016)

With references, with summary in English

ISBN: 978-94-6257-731-2 


\begin{abstract}
Mitigation of methane production from dairy cows is critical to reduce the dairy industry's contribution to the production of greenhouse gases. None of current used methane measurement methods are flawless and application of the methods is limited to assess the effects of methane mitigation methods under practical conditions. The main objective of this thesis is to design, test, and validate methods to determine or rank the methane production of individual dairy cows at farm house level.

As a start, I evaluated merits and drawbacks of existing methane measurement methods and discussed against 14 requirements of methane measurement methods to assess methane mitigation strategies. This review study revealed that none of existing methods meet all requirements, and pointed out that sampling of breath air during the lying period of cows in cubicles could be a practical direction to measure methane production of individual cows under farm conditions. Therefore, we first assessed methane concentration levels and variations in time, and around cubicles, explored effects of barn and management factors on them, and assessed the effect of the variation of the background methane concentrations on assessing methane production of individual dairy cows in cubicles. Then, we designed and constructed an artificial reference cow (ARC) that mimics the methane production of real cows with known pre-set methane production rates and dynamics of eructations. With the acquired background information and the developed ARC, we assessed the uncertainty of a breath methane concentration (BMC) method in a feeder and developed a cubicle hood sampler (CHS) that measures methane fluxes from lying cows in cubicles. The observed uncertainty related to random errors of the BMC method can be overcome by sufficient numbers of repetitions. However identified uncertainty with a systematic nature, related to inconsistent relation between concentration and production rate, cannot be compensated by repeated measurements and requires further investigation into the widely used BMC method before it can be used with confidence. Compared to the BMC method, the developed CHS is not subject to such systematic effects and allows prolonged measurement periods. Performance test under field conditions showed that the designed CHS accurately measured methane fluxes provided by the ARC.

Overall, in this thesis I assessed the measurement error of current three methane measurement principles (flux, breath concentration \& tracer gas), provided information to limit the measurement variation, and assessed the availability to determine or rank the methane production of individual dairy cows at farm house level. The newly developed ARC can be used as a known reference source to calibrate and develop practical methane measurement methods, and the CHS is sufficiently accurate to measure methane production of individual cows at farm house level.
\end{abstract}





\section{Contents}

Chapter $1 \quad$ General introduction $\quad 1$

Chapter 2 Evaluation of measurement principles to measure the methane 11 production of individual dairy cows on farm: a review

Chapter 3 Temporal and spatial variation of methane concentrations around lying cubicles in dairy barns

Chapter 4 Design and test of an artificial reference cow to simulate methane release through exhalation

Chapter $5 \quad$ Uncertainty assessment of a breath methane concentration method to determine methane production of dairy cows

Chapter 6 Design and evaluation of a methane flux measurement method for dairy cows in cubicles

Chapter $7 \quad$ General discussion and conclusions

References

Publication list

WIAS Training and Supervision Plan

Curriculum vitae 

CHAPTER 1

General introduction 


\section{Chapter 1}

\section{The greenhouse effect and the contribution of methane production from ruminants}

Since the observed increase in atmospheric temperature, much more attention is paid to the greenhouse effect of greenhouse gases. Greenhouse gases, carbon dioxide $\left(\mathrm{CO}_{2}\right)$, methane $\left(\mathrm{CH}_{4}\right)$, and nitrous oxide $\left(\mathrm{N}_{2} \mathrm{O}\right)$, have different impacts on the greenhouse effect. The Kyoto Protocol, which was adopted by the UNFCC member countries in 1997, forced to reduce overall emissions of such gases by at least 5\% below the 1990 levels in the commitment period 2008 to 2012 (UNFCC, 1997). National goals range from 8\% reduction for the European Union, also followed by Netherlands, which equals to 195 Mtonnes $\mathrm{CO}_{2}$. During the most recent UN Climate Change Conference in Paris, there was agreement on the longterm goal of keeping the increase in global average temperature to well below $2{ }^{\circ} \mathrm{C}$ above pre-industrial levels, which requires significant reduction of greenhouse gases reduction in coming years (UNFCC, 2016).

Obviously, most attention is paid to $\mathrm{CO}_{2}$ emission because of its contribution of about $60 \%$ to the anthropogenic greenhouse gas effect. However, nowadays more focus of research is transferring to methane emission, which equals to $20 \%$ of the total greenhouse effect. With the relatively short atmospheric lifetime (12 years as compared to 120 years of $\mathrm{CO}_{2}$ ), and 28 times the global warming potential of $\mathrm{CO}_{2}$ per gram (Myhre et al., 2013), the rate of climate change can be alleviated more effectively by reducing $\mathrm{CH}_{4}$ emission than by $\mathrm{CO}_{2}$. Overall, livestock activities contribute an estimated $14.5 \%$ to the total anthropogenic greenhouse gas emissions (Gerber et al., 2013), with large differences between countries and animal types. It was estimated that methane emission from dairy cows contributes $4 \%$ $( \pm 26 \%$, margin error) of anthropogenic greenhouse gas emissions (FAO, 2010). On average, a dairy cow produces 250 to 400 gram methane per day (Bannink et al., 2011), which is mainly emitted through the mouth and nose by exhalation and eructation (Murray et al., 1999; Lassey, 2007; Sejian et al., 2011).

The release of methane by dairy cows also represents a loss of energy for the animal. As a product of ruminal fermentation, methane is a cow's metabolic way to dispose of hydrogen that is produced during microbial metabolism. In disposing hydrogen, dairy cows lose $2-12 \%$ 


\section{General introduction}

of their gross energy intake, or 5-14\% of their digestible energy intake, in the process (Blaxter and Clapperton, 1965; Johnson and Johnson, 1995; Yan et al., 2010). If methane production in dairy cows could be reduced, then dairy cows would retain more energy that may potentially enhance their production and feed efficiency. Therefore, mitigating methane production from dairy cows will benefit not only the environment, but also the cows themselves. But one should be aware that such benefits for cows and farmers might be small. For instance, reduction of methane production by $10 \%$ can save $0.2-1.2 \%$ of dairy cows' energy loss, which may increase the milk production. Although such increasing may not be dramatic, farmers still get benefits by reducing methane production.

\section{Reduction strategies for enteric methane emission from cows}

Enteric methane from dairy cows can be mitigated through nutritional manipulations, farm management, and breeding animals with lower methane production (Cottle et al., 2011). Changes in diet composition may reduce methane production per unit feed by well over $60 \%$ (McGinn et al., 2006). Cattle ingesting a highly digestible grass produced relatively less methane than those ingesting more fibrous forage (Blaxter and Clapperton, 1965; Benchaar et al., 2001). A proper rotational grazing system can improve the quality of the land, promote the productivity, and reduce methane emission (DeRamus et al., 2003). Improvement of the feeding system can help to enhance the nutrition and increase the digesting efficiency (Cottle et al., 2011). Through breeding the genetic variation in methane production between individuals is used to reduce methane emissions (Hegarty, 2004; Bell et al., 2010; De Haas et al., 2011). Animal selection based on this individual variation could achieve $10-20 \%$ reduction in the methane losses from dry matter during digestion (Waghorn et al., 2006). While nutritional manipulation and farm management can immediately reduce methane production, breeding has gained more research interests because of its inexpensive, cumulative, and permanent effects (De Haas et al., 2011). To assess the effect of any methane mitigation method, including those related to breeding, we have to be capable of measuring the methane production from dairy cows. Measurement methods should meet requirements with regard to accuracy, number of animals included, representativeness for conditions (animal behaviour and farm management) and time 


\section{Chapter 1}

aspects (variations), practicalities (labour and technical aspects), and costs. These requirements will differ depending on goals and mitigation strategies.

\section{Existing techniques to measure methane production from individual cows}

Different methods are used to perform individual measurements, including the respiration chamber (Murray et al., 1999; Blaxter and Clapperton, 1965; Derno et al., 2009), $\mathrm{SF}_{6}$ tracer gas techniques (Grainger et al., 2007; Pinares-Patiño et al., 2008), the laser methane detector technique (LMD) (Chagunda and Yan, 2011; Chagunda et al., 2009), the breath methane concentration method (Garnsworthy et al., 2012), $\mathrm{CO}_{2}$ tracer gas method (Madsen et al., 2010), and the methane flux method, as exemplified by the GreenFeed system (Huhtanen et al., 2015; Dorich et al., 2015).

The respiration chamber is currently regarded as the reference method because of its accurate results. But the small and restricted space can modify cows' behaviour, reduce their feed intake, and induce variance factors. Meanwhile, it is time-consuming, and costly to apply such a method at large scale in practice. The $\mathrm{SF}_{6}$ technique is widely used in pastured dairy cows. This method is also costly and complex necessary arrangements limit its applied range, especially when large-scale application on dairy farms is considered. The LMD is a simple hand-held gas detector, which measures integrated concentrations of methane between the equipment and the target point. LMD appears to be a rapid measurement method to check the instant methane concentrations, but is not suitable to determine methane production.

The breath methane concentration method measures methane concentrations in a cow's breath air when the cow is visiting the milking robot or a feed station (Garnsworthy et al., 2012). The peak methane concentration is used to calculate a methane emission index. This index positively correlates with the daily methane production measured in a respiration chamber (Garnsworthy et al., 2012). The relation between the actual methane flux and the measured methane concentration mainly depends on how consistently the emitted methane is diluted before the breath air is sampled by the analyser, which can be affected by ambient airflow, cow's head movement, and breath volume. The $\mathrm{CO}_{2}$ tracer gas method uses the 


\section{General introduction}

$\mathrm{CO}_{2}$ production of dairy cows as a tracer gas. The measurement system is similar to that used in the breath methane concentration method. The $\mathrm{CH}_{4} / \mathrm{CO}_{2}$ concentration ratio is used to calculate the daily methane production by multiplying the ratio with the calculated daily $\mathrm{CO}_{2}$ production (Madsen et al., 2010). However, the uncertainty of the $\mathrm{CO}_{2}$ production model can be introduced into the predicted methane production.

Conversely, the GreenFeed method directly measures the actual methane fluxes emitted from the dairy cows when the cows visit a feed bin (C-lock, 2014; Hammond et al., 2015; Huhtanen et al., 2015). Although the GreenFeed measures methane fluxes from individual cows, Hammond et al. (2015) reported that the GreenFeed method could not detect the difference between cows in methane production due to limited measurement numbers and short sampling time for each cow, being restricted by the duration of feed bin visits.

To measure the methane production of individual dairy cows for any methane mitigation method, and especially those related to breeding strategies, measurement methods should not only meet the earlier mentioned requirements, but additionally must be applicable for a large number of cows at commercial farms. However, current methane-measuring techniques are limited either because of technical complexity and costs, or because of short sampling periods (Storm et al., 2012). Because of diurnal variations of methane production within cows, a representative sampling is needed to measure daily methane production of dairy cows. Given this, new measurement techniques need to be developed to widen the options to measure the methane production from individual cows under farm conditions, and more insight is needed in the performance in terms of measurement uncertainty of existing measurement methods, which leads to the main research question of this thesis: Which novel measurement methods can be developed for assessing the methane production of individual cows under barn conditions, and what is the performance in terms of measurement uncertainty of existing and novel measurement methods operated in dairy barns?

\section{Development of a methane measurement method}

To develop a new method, a reference method or gold standard is needed to assess the accuracy of the new method. Currently, the respiration chamber is used to validate the 


\section{Chapter 1}

measurement results of other methods. However, a respiration chamber is a timeconsuming and costly reference method to manage, and may produce biased results when compared to methane release under barn conditions. Considering these shortcomings, a more practical reference technique would be helpful in research efforts aimed at developing improved farm methods for measuring the methane production of cows. An alternative reference method is proposed that represents the methane production of dairy cows. This alternative method should precisely control an adjustable flux level and reflect the variations in time resulting from exhalation and eructation.

Besides the reference method, information on aerial conditions in barns is also required. Aerial conditions like air velocity and gaseous concentrations around the cows' lying area are highly variable in time and space and make it therefore challenging to capture all released methane from individual cows in barns. To develop a new methane measurement method applicable in a barn, knowledge of the levels and variability of different methane sources and methane concentrations around the cows is needed.

The methane production of individual cows is currently determined either by measuring emitted methane concentrations or by measuring methane fluxes. Recently developed measurement set-ups based on short-term monitoring of methane concentrations in the feeder of milking robots seem promising. This is a novel on-farm method that is easy to manage for a large number of cows. Yet, disturbing effects of airflow patterns, cows' head movement, breath frequency, and tidal volume on measured methane concentrations have not been studied. Such information is crucial to assess the performance of the breath methane measurement.

With the reference method and information on aerial conditions in the barn, a new methane measurement method can be designed, developed, and the performance can be assessed. A measurement method based on directly monitoring methane fluxes during longer-term measurement periods, instead of methane concentrations during short-term measurement periods, could provide more and better information. In free stall barns, cows typically spend up to 14 hours lying, resting, and ruminating in their cubicles, while generally remaining in a stable position. This period could be used to measure the methane flux produced by the lying cows by placing a sample hood near their heads. Like other methods, the performance 


\section{General introduction}

of this method depends on factors such as variable airflow patterns in the barn, sampling distance between the cow's mouth and the hood, and variable background gas concentrations. Thus, to develop an effective sample hood system in a cubicle, research is needed to assess the effects of cow and barn factors. Based on this information unwanted effects can be overcome by adjusting the sample hood design.

\section{Objectives and outline of the thesis}

The main objective of this thesis is to design, test, and validate methods to determine or rank the methane production of individual dairy cows at farm house level. Because cows produce $85-90 \%$ of their methane through the nose and mouth by exhalation and eructation, in this thesis we refer to this exhaled methane as 'methane production of individual cows', being the major proportion and exclude the small quantity produced through the rectum as flatus.

This objective is subdivided (Figure 1) in a review on existing knowledge, measurement requirements and methods to measure methane production of dairy cows (Chapter 2), characterisation of aerial conditions around cubicles in dairy barns and the implication of the accuracy of methane measurement methods (Chapter 3), design and test of a reference method that simulates the methane production of cows (Chapter 4), assessment of the performance of an existing breath concentration method (Chapter 5), and design and test of a methane flux method to assess the methane production of individual cows (Chapter 6).

Figure 1 shows the overview structure of the thesis. In Chapter 2, we review existing methods for measuring methane production of cows both at an individual and barn level. Options for mitigation of methane production from cows are listed and followed by requirements for methane measurement methods. Existing methods are categorized and described, and evaluated against the requirements. Finally, perspectives for the further development of individual measurement methodology at farm level are addressed in the discussion. 


\section{Chapter 1}

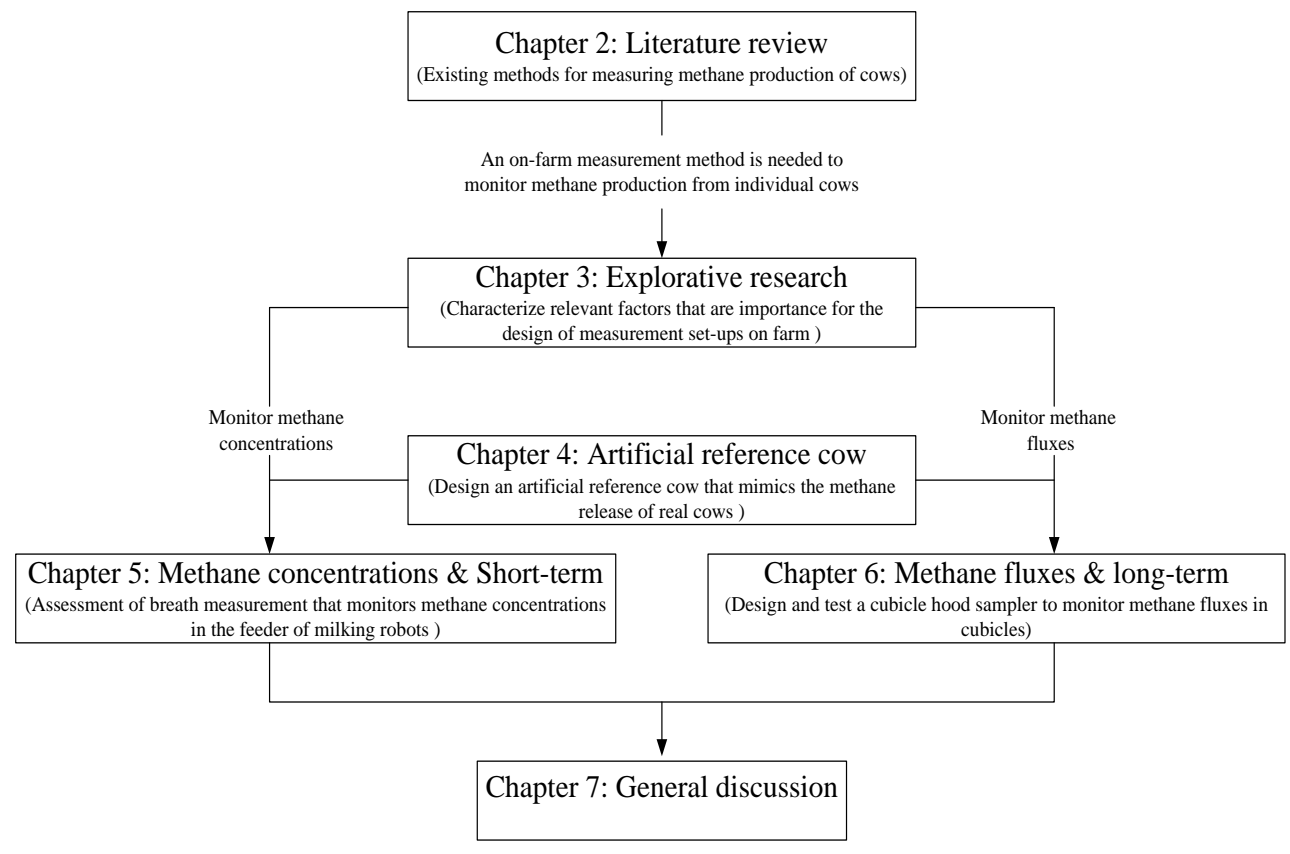

Figure 1. Overview of the thesis structure with the goal of each Chapter: Chapter 2 gives the overview of existing methane measurement methods and lists requirements for measuring methane production of individual cows in barns. Chapter 3 characterizes relevant factors in the barns and Chapter 4 introduces an artificial reference cow. With the acquired background information and the developed reference method, Chapter 5 assesses a methane concentration method in the feeder of milking robot and Chapter 6 develops a methane flux method in cubicles. In the end, Chapter 7 summarized and discussed in a broader perspective.

In Chapter 3, we measure methane concentrations in and around cubicles at cows' lying level in a summer and winter period. The level and dynamics in time and space of methane concentrations at different positions in non-occupied and occupied lying cubicles are investigated. We characterize relevant factors, i.e. ventilation rate, climate factors, cows' absence, and background methane concentration that are of importance for the design of measurement methods for monitoring individual methane production of animals resting in cubicles.

In Chapter 4 we design and construct an artificial reference cow (ARC) that mimics the methane emission of real cows with known pre-set methane production rates and dynamics of eructations. The ARC can be used to evaluate methods under a wide variety of practical 


\section{General introduction}

conditions in barns. This chapter describes the working principle and characteristics of the ARC. The methane mass balance of the ARC, defined as the difference between the mass controllers imposed input and measured output, is tested under three settings. Methane concentration release patterns produced by five simulated cows are compared to patterns measured from real cows.

In Chapter 5 we assess the performance of the breath methane measurement method as applied in a feed bin of a milking robot or feed station with the ARC, both in a laboratory and a barn. The relation between measured methane concentrations and controlled methane fluxed by the ARC is investigated, and the method's capacity to discriminate cows with different methane production is evaluated. The effects on measured methane concentration of variations from turbulent aerial conditions, cows' head movement, breath frequency, and tidal volume were also evaluated.

In Chapter 6 we design a cubicle hood sampler (CHS), representing a measurement method that measure methane fluxes emitted by cows lying in a cubicle. The performance of the CHS is assessed with the ARC under laboratory and barn conditions. The measured flux by the CHS is compared with the imposed flux controlled by the ARC, and we investigate to what extent this method can detect the variation of methane production between cows.

In the final Chapter 7 the findings from the previous chapters are summarized and discussed in a broader perspective. Recommendations are made for the future research. 



\section{CHAPTER 2}

Evaluation of measurement principles to measure the methane production of individual dairy cows on farm: a review

Liansun $\mathrm{Wu}$ 


\title{
Chapter 2
}

\begin{abstract}
Efforts to mitigate methane emissions from dairy cows are critical to reduce the contribution of dairy farming to global warming, and potentially also enhances production efficiency. To assess the effects of methane mitigation strategies, methane production of dairy cows has to be measured. But none of the current methods is flawless and thus further development of methods is necessary to enable assessment of effects of mitigation strategies and measures, and implementation by monitoring. To design new methods it is essential to identify key functions of the measurement system and list precisely formulated and quantifiable requirements. However, a detailed analysis of mitigation strategies for methane production of dairy cows and what that means for a measurement method (set-up and combination of components), sampling strategy (frequency, duration of measurements, and number of animals), quality of specific devices (errors and delay), and practical issues (e.g. costs) is missing.

The objective of this paper is to give an overview of: (a) requirements for an on farm method to assess levels and variation in methane production of individual cows; (b) existing principles and methods for measuring methane production of dairy cows, and their evaluation against the requirements for an on farm method to measure levels and variation in methane production of individual cows; and (c) identify the knowledge gaps and the research agenda to further develop on farm methods.

We first summarized 14 requirements of methane measurement methods to assess methane mitigation strategies. Then we reviewed existing measurement methods in three categories that differ in measurement principle. Merits and drawbacks of the methods were evaluated and discussed against the requirements.

Methane concentration methods are easy and low cost, but physiological differences between cows (e.g. variations of tidal volume between cows) and air flow patterns around sampling locations that differ between barns may introduce a systematic error on the measured methane concentration. The methane tracer gas method has no problem from these systematic sources but has problems in determining tracer gas production (predicted $\mathrm{CO}_{2}$ production or controlled $\mathrm{SF}_{6}$ production). The GreenFeed method, being a farm implementation of a flux method, is currently the best available approach to measure
\end{abstract}




\section{Evaluation of measurement principles: a review}

methane production of individual cows in the farm. However, there is uncertainty about the representativeness of the results because methane production is only measured during short feed bin visits.

This review study revealed that none of existing methods meet all requirements to evaluate the effects of methane mitigation methods. To measure methane production rates of individual cows under farm conditions, sampling of breath air during the lying period of cows in cubicles could be a practical direction. To rank cows in methane production rates, the $\mathrm{CH}_{4} / \mathrm{CO}_{2}$ ratio method is a promising method, but requires further research to assess its accuracy, especially with respect to the representativeness of the short sampling periods.

Keywords: methane, dairy cow, measurement requirements, measurement principle

\section{Introduction}

Global warming caused by anthropogenic greenhouse gas production (GHG) is of increasing concern. Livestock contributes an estimated $14.5 \%$ to the total anthropogenic GHG emissions (Gerber et al., 2013). Among livestock, methane $\left(\mathrm{CH}_{4}\right)$ emissions from dairy cows sector is estimated to contribute $4 \%( \pm 26 \%)$ of anthropogenic greenhouse gas emissions (FAO, 2010). In dairy farming, $\mathrm{CH}_{4}$ contributes about $52 \%$ to the total GHG emissions at dairy chain level (Gerber et al., 2010). The global warming potential of $\mathrm{CH}_{4}$ is 28 times that of carbon dioxide $\left(\mathrm{CO}_{2}\right)$, with an atmospheric lifetime of respectively 120 and 12 years (Myhre et al., 2013). Thus, efforts to mitigate $\mathrm{CH}_{4}$ emissions from dairy cows are critical to reduce the contribution of dairy farming to global warming.

As a by-product of the microbial fermentation process, dairy cows produce about $300 \mathrm{~g}$ $\mathrm{CH}_{4}$ per day (Bannink et al., 2011), which is emitted through eructation, respiration, and in a small quantity as flatus (Murray et al., 1999; Lassey, 2007; Sejian et al., 2011). Microorganisms (bacteria, protozoa, and fungi) digest the feed components, producing volatile fatty acids (VFA), mainly acetate, propionate, and butyrate that are subsequently used as a source of energy by the host animal. Hydrogen gas $\left(\mathrm{H}_{2}\right)$ and $\mathrm{CO}_{2}$ as end products in the fermentation process are the major substrates used by methanogens to produce methane (Moss et al., 2000; Martin et al., 2010). As a result of the $\mathrm{H}_{2}$ sink in the rumen by methanogens, the concentration or partial pressure of $\mathrm{H}_{2}$ in the rumen is generally kept low. 


\section{Chapter 2}

Formation of methane in the rumen is the major way to remove hydrogen, to avoid inhibition of the fermentation processes by a hydrogen overload (Boadi et al., 2004; Ellis et al., 2008). Methane emissions results in about 2-12\% loss of the gross energy (GE) intake, or 5-14\% of digestible energy intake of ruminants (Blaxter and Clapperton, 1965; Johnson and Johnson, 1995; Yan et al., 2010). Therefore, reduction of methane production from dairy cows per unit of digestible energy will not only reduce the global greenhouse impact, but potentially also enhances production efficiency.

Mitigation methods can be developed based on understanding of the mechanisms and processes involved in methane production and the observed variation in monitored production data. Variations in methane production between cows are reported in many studies (Blaxter and Clapperton, 1965; Johnson and Johnson, 1995; Marik and Levin, 1996; Lassey et al., 1997; Boadi et al., 2002; Grainger et al., 2007). A certain part of this measured variation is likely to be the result of measurement error, but the major part can be attributed to true individual variation caused by physiological status (e.g. health status, parity, and pregnancy), management (e.g. nutrition type, quantity, number of meals, and timing), and genetic factors. Changes in diet composition may reduce methane production per unit feed by well over 60\% (McGinn et al., 2006). Using the variation between individuals through genetic selection may be another approach to reduce methane emissions (Hegarty, 2004; Bell et al., 2010; De Haas et al., 2011).

To assess the effects of these mitigation strategies, methane production of dairy cows has to be measured. There are several techniques to measure methane production from dairy cows, at house ( $\geq 100$ animals), group $(\approx 10$ animals) or individual level, using the flux, tracer gas or concentration method for indoor or outdoor conditions, see Table 1 (options per aspect are not connected by column; Blaxter et al., 1972; Aulick et al., 1983; Boadi et al., 2002; Grainger et al., 2007; Chagunda et al., 2009). Effects of mitigation are generally first measured under controlled experimental conditions, followed by measurements under practical conditions, and field monitoring. None of the current methods is flawless, they can only be applied in specific circumstances, and they all require careful consideration before application, as reviewed by Storm et al. (2012). So, further development of methods is necessary to enable assessment of effects of mitigation strategies and measures, and 


\section{Evaluation of measurement principles: a review}

implementation by monitoring. To design new methods it is essential to identify key functions of the measurement system and list precisely formulated and quantifiable requirements (Cross, 2008). However, a detailed analysis of mitigation strategies for methane production of dairy cows and what that means for a measurement method (set-up and combination of components), sampling strategy (frequency, duration of measurements, and number of animals, Table 1), quality of specific devices (errors and delay), and practical issues (e.g. costs) is missing.

The flux method, the most accurate and precise method, and generally considered as the gold standard (Blaxter and Clapperton, 1965; Storm et al., 2012), is satisfactorily applied for cases with a limited number of animals under experimental conditions during a limited time period. Especially the need for a mechanical ventilation system, and high costs limit the application under practical conditions and for a large number of animals over a longer time period. The tracer gas and concentration methods can more easily be applied in practice, even to a high number of animals and at individual level. However, accuracy and precision of these methods are under discussion (Huhtanen et al., 2015; Hegarty, 2013). So, in this paper we focus on measurement methods for a large number of individual cows in naturally ventilated building in practice.

Table 1 List of options for various aspects related to the measurement of methane production of dairy cows when mitigation measures are applied.

\begin{tabular}{lcccc}
\hline Aspect & Option-1 $^{1)}$ & Option-2 $^{1)}$ & Option-3 $^{1)}$ & Option-4 $^{1)}$ \\
\hline Type of method ${ }^{2)}$ & Flux & Tracer gas & Concentration & - \\
Group size of animals per measurement & 1 & 2 & $\approx 10$ & $\geq 100$ \\
Conditions & Experimental & Semi-practical & Practical & - \\
Type of ventilation system & Mechanical & Natural & Mixed & Outdoor \\
Number of measurements & Once (1 period) & $2-5$ & $10-100$ & $\geq 100$ \\
Duration of one measurement (time) & Minutes-Hours & Days-Weeks & Months & Years \\
Total number of animals to assess & 1 & $\approx 10$ & $\approx 100$ & $\geq 1000$ \\
\hline
\end{tabular}

${ }^{1)}$ The list of options per aspect are not connected in columns with options for other aspects;

2) The working principles of these methods and available techniques are described in detail in Chapter 5; flux = flow rate $\times$ concentration;

${ }^{3)}$ A measurement is defined as the act of continuously (or with fixed small time intervals) taking measurements of gas concentration and airflow during a time-interval.

The objectives of this paper review are therefore to give an overview of: 


\section{Chapter 2}

(a) Requirements for an on farm method to assess levels and variation in methane production of individual cows;

(b) Existing principles and methods for measuring methane production of dairy cows, and their evaluation against the requirements for an on farm method to measure levels and variation in methane production of individual cows;

(c) Identify the knowledge gaps and the research agenda to further develop on farm methods.

The first section (Chapter 2) of this review paper describes options of mitigation of methane production by animal management and then underpins the requirements of the methane measurement methods to evaluate management methods. The following section (Chapter 3) describes options of mitigation of methane production by genetic factors and also underpins the requirements of the methane measurement methods. Additional practical, economic and technical requirements are listed in Chapter 4. The next section (Chapter 5) describes current methane measurement methods classified in three main working principles, which are evaluated against the requirements in Chapter 6. Finally, perspectives for the further development of measurement methods at farm level are addressed in Chapter 7.

\section{Management based mitigation strategies and requirements for methane measurement methods}

Several management based enteric methane mitigation strategies have been proposed (Hristov et al., 2013b; a; Knapp et al., 2014), which mainly include rumen manipulation, change of feeding / nutrition, and adaptation of farm management. Mitigation by measures that manipulate rumen fermentation reactions includes: (1) immunisation and biological control; (2) use of probiotics (acetogens, yeasts, and lactic acid bacteria); and (3) elimination of protozoa (Ellis et al., 2016; Martin et al., 2010). Most of the experiments related to these measures were carried out in vitro, and still have to be confirmed in vivo, which require a measurement method with experimental farming conditions. Adding lipids to the diet is estimated to give up to $40 \%$ methane reduction at high level of liquid supplementation (Jordan et al., 2006), and 10-25\% reduction in practice (Beauchemin et al., 


\section{Evaluation of measurement principles: a review}

2008). Level of supplementation, fat source, fatty acid profile, and type of the diet are the factors that affect the reduction efficiency of adding lipids. Diets containing a mixture of C12:0, C14:0, linseed oil, and Ca fumarate successfully lowered daily methane emission by 10\% (van Zijderveld et al., 2011). To assess these effects, methane measurement methods therefore should at least measure daily methane production and detect variations within and between cows in methane production. Ionophores such as monensin are also known to reduce methane losses. It was reported that monensin lowered methane emission in beef cattle up to $30 \%$, but reduced levels were restored within 2 months (Beauchemin et al., 2008). So, long term measurement methods are required to assess this long term effects.

Mitigation through feed composition is thought to be an effective tool of reducing enteric $\mathrm{CH}_{4}$ production. Digestible fibre is commonly considered to be the major contributor to methanogenesis (Moss et al., 2000). Cattle ingesting a highly digestible grass produced relatively less $\mathrm{CH}_{4}$ per unit of feed than those ingesting more fibrous forage (Blaxter and Clapperton, 1965; Kurihara et al., 1999; Benchaar et al., 2001; DeRamus et al., 2003). Johnson et al. (2002) found that total farm GHG emissions increased with the proportion of forage. However, an LCA system analysis of GHG emission in cattle production revealed that switching from more mature to less mature grass reduced GHG emissions per unit milk, and was most cost-effective (Middelaar and Dijkstra, 2014). To better understand the effect of feeding mitigation methods, $\mathrm{CH}_{4}$ reduction should not only be expressed in methane production, but also per unit of production, e.g. milk production. In view of the strong correlation between $\mathrm{CO}_{2}$ and milk production, methane measurement together with $\mathrm{CO}_{2}$ measurement would be convenient to analyse methane conversion in feeding mitigation methods.

Farm management (stock numbers, reproductive rate, grazing management, and finishing in feedlots) is another direction for reducing methane production. Reproductive rate influences the age structure and therefore overall feed efficiency of the system, both beneficial to improve profitability and reducing methane production (Eckard et al., 2010). A proper rotational grazing system can improve the quality of the land, promote the feed efficiency, and reduce methane emission (DeRamus et al., 2003). Improvement of the feeding system can help to enhance the nutrition and increase the digesting efficiency (Cottle et al., 2011). 


\section{Chapter 2}

Therefore, changes in farm management are more easily measured by methane measurement methods that can handle a group of dairy cows.

Management mitigation strategies can directly and quickly reduce methane production of dairy cows. Most effects of management mitigation strategies can be assessed with a small number of animals under experimental conditions, followed by measurements under practical conditions with a group of animals. But the measurement results at group levels can be affected by the variations between cows in the group. So, the measurement is better performed at individual level. The effects on reducing methane production before and after using the mitigation strategies should be measured, which depend on the accuracy of the measurement methods. Such effects can last for a short or long term, which requires that the measurement method can be operated during sufficient long time period. The relation between management and methane production of individual cows may vary from farm to farm, interactions, etc. Therefore, it must be possible to operate the measurement method on different farms.

The international goal is to reduce GHG emissions by at least $5.2 \%$ in the period $2008-2012$ as compared to the 1990 levels, and further reductions are foreseen (UNFCC, 1997). Effects of management measures range up to $40 \%$ for $\mathrm{CH}_{4}$ production of dairy cows. So, we think that the smallest relevant effect of interest is a reduction of the $\mathrm{CH}_{4}$ production of cows by at least $5 \%$.

In short, to be able to use the between and within variation in methane production from dairy cows for on farm abatement of methane emissions, the following set of requirements for the measurement method have to be met:

1. The enteric $\mathrm{CH}_{4}$ production leaving the nostrils and mouth of an individual cow has to be measured;

2. Within day, day to day, seasonal variation, and long term effects in methane production of a cow has to be taken into account in the sampling strategy (frequency and duration of measurements) to achieve representative data;

3. The measurement accuracy of the overall measurement and sampling system should enable to assess an absolute difference in methane production of $15 \mathrm{~g} /$ day (being approx. 5\%) for a treatment against a reference for a group of cows during a certain 
Evaluation of measurement principles: a review

time period under experimental conditions;

4. The measurement system can be implemented on commercial farms;

5. The methane production must be quantified by measuring the gas concentration in the airflow with the exhaled breath, and the flow rate of the airflow. Details of measurement methods will be presented in Section 5 .

\section{Genetic mitigation strategies and requirements of methane measurement methods}

Between-animal variation in fermentation, rumen turnover rate, and feed efficiency was already noted by many researchers (Hegarty, 2004; Alford et al., 2006; Hegarty et al., 2007; De Haas et al., 2011). It provides an opportunity for using this diversity when selecting for livestock with improved productivity and efficiency, if the variation is (partly) heritable (Hegarty and McEwan, 2010). Differences of rumen microbial population genomes are likely to reflect between-animal differences in the type of rumen microbe population (Hegarty, 2004; Guan et al., 2008), digestive function (Hegarty, 2004), feed intake (Arthur et al., 2001; Hegarty et al., 2007), and feed-use efficiency (Waghorn and Hegarty, 2011), which all affect the methane production per animal, although it should be noted that globally, differences in microbial community compositions are predominantly attributable to diet, with the host being less influential (Henderson et al., 2015).

Animal selection could achieve a 10-20\% reduction in the methane losses from dry matter (DM) during digestion (Waghorn et al., 2006). Eckard et al. (2010) also suggested that animal breeding could achieve a reduction of up to $10-20 \%$ in methane production per unit of DM intake. Instead of genetic improvement strategies in the past associated with output, selecting livestock that consumes less feed for a given level of production (net feed efficiency - NFE or residual feed intake - RFI) has received more attention recently (Arthur and Herd, 2005; Hegarty et al., 2007; Waghorn and Hegarty, 2011). Okine et al. (2001) showed that Canadian steers with high NFE had 21\% lower methane production (MP, g/day) than low NFE steers. It is stated that selection for reduced RFI can lead to worthwhile methane abatement (Alford et al., 2006; Waghorn et al., 2006; Waghorn and Hegarty, 


\section{Chapter 2}

2011). The genetic variation in RFI and calculated methane production suggests that reductions of methane emissions by selecting in the order of 11 to $26 \%$ in 10 years are theoretically possible (De Haas et al., 2011). It has to be noted here that various authors found only a weak relation between RFI and actually measured methane production (Münger and Kreuzer, 2008). Therefore, a part of the individual variation of methane emissions may be caused by individual genotype, and methane mitigation via animal genetics may be possible, but more data on actually measured methane production is required.

Breeding cows with relevant traits for productivity is a cost-effective technique with a permanent effect. Current breeding programmes can be extended with breeding goals on methane production. To utilize the genotypic variation between cows and select for low methane conversion cows, information from thousands of individual animals under practical farming circumstances is required. Such a large-scale measurement method for methane production should be first integrated in practical production systems. To breed cows with lower methane production, the variations of methane production within and between cows caused by genetic difference should be revealed, which depends on the accuracy of the measurement methods. The measurement methods should also be operated for a long time to assess the permanent effects of genetic mitigation strategies.

Except the requirements already listed in section 2, to be able to use the between and within variation in methane production from dairy cows for genetic mitigation, the following requirements have to be met:

6. The within and between cows variation in methane production must be assessed;

7. A representative value for the $\mathrm{CH}_{4}$ production during a complete lactation period should be assessed;

8. The methane production of consecutive lactation periods should be assessed;

9. The methane production of a large number $(20,000 \sim 50,000)$ of cows should be measured;

10. The measurement accuracy of the overall measurement system should enable to assess an absolute difference in methane production between cows of $15 \mathrm{~g} /$ day (being approx. $5 \%$ ) for a complete lactation cycle; 
Evaluation of measurement principles: a review

11. The ID of individual cows has to be connected to the measured data.

\section{Additional practical, economic, and technical requirements to measure methane production of cows}

In addition to the requirements given at the end of section 2 and 3, this section lists and underpins requirements related to practical on farm situations, economic aspects, and technical aspects of measuring methane production from individual cows.

12. The cows' behaviour should not be disturbed by the measurement system, and the measurement system is preferably non-intrusive to the cows;

13. The farm management should not be disturbed;

14. Investment, maintenance, and operating costs (money and labour) of the measurement system should be minimized.

\section{Existing measurement methods of methane production from cows}

There are several methods for measuring enteric methane production from cows, which use three main principles:

1) by means of measurement of the methane mass flow as the product of ventilation flow and difference in methane concentration in the in- and outgoing airflow;

2) by means of tracer gases, in which the ventilation rate is determined indirectly, or is not required if the source strength of the tracer gas is known;

3 ) by measurement of the methane concentration (and in one case also the $\mathrm{CO}_{2}$ concentrations) in the breath of a cow only, assuming a positive relationship between methane concentration and methane production.

\subsection{Measurement of methane production by means of mass flow determination}

\subsubsection{Respiration chamber}

The method used for respiration chambers is based on the mass balance of the room. To 


\section{Chapter 2}

determine the aerial losses from the room the ventilation rate through the room and the concentrations in the ingoing and outlet air are measured. The respiration chamber is considered to be an operative and accurate method owing to the available control of all production parameters related to the animal in a comparable small space. Normally, the respiration chamber method includes four major parts: 1) the chamber for animals, 2) the gas sampling and analyser system, 3) the ventilation system and flow measurement, and 4) data acquisition. The accuracy of the respiration chamber method depends on air tightness of the closed chamber, assessment of the fixed chamber volume, and well-calibrated analytical equipment. By aiming at increasing the accuracy and reducing the costs of the construction, the system improved gradually (Aulick et al., 1983; Miller and Koes, 1988; Boadi et al., 2002; Grainger et al., 2007; Derno et al., 2009). A chamber is an artificial, constrained environment. The chamber size is depending on the tested animals. According to the ventilation principle two types can be distinguished: closed-circuit and open-circuit systems. Even et al. (1994) discussed some practical aspects of the day-to-day use of the closed-circuit and the open-circuit systems. The classical main limitation of closed-circuit system is that $\mathrm{CO}_{2}$ and water has to be absorbed from the recirculating flow, but the important advantage of closed-circuit system is that there is virtually no lower limit to its sensitivity. In comparison to closed-circuit systems, open-circuit systems are more complex and costly. This results from the necessary use of high-performance gas analysers and flowmeters. Besides this characteristic, associated with the use of respiratory masks or modern computer-assisted corrections for the volume of the respiration chamber allows real minuteto-minute analysis of respiratory exchanges. Thus nowadays, closed-circuit respiration chambers are widely used for small animals and open-circuit systems are more convenient for larger animals (Even et al., 1994).

Between-animal variation of methane and $\mathrm{CO}_{2}$ production ( $0.1 \%$ and $1.6 \%$, respectively) was quite low in the study of Boadi et al. (2002) with the respiration chamber method. However, Blaxter and Clapperton (1965) reported a coefficient of variation (CV) of 5.0 to $7.5 \%$ between-sheep, with a fixed amount of feed. A CV of $17 \%$ was found for 135 beef steers in respiration chamber in five feeding experiments (Mc Court et al., 2006). Grainger et al. (2007) noted that CV among cows was about $17.8 \%$ when cows were fed ad libitum. 
Evaluation of measurement principles: a review

It is already certified that the data estimated from the respiration chamber method have a low variability compared to other methods (Ulyatt et al., 1999; Grainger et al., 2007; Pinares-Patiño and Clark, 2008; Chagunda and Yan, 2011). Because of its accurate results, the respiration chamber is normally regarded as the standard to validate a newly-developed measurement scenario and the principle. However, absolute accuracy of the respiration chamber showed a big variation between different facilities and required sufficient validation. This measurement uncertainty prior to validation was dominated by uncertainties in sample ducting and flow measurement (Gardiner et al., 2015).

\subsubsection{Ventilated mask and head hood}

Similar to the respiration chamber, a ventilated mask / head hood-type respiration chamber system was designed for sampling respiration gases in a partially enclosed space (Young et al., 1975; Suzuki et al., 2008; Maia et al., 2015; Place et al., 2011). A representative scheme of the measurement system is shown in figure 1 and modified in the study of Maia et al. (2015) and Place et al. (2011). The measurement system includes four main components: (1) air sampling from the mouth or head of a cow; (2) air flow measurement; (3) gases analysis; and (4) data acquisition.

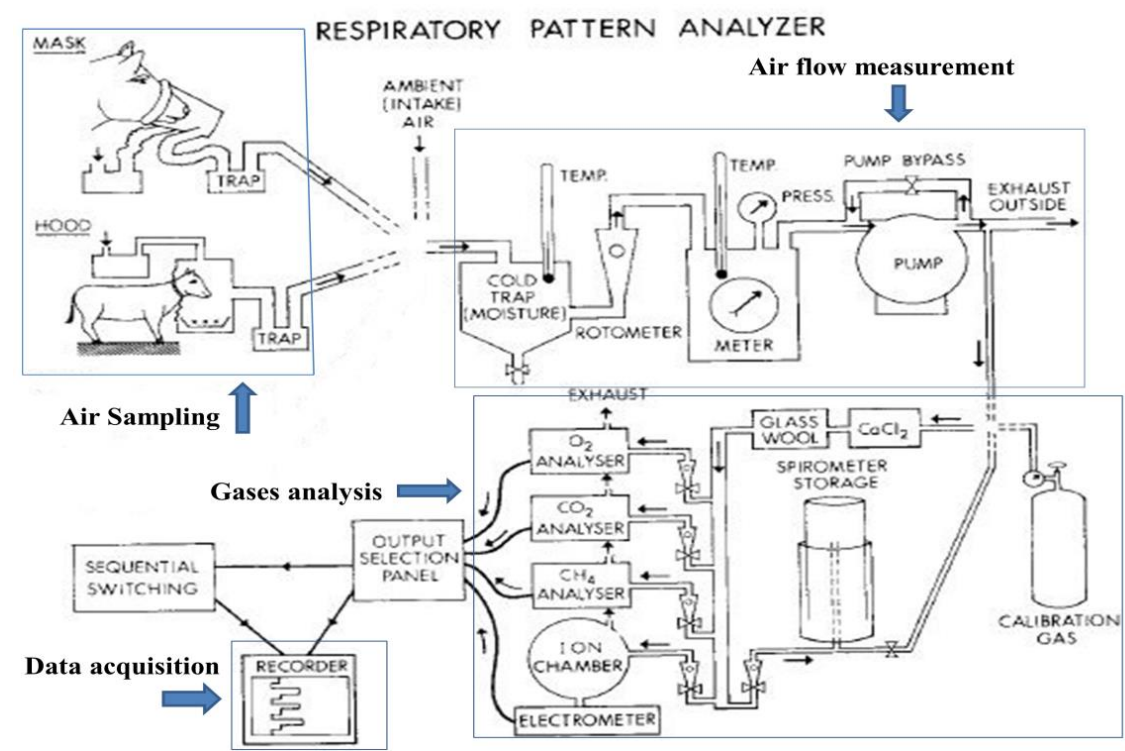

Figure 1 Representative scheme of a ventilated mask / head hood-type respiration chamber system (Young et al., 1975) 


\section{Chapter 2}

The mask and head measurement system share the same operating working principle as the respiration chamber. The cow's head or the mouth is first put into the hood or the mask. Then the system measures methane concentration at air inlet and outlet to calculate the methane concentration difference. The methane concentration difference is then multiplied with measured ventilation flow rate to determine the methane production of the dairy cow. The ventilated mask and head hood measures methane production through eructation and respiration only, excluding methane emitted as flatus.

The recovery rates of hood-type system were $95.7-101.8 \%$, and methane production of four Brahman steers was $228.3 \pm 16.0 \mathrm{~L} /$ day in 7 test days (Suzuki et al., 2008). Place et al. (2011) also measured recovery rates of the head hood ranging from 97.6-99.3\%, and the methane production rates obtained with this system were in agreement with others who used whole animal chambers and the sulphur hexafluoride technique. The accuracy of the system was largely dependent on the accuracy of the gas analysis and measurement of the ventilation rate (Young et al., 1975). The contributions to uncertainty of methane emission rates was $29 \%$ for the gas analyser and $69 \%$ for the ventilation rate (Maia et al., 2015). Thus, accuracy of these instruments should be carefully verified and calibrated.

\subsubsection{Extraction of exhaled breath in milking parlours and feeders}

For measuring methane production from individual cows in milking parlours or concentrate dispensers, another technique is recently developed. Cows visit milking robots and concentrate dispensers regularly and this provides an opportunity to measure the methane production from eructation and respiration.

The so-called GreenFeed system (C-lock, 2014; Hammond et al., 2015; Huhtanen et al., 2015; Dorich et al., 2015) is developed by an American company for measuring $\mathrm{CH}_{4}, \mathrm{CO}_{2}$, and other selected trace gas mass fluxes emitted from the mouth and nose of cows during eructation and respiration. The system is designed for automatic and regular measurements of methane production from many cows every time they visit the feeder. A user-specified 'bait' (usually feed pellets) is delivered to the feed tray to attract animals to visit. The four main parts of GreenFeed system are (1) a feed bin; (2) $\mathrm{CH}_{4}$ and $\mathrm{CO}_{2}$ sensors; (3) an airflow meter; and (4) a fan (see Figure 2). The GreenFeed is normally installed in an extra crate in the barn to avoid influences from other cows. 
Evaluation of measurement principles: a review

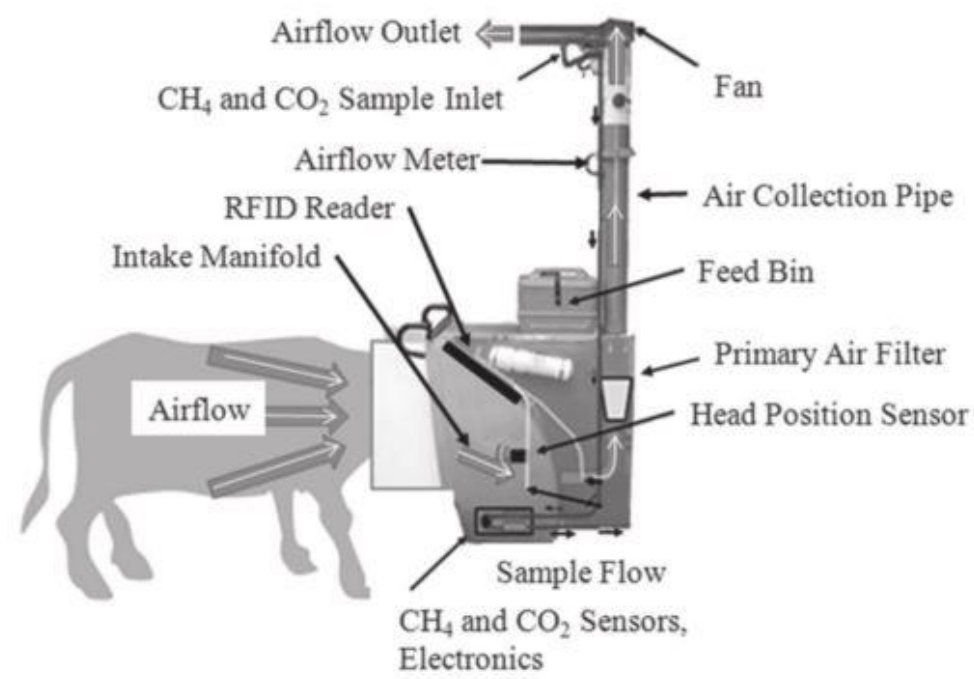

Figure 2 Schematic overview of the GreenFeed system (C-lock, 2014) used to measure methane production of individual cows

Cows in the feed hood are identified by radio frequency identification (RFID). A fan pulls air at a specified mass flow rate from the hood and $\mathrm{CH}_{4}$ and $\mathrm{CO}_{2}$ concentration are continuously measured in sampled air. Then methane production rate (MPR) of the measured cow is calculated as:

$M P R=Q_{\text {air }} \times\left(C_{m}-C_{b}\right) \times \rho \times 10^{-6}$

Where MPR is methane production rate in $\mathrm{g} / \mathrm{min}$; $\mathrm{Q}_{\text {air }}$ is airflow rate during the measurement period in $1 / \mathrm{min} ; \mathrm{C}_{\mathrm{m}}$ is measured methane concentrations of captured air in ppm; $C_{b}$ is background methane concentrations in ppm; $\rho$ is the density of capture air under normal condition in $\mathrm{g} / \mathrm{l}$.

Examples monitored by the system showed that methane production from 24 cows was $432.3 \pm 77.9 \mathrm{~g} / \mathrm{d}$, and the between-cows CV was $18.0 \%$ (C-lock, 2014). Measurement CV of methane production was $22.4 \%$ and a significant relation between dry matter intake and measured methane production was found in the GreenFeed, indicating that this method can be used to obtain reliable enteric methane production data (Dorich et al., 2015). However, in another study, the GreenFeed system was unable to detect significant differences between cows in methane production that were identified using both the respiration chamber and $\mathrm{SF}_{6}$ technique (Hammond et al., 2015), which was in part due to limited 


\section{Chapter 2}

numbers and timing of measurements obtained.

\subsection{Measurement of methane production by means of tracer gases}

\subsubsection{Tracer gas technique with known source strength of an artificial injected gas}

The tracer gas technique for individual cows sets a source of $\mathrm{SF}_{6}$ in the rumen with a known release rate. The methane production can be assessed from the measured concentration ratio of methane to $\mathrm{SF}_{6}$ in the expired breath. This method is widely used in pasture based milk production systems (Marik and Levin, 1996; Grainger et al., 2007; Williams et al., 2011). This method was first introduced by Johnson et al. (1994) and showed that no adverse effects were observed from the $\mathrm{SF}_{6} . \mathrm{SF}_{6}$ permeation tubes with rates of 500-1000 ng of $\mathrm{SF}_{6} / \mathrm{min}$ are prepared and calibrated in the laboratory, and then these permeation devices are placed in a cow's rumen with a balling gun. After that, a collection canister with a stainless steel tubing that serves as the transfer line is attached to a collar around the neck of the cow. Sample integration time is controlled by the length of the capillary transfer line. Air from the collection canister is evaluated by a gas chromatograph, and the methane production rate (MPR; $\mathrm{g} / \mathrm{min}$ ) is calculated as:

$M P R=Q_{S F 6} \times\left(\left(C_{s}-C_{b}\right) /\left(C_{S F 6 s}-C_{S F 6 b}\right)\right) \times 10^{9}$

Where $\mathrm{Q}_{\mathrm{SF}}$ is the SF6 release rate of the permeation tube placed in the rumen in $\mathrm{ng} / \mathrm{min} ; \mathrm{C}_{\mathrm{s}}$ and $\mathrm{C}_{\mathrm{SF} 6 \mathrm{~s}}$ are concentrations of $\mathrm{CH}_{4}$ and $\mathrm{SF}_{6}$ in the collection sample in ppm; $\mathrm{C}_{\mathrm{b}}$ and $\mathrm{C}_{\mathrm{SF} 6 \mathrm{~b}}$ are concentrations of $\mathrm{CH}_{4}$ and $\mathrm{SF}_{6}$ in the ambient air in ppm.

Average methane production rates of cattle during five days measured by the tracer method were $11.6 \pm 3.7 \mathrm{~L} / \mathrm{h}$ which accounted for $7.2 \%$ of GE intake, and day to day methane emissions patterns were very consistent, which associated with the feeding schedule (Johnson et al., 1994). Mean methane production rates of 10 lactating cows were $262.8 \pm$ $9.6 \mathrm{~g} / \mathrm{d}$ with average milk production of $14.1 \pm 0.7 \mathrm{~kg} / \mathrm{d}$. The mean methane production $(\mathrm{g} / \mathrm{d})$ was not different $(\mathrm{P}>0.05)$ between the tracer and respiration chamber method, as found by Johnson et al. (1994) and Boadi et al. (2002). But between-animal variation in methane production was higher with the tracer method which implies that more animals are needed for measurements compared to the respiration chamber method. Grainger et al. (2007) 
Evaluation of measurement principles: a review

found that total $\mathrm{CH}_{4}$ emissions were similar (322 and $331 \mathrm{~g} \mathrm{CH}_{4} / \mathrm{d}$ ), when measured using respiration chambers and $\mathrm{SF}_{6}$ tracer technique. The variability among cows was higher for the $\mathrm{SF}_{6}$ technique $(\mathrm{CV}=19.6 \%)$ than for the respiration chamber technique $(\mathrm{CV}=17.8 \%)$ (Grainger et al., 2007). The study of Pinares-Patiño and Clark (2008) also showed larger between-animal variation for the tracer technique than for the respiration chamber technique (13.8\% vs 5.5\%). The reliability of permeation tubes in releasing $\mathrm{SF}_{6}$ at a steady and predictable rate is a critical factor in the success of the tracer technique. Ulyatt et al. (1999) pointed out that calibration of the permeation tubes should last for 2 months. The $\mathrm{SF}_{6}$ tracer technique was reported to measure $93-95 \%$ of methane production measured by the respiration chamber (Johnson et al., 1994).

\subsubsection{Measurement of individual methane production with $\mathrm{CO}_{2}$ as}

\section{tracer gas}

This new method is developed by Madsen et al. (2010) to use the $\mathrm{CO}_{2}$ production of dairy cows as a tracer gas. A Fourier Transform Infrared (FTIR) instrument for sampling and measuring $\mathrm{CH}_{4}$ and $\mathrm{CO}_{2}$ concentration was placed in front of the cows head in an automated milking system (AMS). Methane production was calculated with the $\mathrm{CH}_{4} / \mathrm{CO}_{2}$ concentration ratio and the $\mathrm{CO}_{2}$ production was calculated based on estimated heat production units of the animals (Pedersen et al., 1998; Madsen et al., 2010; Pedersen et al., 2008; Lassen et al., 2012).

A reasonably good relation $\left(\mathrm{R}^{2}=0.55\right)$ of $\mathrm{CH}_{4}$ production was found between predicted production by the $\mathrm{CO}_{2}$ tracer gas method and the measured production by the respiration chamber method. However, $\mathrm{CH}_{4}$ production rates were on average underestimated by $17 \%$ (Hellwing and Lund, 2013). Uncertainty of this method is related to errors in the estimates of $\mathrm{CO}_{2}$ production by the empirical equations (Huhtanen et al., 2015). $\mathrm{CO}_{2}$ production shows diurnal variation, several feeding strategies may affect $\mathrm{CO}_{2}$ production without affecting feed intake, and $\mathrm{CO}_{2}$ production varies with animal activity, all of which may impact the estimate of $\mathrm{CH}_{4}$ production based on $\mathrm{CH}_{4} / \mathrm{CO}_{2}$ concentration ratio (Hegarty, 2013). To increase the precision of this $\mathrm{CO}_{2}$ tracer gas method, more cows in the experiment or a longer measurement period is suggested (Haque et al., 2014). 


\section{Chapter 2}

\subsection{Measurement of methane production through methane concentration in breath air}

\subsubsection{On-farm methane concentration measurements in breath air}

A novel technique, also called a sniffer method, based on sampling air released by eructation and respiration during milking was developed recently (Garnsworthy et al., 2012a). Sampling tubes were installed in feed bins in the milking stations to monitor the methane concentration of cows' breath during the milking period. By analysing the distinctive patterns of concentration peaks, methane emission rate (MPR; g/min) during each milking was calculated as the product of peak frequency and mean peak area:

$M P R=\sum_{1}^{n} \int_{t 1}^{t 2} f(c) d t \times \frac{1}{n} \times \frac{V}{1000} \times \frac{n}{T} \times \alpha \times \beta \times 10^{3}$

Where $f(c)$ is the methane concentration in ppm function of each peak during milking; $T$ is total milking time in min; $t_{1}$ and $t_{2}$ are start and end time point of each peaks in $s ; n$ is total number of peak; $\mathrm{V}$ is eructation volume in $1 / \mathrm{s} ; \alpha$ is the conversion factor of methane production from 1 to gram under normal condition, which is $0.667 \mathrm{~g} / \mathrm{l} ; \beta$ the is dilution factor. The factor $\beta$ for dilution of eructed air by ambient air was determined by releasing a fixed volume $(2.7 \mathrm{~L})$ of $1.0 \%$ methane in nitrogen to estimate concentrations of methane in gas released by the cows. It is a low-cost method for estimating methane emissions during milking in a large number of cows.

When the system was installed inside the respiration chamber for measuring methane emissions continually, a linear relationship was found between average methane emission rate index during milking on farm and total daily methane production measured by the respiration chamber $\left(n=12\right.$ cows, $\left.R^{2}=0.79\right)$ (Garnsworthy et al., 2012a). Variation of methane production between cows were detected under commercial conditions, which was about $18.9 \%$ between cows and $11.5 \%$ within cows and related to the BW, milk yield, parity, and week of lactation (Garnsworthy et al., 2012b). In another on-farm study, between-cow $\mathrm{CV}$ of $\mathrm{CH}_{4}$ production index can vary from 22 to $67 \%$ among cows within a farm (Bell et al., 2014), which is much more variable and higher than between-cow CV measured by the methane flux method (Huhtanen et al., 2015). Also the results in the study of Huhtanen et al. (2015) showed that concentrations of $\mathrm{CH}_{4}$ and $\mathrm{CO}_{2}$ determined by the sniffer method were poorly correlated with respective gas fluxes, and they suggested that 
Evaluation of measurement principles: a review

the sniffer method may not be able to reliably rank methane production of individual cow within a herd.

\subsubsection{The laser methane detector technique in a path of breath air combined with breath exhalation rate}

The laser methane detector technique (LMD) is a hand-held gas concentration detector, which is based on infrared absorption spectroscopy, using a semiconductor laser as a collimated excitation source (Chagunda et al., 2009). Methane column density between the equipment and the target point is measured as ppm-m. By dividing the measurement distance, the mean concentration along the measurement distance can be calculated. Normally, a point measurement over each exhalation-inhalation (respiratory tidal cycle) was taken according to a 15-25 s measurement period, and the measurement distance is $3 \mathrm{~m}$ to avoid disturbances to the cows. It was used as the mean concentration of breath air from cows. Then the methane production rate (MPR; $\mathrm{g} / \mathrm{min}$ ) can be calculated as below:

$M P R=C_{p} \times V_{t} \times B R \times T \times \alpha \times \beta \times 10^{-6}$

Where $\mathrm{C}_{\mathrm{p}}$ is the point methane measurement results by the LMD converted from ppm-m to ppm; $\mathrm{V}_{\mathrm{t}}$ is the estimated cow's tidal volume in $\mathrm{ml}$; $\mathrm{BR}$ is the estimated breath frequency in breath/min; $\mathrm{T}$ is measurement time in min; $\alpha$ is the conversion factor of methane production from $\mathrm{ml}$ to gram, which is $0.000667 \mathrm{~g} / \mathrm{ml} ; \beta$ is the dilution factor to correct from breath to total methane production, which is 10 (M.G.G. Chagunda, personal communication, March 22, 2013). The LMD only measures methane concentration and later uses estimated tidal volume and breath frequency to calculate the methane flux.

The studies of Chagunda et al. $(2009 ; 2011)$ showed that the use of the LMD to measure individual methane concentrations is technically feasible in dairy cows. Daily methane production was $357.0 \mathrm{~g} / \mathrm{d}$ measured by LMD, which was $17.5 \%$ higher than methane production estimated with an equation $(305.0 \mathrm{~g} / \mathrm{d})$ based on the DM intake. Besides, the variation of the LMD was quite high with a measurement $\mathrm{CV}$ of $90.6 \%$. Further, the correlation coefficient between concentrations measured by the LMD and by the respiration chamber was high $\left(R^{2}=0.80\right)$ and positive $(P<0.001, d f=416)($ Chagunda and Yan, 2011). However, the measurement point of the LMD was placed at the outlet of the respiration chamber, which is not measured close to the cow's noses. This is just simply comparing the 


\section{Chapter 2}

gas analyser used in the respiration chamber and LMD, not the measurement principle of itself.

\subsection{3} Measurement of $\mathrm{CH}_{4}$ and $\mathrm{CO}_{2}$ concentration ratio in breath sample

This measurement system for this method is very similar as for the sniffer method. The cows' breath is sampled with a tube installed in the feed bin of a concentrate feeder or an automatic milking station. Both $\mathrm{CH}_{4}$ and $\mathrm{CO}_{2}$ concentration are measured to calculate the $\mathrm{CH}_{4} / \mathrm{CO}_{2}$ concentration ratio. This ratio is then used to rank cows in methane production: the higher the ratio, the higher the ranked methane production of a cow (Huhtanen et al., 2015; Ogink et al., 2012).

The relation between $\mathrm{CH}_{4} / \mathrm{CO}_{2}$ ratios and methane production of cows $\left(\mathrm{R}^{2}=0.55\right)$ was stronger than the corresponding relation between $\mathrm{CH}_{4}$ concentrations alone and methane production $\left(\mathrm{R}^{2}=0.09\right)$ (Huhtanen et al., 2015). The estimated repeatability of methane production rates in terms of the $\mathrm{CH}_{4} / \mathrm{CO}_{2}$ ratio was 0.37 for Holstein and 0.35 for Jerseys (Lassen et al., 2012). The measurement $\mathrm{CV}$ of $\mathrm{CH}_{4} / \mathrm{CO}_{2}$ ratio was relative small (6-8\%) as measured in the GreedFeed method (Huhtanen et al., 2013). But the measurement CV increased to $15-20 \%$ with the breath methane concentration method (section 5.3.1). The extra variation is mainly caused by the mixing of $\mathrm{CH}_{4}$ and $\mathrm{CO}_{2}$ concentration and dilution effects before the breath air sampled.

\section{Evaluation of the methods against the list of requirement}

Eight methods to measure methane production of individual cows are described in chapter 5 and listed in Table 2 . The challenge is to reach at a sufficiently accurate method to assess the representative methane production of many individual dairy cows on farm at a minimum of costs. Table 2 shows the evaluation of all 8 methods against the list of requirements.

Merits and drawbacks of the existing methods are identified, which helps to select a suitable method for different applications, identify weaknesses and strengths, and identify the design challenge for new methods.

The breath concentration methods are technically the simplest and have low costs. But the 


\section{Evaluation of measurement principles: a review}

ventilation rate is not measured, and consequently the real methane flux cannot be calculated, resulting in low accuracy. In the breath methods only the methane concentration is measured, and in one case also the $\mathrm{CO}_{2}$ concentration, and used as a proxy to assess the methane production rate. However, the methane concentration can easily be influenced by the airflow around the feed bin. Thus, the dilution of breath air will vary in time and between places (in the barn, location of barns), making it harder to compare results on location A and location B measured at different times. Such variations will introduce a big random error and consequently requires a large number of measurements to achieve a certain level of precision. Moreover, physiological differences between cows (e.g. variations of tidal volume between cows) and air flow patterns around sampling locations that differ between barns may introduce a systematic error on the measured methane concentration. As a result, the methane concentrations of breath air will vary between cows with the same methane production rate, disturbing the relation between concentration and production rate.

In practice, some researchers use the $\mathrm{CH}_{4} / \mathrm{CO}_{2}$ ratio to directly express differences in methane production. This ratio approach is a simplification of the tracer gas method with the difference that cow differences in individual $\mathrm{CO}_{2}$ production are not accounted for. The ratio method considerably compensates the previously mentioned drawbacks of the breath methane methods by including the $\mathrm{CO}_{2}$ concentration in the measurement. By assuming constant $\mathrm{CO}_{2}$ production among cows, random and systematic effects on the dilution of breath samples are thus to a large extent eliminated by taking the $\mathrm{CH}_{4} / \mathrm{CO}_{2}$ ratio as a ranking measure for methane production. The $\mathrm{CH}_{4} / \mathrm{CO}_{2}$ ratio directly shows the proportion of the $\mathrm{C}$ excreted that is not metabolized to $\mathrm{CO}_{2}$, which may be used for expressing the efficiency of the microbial fermentation of the feed (Madsen et al., 2010). However, the level of feed intake, efficiency of energy utilizations, and body energy balance may also influence the gas ratio (Huhtanen et al., 2015). As such this approach is neglecting cow differences in $\mathrm{CO}_{2}$ production. So far, little research has been done on the accuracy of this approach compared to a gold standard. Yet, it is easily understood that the inclusion of this additional $\mathrm{CO}_{2}$ concentration measurement is improving the accuracy of the breath concentration methods in circumstances where large variability in sample dilution can be 


\section{Chapter 2}

expected.

The measurement system of breath concentration methods (also other methods that use the feed bin) can easily be integrated in the farm and thus the cow's normal behaviour and farm management are not disturbed. However, use of the feed bin also limits the measurement time to a maximum 2 to 3 times of 6 minutes per day per cow. With such a short measurement time the daily pattern of variation in methane production is not measured, and thus this approach may not yield representative values. This might be overcome if measurement results of multiple days on different times of multiple cows are combined. But next to having a short measurement interval, measurements only performed during feeding may introduce bias in methane production because of the strong influence of feeding on cow's methane production.

The tracer gas methods are more costly, especially in $\mathrm{SF}_{6}$ method, than the breath concentration method, but perform better. The methane production rate can be measured by indirectly assessing ventilation rates with tracer gases. Accuracy of daily methane production from this method is mainly dependent on tracer gas production (predicted $\mathrm{CO}_{2}$ production or controlled $\mathrm{SF}_{6}$ production). The prediction uncertainty of the $\mathrm{CO}_{2}$ production model will be included in the uncertainty of the predicted methane production. Also $\mathrm{CH}_{4}$ production may be overestimated because of the overestimation of $\mathrm{CO}_{2}$ production with improved feed efficiency (Huhtanen et al., 2015). The $\mathrm{SF}_{6}$ method needs careful calibration of $\mathrm{SF}_{6}$ release rate of the permeation tube, and is very laborious in its operation. Besides, the cow attached sampling equipment of the $\mathrm{SF}_{6}$ method could disturbs cows' normal behaviour and may affect the measurement data.

The methane flux method is compared to the breath concentration and tracer gas methods, the most accurate approach as it measures methane flux with controlled ventilation rates. Generally this approach as implemented in respiration chambers is considered as the gold standard for measuring individual methane production of cows. The measurement error can be minimised by adequate calibration. However, the measurement system of respiration chamber and head hood or mask method is hard to be implemented in the farm and these methods are very costly to measure a large number of cows. In addition the impact on cow behaviour by confining animals in respiration chambers and the attachment of head masks 


\section{Evaluation of measurement principles: a review}

may have adverse effects.

Given this, the GreenFeed method is currently the best approach of the flux method to measure methane production rate of individual dairy cows in the farm. Although the GreenFeed method is close to fulfil the requirements (Table 2), short sampling time and sampling under non-representative conditions (same as other methods measured in feed bin) may influence the representative of the measurement values.

To overcome the limitations of short sampling time in feed bin sampling setups, the fixed position of cows lying in cubicles could be utilized. In free stall barns, cows typically spend up to 14 hours lying, resting, and ruminating in their cubicles (Hafez and Bouissou, 1975), while generally remaining in a stable position. Most of the methane is released during ruminating. Considering this, this period could be used to measure the methane flux emitted produced from the lying cows by applying methane flux methods, for instance, placing a sample hood near their heads. 
Chapter 2

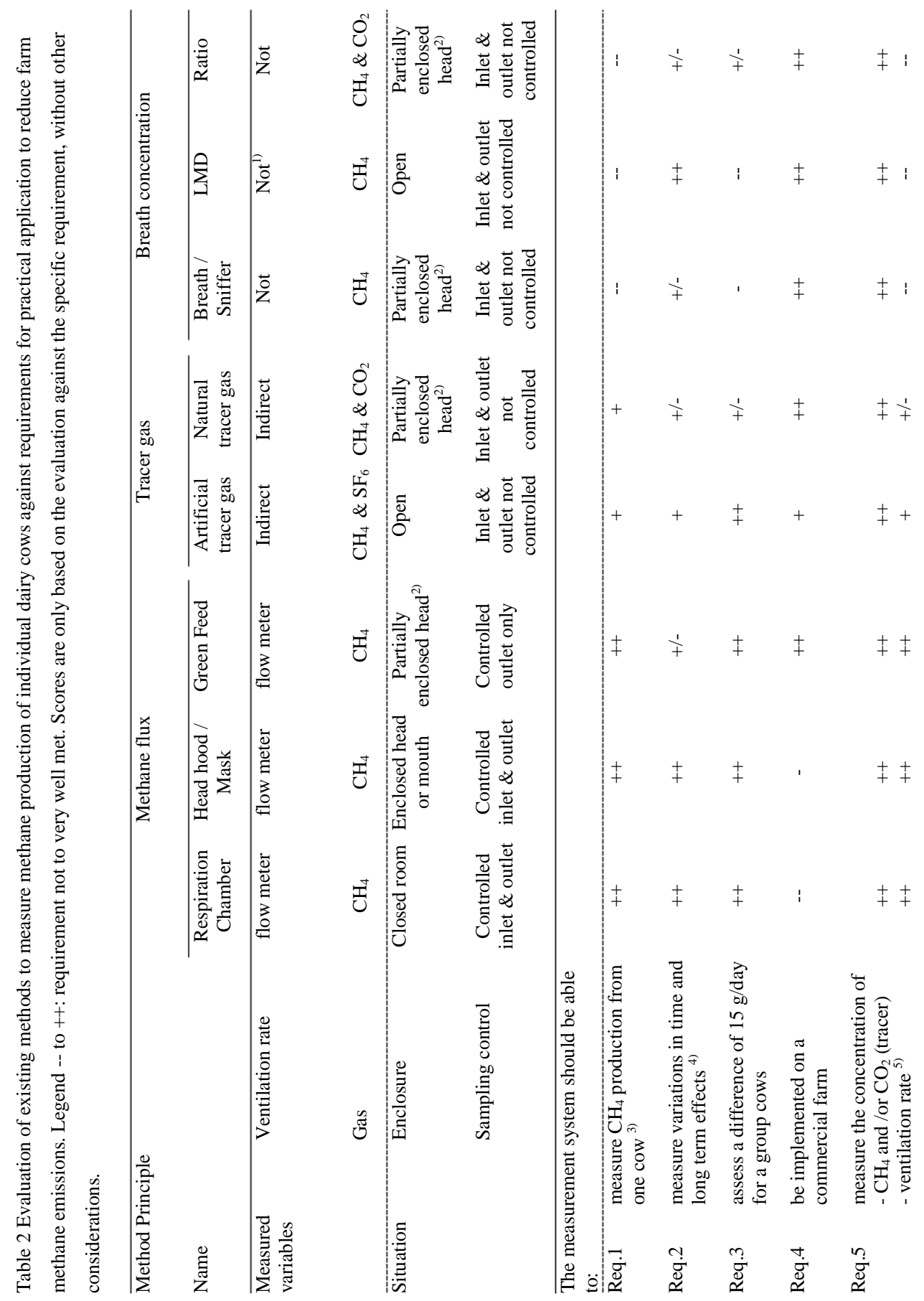


Evaluation of measurement principles: a review

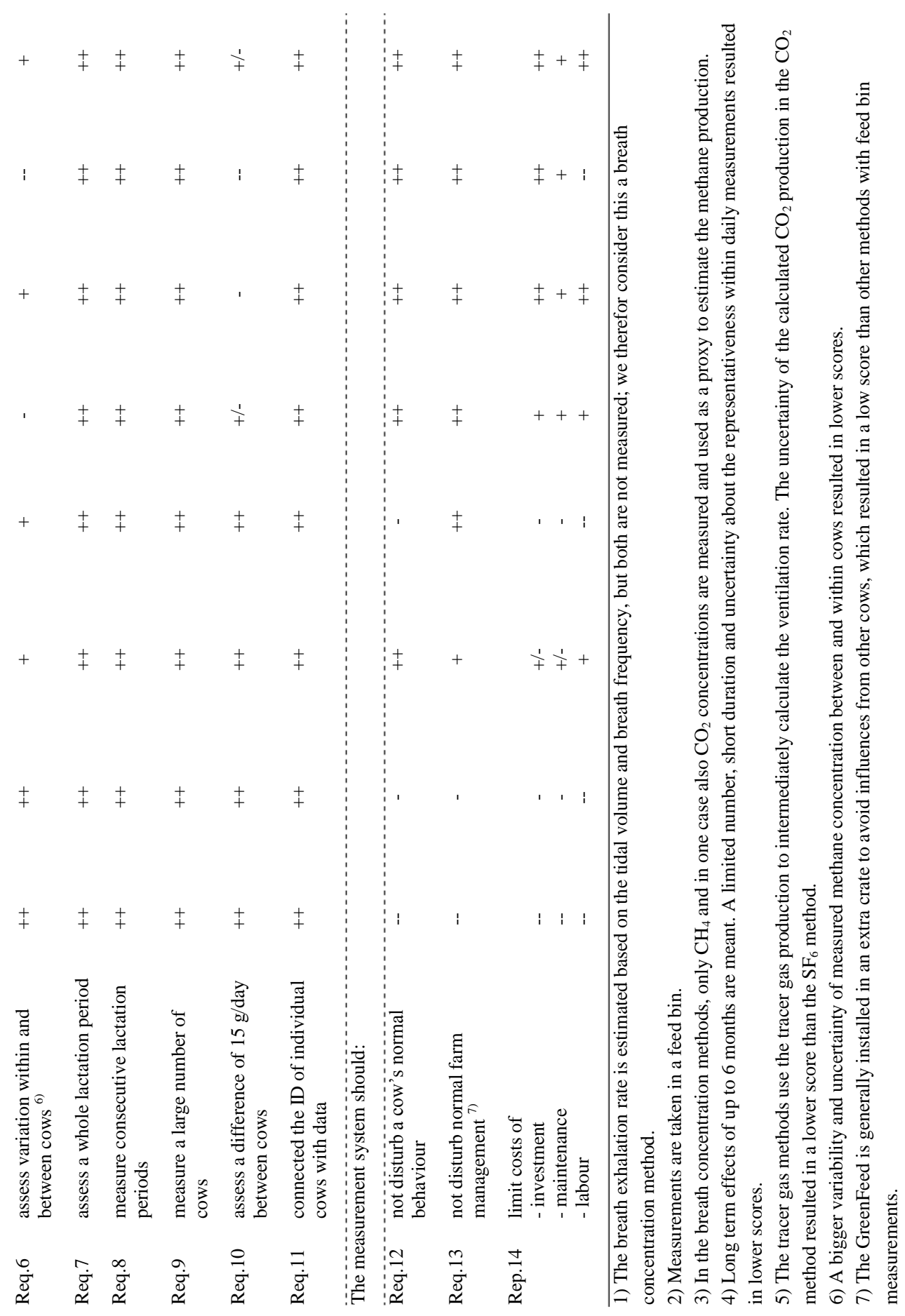




\section{Chapter 2}

\section{Conclusions}

In this study, we explored the potential of different measurement method to evaluate the effects of methane mitigation methods. Measurement requirements were listed, strengths and weaknesses of existing techniques for measuring methane emission from individual cows discussed and assessed against the requirements. Perspectives for improvement and development of methane measurement methods were summarized. The main conclusions of this study are:

- None of existing methods meet all requirements to evaluate the effects of methane mitigation methods.

- New measurement methods are still needed to measure a large number of individual dairy cows under farm conditions.

- Methane concentration methods are easy and low cost, but the uncertain accuracy of the measurement values severely limits the application of the method. These methods require further evaluation on measurement error, especially the systematic error.

- To rank cows in methane production rates, the $\mathrm{CH}_{4} / \mathrm{CO}_{2}$ ratio method is a promising method; it partially compensates the drawbacks of the methane concentration methods, but requires further research to assess its accuracy, especially with respect to the representativeness of the short sampling periods.

- The GreenFeed method, being a farm implementation of a flux method, is currently the best available approach to measure methane production of individual cows in the farm. However, there is uncertainty about the representativeness of the results because methane production is only measured during short feed bin visits.

- To measure methane production rates of individual cows under farm conditions, a methane fluxes method is required that is capable of sampling a representative periods to capture the daily methane production. Sampling of breath air during the lying period of cows in cubicles could be a practical direction. 
Evaluation of measurement principles: a review

\section{Acknowledgements}

This study was funded by Wageningen UR Livestock Research, the Ministry of Economic Affairs of the Netherlands (Research Program Sustainable Agriculture, KB-12-006.03-002), and the China Scholarship Council. The author also thanks Yvette de Haas and Jan Dijkstra for their help in editing and reviewing the text. 



\section{CHAPTER 3}

\section{Temporal and spatial variation of methane concentrations around lying cubicles in dairy barns}

Liansun $\mathrm{Wu}^{1^{*}}$, Peter W.G. Groot Koerkamp ${ }^{1,2}$, Nico Ogink ${ }^{2}$

1. Farm Technology Group, Wageningen University, P.O. Box 16, 6700 AA, Wageningen,

The Netherlands

2. Wageningen UR Livestock Research, Wageningen University and Research Centre, P.O.

Box 135, 6700 AC, Wageningen, The Netherlands

*Corresponding author: Liansun.wu@wur.nl

This chapter is submitted to Journal of Biosystems Engineering. 


\title{
Chapter 3
}

\begin{abstract}
Cows' long lying period in cubicles could be utilised for measuring methane production of individual cows under barn conditions. However, variable aerial conditions around cubicles are challenging to assess all emitted methane from individual cows. The objective of this study was to (1) assess methane concentration levels and variations in time, and around cubicles; (2) explore influencing factors on them; and (3) assess effects of barn background variability in methane concentrations on assessed individual methane production. We measured methane concentrations around two cubicles in a naturally ventilated dairy barn in a summer and a winter period. The effect of barn background variability in methane concentration on individual cow measurements was analysed in relation to the working principles of the breath methane concentration and methane flux methods. Mean methane concentrations around the cubicle were 29-37 ppm in the summer period and 33-51 ppm in the winter period. Spatial variations of hourly averages of methane concentration around the cubicle were $71 \%$ in the summer and $58 \%$ in the winter period. Temporal variations of hourly averages of methane concentration varied from 115 to $153 \%$ in the summer, and from 57 to $109 \%$ in the winter period among the sample locations. These variations were mainly affected by airflows and barn management. The coefficient of variation (CV) of the background methane concentration strongly influenced the overall measurement $\mathrm{CV}$ of assessed methane production, in both the methane flux and breath methane concentration method. This information can be used to limit measurement variation in methane measurement methods.
\end{abstract}

Keywords: Methane concentration, lying cubicle, concentration variation, method to assess methane production, measurement variation

\begin{tabular}{ll}
\hline Nomenclature & \\
\hline $\mathrm{BM}$ & Cow's body weight $(\mathrm{kg})$ \\
$\mathrm{C}_{\mathrm{br}}$ & Methane concentrations in cows' breath (ppm) \\
$\mathrm{C}_{\mathrm{bg}}$ & Background methane concentration $(\mathrm{ppm})$ \\
$\mathrm{C}_{\mathrm{co} 2 \text {,in }}$ & $\mathrm{CO}_{2}$ concentration indoor (ppm) \\
$\mathrm{C}_{\mathrm{co} 2 \text {,out }}$ & $\mathrm{CO}_{2}$ concentration outdoor (ppm) \\
$\mathrm{C}_{\mathrm{i}}$ & Mean methane concentration at sample location i (ppm) \\
$\mathrm{C}_{\mathrm{ij}}$ & Methane concentration of sample location (i) in hour $(\mathrm{j})(\mathrm{ppm})$ \\
\hline
\end{tabular}




\section{Temporal and spatial variation of methane concentration}

\begin{tabular}{|c|c|}
\hline $\mathrm{C}_{\mathrm{j}}$ & Mean methane concentration in the same hour (j) of all days (ppm) \\
\hline $\mathrm{C}_{\mathrm{jk}}$ & $\begin{array}{l}\text { Methane concentration of all sample locations in each hour (j) of each } \\
\text { measurement day (k) (ppm) }\end{array}$ \\
\hline$C_{k}$ & Mean methane concentration in the same day (k) of all hours (ppm) \\
\hline $\mathrm{C}_{\mathrm{ijk}}$ & $\begin{array}{l}\text { Methane concentration of sample location (i) in hour (j) and day (k) } \\
(\mathrm{ppm})\end{array}$ \\
\hline $\mathrm{C}_{\mathrm{ijl}}$ & $\begin{array}{l}\text { Methane concentration in every three minutes (1) of a sample location } \\
\text { (i) in a certain hour (j) (ppm) }\end{array}$ \\
\hline $\mathrm{C}_{\text {outdoor }}$ & Background methane concentration in the atmosphere $(\mathrm{ppm})$ \\
\hline $\mathrm{C}_{1 \mathrm{~m}}$ & $\begin{array}{l}\text { Methane concentration of sampled exhaled air in the methane } \\
\text { concentration method (ppm) }\end{array}$ \\
\hline $\mathrm{C}_{2 \mathrm{~m}}$ & $\begin{array}{l}\text { Methane concentration of the airflow in the methane flux method } \\
(\mathrm{ppm})\end{array}$ \\
\hline $\mathrm{CV}_{\text {between-days }}$ & $\begin{array}{l}\text { Between days coefficient variation of methane concentration at sample } \\
\text { locations }(\%)\end{array}$ \\
\hline $\mathrm{CV}_{\text {between-hours }}$ & $\begin{array}{l}\text { Between hours coefficient variation of methane concentration at } \\
\text { sample locations }(\%)\end{array}$ \\
\hline $\mathrm{CV}_{\text {i-temporal }}$ & $\begin{array}{l}\text { Temporal coefficient of variation of methane concentration at sample } \\
\text { location (i) }(\%)\end{array}$ \\
\hline $\mathrm{CV}_{\mathrm{i} \text {-within-hour }}$ & $\begin{array}{l}\text { Within-hour coefficient of variation of methane concentration at } \\
\text { sample location (i) }(\%)\end{array}$ \\
\hline $\mathrm{CV}_{\mathrm{ij}-\text {-within-hour }}$ & $\begin{array}{l}\text { Within-hour coefficient of variation of methane concentration in hour } \\
\text { (j) at sample location (i) }(\%)\end{array}$ \\
\hline$C V_{\text {jk-spatial }}$ & $\begin{array}{l}\text { The spatial coefficient of variation of methane concentration between } \\
\text { sample locations in hour }(\mathrm{j}) \text { of measurement day }(\mathrm{k})(\%)\end{array}$ \\
\hline $\mathrm{CV}_{\text {spatial }}$ & $\begin{array}{l}\text { Spatial coefficient of variation of methane concentration between } \\
\text { sample locations }(\%)\end{array}$ \\
\hline $\mathrm{F}$ & Capture flow rate $\left(1 \mathrm{~min}^{-1}\right)$ \\
\hline $\mathrm{G}_{\mathrm{co} 2}$ & Total $\mathrm{CO}_{2}$ production by the dairy cows $\left(\mathrm{m}^{3} \mathrm{~h}^{-1}\right)$ \\
\hline HPU & Heat production unit $(\mathrm{W})$ \\
\hline MP & Milk production $\left(\mathrm{kg}\right.$ day $\left.^{-1}\right)$ \\
\hline $\mathrm{m}$ & Number of measurement days \\
\hline $\mathrm{MC}_{\mathrm{m}}$ & Methane concentration produced by manure (ppm) \\
\hline $\mathrm{MC}_{\mathrm{t}}$ & Overall methane concentration produced by cows and manure (ppm) \\
\hline $\mathrm{MPR}_{1}$ & $\begin{array}{l}\text { Methane production rate of a cow in the breath methane concentration } \\
\text { method }\left(\mathrm{g} \mathrm{min}^{-1}\right)\end{array}$ \\
\hline $\mathrm{MPR}_{2}$ & Methane production rate of a cow in the methane flux method $\left(\mathrm{g} \mathrm{min}^{-1}\right)$ \\
\hline $\mathrm{MPR}_{\mathrm{bg}}$ & Methane production rate with variable $\mathrm{C}_{\mathrm{bg}}\left(\mathrm{g} \mathrm{min}^{-1}\right)$ \\
\hline $\mathrm{MPR}_{1 \delta}$ & Methane production rate with variable $\delta\left(\mathrm{g} \mathrm{min}^{-1}\right)$ \\
\hline $\mathrm{MPR}_{2 \tau}$ & Methane production rate with variable $\tau\left(\mathrm{g} \mathrm{min}^{-1}\right)$ \\
\hline $\mathrm{n}$ & Number of measurement hours \\
\hline$n_{k}$ & Number of hours with values within a measurement day \\
\hline $\mathrm{n}_{\mathrm{s}}$ & Number of sample locations around the cubicle \\
\hline $\mathrm{n}_{\mathrm{z}}$ & Measurement number with an hour \\
\hline NP & Number of days in pregnancy \\
\hline $\mathrm{P}_{\mathrm{m}}$ & Percent of overall methane concentration that caused by manure (\%) \\
\hline Q & Cow's exhalation rate $\left(1 \mathrm{~min}^{-1}\right)$ \\
\hline $\mathrm{SD}_{\mathrm{Ci}}$ & Standard deviation of concentration $\mathrm{C}_{\mathrm{i}}(\%)$ \\
\hline $\mathrm{SD}_{\mathrm{Cij}}$ & Standard deviation of concentration $\mathrm{C}_{\mathrm{ij}}(\%)$ \\
\hline $\mathrm{SD}_{\mathrm{Cj}}$ & Standard deviation of concentration $\mathrm{C}_{\mathrm{j}}(\%)$ \\
\hline $\mathrm{SD}_{\mathrm{Cjk}}$ & Standard deviation of concentration $\mathrm{C}_{\mathrm{jk}}(\%)$ \\
\hline
\end{tabular}




\section{Chapter 3}

\begin{tabular}{|c|c|}
\hline $\mathrm{SD}_{\mathrm{Ck}}$ & Standard deviation of concentration $\mathrm{C}_{\mathrm{k}}(\%)$ \\
\hline VR & Ventilation rate of the barn in $\left(\mathrm{m}^{3} \mathrm{~h}^{-1}\right)$ \\
\hline$\alpha$ & Coefficient of variation of $\mathrm{C}_{\mathrm{bg}}(\%)$ \\
\hline$\rho$ & Methane density $\left(\mathrm{g}^{-1}\right)$ \\
\hline$\delta$ & $\begin{array}{l}\text { Sampled fraction of the exhaled breath air of a cow sampled in the } \\
\text { mixed air at the sampling point, in text denoted as SFMC }\end{array}$ \\
\hline$\tau$ & $\begin{array}{l}\text { Captured fraction of the methane flux produced by a cow, in text } \\
\text { denoted as CFMF }\end{array}$ \\
\hline$\theta_{\text {MPRbg }}$ & $\begin{array}{l}\text { Coefficient of variation of measured methane production as a result of } \\
\text { variability of } \mathrm{C}_{\mathrm{bg}}(\%)\end{array}$ \\
\hline$\theta_{\mathrm{MPR} \delta}$ & $\begin{array}{l}\text { Coefficient of variation of measured methane production as a result of } \\
\text { variability of } \delta(\%)\end{array}$ \\
\hline$\theta_{\mathrm{MPR} \tau}$ & $\begin{array}{l}\text { Coefficient of variation of measured methane production as a result of } \\
\text { variability } \tau(\%)\end{array}$ \\
\hline
\end{tabular}

\section{Introduction}

There is an increasing interest in mitigation of methane $\left(\mathrm{CH}_{4}\right)$ emission of ruminants due to the strong relation between methane emission and the greenhouse effect that links to global climate change. Enteric $\mathrm{CH}_{4}$ production as part of digestive processes of ruminants significantly contributes to greenhouse gas (GHG) inventories (35-50\% of total global warming) (Sejian, Lal, Lakritz, \& Ezeji, 2011). Among ruminants, methane production from dairy cows contributes $4 \%( \pm 26 \%)$ of anthropogenic greenhouse gas emissions (Gerber, Vellinga, Opio, Henderson, \& Steinfeld, 2010).

Breeding cows with lower methane production can permanently mitigate methane emission from dairy cows, but requires a large number of methane production records from individual cows (De Haas et al., 2011). The high number of cow data required for breeding implies that farm measurement methods are needed. Current methods involve breath methane concentration and sometimes flux measurement during short periods of stay in automatic milking systems or concentrate feeders. However, these methods have shortcomings either related to their technical complexity, costs, limited representation, or too short sampling periods (Storm, Hellwing, Nielsen, \& Madsen, 2012). Typically, in free stall barns, cows spend up to 14 hours lying, resting, and ruminating in cubicles. During this period, the cows are lying in a certain position and only occasionally change their position. Therefore, such a long lying period could be utilised to measure methane emission from individual dairy cows. However, aerial conditions like air velocity and gaseous 


\section{Temporal and spatial variation of methane concentration}

concentrations around the cubicles are highly variable in time and space and make it therefore challenging to assess all emitted methane from individual cows without disturbances from the environment. To design a method for monitoring methane emission of individual dairy cows in cubicles, we first need to know the levels and variations of aerial methane concentrations around the cubicles and then identify factors that cause these variations under practical conditions.

Various studies have investigated methane emissions from the whole barn (Bjerg, Zhang, Madsen, \& Rom, 2012; Groot Koerkamp et al., 1998; N. M. Ngwabie, Jeppsson, Gustafsson, \& Nimmermark, 2011; Ngwa M. Ngwabie, Vanderzaag, Jayasundara, \& Wagner-Riddle, 2014; Saha et al., 2014). Clear diurnal variations of methane emissions were observed but no clear trend between the seasons were found (Jungbluth, Hartung, \& Brose, 2001; Saha et al., 2014). On an average day, methane emissions ranged from 7 to 15 $\mathrm{g} \mathrm{LU}^{-1} \mathrm{~h}^{-1}(1 \mathrm{LU}=500 \mathrm{~kg}$ animal weight) (N. M. Ngwabie et al., 2011). The variations of methane emissions were strongly related to 1) barn ventilation rate, 2) animal activity, 3) climate factors, 4) manure management, and 5) $\mathrm{CO}_{2}$ emission rates. The ventilation rate had a negative effect on the methane concentration in the barn. With higher ventilation rates, more outdoor air exchanged and diluted the methane in the barn that resulted in lower methane concentrations. The cows' activities, for instance, related to the feeding schedule, had strong positive effects on the methane emission. Methane emissions increased by $50 \%$ approximately $1 \mathrm{~h}$ after feeding because the cows ruminated and emitted methane (N. M. Ngwabie et al., 2011). A significant relation ( $\mathrm{P}<0.01)$ between methane emissions and climate factors was found, including the air temperature, air velocity, but not always with air humidity. The air temperature strongly affected the cows' activities that consequently influenced the methane emission (Joo et al., 2015; N. M. Ngwabie et al., 2011). Higher air velocity increased the ventilation rate of the barn that consequently increased methane emissions from the barn (Wu, Zhang, \& Kai, 2012). The methane emission of the barn was also dependent on floor type and the manure-handling method (Zhang et al., 2005). Although the dairy cows were the major methane contributor, emissions from manure in the slurry pit still represented $19 \%$ of the total barn methane emission (Ngwa M. Ngwabie et al., 


\section{Chapter 3}

2014). In short, methane emissions from the whole barn varied in time and were influenced by ventilation rate, animal activity, climate factors, and manure management in the barn.

No studies so far explored the variability of methane concentrations around the cows in the cubicles, nor effect of sources or factors on them. The available known studies measured methane concentrations at the outlets of the house and $2 \mathrm{~m}$ above the floor, while the cows' lying area in the cubicle is below $1 \mathrm{~m}$ height. The aerial conditions in the cubicle are different since cows are lying and emitting methane there. Therefore, knowledge of the variations of methane concentration around the cubicles, and their subsequent effects, is required to develop a method to assess methane production from individual cows lying in a cubicle. Under different aerial conditions, the effect of ventilation rate, animal activity, indoor climate factors, and methane released from manure should also be explored. Since cows are lying next to each other in the cubicles, background methane concentration in a cubicle can also be affected by the cows lying next to this cubicle. The characteristics of these variable background conditions caused by the complex airflow, adjacent cows, and manure are of importance in developing methods to distinguish the methane emitted from individual cows in a selected cubicle.

Given this, the objectives of the study are to 1) assess methane concentration levels and variations in time, and around lying cubicles; 2) explore the effects of barn ventilation rate, indoor climate factors, presence or absence of cows, and methane released from manure on aerial methane concentrations at the lying level; and 3) assess the effect of the variation of the background methane concentrations on assessing methane production of individual dairy cows in cubicles, either by a methane concentration or a flux method.

\section{Materials and methods}

Measurements were taken in two periods, from August 14 to October 01, 2012 and from December 24, 2012 to January 07, 2013, covering a summer and a winter period.

\subsection{Dairy cow building}




\section{Temporal and spatial variation of methane concentration}

This experiment was carried out in an experimental dairy cow house of Wageningen University. The dairy cow house was equipped with a natural ventilation system, which included large openings on the side walls and an open ridge, and slatted floors in the cow area with manure storage below (Figure 1). There were 23 cows housed in the barn (with 32 cubicles) during this experiment that received the same feeding management. Cows were fed once daily at $1100 \mathrm{~h}$, and milked twice daily at 0600 and $1630 \mathrm{~h}$. The side door of the barn was open between 0800 and $1630 \mathrm{~h}$ in the summer period to enable cows to pasture. Manure on the slatted floor was scraped per day.

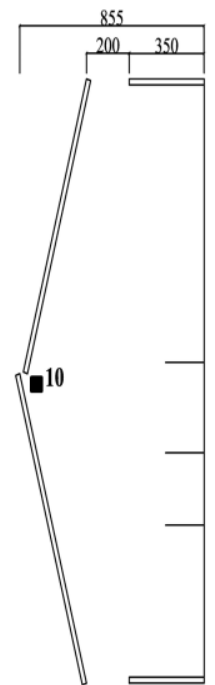

$\mathbf{9}$

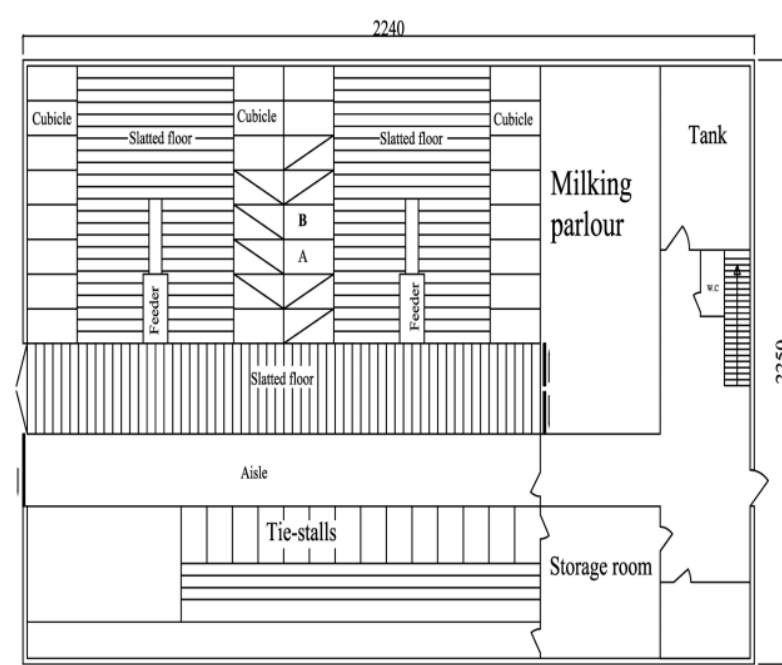

a

Figure 1. Cross-section (left) and plan view of the experimental dairy cow barn. The dairy cow barn had tie and free stalls. Only the free stalls were occupied by cows during the experiment. During the experiment, gas sample locations were placed around cubicles A and B. In addition, sample locations 9 and $10(\boldsymbol{\varpi})$, as indicated in cross section left, were placed to analyse the ventilation rate in the winter. Dimensions are in centimetres.

\subsection{Gas concentrations}

Gas concentrations of $\mathrm{CH}_{4}$ and $\mathrm{CO}_{2}$ were measured with an INNOVA gas monitor 1312 (AirTech Instruments, Denmark) coupled with a multi-point switcher. The gas monitor was calibrated before and after the measurements. The switcher continually drew the air from all sampling locations with a flow rate of $2 \mathrm{~L} \mathrm{~min}^{-1}$ by a pump connected to the exhaust of 


\section{Chapter 3}

the switcher. The switcher sequentially opened the channels to the INNOVA gas monitor to analyse the air from each location. Each location had a measurement period of 3 minutes. Only the value measured in the last minute was used to ensure that the measurement chamber of the gas monitor was completely flushed, so no air of the previous sample location was present.

Nine sample locations were placed at a height of $0.3 \mathrm{~m}$ around two cubicles indicated with A and B in Figure 2. Sample locations 1-7 were in the same line, and locations $3 \mathrm{a}$ and $4 \mathrm{a}$ were in front of the cubicles A and B. Another sample location (8) was placed at a height of $3.5 \mathrm{~m}$ to measure the background concentration in the barn. In addition, during the winter period we placed one sample location (10) close to the ridge, and one (9) outside at a height of $3.5 \mathrm{~m}$ (Figure 1) to assess the ventilation rate. At sample locations of 1, 3, 3a, 4, 4a, 5, 7, and 8 , we collected continually gas measurements during $24 \mathrm{~h}$ to assess the variation within an hour in the summer period. Sample tubes around the cubicles were installed inside steel sticks so that cows could not bite the tubes. Cows were free to use cubicles A and B, while the two adjacent cubicles at each side and the four opposite cubicles were closed.
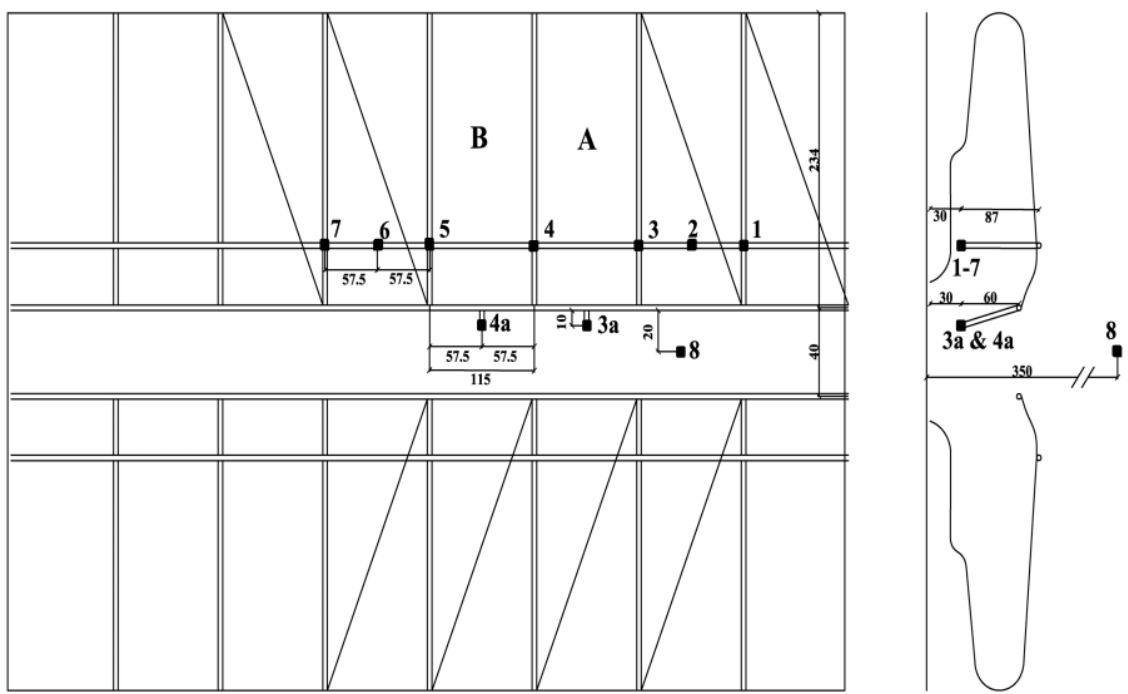

Figure 2. Plan view (left) and cross-section of the cubicles with the distribution of the 9 sample locations around cubicles A and B marked as 1-7, 3a, and 4a. In addition, sample location 8 was places at $3.5 \mathrm{~m}$ above the cubicles. Dimensions are in centimetres. 
Temporal and spatial variation of methane concentration

\subsection{Climate data and animal activity}

Air temperature and humidity were measured every 3 minutes using a sensor (HygroClip S3, Rotronic) that was placed at sample location 8. An air velocity sensor (SS 20.01, SCHMIDT Technology) was installed at the height of $0.3 \mathrm{~m}$ in the cubicle beside cubicle A; it measured air velocity every 3 minutes. In front of the cubicles $\mathrm{A}$ and $\mathrm{B}$, two video cameras were installed to continually record the cows' presence or absence in the cubicles.

\subsection{Ventilation rates}

The ventilation rate in the winter period was calculated by the $\mathrm{CO}_{2}$ mass balance method, using the following equation:

$\mathrm{VR}=\frac{10^{6} \mathrm{G}_{\mathrm{co}_{2}}}{\mathrm{C}_{\mathrm{co}_{2}, \mathrm{in}^{-}-\mathrm{C}_{\mathrm{co}_{2}, \mathrm{out}}}}$

Where, VR is the ventilation rate of the barn in $\mathrm{m}^{3} \mathrm{~h}^{-1} ; \mathrm{C}_{\mathrm{co}_{2} \text {, in }}$ is the indoor $\mathrm{CO}_{2}$ concentration in ppm; $\mathrm{C}_{\mathrm{Co}_{2}, \text { out }}$ is the outdoor $\mathrm{CO}_{2}$ concentration in ppm; $\mathrm{G}_{\mathrm{co}_{2}}$ is the total $\mathrm{CO}_{2}$ production by the dairy cows in $\mathrm{m}^{3} \mathrm{~h}^{-1}$, which is calculated based on the heat production unit (HPU). One HPU is defined as $1000 \mathrm{~W}$ total heat produced by the livestock at an environmental temperature of $20{ }^{\circ} \mathrm{C} . \mathrm{A} \mathrm{CO}_{2}$ production of $2001 \mathrm{HPU}^{-1} \mathrm{~h}^{-1}$ was recommended to use for individual dairy cows (N. M. Ngwabie et al., 2011). The HPU per cow was calculated by the following equation (CIGR, 2002):

$\mathrm{HPU}=\left(5.6 \times \mathrm{BM}^{0.75}+22 \times \mathrm{MP}+1.6 \times 10^{-5} \times \mathrm{NP}^{3}\right) \times 10^{-3}$

Where, BM is the body weight in kg; MP is the milk production in kg per day; NP is the number of days in pregnancy.

\subsection{Data analysis}

Data was analysed using GenStat 16 statistical system (VSN International Ltd., UK). The number of sample locations in summer $(n=10)$ and winter $(n=12)$ were different. Given the 3 minutes sampling time per location we got 1 or 2 measured values per location per hour. To compare measured concentrations at different sample locations in summer and 


\section{Chapter 3}

winter, we selected the first measured value in each hour. Mean methane concentration of each sample location was calculated with hourly data in summer and winter:

$\mathrm{C}_{\mathrm{i}}=\frac{\sum_{\mathrm{k}=1}^{\mathrm{m}} \sum_{\mathrm{j}=1}^{\mathrm{n}} \mathrm{C}_{\mathrm{ijk}}}{\sum_{\mathrm{k}=1}^{\mathrm{m}} \mathrm{n}_{\mathrm{k}}}$

Where, $C_{i}$ is the mean methane concentration at sample location $i$ in ppm; $C_{i j k}$ is the measured methane concentration of sample location (i) in hour (j) and day (k) in ppm; $n_{k}$ is the number of hours with values within measurement day k (24 or less in case of missing values); $\mathrm{m}$ is the number of measurement days. The temporal coefficient of variation (CV) of each sample location was calculated as:

$\mathrm{CV}_{\mathrm{i} \text {-temporal }}=\frac{\mathrm{SD}_{\mathrm{Ci}}}{\mathrm{C}_{\mathrm{i}}} \times 100 \%$

Where, $\mathrm{SD}_{\mathrm{Ci}}$ is the standard deviation of methane concentration at each sample location in ppm. The spatial CV between sample locations was calculated in two steps. First, we calculated the spatial CV between sample locations in each hour of each measurement day:

$\mathrm{C}_{\mathrm{jk}}=\frac{\sum_{\mathrm{i}=1}^{\mathrm{ns}} \mathrm{C}_{\mathrm{ijk}}}{\mathrm{n}_{\mathrm{s}}}$

$\mathrm{CV}_{\mathrm{jk}-\text { spatial }}=\frac{\mathrm{SD}_{\mathrm{cjk}}}{\mathrm{C}_{\mathrm{ik}}} \times 100 \%$

Where, $\mathrm{SD}_{\mathrm{Cjk}}$ is the standard deviation of methane concentration of all sample locations in each hour $\mathrm{j}$ of each measurement day $\mathrm{k}$ in $\mathrm{ppm} ; \mathrm{n}_{\mathrm{s}}$ is the number of sample locations around the cubicle, which is 9. Second, the spatial CV between sample locations was calculated with each $\mathrm{CV}_{\mathrm{jk}-\text { spatial }}$ :

$\mathrm{CV}_{\text {spatial }}=\sqrt{\frac{\sum_{\mathrm{k}=1}^{\mathrm{m}} \sum_{\mathrm{j}=1}^{\mathrm{n}}\left(\mathrm{CV}_{\mathrm{jk}-\text { spatial }}\right)^{2}}{\sum_{\mathrm{k}=1}^{\mathrm{m}} \mathrm{n}_{\mathrm{k}}}}$

To analyse diurnal and daily variation of methane concentration at the sample locations around the cubicle, we calculated the methane concentration in each hour at the sample 


\section{Temporal and spatial variation of methane concentration}

locations by the following steps. The mean methane concentration of all 9 sample locations in each hour $\left(\mathrm{C}_{\mathrm{jk}}\right)$ was first calculated for every measurement day, so the spatial variation was removed. When we analysed diurnal and daily variation of one sample location, we could skip the step to calculate $\mathrm{C}_{\mathrm{jk}}$. Then the mean methane concentration in the same hour of all days $\left(\mathrm{C}_{\mathrm{j}}\right)$ was averaged as the specific hourly result and the mean methane concentration in the same day of all hours $\left(\mathrm{C}_{\mathrm{k}}\right)$ was averaged as the specific daily result:

$$
\begin{gathered}
C_{j}=\frac{\sum_{k=1}^{m} C_{j k}}{m} \\
C_{\mathrm{k}}=\frac{\sum_{\mathrm{j}=1}^{\mathrm{n}} C_{\mathrm{jk}}}{\mathrm{n}}
\end{gathered}
$$

Therefore, the between days and between hours CV were calculated as:

$$
\begin{aligned}
& \mathrm{CV}_{\text {between-days }}=\frac{\mathrm{SD}_{\mathrm{Cj}}}{\mathrm{C}_{\mathrm{j}}} \times 100 \% \\
& \mathrm{CV}_{\text {between-hours }}=\frac{\mathrm{SD}_{\mathrm{Ck}}}{\mathrm{C}_{\mathrm{k}}} \times 100 \%
\end{aligned}
$$

Where, $\mathrm{SD}_{\mathrm{Ck}}$ is the standard deviation of daily methane concentration in $\mathrm{ppm} ; \mathrm{SD}_{\mathrm{Cj}}$ is the standard deviation of the hourly methane concentration in ppm. To analyse the within hour $\mathrm{CV}$ of methane concentrations at the sample locations we used the one-day continual measurement; we first calculated the within-hour CV in each hour:

$$
\begin{aligned}
& \mathrm{C}_{\mathrm{ij}}=\frac{\sum_{\mathrm{l}=1}^{\mathrm{Z}} \mathrm{C}_{\mathrm{ijl}}}{n_{z}} \\
& \mathrm{CV}_{\mathrm{ij} \text {-within-hour }}=\frac{\mathrm{SD}_{\mathrm{Cij}}}{\mathrm{C}_{\mathrm{ij}}} \times 100 \%
\end{aligned}
$$

Where, $\mathrm{C}_{\mathrm{ijl}}$ is the measured methane concentration in every three minutes (1) of a sample location (i) in a certain hour (j) in ppm; $n_{z}$ is the number of measurements within an hour; $\mathrm{SD}_{\mathrm{Cij}}$ is the standard deviation of $\mathrm{C}_{\mathrm{ijl}}$ in $\mathrm{ppm}$; Then the within-hour $\mathrm{CV}$ at the sample location was calculated with each $\mathrm{CV}_{\mathrm{ij}-\text { within-hour: }}$ 


\section{Chapter 3}

$\mathrm{CV}_{\mathrm{i}-\text { within-hour }}=\sqrt{\frac{\sum_{\mathrm{j}=1}^{\mathrm{n}}\left(\mathrm{CV}_{\mathrm{ij}-\text { within-hour })^{2}}\right.}{\mathrm{n}}}$

Effects of daily temperature, humidity, air velocity, and ventilation rate on the average daily methane concentration of sample locations around the cubicle were studied by a linear regression model. The effect of the presence and absence of cows on methane concentration at the sample locations around the cubicle was analysed for four situations: (1) situation-00 where both cubicles A and B were empty; (2) situation-10 where only cubicle A was occupied; (3) situation-01 where only cubicle B was occupied; (4) situation-11 where both cubicles A and B were occupied. During the summer period, all cows normally pastured outside between 1000 and 1500h, while cows stayed inside all day during the winter period. To exclude the effect of pasturing, we assessed the effect of cows' absence and presence in the cubicles on methane concentrations from 1800 to $0500 \mathrm{~h}$.

The methane produced by manure $\left(\mathrm{MC}_{\mathrm{m}}\right)$ only was calculated with concentration data of the sampling location 8 from 1200 to $1400 \mathrm{~h}$ during the summer period (no cows present). The total methane production by manure plus cows $\left(\mathrm{MC}_{\mathrm{t}}\right)$ was calculated with concentration data of the same sampling point between 1900 and $0500 \mathrm{~h}$ when both cubicles $A$ and $B$ were occupied by cows. Subsequently, the relative contribution of manure $\left(\mathrm{P}_{\mathrm{m}}\right)$ in the overall methane production was calculated as:

$\mathrm{P}_{\mathrm{m}}=\frac{\mathrm{MC}_{\mathrm{m}}-\mathrm{C}_{\text {outdoor }}}{\mathrm{MC}_{\mathrm{t}}-\mathrm{C}_{\text {outdoor }}} \times 100 \%$

Where, $\mathrm{C}_{\text {outdoor }}$ is the background methane concentration of $1.8 \mathrm{ppm}$ in the atmosphere suggested by IPCC (2013).

To explore the possibility to assess the methane production of individual dairy cows in cubicles, we analysed the application of the breath methane concentration and the flux method. Methane production of individual cows follows from the product of the cow's air exchange rate and the difference between the emitted and inhaled methane concentration:

$\mathrm{MPR}=\mathrm{Q} \times\left(\mathrm{C}_{\mathrm{br}}-\mathrm{C}_{\mathrm{bg}}\right) \times \rho \times 10^{-6}$ 


\section{Temporal and spatial variation of methane concentration}

Where, MPR is the methane production rate in $\mathrm{g} \mathrm{min}^{-1}$; $\mathrm{Q}$ is the cow's air exchange rate in 1 $\min ^{-1}$, which can be calculated by multiplying the cows' tidal volume and breath frequency; $\mathrm{C}_{\mathrm{br}}$ is the methane concentration in the cows' breath during exhalation in ppm; $\mathrm{C}_{\mathrm{bg}}$ is the methane concentration of the background air that is inhaled in ppm; $\rho$ is the methane density under normal condition in $\mathrm{g}^{-1}$.

In a breath methane concentration method, a sampling tube is normally placed closely to the cow' nose to continuously analyse the methane concentrations in the cow's breath. Due to mixing of the breath air with the background air, the measured methane concentration $\left(\mathrm{C}_{\mathrm{m}}\right)$ can be derived as follows:

$\mathrm{C}_{\mathrm{m} 1}=\delta \times \mathrm{C}_{\mathrm{br}}+(1-\delta) \times \mathrm{C}_{\mathrm{bg}}$

Where, $\mathrm{C}_{\mathrm{m} 1}$ is the measured methane concentration in ppm, $\delta$ (range 0-1) is the sampled fraction of the exhaled breath air in the mixed air that is measured (SFMC). By integrating Equations 16-17, the methane production of an individual cow can be determined by the breath methane concentration as follows:

$\mathrm{MPR}_{1}=\mathrm{Q} \times\left(\mathrm{C}_{\mathrm{m} 1}-\mathrm{C}_{\mathrm{bg}}\right) \times \frac{1}{\delta} \times \rho \times 10^{-6}$

In a methane flux method, the breath air of a cow is captured by an airflow and the methane concentration of the airflow is measured. The methane production rate of a cow is then calculated using the measured methane concentration and airflow rate.

$\mathrm{MPR}_{2} \times \tau=\mathrm{F} \times\left(\mathrm{C}_{\mathrm{m} 2}-\mathrm{C}_{\mathrm{bg}}\right) \times \rho \times 10^{-6}$

Where, $\tau$ (range $0-1$ ) is the captured fraction of the real methane flux from the cow's rumen (CFMF); $\mathrm{F}$ is the capture flow rate in $1 \mathrm{~min}^{-1} ; \mathrm{C}_{\mathrm{m} 2}$ is the methane concentration of the airflow in ppm. So, the methane production of the methane flux method can be calculated as:

$\mathrm{MPR}_{2}=\mathrm{F} \times\left(\mathrm{C}_{\mathrm{m} 2}-\mathrm{C}_{\mathrm{bg}}\right) \times \frac{1}{\tau} \times \rho \times 10^{-6}$ 


\section{Chapter 3}

With Equation 18 and 20, effects of background methane variations on measured methane production can be analysed in both the methane concentration and flux method.

$$
\begin{aligned}
& \mathrm{MPR}_{1 \mathrm{bg}}=\mathrm{Q} \times\left(\mathrm{C}_{\mathrm{m} 1}-\mathrm{C}_{\mathrm{bg}} \times\left(1 \pm \frac{\alpha}{100}\right)\right) \times \frac{1}{\delta} \times \rho \times 10^{-6} \\
& \mathrm{MPR}_{2 \mathrm{bg}}=\mathrm{F} \times\left(\mathrm{C}_{\mathrm{m} 2}-\mathrm{C}_{\mathrm{bg}} \times\left(1 \pm \frac{\alpha}{100}\right)\right) \times \frac{1}{\tau} \times \rho \times 10^{-6}
\end{aligned}
$$

Where, $\mathrm{MPR}_{1 \mathrm{bg}}$ and $\mathrm{MPR}_{2 \mathrm{bg}}$ are the measured methane production rates of an individual cow under variable of background concentration of methane, in $\mathrm{g} \min ^{-1} ; \alpha$ is the measurement $\mathrm{CV}$ of the background methane concentration in \%. By integrating Equation 18 and 21, and Equation 20 and 21, we can express the CV $(\theta)$ of measured methane production both in the methane concentration and the flux method:

$$
\begin{aligned}
& \theta_{\mathrm{MPR} 1 \mathrm{bg}}= \pm \frac{\mathrm{MPR}_{1 \mathrm{bg}}-\mathrm{MPR}_{1}}{\mathrm{MPR}_{1}} \times 100 \%= \pm \alpha \times \frac{\mathrm{Cbg}_{\mathrm{bg}} \times \rho}{\mathrm{MPR}_{1} \times \delta} \times 10^{-6} \\
& \theta_{\mathrm{MPR} 2 \mathrm{bg}}= \pm \frac{\mathrm{MPR}_{2 \mathrm{bg}}-\mathrm{MPR}_{2}}{\mathrm{MPR}_{2}} \times 100 \%= \pm \alpha \times \frac{\mathrm{Cbg}_{\mathrm{bg}} \times \rho}{\mathrm{MPR}_{2} \times \tau} \times 10^{-6}
\end{aligned}
$$

To analyse the CV $(\theta)$ of measured methane production, we used three levels for $\alpha(50,80$, and $150 \%)$ and $\mathrm{C}_{\mathrm{bg}}(20,35$, and $50 \mathrm{ppm})$ based on measured results in this study. Besides, the SFMC ( $\delta$ ) is analysed in six levels from 0.05 to 0.3 in methane concentration method (Equation 23) and captured flow rate (F) is analysed in four levels from 50 to $200 \mathrm{~m}^{3} \mathrm{~h}^{-1}$ in the methane flux method (Equation 24). For other variables, we used a mean methane production of $300 \mathrm{~g} \mathrm{day}^{-1}$ for $\mathrm{MPR}_{1}$ and $\mathrm{MPR}_{2}$ (Blaxter and Clapperton, 1965; Yan et al., 2010), $0.668 \mathrm{~g} \mathrm{l}^{-1}$ for $\rho$ under normal conditions, $1321 \mathrm{~min}^{-1}$ for Q (Gallivan, McDonell, \& Forrest, 1989; Stevens, 1981), and 0.95 for $\tau$ (Wu et al, 2016a; unpublished).

The influence of the measurement $\mathrm{CV}$ of SFMC and CFMF on the measured methane production were calculated as follows:

$$
\begin{aligned}
& \mathrm{MPR}_{1 \delta}=\mathrm{Q} \times\left(\mathrm{C}_{\mathrm{m} 1}-\mathrm{C}_{\mathrm{bg}}\right) \times \frac{1}{\delta \times\left(1 \pm \beta_{1} / 100\right)} \times \rho \times 10^{-6} \\
& \mathrm{MPR}_{2 \tau}=\mathrm{F} \times\left(\mathrm{C}_{\mathrm{m} 2}-\mathrm{C}_{\mathrm{bg}}\right) \times \frac{1}{\tau \times\left(1 \pm \beta_{2} / 100\right)} \times \rho \times 10^{-6}
\end{aligned}
$$


Temporal and spatial variation of methane concentration

Where $\mathrm{MPR}_{1 \delta}$ and is $\mathrm{MPR}_{2 \tau}$ are the measured methane production of an individual cow under variable of SFMC and CFMF, in $\mathrm{g} \min ^{-1} ; \beta$ is the $\mathrm{CV}$ of SFMC and CFMF in \%. By integrating Equation 18 and 25, and Equation 20 and 26, we can express the CV $(\theta)$ of measured methane production both in methane concentration and flux method:

$$
\begin{aligned}
& \theta_{\mathrm{MPR} 1 \delta}== \pm \frac{\mathrm{MPR}_{1 \delta}-\mathrm{MPR}_{1}}{\mathrm{MPR}_{1}} \times 100 \%= \pm \frac{\beta_{1} / 100}{1+\beta_{1} / 100} \times 100 \% \\
& \theta_{\mathrm{MPR} 2 \tau}== \pm \frac{\mathrm{MPR}_{2 \tau}-\mathrm{MPR}_{2}}{\mathrm{MPR}_{2}} \times 100 \%= \pm \frac{\beta_{2} / 100}{1+\beta_{2} / 100} \times 100 \%
\end{aligned}
$$

\section{Results and discussion}

\subsection{Spatial and temporal variation of the methane concentration in and around the cubicles}

\subsubsection{Spatial variation}

Figure 3 shows the mean methane concentrations $\left(C_{i}\right.$, see Equation 3$)$ and temporal $C V$ $\left(\mathrm{CV}_{\mathrm{i} \text {-temporal, }}\right.$, see Equation 4) at sample locations 1-7 and 8 during the summer and winter period. Mean methane concentrations in the summer period at location 1-7 (29-37 ppm) were slightly lower than in the winter period (33-51 ppm), which was attributed to the higher ventilation rate in summer. Methane concentrations at location 1-7 around the cubicles were in the summer $9 \mathrm{ppm}$ and in the winter period $6 \mathrm{ppm}$ higher than at location 8 above the cubicles; sample locations 1-7 were closer to the cows, being the main methane source in the barn (Holter \& Young, 1992; Ngwa M. Ngwabie et al., 2014). The highest methane concentrations were measured at sample locations $3 \mathrm{a}$ and $4 \mathrm{a}$, both in the summer and winter; these locations were closest to the cows' mouth and the least dilution with other air occurred. The slightly higher methane concentrations at location 2 and 6 , in the empty cubicles besides A and B, as compared to location 3, 4, and 5 within cubicle A and B could be explained by the often seen side-ward head position of the cows in cubicle A and B. Sample locations 1 and 7 had higher methane concentrations than sample locations 2 and 6 in summer, but not in winter. This was attributed to the airflow pattern in the barn, as 


\section{Chapter 3}

location 1 and 7 were not directly influenced by cows. The spatial $\mathrm{CV}\left(\mathrm{CV}_{\text {spatial }}\right.$, see Equation 7) between sample locations 1-7 was 71\% in summer and 58\% in winter (Table 1), which exemplified the large range of measured concentrations (3-151 ppm in summer and 12-117 ppm in winter period). In short, methane concentrations around the cubicles were higher than above the cubicles and varied between locations because of the cows' head position and airflow pattern.

Table 1. Spatial, temporal, between-days, between-hours, and within-hour coefficient of variance of methane concentration measured at sample locations 1-7 in the cubicle and 8 in the head space of the barn during summer and winter.

\begin{tabular}{|c|c|c|c|c|c|c|c|c|c|}
\hline \multirow{3}{*}{ Location } & \multicolumn{9}{|c|}{ Coefficient of variance (\%) } \\
\hline & \multicolumn{2}{|c|}{ Spatial } & \multicolumn{2}{|c|}{ Temporal } & \multicolumn{2}{|c|}{ Between-days } & \multicolumn{2}{|c|}{ Between-hours } & \multirow{2}{*}{$\begin{array}{c}\text { Within-hour } \\
\text { Summer }\end{array}$} \\
\hline & Summer & Winter & Summer & Winter & Summer & Winter & Summer & Winter & \\
\hline 1 & & & 141 & 76 & 108 & 56 & 110 & 58 & 84 \\
\hline 2 & & & 131 & 79 & 109 & 62 & 98 & 65 & - \\
\hline 3 & & & 114 & 73 & 99 & 53 & 89 & 58 & 75 \\
\hline $3 a$ & & & 150 & 109 & 119 & 77 & 113 & 74 & 78 \\
\hline 4 & 71 & 58 & 146 & 57 & 97 & 48 & 97 & 53 & 103 \\
\hline $4 a$ & & & 148 & 76 & 111 & 55 & 105 & 60 & 78 \\
\hline 5 & & & 120 & 72 & 98 & 56 & 98 & 63 & 89 \\
\hline 6 & & & 153 & 91 & 115 & 63 & 101 & 71 & - \\
\hline 7 & & & 115 & 59 & 102 & 49 & 100 & 54 & 80 \\
\hline $1-7$ & - & - & - & - & 64 & 34 & 65 & 33 & - \\
\hline 8 & - & - & 65 & 38 & 55 & 35 & 58 & 30 & 34 \\
\hline
\end{tabular}




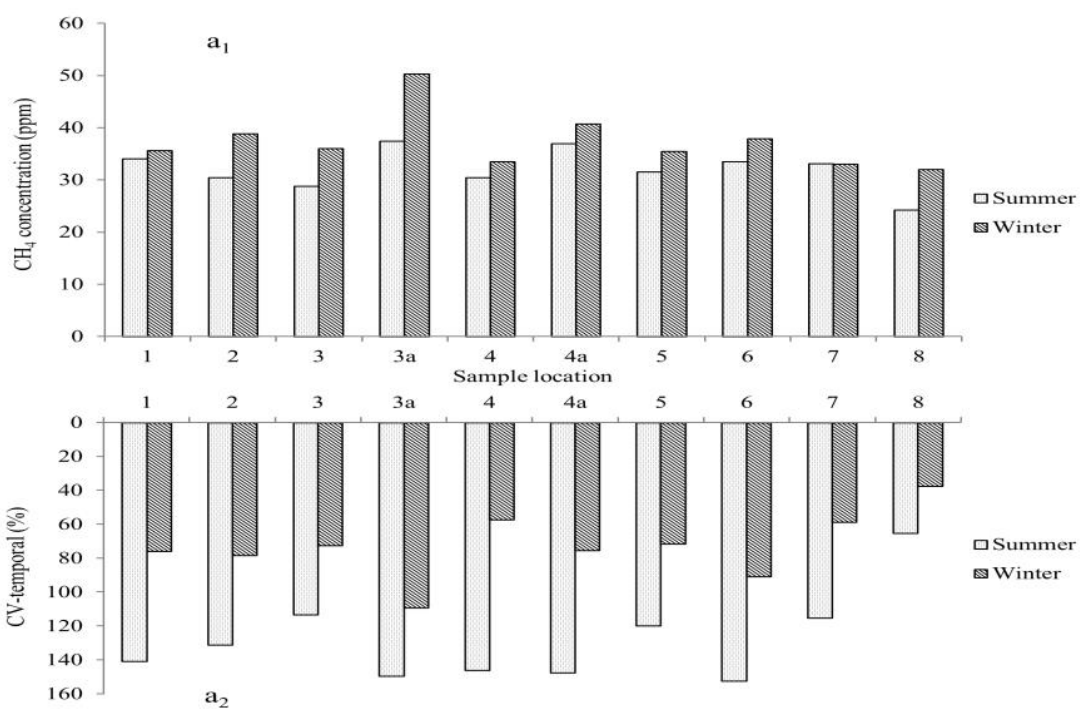

Figure 3. Spatial variation of the methane concentration $\left(a_{1}\right)$ and temporal coefficient of variation $\left(a_{2}\right)$ at sample locations 1-8 in summer and winter. Mean methane concentration at each sample location $\left(\mathrm{C}_{\mathrm{i}}\right)$ and temporal coefficient of variation $\left(\mathrm{CV}_{\mathrm{i} \text {-temporal }}\right)$ were calculated by Equation 3 and 4 respectively.

\subsubsection{Temporal variation}

Besides the spatial variations, methane concentrations at sample locations 1-8 also showed temporal variations (Figure $\left.3, \mathrm{a}_{2}\right)$. In the summer period, temporal $\mathrm{CV}\left(\mathrm{CV}_{\mathrm{i} \text {-temporal }}\right.$, see Equation 4) was $114-153 \%$ at sample locations 1-7 around the cubicles and only $66 \%$ at sample location 8 above the cubicles. Temporal CV in winter was lower, with $57-109 \%$ at sample locations 1-7 around the cubicles and only 38\% at sample location 8 above the cubicles. The higher temporal CV at location 1-7 could be explained by the variation in methane concentration in breath air during an eructation from an individual cow, which can vary from 300-3000 ppm (Chagunda, Ross, \& Roberts, 2009; Garnsworthy, Craigon, Hernandez-Medrano, \& Saunders, 2012; Lassen, Løvendahl, \& Madsen, 2012). The lower temporal $\mathrm{CV}$ at sample location 8 was explained by the mixing of methane from the various sources (cows, manure, and pit) with barn air. Both the level and CV of methane concentrations at location 8 were in the same range as in other studies (Groot Koerkamp et al., 1998; N. M. Ngwabie, Jeppsson, Nimmermark, Swensson, \& Gustafsson, 2009; Wu et 


\section{Chapter 3}

al., 2012) and agree with the range of mean dairy barn concentration in the Netherlands (Mosquera et al., 2013). Temporal CV in summer was higher than in winter at sample locations 1-8 because of smaller and probably less variable ventilation rates in winter due to (partly) closing of ventilation openings. Sample locations with higher mean methane concentrations, for instance $3 \mathrm{a}$ and $4 \mathrm{a}$, also had a higher temporal $\mathrm{CV}$ because of variation caused by the cows' presence. But at sample locations 1 and 7, most variation must have been caused by the airflow pattern in the barn. In short, temporal variation around the cubicles was substantially higher than above the cubicles, and affected by presence of cows and ventilation rate and pattern.

\subsection{Diurnal and daily variation of the methane concentration in and around the cubicles}

\subsubsection{Diurnal variation}

Diurnal variation of methane concentration $\left(\mathrm{C}_{\mathrm{j}}\right.$, see Equation 8$)$ at sample locations 1-7 and 8 are shown in Figure $4\left(a_{1}\right.$ and $\left.b_{1}\right)$. Sample location 8 had a similar overall diurnal variation as sample locations 1-7, both in summer and winter. Between-hours CV $\left(\mathrm{CV}_{\text {between-hours }}\right.$, see Equation 11) was $65 \%$ and $33 \%$ at sample locations $1-7$, and $58 \%$ and $30 \%$ at sample locations 8 , in summer and winter respectively (Table 1). This corresponded with the higher methane concentrations and steeper changes between hours at sample locations 1-7, as seen in Figure 4. In the summer period, methane concentrations at sample locations 1-7 and 8 were higher than during the day than the night. Between-days CV $\left(\mathrm{CV}_{\text {between-days }}\right.$, see Equation 10$)$ during the day was about twice as high as during the night. In the day, cows were pastured outside and ventilation rates were also higher than in the night. Diurnal variations of methane concentration were also affected by the management. A first drop of the methane concentration was seen at $0600 \mathrm{~h}$ when cows were milked in the milking parlour. A second drop was visible at $0800 \mathrm{~h}$ when the side door of the barn was opened for cows to pasture outside, which caused a higher ventilation rate and less methane produced as the number of cows in the barn was reduced. The increase at $1300 \mathrm{~h}$ was probably related to the supply of feed at $1100 \mathrm{~h}$ and some cows returned from pasture. Such 


\section{Temporal and spatial variation of methane concentration}

an increase was also reported in other studies (N. M. Ngwabie et al., 2011; Wu et al., 2012). When all cows were back to the barn at $1700 \mathrm{~h}$, methane concentrations increased again.
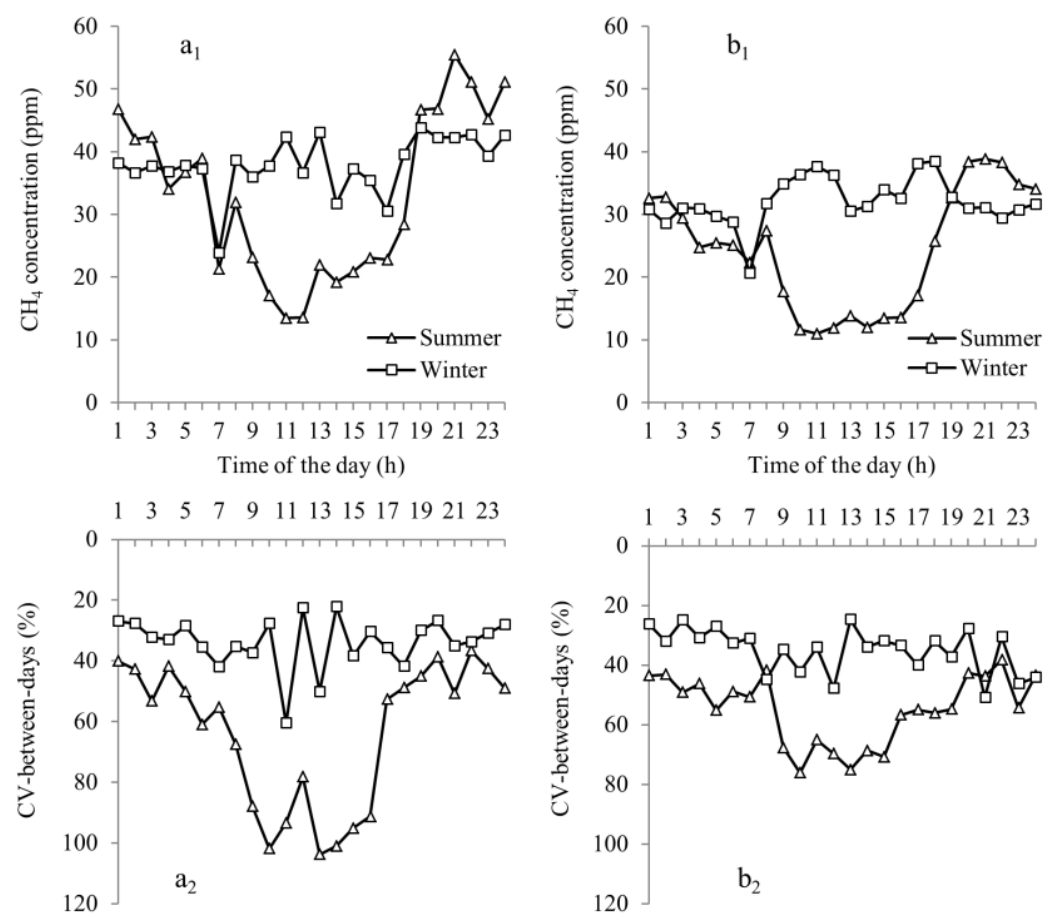

Figure 4. Diurnal mean methane concentration and between-days coefficient of variation at sample location 1-7 ( $\mathrm{a}_{1}$ and $\left.a_{2}\right)$ and $8\left(b_{1}\right.$ and $\left.b_{2}\right)$ during the summer and winter period. Methane concentration in each hour $\left(C_{j}\right)$ and between-days coefficient of variation $\left(\mathrm{CV}_{\text {between-days }}\right)$ at the sample locations were calculated by Equation 8 and 10 respectively.

In the winter period, methane concentrations varied less between day and night. The largest fluctuations of between-days $\mathrm{CV}$ at sample locations 1-7 were between 1000 and $1500 \mathrm{~h}$, which may be related to the cows' activity in the day. A methane concentration drop was seen at $0600 \mathrm{~h}$ related to the milking time. But no clear feeding effect on methane concentrations was seen. Summarizing, diurnal variations of methane concentrations around the cubicle were higher than above the cubicle. Methane concentrations both around and above cubicles had higher variations in summer than in winter. These variations were mainly affected by the ventilation rate and management (milking and feeding). 


\section{Chapter 3}

\subsubsection{Daily variation}

Daily variation of methane concentrations $\left(C_{k}\right.$, see Equation 9$)$ at sample location 1-7 and 8 are shown in Figure 5. Sample location 1-7 showed higher methane concentrations than sample location 8 , both in the summer and winter period. These differences were caused by the closer sample distance to the cows of sample locations 1-7. The daily variation was mainly caused by different ventilation rates and patterns. With a lower ventilation rate in winter, between days CV was lower both at sample location 1-7 and 8 (Table 1). In short, sample locations around the cubicle showed higher daily methane concentrations than the sample location above the cubicles, however pattern of variation were similar.

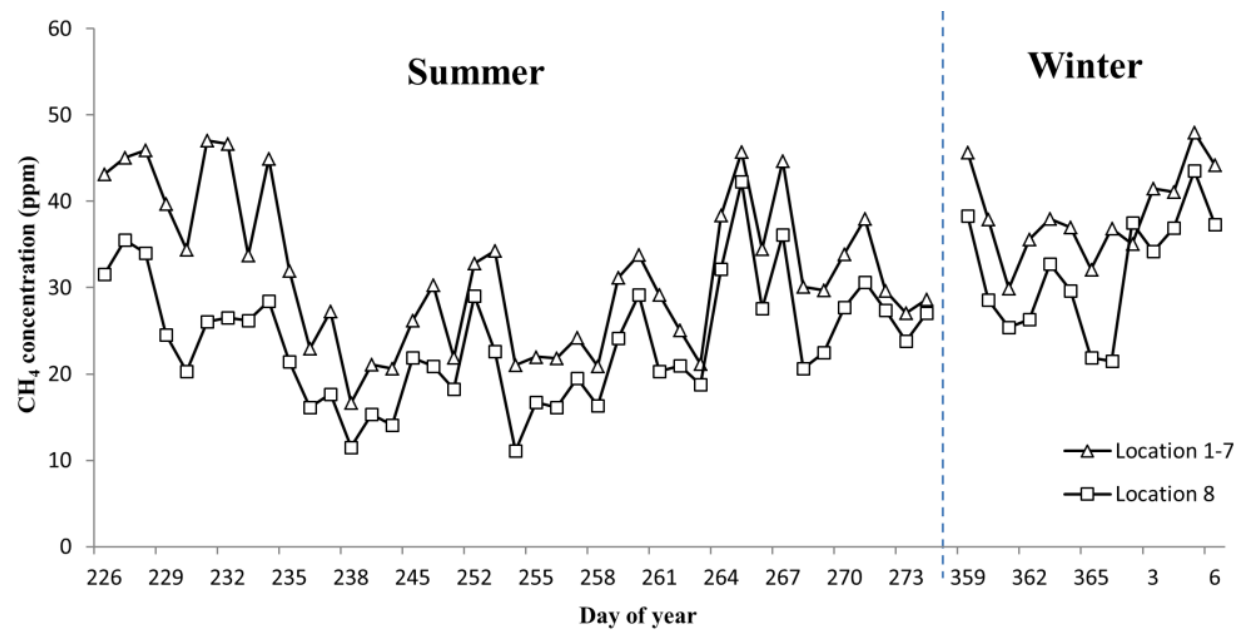

Figure 5. Daily mean methane concentration at sample location 1-7 and 8 during the summer and winter period. Mean methane concentration at each day $\left(C_{k}\right)$ was calculated by Equation 5 and 9 .

\subsection{Effects of cows' presence, indoor climate, ventilation rate, and the contribution of manure to the methane concentration}

\subsubsection{Cows'presence}

The methane concentrations around the cubicles varied from 24 to $53 \mathrm{ppm}$, and 19-55 ppm in summer and winter respectively, and the effects of cows' presence on them are shown in Figure 6. Cows' presence increased methane concentrations remarkably at sample location 


\section{Temporal and spatial variation of methane concentration}

1-7, both in the summer and winter period, with generally the highest methane concentrations in situation-11. The methane concentration levels in situation-01 and situation-10 were generally higher than in situation -00 , but the extent varied between sample locations. These variations were attributed to the cows' head position and movement and the airflow patterns around the cubicle. The methane concentration at sample location 8 above the cubicles was also lowest for situation-00, but showed much less variation between the four situations. Hence, cows' presence increased methane concentrations at cubicle level, and differences between sample locations were mainly caused by the cows' head movement and airflow pattern.
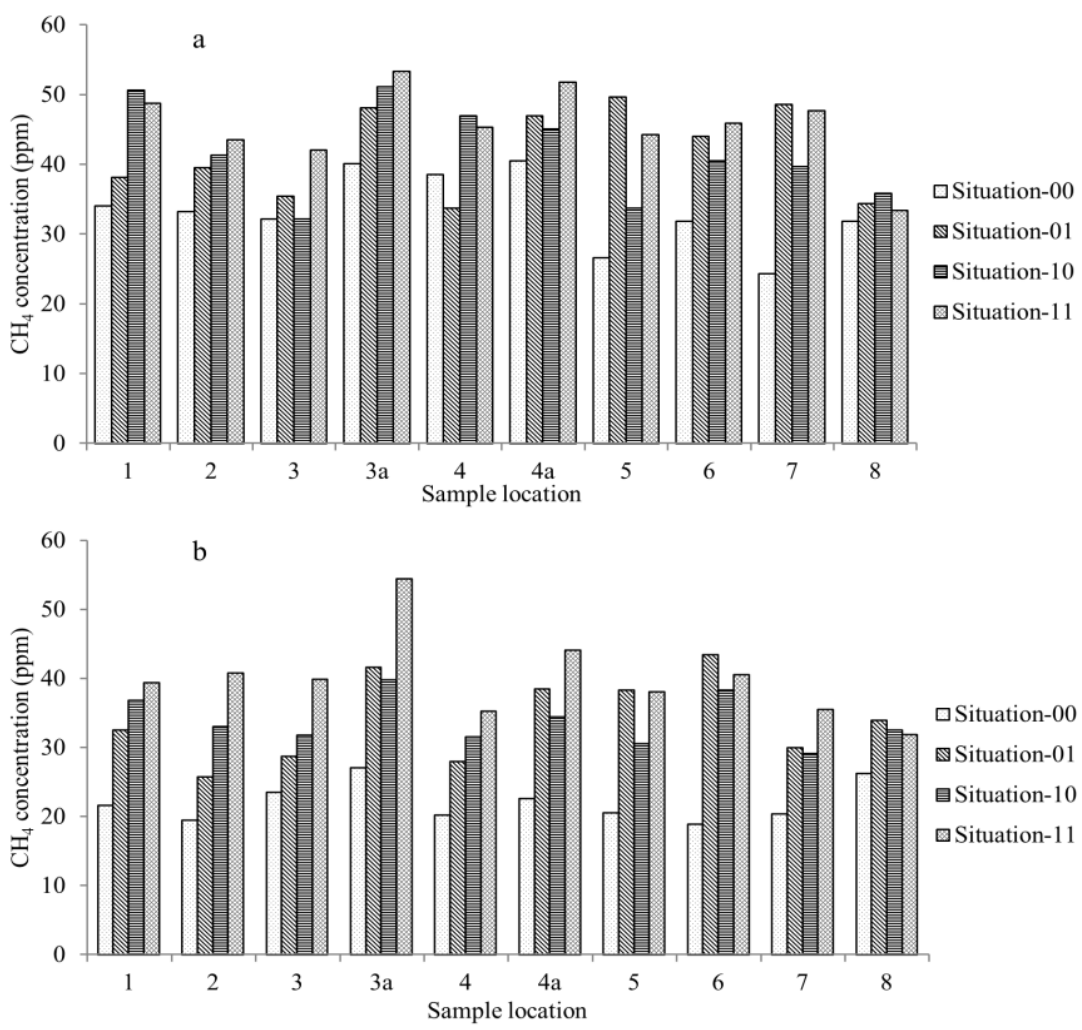

Figure 6. Methane concentration at sample locations 1-8 during the summer (a) and winter (b) period with cows' presence in cubicles A and B. Situation-AB: A or B $=0$ means the cubicle was empty, while A or B $=1$ means the cubicle was occupied by a cow. 


\section{Chapter 3}

\subsubsection{Indoor climate and ventilation rate}

Effects of indoor climate and ventilation rate on daily methane concentrations at sample locations 1-7 during summer and winter are shown in Figure 7. Indoor air temperature showed a positive correlation with methane concentrations, which was probably related to the cows' activity and higher anaerobic decomposition of manure, as methane is the product of enteric fermentation and anaerobic decomposition of manure in the barn (Moss, Jouany, \& Newbold, 2000). In general, cows are less active when it is hot. When the temperature increased, cows probably rested and had more time to ruminate. Also methane produced by manure increases by a higher temperature (Pereira et al., 2011). Indoor air humidity had a negative relation in the summer, and a positive relation in the winter with methane concentration. In the summer, air velocity ranged between 0.10 and $0.35 \mathrm{~m} \mathrm{~s}^{-1}$ around the cubicles, and showed a negative effect on the methane concentration. With a higher air velocity, emitted methane is quicker diluted and transported away. In the winter, the ventilation rate of the barn was 4.5-9.9 $\mathrm{m}^{3} \mathrm{~s}^{-1}$, which equalled to $704-1550 \mathrm{~m}^{3} \mathrm{~h}^{-1}$ per cow. The increasing ventilation rate also had a negative effect on the methane concentration as had air velocity. In short, indoor air temperature had a positive and air velocity and ventilation rate had a negative effect on methane concentration around the cubicles, both in the summer and winter. 


\section{Temporal and spatial variation of methane concentration}
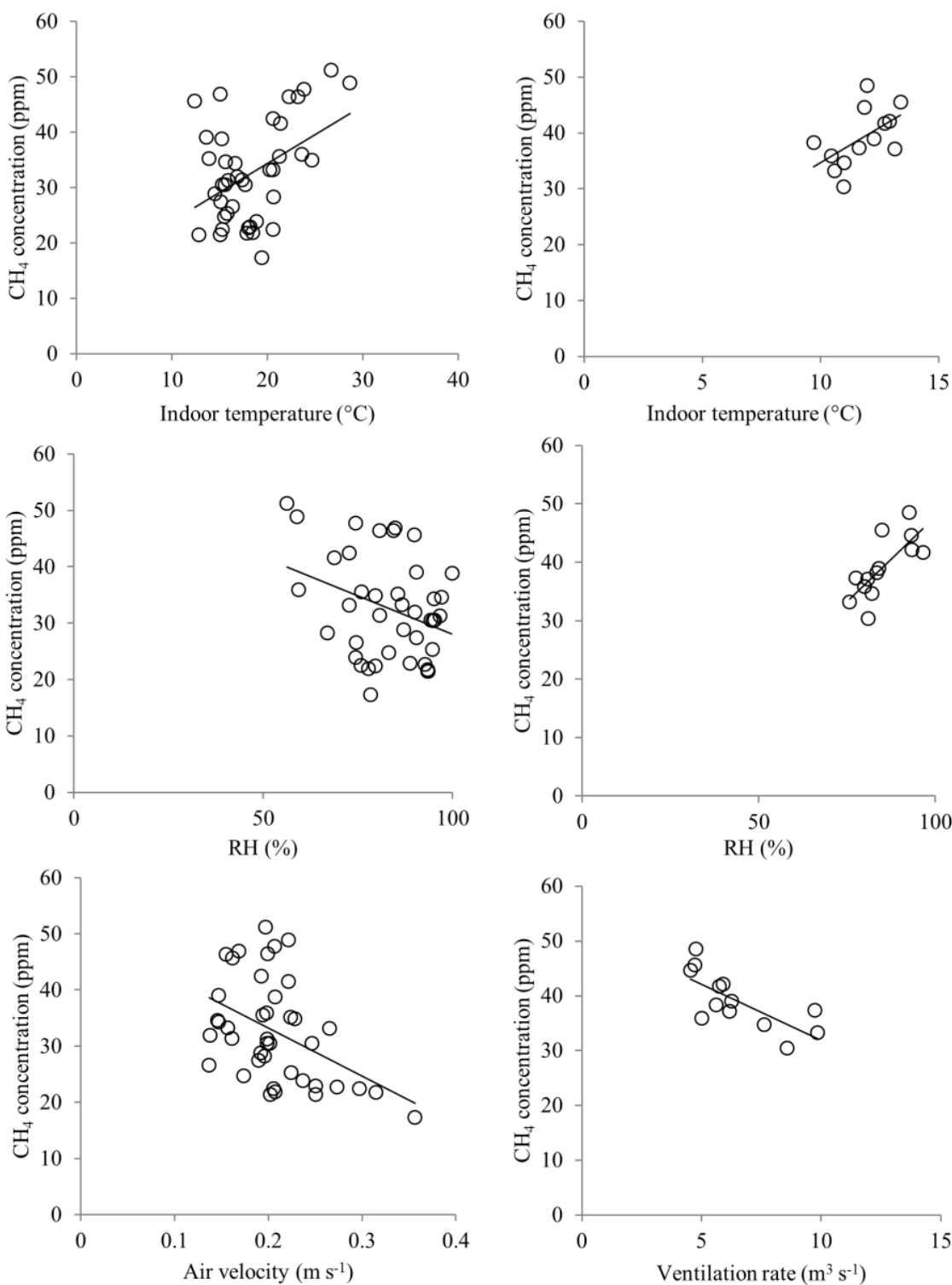

Figure 7.The relation between methane concentration at sample locations 1-7 during summer (graphs left) and winter (graphs right) period, and indoor temperature, relative humidity $(\mathrm{RH})$, air velocity, and ventilation rate The symbols represent the daily mean methane concentration at the sample locations 1-7 around the cubicles, and trendlines. 


\section{Chapter 3}

\subsubsection{Methane released from manure}

Anaerobic decomposition makes manure the second important methane source after the cows' enteric fermentation. Methane concentration at sample locations 8 was 8 ppm when no cows were present. When cows were present in the barn the methane concentration at sample location 8 increased to $32 \mathrm{ppm}$. Therefore, methane concentration produced by manure in the storage beneath the slatted floor attributed for $25 \%$ to the total methane concentration produced together by manure and cows at sample location 8 , which is close to the $19 \%$ emission contribution reported by Ngwa M. Ngwabie et al. (2014).

\subsection{Effects of background methane concentration around the cubicles on monitoring individual methane production of cows}

\subsubsection{Background methane concentration level and measurement CV}

Methane production from individual cows is currently determined by breath methane concentration or methane flux methods (Blaxter, Brockway, \& Boyne, 1972; Garnsworthy et al., 2012; Huhtanen, Cabezas-Garcia, Utsumi, \& Zimmerman, 2015). The principles of these two methods are shown in Equation 18 and 20, which show considerable similarity how to calculate the individual methane production rate of a cow. Both methods, and consequently the measurement $\mathrm{CV}$ of them, are affected by the background $\left(\mathrm{C}_{\mathrm{bg}}\right)$ methane concentration, as shown in Equation 23 and 24.

In the breath methane concentration method, measurement $\mathrm{CV}$ of methane production decreases exponentially with increasing SFMC (delta in denominator in Equation 23) for different background methane concentration levels and measurement CV (Figure 8, $\mathrm{a}_{1}$ and $\mathrm{a}_{2}$ ). In the methane flux method, measurement $\mathrm{CV}$ of methane production linearly increases with increasing capture flow rate ( $\mathrm{F}$ in nominator in Equation 24). With a low SFMC or a high capture flow rate, the measured methane concentration is low and close to the background methane concentration. Therefore, effects of variable background methane concentration increases, causing the increase of measurement $\mathrm{CV}$ of methane production. 


\section{Temporal and spatial variation of methane concentration}
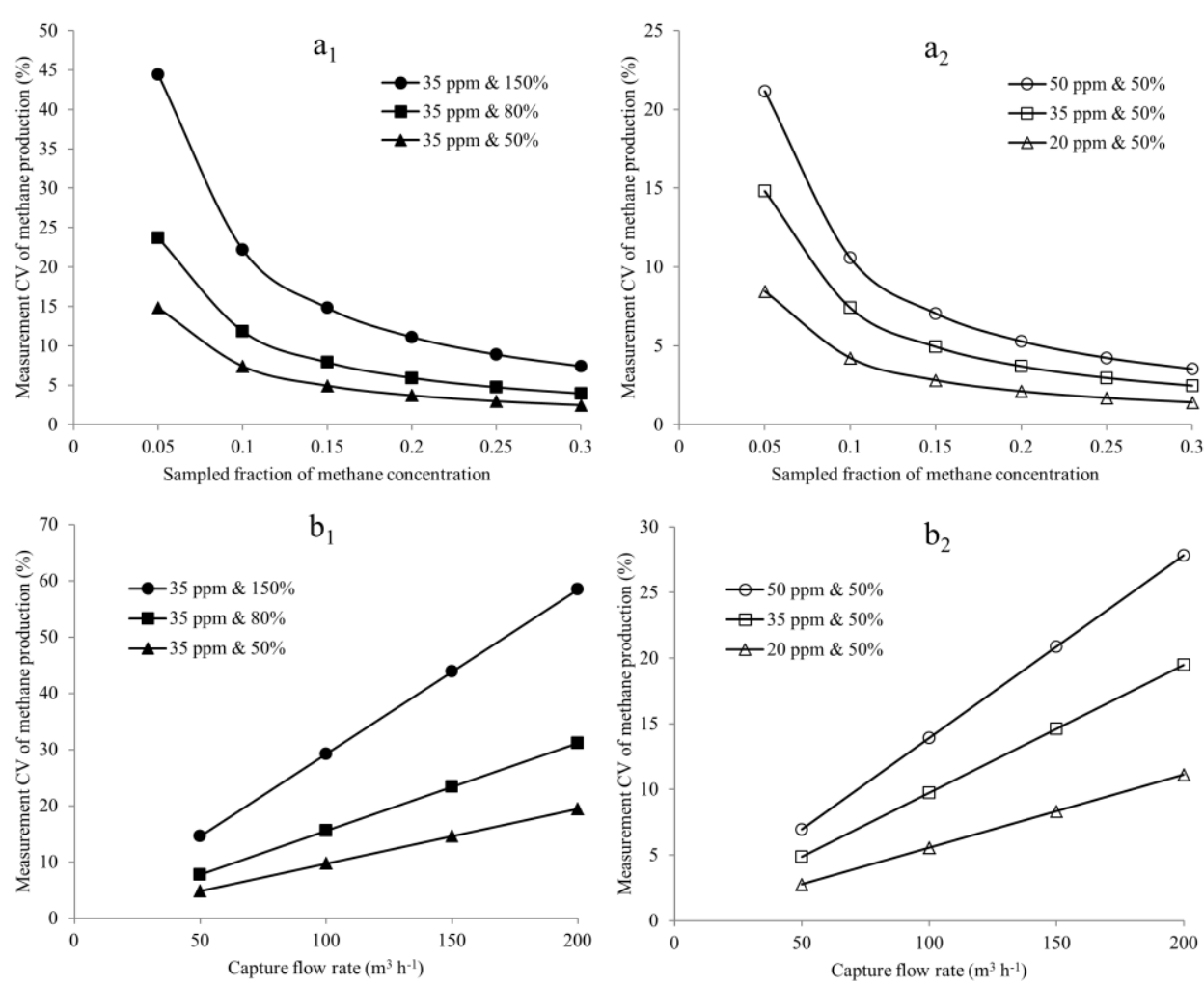

Figure 8. The relation between the measurement coefficient of variation $(\mathrm{CV})$ of the assessed methane production of an individual cow and the sampled fraction of methane concentration (SFMC) in a breath methane concentration method $\left(a_{1}\right.$ and $\left.a_{2}\right)$, and capture flow rate in a methane flux method $\left(b_{1}\right.$ and $\left.b_{2}\right)$, for three levels of background concentration (in ppm) and three levels of the coefficient of variation (in \%). The effects were analysed at a daily methane production of $300 \mathrm{~g} \mathrm{day}^{-1}$.

At a same level of background methane concentration, a higher measurement CV of background methane concentration increases measurement $\mathrm{CV}$ of methane production, both in the methane concentration and the flux method (Figure 8, $a_{1}$ and $b_{1}$ ). A higher measurement $\mathrm{CV}$ of background methane increases variations of measured methane concentration from cows. With these increased variations, the measurement $\mathrm{CV}$ of methane production correspondingly increases. Similarly, at the same measurement CV of background methane concentration, a higher background methane concentration increased the measurement $\mathrm{CV}$ of the methane production (Figure $8, \mathrm{a}_{2}$ and $\mathrm{b}_{2}$ ). This follows from the 


\section{Chapter 3}

fact that a higher background methane concentration results in a smaller difference between measured and background methane concentration, and consequently results in a stronger impact of measurement errors in methane concentration.

\subsubsection{Reduction of the measurement CV of measured methane production}

The effects of variable background methane concentration can be decreased by increasing SFMC in the breath methane concentration method or by decreasing the capture flow rate in the methane flux method. In the breath methane concentration method, measurement $\mathrm{CV}$ of methane production decreases below $10 \%$ when the SFMC increases from 0.05 to 0.3 . Similarly, in the methane flux method, measurement CV of methane production decreases below $15 \%$ when the capture flow rate decreases from 200 to $50 \mathrm{~m}^{3} \mathrm{~h}^{-1}$. With a high SFMC or a low capture flow rate, measured methane concentration $\left(\mathrm{C}_{\mathrm{m}}\right)$ in both methods would be much higher than the background methane concentration, and thus lower the effect on the measured methane production. In the breath methane concentration method, the SFMC can be increased by shortening the sampling distance or reducing aerial disturbances. This was also found experimentally, where the SFMC increased from 0.05 in a cubicle to 0.30 in a feeder of a milking robot (Wu et al, 2016b; unpublished). In the methane flux method, the capture flow rate can easily be reduced by a controlled fan; however this can reduce the CFMF (Wu et al, 2016a; unpublished), and might introduce a systematic error.

\subsubsection{SFMC and CFMF}

Besides the effects of background methane variation, measured methane production can also be affected by a variable SFMC due to unstable barn conditions. The SFMC in the feeder of milking robot was 0.31 on average, and had a measured CV of $24 \%$ (Wu et al, 2016b; unpublished). With this measurement CV, measurement CV of the measured methane production is $19.4 \%$ (Equation 23). Such measurement CV would even be higher in the cubicle because of more disturbed and variable conditions. In a methane flux method, the measurement $\mathrm{CV}$ of CFMF is much smaller because of more controlled and stable conditions. An estimated measurement $\mathrm{CV}$ of $5.0 \%$ results in a measurement $\mathrm{CV}$ of $4.7 \%$ for the measured methane production (Equation 24). 


\section{Temporal and spatial variation of methane concentration}

Given the large effects of the background methane concentration and the SFMC on the measured methane production, we conclude that the breath methane concentration method cannot be used in cubicles. The measurement $\mathrm{CV}$ of the measured methane production could go up to approx. $45 \%$ due to disturbed aerial conditions (Figure 8, $\mathrm{a}_{1}$ ). Additionally, with the variation of SFMC, the measurement CV would be even higher. However, the breath methane concentration method can be used in the feeder of milking robot because of a much higher SFMC (0.30) due to limited and stable mixing of air. Conversely, the methane flux method is more suitable for use in the cubicles. The negative effects of a variable background concentration in this method can be controlled by a reduced capture flow rate (Figure $8, b_{1}$ and $b_{2}$ ), and frequent spatial background methane concentration measurements. Moreover, the measurement CV of CFMF has only small effects because of more controlled and stable conditions in the methane flux method.

\section{Conclusions}

Methane concentrations were measured in and around cubicles of a naturally ventilated dairy barn in summer and winter. The following conclusions were drawn.

- Mean methane concentrations around the cubicle were 29-37 ppm in the summer period and 33-51 ppm in the winter period. Spatial variations of hourly averages of methane concentration around the cubicle were $71 \%$ in the summer and $58 \%$ in the winter period. Temporal variations of hourly averages of methane concentration varied from 115 to $153 \%$ in the summer, and from 57 to $109 \%$ in the winter period among the sample locations around the cubicle. These variations were mainly affected by the airflow patterns and barn management.

- Methane concentrations around the cubicles were positively affected by the presence of cows in the cubicles, and negatively by a higher air velocity around the cubicles and the ventilation rate of the house. The relative contribution of manure in the slurry pit on methane concentration was $25 \%$.

- The level and measurement CV of the background methane concentration strongly increase the overall measurement $\mathrm{CV}$ in both the methane flux and the breath 


\section{Chapter 3}

methane concentration methods. The measurement $\mathrm{CV}$ of assessed methane production of individual cows decreased exponentially with a higher captured fraction of the breath in a concentration method, and increased linearly with higher flow rates in a flux method.

- This study provided essential information to apply both methane concentration and flux methods in dairy barns to assess methane production of individual cows in such a way that measurement $\mathrm{CV}$ of the assessed methane production can be limited.

\section{Acknowledgements}

This study was funded by Wageningen UR Livestock Research, the Ministry of Economic Affairs of the Netherlands (Research Programme Sustainable Agriculture, KB-12-006.03002), and the China Scholarship Council. The authors are thankful to Johan Ploegaert of Wageningen UR Livestock Research, Ries Verkerk and Willem van Ommeren of Wageningen UR Animal Science Group for their technical assist in carrying out the experiments in the dairy barn of Wageningen University. 


\section{CHAPTER 4}

\section{Design and test of an artificial reference cow to simulate methane release through exhalation}

Liansun $\mathrm{Wu}^{1 *}$, Peter W.G. Groot Koerkamp ${ }^{1,2}$, Nico Ogink ${ }^{2}$

1. Farm Technology Group, Wageningen University, P.O. Box 16, 6700 AA, Wageningen,

The Netherlands

2. Wageningen UR Livestock Research, Wageningen University and Research Centre, P.O.

Box 135, 6700 AC, Wageningen, The Netherlands

*Corresponding author: Liansun.wu@wur.nl

This chapter is published in Journal of Biosystems Engineering. 136:39-50. 


\section{Chapter 4}

\section{Abstract}

To mitigate methane emission from dairy cows, a technique is needed to evaluate individual methane emission from a large number of cows under practical conditions in barns. For developing such a measurement technique, a known reference source that can simulate cow exhalation of methane would be a powerful tool to improve and validate measurement methods. The objective of this research was to design, construct, and test an artificial reference cow (ARC). We built a device that simulated exhaling and inhaling cycles and eructation. The ARC consisted of a cylinder in which methane was injected by mass flow controllers and ejected by a piston in the cylinder. The methane mass balance of the ARC, defined as the difference between the mass controllers imposed input and measured output, was tested under three settings. Methane concentration release patterns produced by five simulated cows were compared to patterns measured from real cows. Average methane concentration in exhaled gas had a mean difference of $2.8 \%$ between measured and predicted results. The output methane mass was strongly linearly related to the input methane mass. Methane concentration release patterns produced by the five simulated cows had a sinusoidal curve with similar time interval and comparable methane concentration level as real cows. It is concluded that the ARC properly represented the methane production release, and that the system precisely controlled methane concentration and production. The ARC can be used as a known reference source to develop practical methane measurement methods.

Keywords: Methane emission, dairy, artificial reference cow, mass balance, concentration pattern

\begin{tabular}{ll}
\hline Nomenclature & \\
\hline $\mathrm{BF}$ & Breath frequency (times per minute) \\
$\mathrm{C}_{\mathrm{a}}$ & Methane concentration in ambient air (ppm) \\
$\mathrm{C}_{\mathrm{e}}$ & Mean methane concentration in the exhaled gas (ppm) \\
$\mathrm{C}_{\mathrm{ex}, \text { in }}$ & Methane concentration inside the cylinder of ARC during \\
& exhaling or inhaling $\left(\mathrm{g} \mathrm{l}^{-1}\right)$ \\
$\mathrm{F}$ & Methane flow rate controlled by MFC $\left(\mathrm{min}^{-1}\right)$ \\
$\mathrm{M}$ & Methane mass injection rate by MFC $\left(\mathrm{g} \mathrm{s}^{-1}\right)$ \\
\hline
\end{tabular}




\section{Design and test of an artificial reference cow}

\begin{tabular}{ll}
\hline $\mathrm{M}_{\text {in }}$ & ARC's methane input and output $(\mathrm{g})$ \\
$\mathrm{M}_{\text {out }}$ & ARC's methane input and output $(\mathrm{g})$ \\
$\mathrm{T}_{\mathrm{e}}$ & Measurement time (minute) \\
$\mathrm{T}_{\mathrm{v}}$ & Tidal volume (l) \\
$\mathrm{V}$ & Gas exchange volume rate $\left(\mathrm{s}^{-1}\right)$ \\
$\mathrm{x}$ & Methane mass accumulation rate in the cylinder $\left(\mathrm{g} \mathrm{s}^{-1}\right)$ \\
$\rho$ & Methane density $\left(\mathrm{g}^{-1}\right)$ \\
\hline
\end{tabular}

\section{Introduction}

Efforts to mitigate methane emission from dairy cows are critical to reduce the dairy industry's contribution to the production of greenhouse gases and subsequently to global warming. Among ruminants, dairy cows have been identified as the significant producer of methane emission as they account for $4 \%$ of the anthropogenic greenhouse gas emissions (FAO, 2010). The release of methane by dairy cows also represents a loss of energy for the animal. Mitigating methane emission from dairy cows will therefore benefit not only the environment but may also improve the feed efficiency of cows.

The heritability of methane emission in ruminants was demonstrated in a large scale study with sheep based on respiration chamber measurements (Pinares-Patiño and Hickey, 2013). There are strong indications that methane emission from dairy cows can be mitigated by breeding cows with low methane emission but a breeding approach requires a large number of methane production records from individual cows (De Haas et al., 2011). The high number of cow datasets required for breeding implies that farm measurement methods are needed. In research, the respiration chamber method is considered as the gold standard for determining individual methane production from cows. However, this laboratory method is not suitable for measurements on a large number of animals. Currently, three main techniques are used to measure methane emission from individual cows under farm conditions: 1) the sulphur hexafluoride $\left(\mathrm{SF}_{6}\right)$ tracer method (Grainger et al., 2007; Johnson et al., 1994; Lassey et al., 2011), 2) the breath concentration method (Garnsworthy et al., 2012; Lassen et al., 2012), and 3) the GreenFeed method (C-lock, 2014) The $\mathrm{SF}_{6}$ method is an invasive method that requires inserting a permeation tube into the rumen and attaching a collection canister around its neck, and as such not suited for large scale farm application. 


\section{Chapter 4}

In contrast, the breath concentration method is a non-invasive on-farm method for individual cows, based on monitoring cows' exhaled air in concentrate feeders when visiting the milking parlour. This method monitors the methane concentration in the mixed air near a cow's head during a short period of feeding, and can only be considered as an indirect measure of a cow's actual daily methane production. Conversely, the GreenFeed method is monitoring both methane and carbon dioxide fluxes emitted from the dairy cows when visiting a feeder. However, compared to the average 10 hours ruminating per day per cow, monitoring intervals based on the feeding or milking period are relatively short to determine the daily methane production. Each of the three mentioned methods has limitations either related to its technical complexity and costs or to the short sampling periods. Further improvement of these methods and new concepts of cow monitoring are helpful in implementing a breeding strategy.

The measurement accuracy of the $\mathrm{SF}_{6}$ tracer method, the breath methane-measurement method, and the GreenFeed method is generally validated by comparing the recorded cow values to those derived for the same cows from the respiration chamber method. This method is set as the reference for developing new methods because of its accurate measurement results (Aulick et al., 1983; Hellwing et al., 2012; Rosenbaum et al., 1969; Blaxter et al., 1972; Pinares-Patiño and Waghorn, 2012). In this method a cow is housed in a small confined chamber for several days to monitor its methane release. However, a small and restricted chamber can modify a cow's behaviour, reduce their feed intake and consequently influence methane production (Garnsworthy et al., 2012; Lassen et al., 2012). Moreover, use of the respiration chamber is limited by the time it takes to train an animal for the specific measurement conditions, the number of animals it can handle, and the large expense of building and maintaining a chamber. In short, a respiration chamber is a timeconsuming and costly reference method to manage, and may produce biased results when compared to methane release under farm conditions. Considering these shortcomings, a more practical reference technique would be helpful in research efforts aimed at developing improved farm methods for monitoring cow methane emission. Such an alternative technique could be provided by developing an artificial reference cow (ARC) that mimics the methane release of real cows with known pre-set quantities and that can be used to 


\section{Design and test of an artificial reference cow}

evaluate methods under a wide variety of practical conditions in barns. This would enable instant evaluation of new monitoring methods under barn conditions with high precision, contrary to using real test cows whose methane flux has to be determined in respiration chambers before or afterwards the barn test.

The objective of this study is to design, construct, and evaluate an ARC that meets the following requirements:

- The ARC should be capable of providing cow exhalations with pre-set methane production rates at a high precision level;

- The ARC with known methane production rates and should be capable of mimicking methane release patterns, exhalation volumes and temperatures that are typical for real cows;

- The ARC should operate accurately and stably for a long period under a wide variety of practical laboratory and barn conditions.

The first section of this paper (2.1) describes the schematic and working principle of the ARC we developed, and explains how the basic properties of the ARC were designed to mimic real cow exhalation properties. The following sections (2.2 and 2.3) describe the equipment and equations used in the experimental evaluation of the system. The setup of the ARC evaluation was based on comparing controlled input and measured output at different parameters settings, and comparing realised methane concentration patterns with real cow patterns (2.4 and 2.5). Results of the laboratory evaluation are reported and discussed in section 3 , and conclusions in section 4 .

\section{Materials and methods}

\subsection{Construction of the artificial reference cow}

On average, a dairy cow produces 250 to $400 \mathrm{~g}$ methane per day (Bannink et al., 2011), which is mainly released through eructation from the rumen $(>90 \%)$ and only a small 


\section{Chapter 4}

quantity through the rectum as flatus (Lassey, 2007; Murray et al., 1976; Sejian et al., 2011). This study is focussing on the exhaled methane produced in the rumen because this is by far the major proportion, and as such a good representative of total methane production. This exhalation-based approach is also adapted to current field methods as described before. In the design process of the ARC, only the release through exhalation was considered.

\subsubsection{The working principle}

The ARC (Figure 1) was designed and constructed to simulate a cow's methane production and exhalation procedures during respiration and eructation. The ARC consisted of an aluminium cylinder (Length $\times$ diameter $=40 \times 20 \mathrm{~cm}, 121$ ) to provide a cow's tidal and residual volume during respiration. A rubber piston connected to an actuator was placed inside the cylinder. The actuator was operated by compressed air that drove the piston horizontally up and down to simulate a cow's inhaling and exhaling processes.

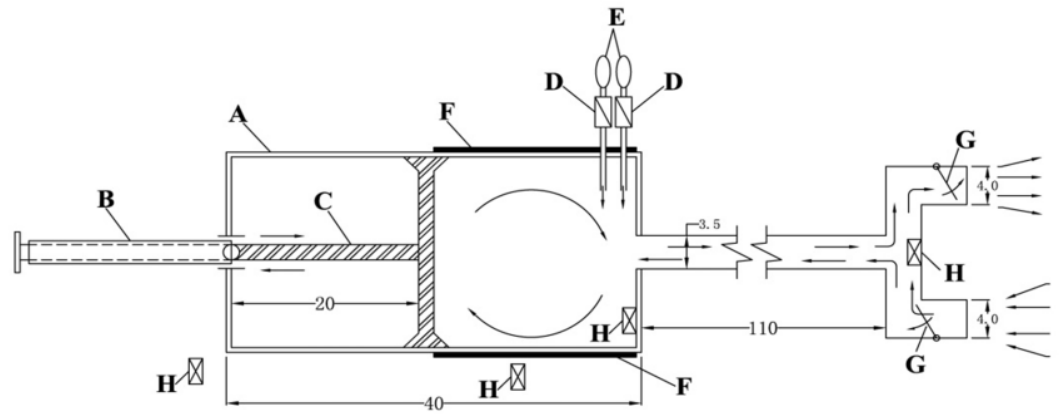

Figure 1. Schematic overview of the ARC: (A) a $40 \times 20 \mathrm{~cm}$ cylinder, (B) an actuator, (C) the stroke of the actuator that can move the piston between 0 and $20 \mathrm{~cm}$, (D) two mass flow controllers, (E) two pure $\mathrm{CH}_{4}$ and $\mathrm{CO}_{2}$ cylinders, (F) a $20 \times 62 \mathrm{~cm}$ heating mat, $(\mathrm{H})$ four methane sensors placed inside the cylinder, in the nose and on the side of the cylinder, $(G)$ two one-way valves in the nose that were only installed and used for the total mass balance experiment.

The ARC also contained two mass flow controllers (MFC). These instruments controlled the artificial reference cow's methane and carbon dioxide production rates from two attached pure $\mathrm{CH}_{4}$ and $\mathrm{CO}_{2}$ cylinders. Although the ARC is capable of controlling $\mathrm{CO}_{2}$ production, this study only focused on methane production. A $20 \times 62 \mathrm{~cm}$ silicon heating mat covered the cylinder's left side so that the gas inside was uniformly warmed to the 


\section{Design and test of an artificial reference cow}

temperature of the cow's breath. A $110 \mathrm{~cm}$ long plastic tube was connected to the right side of the cylinder's middle to simulate the cow's respiration tract. At the end of the tube, two round openings with $4 \mathrm{~cm}$ diameter mimicked the cow's nose. In addition, four methane sensors (MQ-4, Hanwei electronics) were located at different positions in the ARC: one inside the cylinder, one in the nose, and two externally on the outside of the cylinder (Figure 1). Each methane sensor was set to sound an emergency alarm if the methane concentration was too high because the controls had failed or because the ARC was leaking methane.

\subsubsection{Characteristics and control of the ARC}

(1) Breath frequency and tidal volume

The characteristics of the respiration pattern, such as breath frequency and tidal volume, are the main features of the ARC. The ARC's breath frequency and tidal volume are determined by the actuator's stroke length and the piston's movement time. The actuator's stroke length could be adjusted between 0 and $20 \mathrm{~cm}$, which means the piston's movement could simulate 0-6 1 tidal volume. The compressed air volume could be adjusted by the valve connected to the actuator allowing the breath frequency to be simulated between 20 to 40 times per minute. The total exhalation capacity of an adult Holstein Friesian cow is about 128-136 $1 \mathrm{~min}^{-1}$ and the breath frequency is about 20-40 times per minute (Gallivan et al., 1989a; b; Stevens, 1981). A representative total exhalation capacity of $1321 \mathrm{~min}^{-1}$ can be based on a tidal volume for each inhaling or exhaling of 4.41 at a breath frequency of 30 times per minute. During the experiment the stroke length of the actuator was adjusted to $14.7 \mathrm{~cm}$ to provide a tidal volume of 4.41 and the piston was operated to move one stroke length every one-second to simulate a cow's average tidal volume and breath frequency.

\section{(2) Methane production rate}

The methane production rate of the ARC was controlled by one of the two MFC's. The model of the MFC was F-201CV-5KO (Bronkhorst high tech B.V.) with a control range of 0 to $51 \mathrm{~min}^{-1}$ for methane gas. The MFC consisted of a thermal mass flow sensor, a precise control valve and a microprocessor based proportional-integral-derivative (PID) controller 


\section{Chapter 4}

with signal and fieldbus conversion. The MFC not only controlled the desired flow rate but also gave instantaneous flow rate readings. According to the manufacturer's specification, accuracy of the MFC is $\pm 0.5 \%$ reading deviation (RD) plus $\pm 0.1 \%$ full scale (FC). The MFC was calibrated in the standard condition $\left(20^{\circ} \mathrm{C}, 101325 \mathrm{~Pa}\right)$. During the experiment, controlled methane flow rates were corrected for actual temperature and air pressure according to the factory user manual.

Some studies have presented methane concentration release patterns measured from dairy cows in feeders during visits to milking robots (Garnsworthy et al., 2012; Lassen et al., 2012). These studies show that cows do not emit methane at a constant level. In general patterns show repeating sinusoidal curves combined with random fluctuations, which can be associated with the occurrence of an eructation. By controlling the MFC with different methane injecting flow rates and time, the ARC has the ability to simulate a variety of fluctuation patterns and production levels that resemble the release of real cows.

(3) Temperature of the breath

The temperature of the cow's breath at release is about $5-6{ }^{\circ} \mathrm{C}$ higher than ambient temperature (Stevens, 1981). The ARC was tested and validated in the air quality laboratory of Wageningen UR Livestock Research. The air temperature in the lab was 18$24{ }^{\circ} \mathrm{C}$ during the test period. Therefore, the temperature of the ARC's breath was maintained between 23 to $29^{\circ} \mathrm{C}$. The heating mat's capacity is 150 watt and it takes only a few minutes to warm the gas inside the cylinder to the desired temperature. To maintain a steady temperature operation, a PID controller in Labview was applied. In general, the breath volume of the artificial cow was first warmed for about 4 minutes before being used for any measurement.

(4) System \& safety control

The ARC was controlled by three separate operating systems: Labview, a Programmable Logic Controller (PLC), and a heating controller. Labview operated and processed the main functions of the $\mathrm{ARC}$, including its piston movement time, $\mathrm{CH}_{4}$ injection rates, gas 


\section{Design and test of an artificial reference cow}

temperature, and the methane sensor's signals. The PLC and heating controller monitored the piston's movement signals and the gas temperature inside the cylinder.

The ARC used two separate control procedures to avoid, in case of malfunctioning, excessive accumulation of methane inside the cylinder or leaking from the cylinder. The first procedure involved continuously monitoring of methane concentration by four methane sensors. Exceeding pre-set alarm levels would result in signals to the Labview control program to stop the methane injections. The second procedure continuously monitored the piston movement with a PLC. If the piston stopped moving, the PLC cut off power.

\subsection{Fourier transform infrared spectroscopy (FTIR) gas analyser}

Methane concentration was analysed by a portable multicomponent Fourier transform infrared spectroscopy (FTIR) gas analyser. The FTIR included a gas analyser (Gasmet DX 4000, Gasmet Technologies Oy, Helsinki, Finland), a portable sampling system, a heating line, and a cooling device. The gas analyser (DX4000) continuously sampled the gas with $4.01 \mathrm{~min}^{-1}$ and analysed its concentration in the sample cell $(0.41)$. The measurement interval frequency can be set between 1-300 s.

The FTIR in this study was calibrated for methane in the range of 0 to $3000 \mathrm{ppm}$. We used three span gas cylinders with known methane concentrations (3000, 1500, and 32.2 ppm). The measurement results with 3000,1500 , and $32.2 \mathrm{ppm}$ methane gas had $0.1 \%, 0.7 \%$, and $0.6 \%$ difference compared to the known concentration, respectively. According to the data of span gas calibration, FTIR independently takes 19 (s.d. 1) s to reach $95 \%$ of the span gas concentration and another 7 (s.d. 1) s more to reach $99 \%$ of the final level. This response period for a steady span gas flow results from the sampling flow rate, sampling tube volume and sample cell volume. For a dynamic gas flow, the analyser response is additionally affected by the ratio between sampling rate and sample cell volume, determining the rate of full sample cell refreshment. Based on the sample cell size $(0.41)$ and the sampling rate $\left(4.01 \mathrm{~min}^{-1}\right)$, the sampling cell needs at least $6 \mathrm{~s}$ to be completely refreshed. Since the gas is continuously transported through the sample cell and mixed, the 


\section{Chapter 4}

measured concentration represents a moving average over the preceding $6 \mathrm{~s}$. Hence, variation between recorded values based on measurement intervals smaller than $6 \mathrm{~s}$ will be partly smoothed by preceding gas concentrations, meaning that short term variation within $6 \mathrm{~s}$ cannot be monitored in full detail.

\subsection{Concentration pattern evaluation model}

Based on the methane mass balance between input (injected by MFC and inhaled gas) and output (exhaled gas) of the ARC, an evaluation model was developed to assess the methane concentration pattern produced by the ARC:

$\int_{0}^{t} x d t=\int_{0}^{t} M d t+\int_{0}^{t} C_{e x, i n} \times V d t$

where: $\mathrm{x}$ is methane mass accumulation rate in the cylinder in $\mathrm{g} \mathrm{s}^{-1} ; \mathrm{M}$ is methane mass injection rate by MFC in $\mathrm{g} \mathrm{s}^{-1} ; \mathrm{C}_{\mathrm{ex}}$, in is methane concentration in $\mathrm{g}^{-1}$, which is methane concentration inside the cylinder during exhaling or ambient methane concentration during inhaling; $\mathrm{V}$ is gas exchange volume rate in $1 \mathrm{~s}^{-1}$, which is positive value during inhaling and negative value during exhaling; The left side of the equation gives the methane mass accumulated in the cylinder. The right side of the equation includes two methane flows components of the ARC: one is the methane injected by the MFC and the other one is the methane exchanged during inhaling and exhaling. This evaluation model assumes that all gas is completely mixed inside the cylinder, including injected methane. The methane mass accumulation rate is solved in every $0.1 \mathrm{~s}$ time step. During the exhaling period, $\mathrm{C}_{\mathrm{ex}}$, in calculated at $t_{-1}$ is applied to solve methane mass accumulation rate $x$ at $t_{i}$.

The evaluation model can be used for the following three purposes. First, the evaluation model can be used to validate the operation accuracy of the ARC by comparing the emitted methane concentration calculated from the model and measured at the ARC's nose. Second, the evaluation model was operated to determine the methane injecting strategy of the methane MFC to simulate methane concentration patterns of real cows. Third, the methane concentration pattern produced by the ARC can be analysed in any time resolution with the evaluation model. Due to the gas mixing effects and refresh time in the sample cell of the 


\section{Design and test of an artificial reference cow}

gas analyser, methane concentration changes in less than this refresh time cannot be accurately detected by the gas analyser. The evaluation model, however, can estimate such pattern variations.

\subsection{Measurements with the ARC}

\subsubsection{Methane mass balance of the ARC}

The accuracy with which a defined reference flow of methane can be produced from the system is a critical evaluation factor that shows whether the ARC is working properly. This can be studied by investigating whether the mass balance, defined as the difference between the controlled input and the measured output, is equal to zero. We performed an experiment with the aim to evaluate the mass balance at different settings of the system. The experimental setup is shown in Figure 2. Two one-way valves (Figure 1 and 2) were mounted at the ARC's nose. One valve was open only during inhalation and the other one was open only during exhalation. Thus, the ARC's inhalations and exhalations could be analysed separately. A $3 \mathrm{~m}$ tube with a $50 \mathrm{~mm}$ diameter was fixed to the exhaling nose. The exhaled gas was continuously sampled at a rate of $41 \mathrm{~min}^{-1}$ and analysed for the methane concentration by the FTIR every 2 or 3 seconds. During the experiment, pure methane was injected with fixed flow rates controlled by MFC.

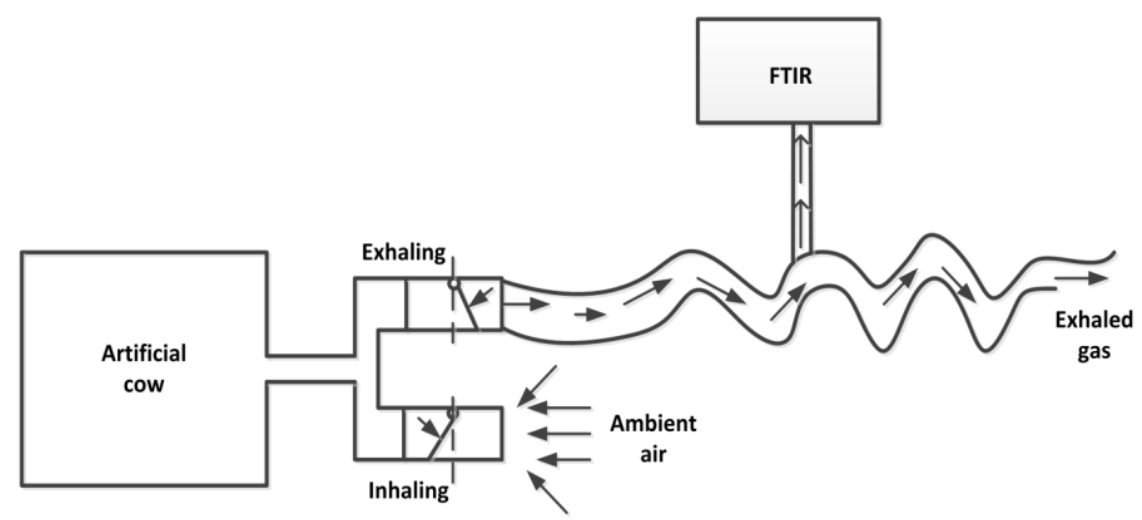

Figure 2. Schematic overview of the experimental set-up to evaluate the methane mass balance of the ARC. 


\section{Chapter 4}

The methane mass balance experiment was conducted in the air quality laboratory of Wageningen UR Livestock Research with the ARC set at different parameters (Table 1). In these tests, the emitted methane concentration by the ARC could be varied with different tidal volumes and breath frequencies. Combined with different levels of methane flow rates, the ARC produced methane concentration ranges similar to those produced by real cows, which is 300-3000 ppm (Chagunda et al., 2009; Garnsworthy et al., 2012; Lassen et al., 2012). The methane's injection flow rate was operated from 0.05 to $0.401 \mathrm{~min}^{-1}$, tidal volume was operated from 4.41 to 6.01 , and breath frequency was operated from 20 to 30 times per minutes. Methane flow rates of test-1, test-2, and test-3 were tested at eight, six, and three levels, respectively. Each level of methane flow rate was conducted for about 8 minutes and repeated four times. During the experiments, the ARC directly exhaled the gas to an exhaust pipe that transported the air of the ARC out of the laboratory to avoid contamination of the laboratory background. The background methane concentration in the lab was measured before each trial. In the methane mass balance calculations, both first and last 60 seconds of the FTIR recorded measurement values were excluded.

Table 1. Methane flow rate, breath frequency, and tidal volume during three test rounds in the methane mass balance experiment.

\begin{tabular}{cccc}
\hline Test & Methane flow rate $\left(1 \mathrm{~min}^{-1}\right)$ & Breath frequency (Times per minute) & Tidal volume (l) \\
\hline 1 & $0.05 ; 0.10 ; 0.15 ; 0.20 ; 0.25 ; 0.30 ; 0.35 ; 0.40$ & 30 & 6.0 \\
2 & $0.05 ; 0.10 ; 0.15 ; 0.20 ; 0.25 ; 0.30 ;$ & 30 & 4.4 \\
3 & $0.05 ; 0.15 ; 0.25 ;$ & 20 & 4.4 \\
\hline
\end{tabular}

The methane injected by MFC and inhaled from the ambient environment was the ARC's methane input, and the exhaled air was the ARC's methane output. The input and output methane mass can be calculated according to the following two equations:

$M_{\text {in }}=\left(F \times T_{e}+B F \times T_{e} \times T_{v} \times C_{a} \times 10^{-6}\right) \times \rho$

$M_{\text {out }}=C_{e} \times B F \times T_{e} \times T_{v} \times \rho \times 10^{-6}$

where: $\mathrm{M}_{\mathrm{in}}, \mathrm{M}_{\mathrm{out}}$ are the ARC's methane input and output in $\mathrm{g} ; \mathrm{F}$ is the methane flow rate controlled by MFC in $1 \mathrm{~min}^{-1} ; \mathrm{T}_{\mathrm{e}}$ is the measurement time in minute; $\mathrm{BF}$ is the breath frequency in times per minute; $\mathrm{T}_{\mathrm{v}}$ is the tidal volume in $1 ; \mathrm{C}_{\mathrm{a}}$ is the methane concentration 


\section{Design and test of an artificial reference cow}

in ambient air in ppm, at a measured background level of 2-4 ppm during the experiment period; $\rho$ is the methane density in $\mathrm{g}^{-1} ; \mathrm{C}_{\mathrm{e}}$ is the mean methane concentration in the exhaled gas measured by FTIR in ppm. By using the equations, the overall methane mass in the input and output of the ARC during a sampling period can be analysed and compared for each measurement.

\subsubsection{Methane concentration pattern of the ARC}

Methane concentration release pattern of a real cow is another crucial characteristic that the artificial reference cow had to simulate. We performed an experiment with the aim to evaluate whether realistic concentration patterns could be simulated by the ARC. To obtain actual methane concentration patterns, breath of real cows that were being milked by a milking robot was directly sampled and analysed. The measurements were taken in a dairy barn with 100 cows that were milked with an automatic milking robot in Lelystad, The Netherlands. A sampling tube was placed close to the cow's head in the milking robot so that the cow's breath was continuously sampled at a rate of $41 \mathrm{~min}^{-1}$. During the experiment a cow generally visited a milking robot 2 to 3 times daily. During each visit, methane concentration in the sampled breath was analysed by the FTIR analyser, one value per 2 or 3 seconds for two days.

With the field measurement data and the concentration pattern evaluation model (equation 1), operational parameters of the ARC (e.g., methane injecting strategy, tidal volume, and breath frequency) were set to simulate the methane concentration pattern representative for real cows. To validate the methane concentration pattern produced by the ARC, parallel lab experiments mimicking the field measurement setup were conducted in the air quality laboratory of Wageningen UR Livestock Research (Figure 3). The ARC's nose was placed into a mimic feed bin with the same dimension and shape as the one the real cows used in the milking robot. The mimic feed bin made of cardboard was $60.5 \times 46.0 \times 29.0 \mathrm{~cm}$ (length, width, and height) and was partially enclosed. The inlet of sampling tube was positioned $5 \mathrm{~cm}$ away from the nose. The ARC's breath was continuously sampled at a rate of $41 \mathrm{~min}^{-1}$ and analysed by FTIR analyser one value per 2 or 3 seconds. 


\section{Chapter 4}

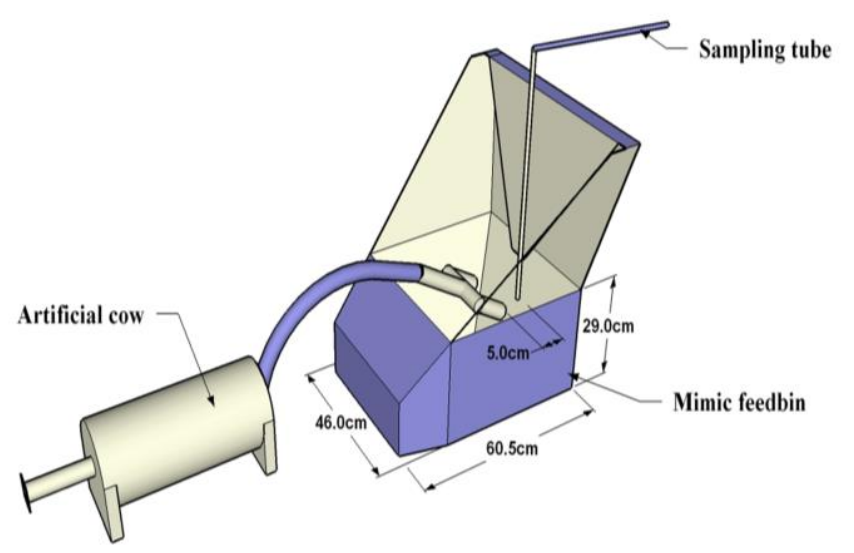

Figure 3. Schematic overview of the experimental set-up to validate methane concentration pattern from the ARC.

The ARC simulated five different cows with controlled daily methane production rates at flux levels of 200, 250, 300, 350, and $400 \mathrm{~g} \mathrm{day}^{-1}$, respectively. At each flux level, methane flow rates were increased and decreased stepwise by the MFC. Combined with these different overall production rates, also eructation patterns were simulated, which were based on measurements of methane concentrations in breath air of real cows. Each eructation lasted $36 \mathrm{~s}$ and, by means of different methane injection rates, a sinusoidal curve of methane concentration was produced.

At the start of this simulation experiment, the ARC was running without injecting methane until the breath air had warmed to the desired temperature (about $25^{\circ} \mathrm{C}$ ). Then, each simulated cow performed 6 eructation cycles of $36 \mathrm{~s}$ each, taking $216 \mathrm{~s}$ in total, and denoted as one measurement. A 10 minute interval was taken between every two measurements to ensure methane emitted into the feed bin from the previous testing had completely cleared. The measurement for each simulation cow was repeated five times.

\subsection{Statistical analysis}

Data were analysed using GenStat 16 statistical system (VSN International Ltd., UK). In the mass balance experiment, methane concentration measured from ARC was first compared with the theoretically calculated value from the evaluation model. Then the 


\section{Design and test of an artificial reference cow}

relation between the ARC's methane mass input and output was investigated with a linear regression model. In the second experiment focussing on methane release patterns, methane concentration patterns measured from 100 real cows were first filtered and only complete fluctuation cycles were selected. Then each fluctuation cycle was analysed for five parameters: methane concentration at start, peak, and end point; time interval from start to peak, and peak to end. Similarly, measured methane concentration patterns released from the artificial cow were first filtered and then selected complete fluctuation cycles were also analysed in those five parameters. In the end, the levels of the five parameters were compared between the ARC and real cows.

\section{Results and discussion}

\subsection{Mass balance checking of the ARC}

\subsubsection{Methane concentration produced by the ARC}

Methane concentrations measured in the exhalation tube and concentrations predicted by the evaluation model from test-1, test-2, and test- 3 of the mass balance experiment are shown in table 2. Measured methane concentration in defined methane flow rates varied from 376.9 ppm (s.d. 8.4) to 2435.6 ppm (s.d. 36.0) in test-1, $409.3 \mathrm{ppm}$ (s.d. 7.6) to 2306.2 ppm (s.d. 36.5) in test-2, and 601.2 ppm (s.d. 11.9) to 2868.3 ppm (s.d. 37.1) in test-3. Measured methane concentration from the ARC in these three tests already fitted the range that was measured from the real cow (300-3000 ppm). Methane concentration produced by the ARC is determined by methane injection flow rate, tidal volume, and breath frequency. When the methane flow rate increased in each test, methane concentration in the exhaled gas logically increased. From test-1 to test-2, measured methane concentration was higher under the same methane flow rate when the tidal volume decreased from 61 in test- 1 to 4.4 1 in test-2. Tidal volume is air volume that a cow exhaled or inhaled during each breath. With a smaller tidal volume and constant injection methane rate, the methane concentration measured in the cow's breath is then inevitably higher. Similarly, from test-2 to test- 3 , measured methane concentration was higher under constant methane flow rate when the 


\section{Chapter 4}

breath frequency decreased from 30 times per minute to 20 times per minute, meaning that exhaling time increased from $1 \mathrm{~s}$ to $1.5 \mathrm{~s}$. With longer exhaling time and same injection methane rate, more methane produced in each breath resulted in higher methane concentrations. In short, by controlling methane flow rate, tidal volume, and breath frequency, the ARC can simulate different methane concentration levels in the breath air.

Table 2. Predicted methane concentration at the exhaled nose versus measured methane concentration in the tube connected to the exhaled nose under different defined methane flow rates.

\begin{tabular}{|c|c|c|c|c|c|c|}
\hline \multirow[t]{2}{*}{ Test } & \multirow[t]{2}{*}{$\begin{array}{l}\text { Methane flow rate } \\
\qquad\left(1 \mathrm{~min}^{-1}\right)\end{array}$} & \multicolumn{2}{|c|}{$\begin{array}{c}\text { Predicted } \mathrm{CH}_{4} \\
\text { concentration in } 4 \times 6 \\
\text { mins }(\mathrm{ppm})\end{array}$} & \multicolumn{2}{|c|}{$\begin{array}{c}\text { Measured } \mathrm{CH}_{4} \\
\text { concentration in } 4 \times 6 \text { mins } \\
(\mathrm{ppm})\end{array}$} & \multirow{2}{*}{$\begin{array}{c}\text { Average } \mathrm{CH}_{4} \\
\text { concentration } \\
\text { difference } \\
(\%)\end{array}$} \\
\hline & & Mean & $\mathrm{SD}^{\mathrm{a}}$ & Mean & $\mathrm{SD}^{\mathrm{b}}$ & \\
\hline 1 & 0.05 & 387.3 & 33.9 & 376.9 & 8.4 & 2.7 \\
\hline 1 & 0.10 & 672.2 & 58.9 & 662.1 & 26.9 & 1.5 \\
\hline 1 & 0.15 & 957.2 & 84.0 & 930.1 & 12.0 & 2.9 \\
\hline 1 & 0.20 & 1242.2 & 109.0 & 1218.8 & 19.4 & 1.9 \\
\hline 1 & 0.25 & 1527.2 & 134.1 & 1519.8 & 20.4 & 0.5 \\
\hline 1 & 0.30 & 1812.2 & 159.1 & 1825.2 & 26.2 & -0.7 \\
\hline 1 & 0.35 & 2097.2 & 184.2 & 2143.4 & 26.8 & -2.2 \\
\hline 1 & 0.40 & 2382.2 & 209.2 & 2435.6 & 36.0 & -2.2 \\
\hline 2 & 0.05 & 434.0 & 28.2 & 409.3 & 7.6 & 6.0 \\
\hline 2 & 0.10 & 830.9 & 55.3 & 792.2 & 12.3 & 4.9 \\
\hline 2 & 0.15 & 1224.8 & 82.3 & 1165.6 & 20.9 & 5.1 \\
\hline 2 & 0.20 & 1617.1 & 109.0 & 1550.2 & 19.2 & 4.3 \\
\hline 2 & 0.25 & 2002.1 & 134.8 & 1949.2 & 46.2 & 2.7 \\
\hline 2 & 0.30 & 2390.9 & 161.2 & 2306.2 & 36.5 & 3.7 \\
\hline 3 & 0.05 & 635.9 & 42.1 & 601.2 & 11.9 & 5.8 \\
\hline 3 & 0.15 & 1806.7 & 121.8 & 1676.9 & 38.3 & 7.7 \\
\hline 3 & 0.25 & 2967.0 & 200.8 & 2868.3 & 37.1 & 3.4 \\
\hline
\end{tabular}

$\mathrm{SD}^{\mathrm{a}}$ : standard deviation calculated from predicted methane concentration in every $0.1 \mathrm{~s} ; \mathrm{SD}^{\mathrm{b}}$ : standard deviation calculated from measured methane concentration in every 2 or 3 seconds;

Average difference ${ }^{c}$ : (Predicted - Measured)/Measured $\times 100 \%$;

Measured methane concentration agreed within a difference range of $-2.2 \%$ to $7.7 \%$ with predicted methane concentration calculated from the evaluation model. The mean average difference of the three tests was $2.8 \%$ (s.d 2.8). These differences can be caused by components of the ARC (tidal volume, MFC) and the FTIR gas analyser, for instance, the inaccuracy in controlling the tidal volume and the methane's injection rate, or analysing the methane concentration of the exhaled gas. The exact reason is difficult to determine. Yet, with about $2.8 \%$ difference between measured and theoretically predicted, it is demonstrated that the artificial reference cow could accurately control the methane 


\section{Design and test of an artificial reference cow}

concentration level. However, predicted methane concentration always had a larger standard deviation as compared to the measured methane concentration. The evaluation model predicted the actual methane concentration during each exhalation in every $0.1 \mathrm{~s}$, whereas measured exhaling gas mixed first during transport in the output tube before being sampled into the FTIR and analysed every 2 or 3 seconds. Therefore, measured methane concentrations were based on the average values of the actual methane concentrations during each exhalation, whereas the predicted values by the evaluation model were the actual dynamic methane concentrations during each exhalation. In short, the ARC is capable of precisely simulating different methane concentration levels in exhaled gas with defined methane flow rates, breath frequency, and tidal volume.

\subsubsection{Overall methane mass balance between input and output}

The overall methane mass balance between input and output was a crucial factor to evaluate the system's performance. The ARC's methane input and output at defined methane flow rates were calculated by the equation (2) and (3). The results of test-1, test- 2 , and test- 3 are displayed in figure 4. During the experiment, overall methane mass at input was controlled from $0.14 \mathrm{~g}$ to $1.69 \mathrm{~g}$. The output methane mass was strongly linearly related to the input methane mass $\left(\mathrm{R}^{2}>0.99, \mathrm{P}<0.001\right)$. Standard errors of observations were estimated to be 0.012 in test-1, 0.012 in test-2, and 0.0008 in test-3. Standardised residuals were distributed around zero in test- 1 and test- 2 under different defined methane injected rates. In test- 3 with only three methane injection rates, however, residuals were less uniformly distributed around zero. 


\section{Chapter 4}
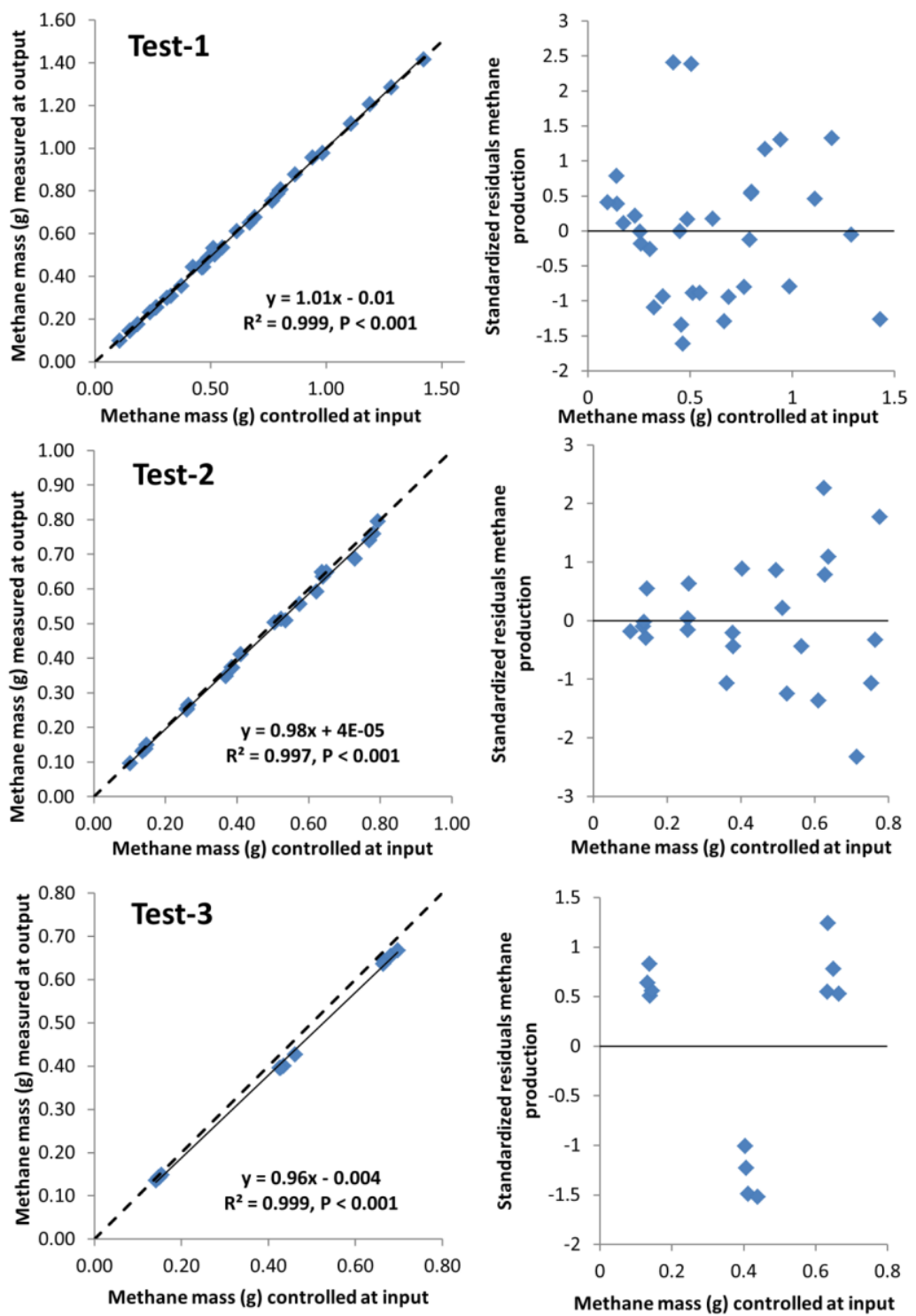

Figure 4. Methane mass (g) controlled at input versus measured at output (left) and standardised residuals (right) versus methane production $(\mathrm{g})$ during each 8 minutes experiment; the dotted line represents the line of equivalence.

The three regression lines between methane mass input and output were close to the equivalence line $(y=x)$, especially in test- 1 and test-2. The slopes of the regression lines in 


\section{Design and test of an artificial reference cow}

test-1 and test-2 did not differ from unity $(\mathrm{P}>0.01)$, but was different in test-3 $(\mathrm{P}<0.01)$. The regression line in test- 3 can be used to calibrate the results when we use the ARC with the tidal volume and breath frequency of test-3. The residual standard deviation, expressed on a percentage basis of the methane input, amounted to $1.73 \%$ in test-1, 2.25\% in test-2, and $5.11 \%$ in test-3. It is likely that deviations were mainly caused by the performance of the $\mathrm{ARC}$, i.e. the accuracy of MFC in controlling methane injection rates and the piston movement (length and time). The MFC affected the methane mass controlled at input, and thereby also the methane concentration in the exhaled gas. The piston movement determined the tidal volume during exhalation. Inaccurate tidal volume could then affect methane mass calculated at output. The FTIR used for analysing methane concentration in the exhaled gas may also have contributed to the deviations to some extent; but calibration accuracy was below $0.7 \%$. The residual standard deviation in test-3 was higher than in test1 and test-2, which may be caused by less measurement data or the performance of the ARC. However, breath frequency of 20 times per minute in test-3 will not be used in the future testing of the ARC because of this relatively low level compared to the real cows' average breath frequency. In conclusion, for our future goal to control methane mass production with defined methane flow rates, tidal volume, and breath frequency, the error variation underlying this accuracy level is substantially lower than the experimental variation that needs to be studied, e.g. 200-400 g methane per cow per day.

\subsection{Formation and validation of methane concentration patterns simulated by the ARC}

\subsubsection{Methane concentration patterns measured from real cows}

Methane concentration directly measured in the sampled breath air showed a pattern of fluctuation (Figure 5), which was mainly caused by the eructation process. Each fluctuation cycle included a quick concentration rise followed by an exponential decay that presented a belch released by the cow, a pattern also found in other studies (Chagunda et al., 2009; Garnsworthy et al., 2012; Lassen et al., 2012). Among four fluctuation cycles (F1 to F4) labelled in figure 5, fluctuation cycles 3 and 4, however, have sub-fluctuations during their 


\section{Chapter 4}

peak level. These sub-fluctuations can be caused by the cows' head movement or variations in airflow around the nose. Cows' head movements can vary the distance between the fixed sample tube and emitted methane by cows. With a longer distance, released methane will be more diluted before sampling, lowering measured methane concentration, and causing a sub-fluctuation during one eructation. Similarly, variable airflow patterns around the cow can create variations on methane dilution, which also can cause the same sub-fluctuation. To have less noise information, measured methane concentrations in the 12 hours data were checked and only complete concentration patterns, i.e. without sub-fluctuations, were selected. In the end, 105 fluctuation cycles were summarised to determine the characteristics of methane concentration pattern from cows.

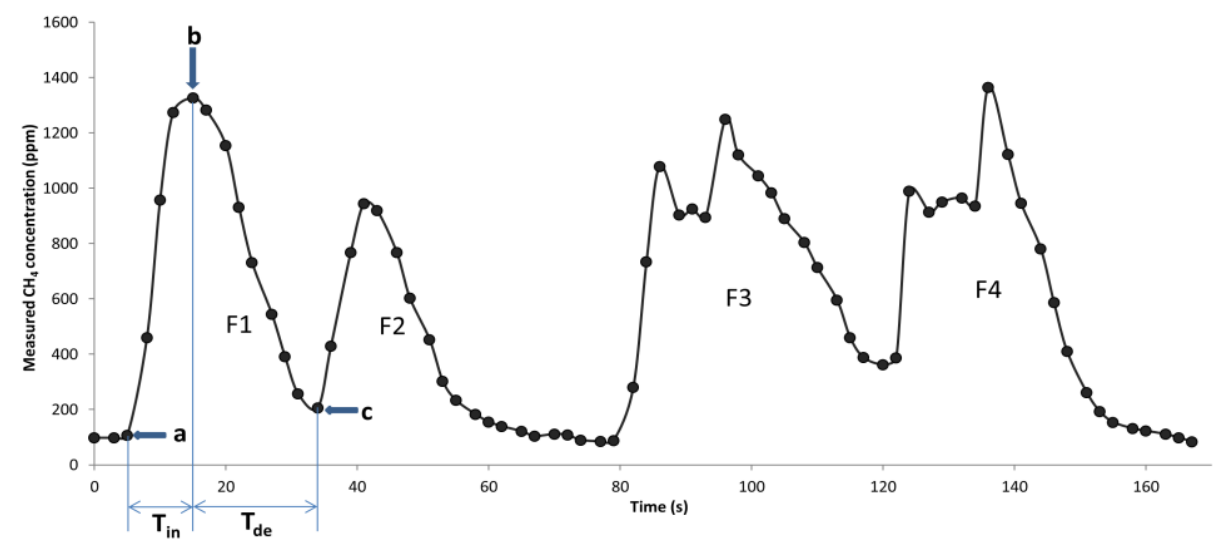

Figure 5. Typical example of the measured methane concentration (ppm) from a real cow. Four methane concentration fluctuation cycles (F1 to F4) are presented. For every complete fluctuation cycle (F1), five following parameters are investigated: methane concentration at start (a), peak (b), and end (c); increase time from start to peak $\left(\mathrm{T}_{\mathrm{in}}\right)$; decrease time from peak to end $\left(\mathrm{T}_{\mathrm{de}}\right)$.

For each selected concentration fluctuation cycle, the following five parameters were determined, as illustrated in Figure 5: methane concentration at start (a), peak (b), and end (c); increase time from start to peak $\left(T_{\text {in }}\right)$; decrease time from peak to end $\left(T_{d e}\right)$. The results in Table 3 show that one fluctuation cycle took on average 35.7 s (s.d. 7.1). Within one fluctuation cycle, methane concentration took $13.1 \mathrm{~s}$ (s.d. 3.5) to increase from start to the peak concentration and then $22.6 \mathrm{~s}$ to decrease from peak to the end concentration. The average methane concentrations of each fluctuation cycle at start, peak, and end were 149.0, 


\section{Design and test of an artificial reference cow}

835.6, and $200.7 \mathrm{ppm}$, respectively. The end concentration was slightly higher than the start concentration. Measured methane concentrations at start, peak, and end had relatively high variations, which could be caused by the following reasons. First, methane concentration parameters summarised in table 3 were sampled from 100 cows. Methane production between cows is variable because of genetic, feed intake, and ration quality (Arthur and Herd, 2005; Vlaming et al., 2008; Waghorn and Hegarty, 2011). With higher methane production, measured methane concentration can be expected higher correspondingly. Second, breath air sampled from cows was diluted by the airflow around the cow. Variations of airflow patterns within and between days can create different dilution rates that lead to variations in measured methane concentration. Third, cows' head movement varies the distance between sampling tube and emitted methane. The varied sampling distances can also influence the dilution rates, which also lead to the variations in measured methane concentration.

Table 3. Summary of the methane concentration parameters measured from 100 real cows' breath.

\begin{tabular}{lrrrr}
\hline & Min & Mean & Max & SD $^{\mathrm{a}}$ \\
\hline Start concentration (ppm) & 11.8 & 149.9 & 537.3 & 114.6 \\
Peak concentration (ppm) & 186.5 & 835.6 & 1365.4 & 293.0 \\
End concentration (ppm) & 26.5 & 200.7 & 611.9 & 121.0 \\
Increase time (s) & 5.0 & 13.1 & 24.0 & 3.5 \\
Decrease time (s) & 12.0 & 22.6 & 40.0 & 6.6 \\
Total time (s) & 22.0 & 35.7 & 55.0 & 7.1 \\
\hline
\end{tabular}

$\mathrm{SD}^{\mathrm{a}}:$ Standard deviation;

\subsubsection{Methane concentration pattern measured from the ARC}

The five simulated cows produced similar methane concentration patterns under the laboratory conditions (Figure 6): methane concentration fluctuated as sinusoidal cycles during the measurement period. Each fluctuation cycle has a quick concentration rise and then a longer decay, which corresponded with the patterns measured from real cows. All fluctuation cycles produced by the five simulated cows were complete. Because these measurements with simulated cows were conducted under stable laboratory conditions and the distance between sampling tube and cow's nose was fixed, extra variations from 


\section{Chapter 4}

disturbed airflow and cow's head movement were not present. The first fluctuation cycle took more time and had a lower methane concentration peak than the next four fluctuation cycles in each of the simulated cows. This can be attributed to time needed to reach a stable dilution and mixing level at the sampling point. Also the gas analyser (FTIR) needed time to respond to a change from low methane concentration to high methane concentration in the breath air. Certain variations were observed on peak and valley methane concentration in the next four methane fluctuation cycles, especially for cow-D. Theses variations could be caused by the operation of the ARC, or dilution rates of breath air in the environment. In short, the ARC simulates different daily methane production levels, and each simulated cow can produce sinusoidal methane concentration curve, like real cows do.

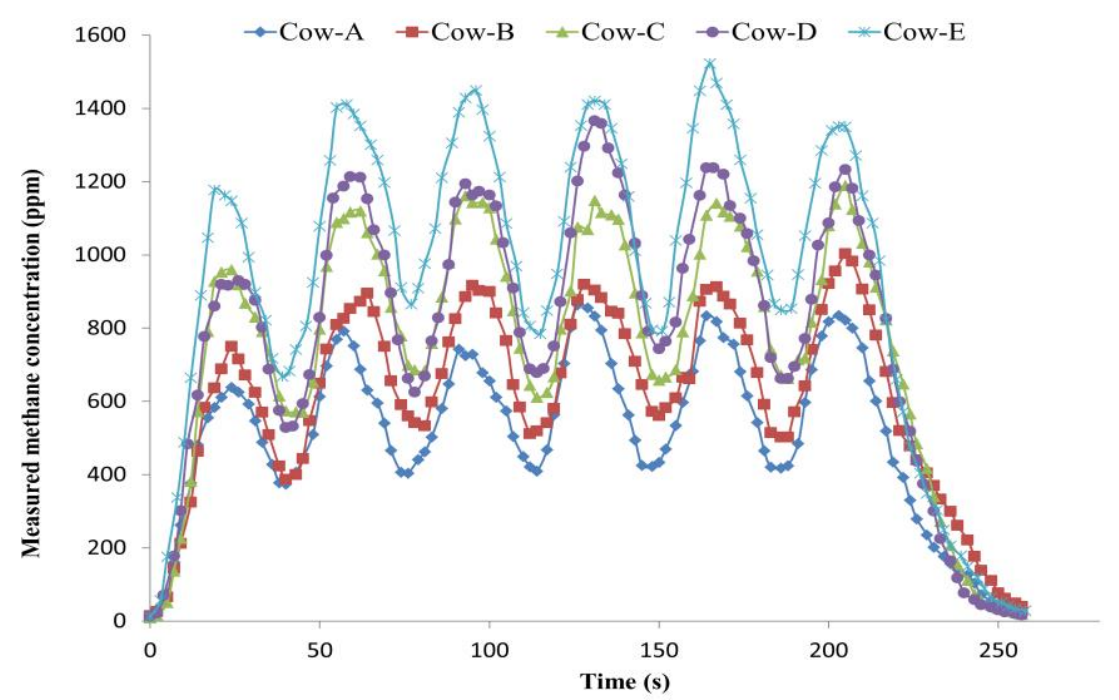

Figure 6. Typical example of the measured methane concentration (ppm) during one measurement period (216 s) for five simulated cows. The six eructations for each simulated cow are visible as sinusoidal patterns. Methane production rates of cow A to E: 200, 250, 300, 350, and $400 \mathrm{~g} \mathrm{day}^{-1}$.

Characteristics of methane concentration patterns produced by the simulated cows were analysed and summarised (Table 4) excluding the first and last fluctuation cycles in the measurement results, due to the relatively low methane concentration level at the first fluctuation cycle and the fact that methane injection had already stopped at the last 


\section{Design and test of an artificial reference cow}

fluctuation cycle. One fluctuation cycle time was controlled precisely at $36.3 \mathrm{~s}$ (s.d. 0.2) between five simulated cows, which was $0.6 \mathrm{~s}$ longer than the mean level measured in the real cow data set. Similarly to the real cow's pattern, methane concentration produced from the artificial reference cow took less time to increase from start to peak (16.5 s) than decrease from peak to end (19.9 s). Measured methane concentration at start, peak, and end were increasing from cow-A to cow-E, when the imposed daily methane production increased from $200 \mathrm{~g} \mathrm{day}^{-1}$ to $400 \mathrm{~g} \mathrm{day}^{-1}$. The average methane concentrations from five simulated cows at start, peak, and end were 593.6, 1098.2, and $603.0 \mathrm{ppm}$, which were 443.7, 262.6, and $402.3 \mathrm{ppm}$ higher than measured in the dataset with real cow cycles. Higher methane concentrations were to be expected because less dilution factors (e.g. airflow pattern and cows' head movement) were present in the laboratory. However, maximum methane concentrations measured from real cows (table 2) at start, peak, and end $(537.3,1365.4$, and $611.9 \mathrm{ppm})$ were in the range of the simulated laboratory values. These maximum values were probably derived from low dilution conditions with low ambient airflow and close sampling to the cow's nose, as is the case for the simulated cows in the laboratory. In short, the ARC precisely controls methane fluctuation cycles under different simulation settings. Both time interval and methane concentration level of methane fluctuation cycles produced by the ARC are comparable to the methane fluctuation cycles measured from the real cows.

Table 4. Summary of the methane concentration parameters measured of five simulated cows A to E during six eructations (The first and last eructation cycle were discarded).

\begin{tabular}{lcccrr}
\hline \multicolumn{1}{c}{ Simulated cow } & Cow-A & Cow-B & Cow-C & \multicolumn{1}{c}{ Cow-D } & Cow-E \\
\hline Mean concentration (ppm) & $594.1(15.7)$ & $714.9(41.6)$ & $843.3(47.0)$ & $986.3(20.3)$ & $1135.3(40.7)$ \\
Start concentration (ppm) & $409.5(28.3)$ & $508.3(51.3)$ & $600.7(57.3)$ & $649.1(73.7)$ & $800.1(71.4)$ \\
Peak concentration (ppm) & $783.8(51.7)$ & $913.2(56.1)$ & $1073.5(62.3)$ & $1286.4(73.7)$ & $1434.3(97.8)$ \\
End concentration (ppm) & $417.6(24.1)$ & $497.6(48.7)$ & $597.7(53.8)$ & $684.8(39.6)$ & $817.5(57.1)$ \\
Increase time (s) & $15.8(2.1)$ & $17.3(2.5)$ & $16.1(2.7)$ & $16.0(2.6)$ & $17.2(2.7)$ \\
Decrease time (s) & $20.7(1.4)$ & $18.7(2.7)$ & $20.4(2.4)$ & $20.5(2.5)$ & $18.9(2.3)$ \\
Total time (s) & $36.5(1.7)$ & $36.1(1.8)$ & $36.5(2.1)$ & $36.5(1.1)$ & $36.1(1.5)$ \\
\hline
\end{tabular}




\section{Chapter 4}

\section{Conclusions}

The ARC designed and constructed in this study properly represented the methane production of a cow. The system is capable of precisely controlling methane concentration and production at pre-set reference values. By controlling the methane injecting flow rates, tidal volume, and respiration frequency, the ARC can simulate different levels of methane production by real cows. The ARC is capable of producing methane concentration patterns that are representative of real cows. Based on the performance characteristics of the ARC, we conclude that this system is a suitable and reliable reference source that can be helpful in developing and improving practical methane measurement methods.

\section{Acknowledgements}

This study was funded by Wageningen UR Livestock Research, the Ministry of Economic Affairs of the Netherlands (Research programme KB Sustainable Agriculture, KB-12006.03-002), and the China Scholarship Council. The authors are thankful to Johan Ploegaert of Wageningen UR Livestock Research, Hennie van Dorland of Wageningen UR for constructing the artificial reference cow. The authors also acknowledge PJMvan Beveren and A van't Ooster of Wageningen UR FarmTechnology Group for developing the concentration pattern evaluation model. 


\section{CHAPTER 5}

\section{Uncertainty assessment of a breath methane concentration method to determine methane production of dairy cows}

Liansun $\mathrm{Wu}^{1^{*}}$, Peter W.G. Groot Koerkamp ${ }^{1,2}$, Nico Ogink ${ }^{2}$

1. Farm Technology Group, Wageningen University, P.O. Box 16, 6700 AA, Wageningen,

The Netherlands

2. Wageningen UR Livestock Research, Wageningen University and Research Centre, P.O.

Box 135, 6700 AC, Wageningen, The Netherlands

*Corresponding author: Liansun.wu@wur.nl

To be submitted to Journal of Dairy Science 


\section{Chapter 5}

\section{Interpretive summary}

The uncertainty of a method to measure methane production of dairy cows was assessed. The method uses the measured methane concentration in the cow's breath during feed bin visit as a proxy for the production rate. We used an artificial reference cow in a feed bin setting that released known methane rates. Error sources were investigated affecting the relation between reference methane release rates and sampled concentrations in the feed bin. In a barn experiment, feed bin concentrations were positively correlated with reference release values $\left(\mathrm{R}^{2}=0.37\right.$, s.e. $=86 \mathrm{ppm}, 800-1700 \mathrm{ppm}$ reference range, 5 minute sampling records). Besides random error factors, systematic cow-linked factors may disturb the relation between sampled breath concentration and production rate. We conclude that the capability of the breath methane concentration method to adequately measure and rank methane production rates among cows is highly uncertain, and requires further investigation into variation sources with a systematic nature.

\footnotetext{
Abstract

The breath methane concentration method measures the methane concentrations of exhaled air in a feeder when the cow is milked in a milking robot or visits a feed station. Measured methane concentrations can be used as proxy for methane production, on the premise that breath methane concentration leaving the animal's mouth area and methane production are closely related. The objective of this study was to assess the uncertainty of a breath methane concentration method in a feeder and its capability to measure and rank cows' methane production. A range of controlled methane fluxes (200-400 g methane/day) from an artificial reference cow (ARC) were dosed in a feed bin, and its exhaled air was sampled (5 minutes) by a tube inside the feeder and analyzed. The ARC simulates the lungs, respiratory tract, and rumen of a cow and releases a variable methane flux to generate a concentration pattern in the exhaled breath that closely resembles a real cow's pattern. The strength of the relationship between reference methane release rates of the ARC and the measured methane concentrations at the sample inlet point in the feeder was analyzed by linear regression, using the coefficient of determination $\left(\mathrm{R}^{2}\right)$ and the residual standard error
} 


\section{Uncertainty assessment of a breath methane concentration method}

(s.e.) as performance indicators. The effect of error sources (source-sampling distance, air turbulence, and cow's head movement) on this relation was experimentally investigated, both under laboratory and barn conditions. In the laboratory, source-sampling distances of 5 and $30 \mathrm{~cm}$ resulted in $\mathrm{R}^{2}$-values of 0.97 and 0.84 , and s.e. of $37 \mathrm{ppm}$ and $75 \mathrm{ppm}$ respectively. From the laboratory to the barn at $30 \mathrm{~cm}$ sampling distance, $\mathrm{R}^{2}$-value decreased to 0.37 and s.e. increased to $86 \mathrm{ppm}$ as a result of barn air turbulence, the latter increasing to a theoretical $94 \mathrm{ppm}$ if modelled variability of cow's head movement was accounted for as well. In practice the effect of these random errors can be compensated by sampling strategies including repeated measurements on each cow over time thus increasing the distinctive power between cows. However, systematic errors that may disturb the relation between concentration and production rate, like cow variation in air exhalation rate and air flow patterns around sampling locations that differ between barns, cannot be compensated by such repeating measurements. As a result, the methane concentrations of breath air will vary between cows with the same methane production. We conclude that the capability of the breath concentration measurement method to adequately measure and rank methane production rates among cows is highly uncertain, and requires further investigation into variation sources with a systematic nature.

Keywords: methane, dairy cow, breath measurement, measurement error

\section{Introduction}

Enteric methane produced by dairy cows has become a global concern because these emissions account for $4 \%( \pm 26 \%)$ of anthropogenic greenhouse gas emissions (Gerber et al., 2013). Enteric methane from dairy cows can be mitigated through nutritional manipulations, farm management, and breeding animals with lower methane production (Cottle et al., 2011). To assess the effects of these mitigation strategies, an accurate and precise methane measurement method is required for dairy cows at commercial farms. Several methods have been developed and used to measure methane production of dairy cows. However, these methods are limited in measuring methane production of a large number of cows under 


\section{Chapter 5}

farm conditions either because of technical complexity and costs or because of short sampling periods (Storm et al., 2012).

Alternative methods have been developed to assess methane production of dairy cows at commercial farms. Breath methane concentration (BMC) methods or sniffer measurement methods measure the emitted methane concentrations of cows in a feeder when they are milked in a milking robot or visit a feed station (Garnsworthy et al., 2012; Lassen et al., 2012; Bell et al., 2014; Chagunda et al., 2009). When a cow is at a milking robot or in a feeding station, a sampling tube attached to a gas analyzer is placed in the feeder in front of the cow's head to continuously analyze methane concentrations in the cow's breath. Measured BMCs are then processed to determine the cow's daily methane production rate. An approach is used where the peak concentration is converted in a so called methane emission index that is correlated with a cow's daily methane production measured in a respiration chamber (Garnsworthy et al., 2012). However, it can be questioned if a cow's actual methane production, a flux calculated as the product of concentration and transporting air volume rate, can be adequately represented by methane concentration only. The strength of the relation between measured methane concentration and the actual methane production of cows depends on two different aspects.

The first aspect is animal related and deals with the relation between methane production and methane concentration at the point where it leaves the mouth/nose area of the animal (further called exhalation point). If the associated air volume rate that transports the methane out of the animal, is constant among cows then variability in methane production will be directly reflected by the variability of methane concentration at the animal's exhalation point. Variability in air exhalation rates of individual cows however can be expected to affect the methane concentration at the exhalation point. The cow's inhalation and exhalation air mixes with the methane eructating from the rumen in the cow's respiratory tract, and the air exhalation volume thus is an important factor in transporting and emitting the methane. A higher air exhalation rate therefore will lead to stronger dilutions of the methane flux from the rumen, causing lower methane concentrations in the breath air at the exhalation point. 


\section{Uncertainty assessment of a breath methane concentration method}

The second aspect is to which extent the animal's breath after exhalation is diluted with barn air at the inlet point of the sampling line. A high dilution variability weakens the relationship between the sampled concentration that is measured in the analyzer and the true methane concentration in the animal's breath at its exhalation point. The dilution of emitted methane from the exhalation point into surrounding barn air can be affected by several factors: the airflow pattern around the cow, the distance between exhalation point and inlet of the sample line, and the effects due to the cow's head movement in the feeder. There is a variable airflow when cows are in the milking robot in the barn as the air flow pattern in dairy barns varies within and between days (Wu et al., 2012; Joo et al., 2015). This airflow mixes with and dilutes the cow's emitted methane in breath. Next to that the location of the sampling inlet in the feed bin is relevant. When the cow's mouth is far from the analyzer tube, breath air will be more diluted before reaching the sample point. Connected to the distance as well is the cow's head movement that changes the distance between the exhalation point and the inlet of the sampling tube. Therefore, the sampling distances influences the dilution rate and causes variations in measured methane concentrations.

Consequently, the measured methane concentration sampled near the cow's head is a vulnerable index in determining methane production. The effects of turbulent aerial conditions, positioning of the sampling inlet point, cow's head movement, and the effect of the air exhalation rate on measured methane concentrations have not yet been studied. This information is crucial to assess the measurement performance of BMC methods.

The objective of this study was to assess the uncertainty of a BMC method and its capability to measure and rank cows' methane production. We investigated the relation between measured BMCs and controlled methane fluxes under both laboratory and barn conditions by using an artificial reference cow (ARC) that released controlled methane fluxes and concentrations (Wu et al., 2015). We experimentally investigated the effects of turbulent aerial conditions, source-sampling distance and the cow's head movement, and used literature sources to explore the effects of variability in air exhalation rate on measured methane concentrations. 


\section{Chapter 5}

\section{Materials and methods}

\subsection{Assessment of the breath methane concentration measurement in the laboratory}

To assess the performance of the breath methane measurement method, we first tested the method with the ARC in the air quality laboratory of Wageningen UR Livestock Research. The ARC is a device developed to release methane patterns from a nose piece that closely resembles a real cow's pattern and to precisely control the released methane flux and concentrations at pre-set values. The ARC is made of a cylinder in which a piston inhales and exhales air with controlled tidal volume, piston frequency and temperature, and in which a mass flow controller doses methane from a gas cylinder. The mixed air is transported by the piston movement to a nose piece. A detailed description of this system and tests of its accuracy is given by Wu et al. (2015). The ARC's nose was placed into a model feed bin with the same dimensions and shape as the actual bin that cows use in a milking robot (Figure 1). The feed bin was made of cardboard $(60.5 \mathrm{~cm} \times 46.0 \mathrm{~cm} \times 29.0$ $\mathrm{cm}$ ) and was partially enclosed. The inlet of the sampling tube was positioned $5 \mathrm{~cm}$ and 30 $\mathrm{cm}$ away from the ARC's nose. Air from the inlet point in the bin was continuously sampled at a rate of $4 \mathrm{~L} / \mathrm{min}$ and analyzed by a Fourier transform infrared spectroscopy (FTIR) gas analyzer one value per 2 or 3 seconds. In addition, a 3D anemometer (WindMaster, Gill Instruments, UK) was placed next to the feed bin to measure air velocity every second during the experiment. 


\section{Uncertainty assessment of a breath methane concentration method}

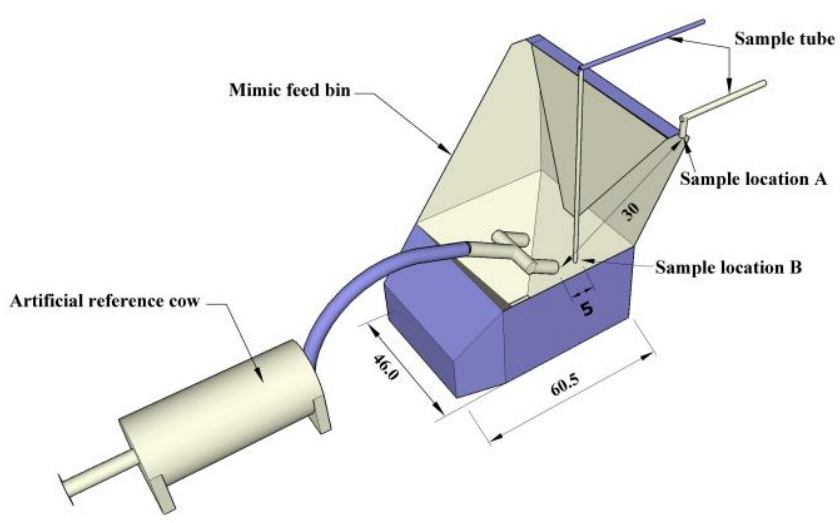

Figure 1. Schematic overview of the experimental set-up in the laboratory. Sample location A was $30 \mathrm{~cm}$ away from the ARC's nose. Sample location B was $5 \mathrm{~cm}$ away from the ARC's nose. The feed bin's right side is removed in the figure for presenting the sample locations.

At the start of the experiment, the ARC was run without injecting methane until the breath air had warmed to the desired temperature of about $25{ }^{\circ} \mathrm{C}$. At the $5 \mathrm{~cm}$ sample distance (Figure 1), the ARC simulated five different cows with controlled release rates from 200 to $400 \mathrm{~g} /$ day, with increments of $50 \mathrm{~g} /$ day. Each flux level was simulated during 3.6 minutes, denoted as one measurement. The measurement for each simulated cow was repeated 5 times. At the $30 \mathrm{~cm}$ sample distances, which is the distance used in the feed bin of a milking robot, the ARC simulated 11 different cows with controlled methane flux levels from 200 to $400 \mathrm{~g} /$ day with increments of $20 \mathrm{~g} /$ day. The tidal volume and breath frequency of each simulated cow were controlled at $4.4 \mathrm{~L}$ and 30 times per minute. Each simulated flux was released during 5 minutes, a time interval that a cow normally spends in the milking robot, and this interval was denoted as one measurement. The measurement for each simulated cow was repeated 4 times. In addition, a 10 min interval was taken between every 2 measurements to ensure that methane released into the feed bin from the previous testing had completely cleared. 


\section{Chapter 5}

\subsection{Assessment of the breath methane concentration measurement in}

the barn

After analyzing breath methane measurements in the laboratory under stable conditions, we assessed the method in a dairy barn under practical conditions. The experiment was carried out in a dairy cow barn in Lelystad, the Netherlands. The dairy cow barn was equipped with a natural ventilation system that included large openings on the side walls and slatted floors in the cow area with manure storage below. The opening area was automatically adjusted based on the barn temperature. Manure on the slatted floor was scraped once a day. The barn was divided into 4 areas. Each area had one milking robot serving about 60 cows. Cows were free to enter the milking robot, but were milked no more than twice a day.

We selected one milking robot to assess the breath measurement with the ARC. When the breath measurement method is used with real cows, the cow's body affects the aerial condition in the milking robot. Because the ARC simulated only the methane production, we made a dummy cow to represent a cow's body in the milking robot. The dummy cow $(220 \mathrm{~cm} \times 65 \mathrm{~cm} \times 140 \mathrm{~cm})$ consisted of a cow's head, body, and four legs and was divided into these three parts for easy handling. Because cows still had to be milked in the milking robot, we had to place and remove the dummy cow after each measurement. The ARC's nose was placed in the feed bin under the dummy cow's head. The inlet of the sampling tube was positioned $30 \mathrm{~cm}$ away from the ARC's nose on the feed bin's right side. The ARC's breath was continuously sampled at the inlet point of the sampling tube at a rate of 4 1/min and analyzed by the FTIR gas analyzer with one value per 2 or 3 seconds.

The ARC simulated 21 different cows with controlled daily methane flux levels from 200 to $400 \mathrm{~g} /$ day with increments of $10 \mathrm{~g} /$ day. The tidal volume and breath frequency of each simulated cow were set at 4.41 and 30 times per minute, as used in the laboratory tests. When each simulated cow was started, the ARC was running without injecting methane until the breath air had warmed to the desired temperature of $25^{\circ} \mathrm{C}$. Then, each flux level was simulated during 5 minutes, representing one measurement. These 21 simulated cow flux levels were randomly tested every half hour from 0830 to $1830 \mathrm{~h}$ during one day, and repeated during four consecutive weeks. 


\section{Uncertainty assessment of a breath methane concentration method}

During this barn experiment, two 3D anemometers measured air velocity in the barn and around the milking robot. One was placed at a height of $180 \mathrm{~cm}$ and $55 \mathrm{~cm}$ away from the barn's east wall and the other at a height of $120 \mathrm{~cm}$ next to the dummy cow's head. During each measurement, air velocity and direction were measured every second. Air temperature and humidity were also measured every half hour with a sensor (HygroClip S3; Rotronic, New York, USA) that was placed in the barn at a height of $2 \mathrm{~m}$.

\subsection{Effect of a cow's head movement}

To analyze the effects of a cow's head movement on the breath concentration measurement, we first observed in the dairy barn the head movement behavior in the feeder of 20 dairy cows over two days from 0900 to $1600 \mathrm{~h}$ with 10 cows per day. For each cow, we observed the duration of the cow's head in three locations (Figure 2): area A, inside in the center of the feed bin (IN-C), where cows take concentrates during milking; area $\mathrm{B}$, at the right top side of the feed bin close to the sampling point (IN-SP); and area C, outside the feed bin (OUT), where cows sniff around. These three locations were defined because of different sample distances between the cow's head and the sample inlet. The sample distance was the shortest in the IN-SP area because the sample inlet was placed on the feed bin's right side. In the OUT-area, the distance was the largest. At different sample distances, the gas analyzer sampled different amounts of the cow's breath air. Therefore, different sampling distances influenced the dilution rate of emitted methane from the exhalation point. 


\section{Chapter 5}

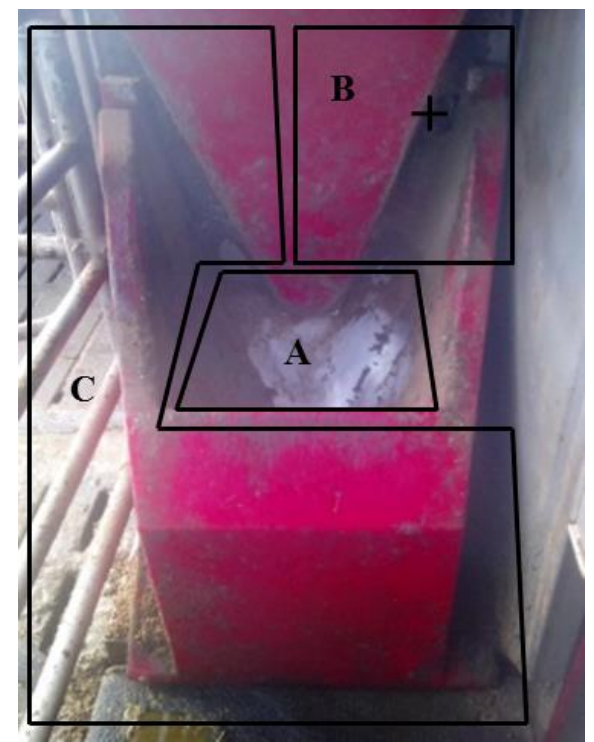

Figure 2. Schematic overview of three locations to analyze cows' head movement in and out of the feed bin. (A) inside the center of the feed bin (IN-C) where cows take concentrates during milking; (B) right top area of the feed bin close to the sampling point (IN-SP); and (C) outside the feed bin (OUT) where cows sniff around. The cross symbol represents the sampling point.

\subsection{Effects of a cow's air exhalation rate}

To explore and assess the effects of air exhalation rate on methane concentrations, we used the concentration pattern evaluation model of the ARC (Wu et al., 2015). This model allowed us to predict effects of variable tidal volume and breath frequency on emitted air's methane concentrations. Values from literature were used in this evaluation. We defined 5 different scenarios to explore the effects of air exhalation rate on measured methane concentrations.

In scenario 1, an air exhalation rate of 132 1/min was used, based on a mean tidal volume of 4.41 and a breath frequency of 30 times per minute (Wu et al., 2015). This air exhalation rate was used in our experiments to represent the mean cow exhalation level, and is based on reported literature values of Holstein Friesian cows. The reported coefficient of variation (CV) of tidal volume between cows is $15 \%$ and the $\mathrm{CV}$ of breath frequency between cows is $16 \%$ (Gallivan et al., 1991, 1989a; Stevens, 1981; Gallivan et al., 1989b). Expressed as 
Uncertainty assessment of a breath methane concentration method

standard deviations of mean levels, the tidal volume varies \pm 0.61 and breath frequency varies \pm 4.9 times per minute from the mean level. These values give an air exhalation rate ranging from 95 to $175 \mathrm{l} / \mathrm{min}$, and were used in scenario 2 and scenario 3 . Because the reported CV was measured from a small number of cows and may also have included substantial measurement errors, we defined two additional scenarios assuming a 5\% variation of tidal volume and breath frequency between cows. With these variations, we estimated an air exhalation rate of $120 \mathrm{l} / \mathrm{min}$ in scenario 4, and $145 \mathrm{l} / \mathrm{min}$ in scenario 5.

\subsection{Statistical analysis and calculations}

Data were analyzed by using GenStat 16 statistical system (VSN International Ltd., UK). All measured methane concentrations of each simulated cow were corrected for methane background present in the laboratory and in the dairy barn by subtracting the measured background methane concentration. This background methane concentration was the mean of methane concentration before and after each measurement when the ARC did not release methane.

\subsubsection{Experiments in the laboratory and barn}

The analysis focused on investigating the effects of the imposed ARC methane flux levels on the methane concentration at the sampling point $\left(\mathrm{MC}_{\mathrm{SP}}\right)$, the variability of dilution rate of $\mathrm{MC}_{\mathrm{SP}}$ when compared to the reference methane concentration at the ARC's exhalation point $\left(\mathrm{MC}_{\mathrm{EP}}\right)$, and the distinctive power of sampling strategies to demonstrate different methane production between cows.

The relation between $\mathrm{MC}_{\mathrm{SP}}$ (in $\mathrm{ppm}$ ) and controlled methane flux (expressed for convenience of comparison in g/day) was investigated with a linear regression model. Coefficients of determination $\left(\mathrm{R}^{2}\right)$, regression slope, and residual standard errors were used as evaluation parameters.

Relationship between $\mathrm{MC}_{\mathrm{EP}}$ and $\mathrm{MC}_{\mathrm{SP}}$ (both in ppm) was expressed as the Captured Fraction of Methane (CFM) by using the following equation: 


\section{Chapter 5}

$\mathrm{CFM}=\frac{\mathrm{MC}_{\mathrm{sp}}}{\mathrm{MC}_{\mathrm{EP}}}$

$\mathrm{MC}_{\mathrm{EP}}$ is calculated by the mean concentration from the evaluation model of the ARC. The relation between CFM and controlled daily methane flux was investigated with a linear regression model. The $\mathrm{CV}$ of $\mathrm{CFM}\left(\mathrm{CV}_{\mathrm{CFM}}\right)$ in each laboratory and barn test was calculated as follows:

$\mathrm{CV}_{\mathrm{CFM}}=\frac{\mathrm{SD}_{\mathrm{CFM}}}{\overline{\mathrm{CFM}}} \times 100 \%$

Where $\overline{\mathrm{CFM}}$ is the mean CFM of imposed methane production rates in each test, and $\mathrm{SD}_{\mathrm{CFM}}$ is the standard deviation of CFM.

To reach a required level of distinctive power in demonstrating a difference in methane production between cows, we investigated effects of repeated measurements that would meet the required distinctive power level. First, we calculated from the required difference in methane production the associated difference in $\mathrm{MC}_{\mathrm{EP}}\left(\triangle \mathrm{MC}_{\mathrm{EP}}\right)$, making use of the constant exhalation rate of the ARC in our experiments. As a next step we converted $\Delta$ $\mathrm{MC}_{\mathrm{EP}}$ into a required difference of concentration at sampling point level $\left(\Delta \mathrm{MC}_{\mathrm{SP}}\right)$, by multiplying $\Delta \mathrm{MC}_{\mathrm{EP}}$ with CFM. Determination of $\Delta \mathrm{MC}_{\mathrm{SP}}$ is based on the difference between concentration means of two cows. To be significant at $\alpha=0.05$ the required difference between the means $\mathrm{MC}_{\mathrm{EP} 1}$ and $\mathrm{MC}_{\mathrm{EP} 2}$ should fulfil Equation 3:

$\left(\left|\mathrm{MC}_{\mathrm{EP} 1}-\mathrm{MC}_{\mathrm{EP} 2}\right|\right) \times \mathrm{CFM}>\mathrm{tc} \times \sqrt{\mathrm{SEM}_{1}^{2}+\mathrm{SEM}_{2}^{2}}$

Where tc is the critical t-value depending on the number of measurements (n), which is 1.95 at $\alpha=0.05$ level for $\mathrm{n}=\infty$, and $\mathrm{SEM}_{1}$ and $\mathrm{SEM}_{2}$ represent the standard errors of both cow means. The SEM based on $n$ measurements can be calculated by equation 4 :

$\mathrm{SEM}=\frac{\mathrm{SD}_{\mathrm{CFM}} \times \mathrm{MC}_{\mathrm{EP}}}{\sqrt{\mathrm{n}}}$

Where SEM is the standard error of mean measured methane concentrations in $\mathrm{ppm}, \mathrm{MC}_{\mathrm{EP}}$ is a chosen representative concentration level, and $\mathrm{n}$ is the number of measurements. By

102 


\section{Uncertainty assessment of a breath methane concentration method}

solving Equation 3 and 4, we can calculate the smallest number of measurements $n$ needed to demonstrate required differences between the methane production rates of two cows.

In the barn experiment, mean air velocity was calculated for each measurement. The relation between measured methane concentration and mean air velocity was investigated with a linear regression model.

\subsubsection{Effects of a cow's head movement}

To assess the effects of a cow's head movement on the variability of CFM-values, use was made of video observations of cows visiting a feed bin in a milking robot. First we estimated the CFM values for each cow's head location in the feed bin (Figure 2). The CFM linked to the IN-C location was derived from the mean CFM of the barn experiment because the ARC's nose was always at this position in the feed bin. The CFM at the IN-SP location was assumed to be 0.10 higher than the CFM of the IN-C location because the cow's head was closer to the sample location thus enabling a higher sampling efficiency by sampling less diluted exhaled air. The CFM of the OUT location was 0 because the cow's head was far away from sample location. With different duration time and CFM for the different head locations, we calculated the CV of CFM between cows caused by the cows' head movements by the following two equations:

$$
\begin{aligned}
& \mathrm{CFMI}_{\mathrm{i}}=\frac{\mathrm{t}_{1 \mathrm{i}}}{\mathrm{T}_{\mathrm{i}}} \times \mathrm{CFM}_{1}+\frac{\mathrm{t}_{2 \mathrm{i}}}{\mathrm{T}_{\mathrm{i}}} \times \mathrm{CFM}_{2}+\frac{\mathrm{t}_{3 \mathrm{i}}}{\mathrm{T}_{\mathrm{i}}} \times \mathrm{CFM}_{3} \\
& \mathrm{CV}_{\mathrm{CFM} \text {-head-movement }}=\frac{\mathrm{SD}_{\mathrm{CFMI}}}{\frac{1}{\mathrm{n}} \times \sum_{\mathrm{i}=1}^{\mathrm{n}} \mathrm{CFMI}_{\mathrm{i}}} \times 100 \%
\end{aligned}
$$

Where CFMI $\mathrm{I}_{\mathrm{i}}$ is CFM index of each observed cow (i); $\mathrm{t}_{1 \mathrm{i}}, \mathrm{t}_{2 \mathrm{i}}$, and $\mathrm{t}_{3 \mathrm{i}}$ are the duration times that the observed cow (i) spent at the IN-C, IN-SP, and OUT location in seconds; $\mathrm{T}_{\mathrm{i}}$ is the total duration time that the observed cow (i) spent in the milking robot in seconds; $\mathrm{CFM}_{1}$, $\mathrm{CFM}_{2}$, and $\mathrm{CFM}_{3}$ are the CFM at the IN-C, IN-SP, and OUT location; $n$ is the number of observed cows, which is 20 in this study; and $\mathrm{SD}_{\mathrm{CFMI}}$ is the standard deviation of the CFMI of all observed cows. After analyzing the CV of CFM caused by head movement, we calculated the total CV of CFM as follows: 


\section{Chapter 5}

$$
C V_{t}=\sqrt{C V_{C M F-h e a d-m o v e m e n t}^{2}+C V_{C M F-\text { barn }}^{2}}
$$

\section{Results and discussion}

\subsection{Laboratory experiment}

Figure 3a shows the methane concentrations $\left(\mathrm{MC}_{\mathrm{SP}}\right)$ measured at the $5 \mathrm{~cm}$ and at the $30 \mathrm{~cm}$ sample distances under controlled methane flux levels. $\mathrm{MC}_{\mathrm{SP}}$ in the range of pre-set methane production levels (expressed in g/day) varied from $539 \mathrm{ppm}$ (s.d. 16.0) to 1,030 ppm (s.d. 28) at the $5 \mathrm{~cm}$ sample distances, and 543 ppm (s.d. 33) to 1,100 ppm (s.d. 92) at the $30 \mathrm{~cm}$ sample distances. Both series of $\mathrm{MC}_{\mathrm{SP}}$ at these two sample distances were strongly linearly related to controlled methane production $\left(\mathrm{R}^{2}=0.97\right.$ and $\left.0.84, \mathrm{P}<0.001\right)$. During the experiment, mean air velocity amounted $0.04 \mathrm{~m} / \mathrm{s}$ (s.d. 0.01). Although aerial conditions were stable in the laboratory, the CFM was 0.60 (s.d. 0.03) at the $5 \mathrm{~cm}$ sample distances and 0.62 (s.d. 0.05) at the $30 \mathrm{~cm}$ sample distances (Figure 3b). Emitted methane reaching the sampling inlet was already considerably diluted compared to the methane concentrations at exhalation point $\left(\mathrm{MC}_{\mathrm{EP}}\right)$. In contrast to the measured concentrations, the CFMs at these two sample distances were not influenced by controlled methane flux. The slope of the regression lines at these two sample distances did not differ from zero $(\mathrm{P}>$ 0.05). The CFM did not differ between the two sample distances ( $\mathrm{P}>0.05)$. This means that the source-sampling distances of $30 \mathrm{~cm}$ could capture methane concentrations similar to those of $5 \mathrm{~cm}$ sampling distance from the cow's nose under laboratory condition. However, measurement variations in CFM at the $30 \mathrm{~cm}$ sample distances $(8.8 \%)$ were higher than those at $5 \mathrm{~cm}$ sample distances $(5.0 \%)$. These variations were mainly caused by the movement of ARC's released air under relatively stable laboratory conditions. Released air disperses around the feed bin and dilutes into the environment. The methane concentration at a longer sample distance is more varied because of less influence from the source. Thus the measurement variations can be expected to be higher at the $30 \mathrm{~cm}$ sample distances. 


\section{Uncertainty assessment of a breath methane concentration method}
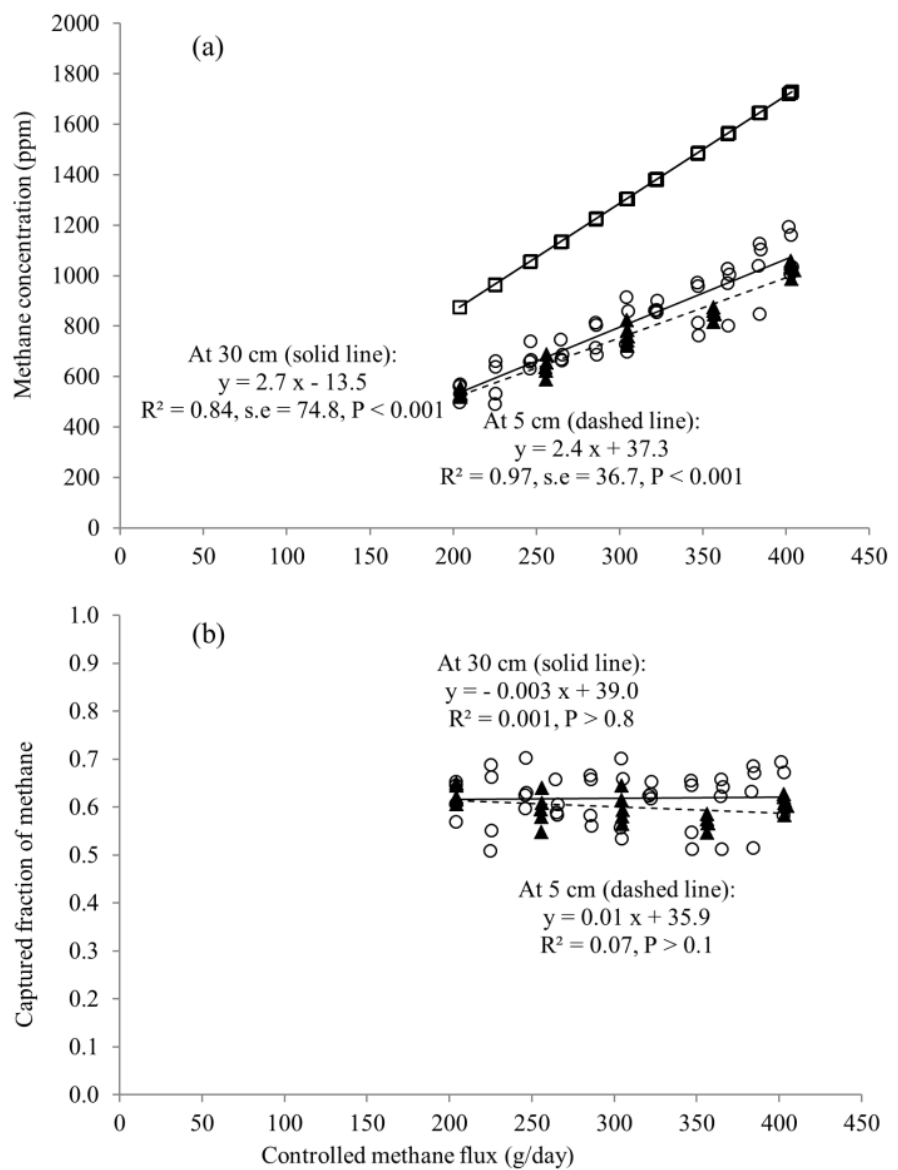

Figure 3. Methane concentrations at the exhalation point and measured concentrations at inlet of sampling line (a) and captured fraction of methane (b) measured at $5 \mathrm{~cm}(\boldsymbol{\Delta})$ and $30 \mathrm{~cm}(\mathrm{O})$ sample distances versus controlled methane flux in the laboratory. Methane concentrations at exhalation point $(\square)$ are predicted mean methane concentrations of the ARC's emitted air.

The standard error of a measurement was $37 \mathrm{ppm}$ at the $5 \mathrm{~cm}$ and $75 \mathrm{ppm}$ at the $30 \mathrm{~cm}$ sample distance. Therefore, the measurement $\mathrm{CV}$ of mean measured methane concentrations amounted to $4.8 \%$ at the $5 \mathrm{~cm}$ and $9.3 \%$ at the $30 \mathrm{~cm}$ sample distances. These measurement CVs under stable laboratory conditions were smaller than the CV of methane production between-cows measured in the respiration chamber (7-17\%) (Blaxter and Clapperton, 1965; Yan et al., 2010). In principle, these measurement errors can be 


\section{Chapter 5}

reduced by repeating measurements. To demonstrate a $30 \mathrm{~g} / \mathrm{day}$ in methane production between cows producing around $300 \mathrm{~g} /$ day, the minimum number of measurements would amount to 3 at the $5 \mathrm{~cm}$ sample distances and 7 at the $30 \mathrm{~cm}$ sample distances (Equation 3 and 4). However, to demonstrate a $5 \mathrm{~g} / \mathrm{day}$ difference between cows around $300 \mathrm{~g} / \mathrm{day}$, the minimum number of measurements would increase to 69 at the $5 \mathrm{~cm}$ sample distances and 225 at the $30 \mathrm{~cm}$ sample distances (Table 1). Based on an average 2 visits to the milking robot per cow per day, minimum number of measurement days are 34.5 for the $5 \mathrm{~cm}$ sample distances and 112.5 for the $30 \mathrm{~cm}$ sample distances.

Table 1. The standard error of a measurement, coefficient of variation (CV) of captured fraction of methane (CFM), and required number of measurement times to demonstrate 5 and $30 \mathrm{~g} /$ day differences between cows around $300 \mathrm{~g} /$ day of the breath methane measurement under four sampling conditions.

\begin{tabular}{|c|c|c|c|c|}
\hline \multirow[t]{2}{*}{ Condition } & \multirow{2}{*}{$\begin{array}{l}\text { Standard error } \\
(\mathrm{ppm})\end{array}$} & \multirow{2}{*}{$\begin{array}{c}\text { CFM's CV } \\
(\%)\end{array}$} & \multicolumn{2}{|c|}{$\begin{array}{c}\text { Number of } \\
\text { measurements }\end{array}$} \\
\hline & & & $30 \mathrm{~g} /$ day & 5 g/day \\
\hline Laboratory + $5 \mathrm{~cm}$ sampling distance & 37 & 5.0 & 3 & 69 \\
\hline Laboratory $+30 \mathrm{~cm}$ sampling distance & 75 & 8.8 & 7 & 225 \\
\hline Barn $+30 \mathrm{~cm}$ sampling distance & 86 & 21.8 & 38 & 1,250 \\
\hline Barn $+30 \mathrm{~cm}$ sampling distance + head movements & 94 & 24.8 & 53 & 1,725 \\
\hline
\end{tabular}

\subsection{Barn experiment}

\subsubsection{Airflow effects}

Table 2 shows the environmental data and CFM of the 4 measurement days, and the difference in climatic conditions between days, especially for air velocity. Air velocity measured at the barn's east wall varied from 0.64 to $1.33 \mathrm{~m} / \mathrm{s}$. This range is consistent with other studies (Wu et al., 2012; Kaharabata et al., 2000). Inside the barn, air velocity decreased to $0.09-0.24 \mathrm{~m} / \mathrm{s}$ around the feed bin of the milking robot. This air velocity was measured at a height of $120 \mathrm{~cm}$ in the cows' active zone. In this zone, Wu et al (2015) also measured a similar range of air velocity around lying cubicles in a cow barn. CFM was negatively related to the air velocity around the feed bin $(\mathrm{P}<0.001$; Figure 4$)$. With a higher air velocity, emitted methane is more easily diluted before it is sampled by the gas analyzer. The highest mean CFM was 0.35 on the second measurement day and the lowest was 0.26 on the third measurement day. These values corresponded with the lowest and highest daily mean air velocity measured. 
Uncertainty assessment of a breath methane concentration method

Table 2. Environmental data and capture fraction of methane of 4 measurement days in the barn.

\begin{tabular}{lcccc}
\hline & \multicolumn{5}{c}{ Measurement day } \\
\cline { 2 - 5 } & 1 & 2 & 3 & 4 \\
\hline Temperature $\left({ }^{\circ} \mathrm{C}\right)$ & $22.7(2.0)$ & $18.7(2.1)$ & $17.0(0.9)$ & $21.2(2.2)$ \\
Relative humidity $(\%)$ & $66.0(7.0)$ & $55.2(3.6)$ & $75.7(7.7)$ & $61.7(7.7)$ \\
Air pressure (pa) & $102.4(0.3)$ & $102.3(0.2)$ & $100.9(1.1)$ & $101.8(0.5)$ \\
Air velocity (m/s): & & & & $0.80(0.33)$ \\
$\quad$ At the east side wall & $0.82(0.27)$ & $0.64(0.17)$ & $1.33(0.29)$ & $0.10(0.04)$ \\
$\quad$ Around the feed bin & $0.12(0.04)$ & $0.09(0.03)$ & $0.24(0.05)$ & $0.33(0.05)$ \\
Captured fraction of methane & $0.30(0.05)$ & $0.35(0.06)$ & $0.26(0.07)$ & \\
\hline
\end{tabular}

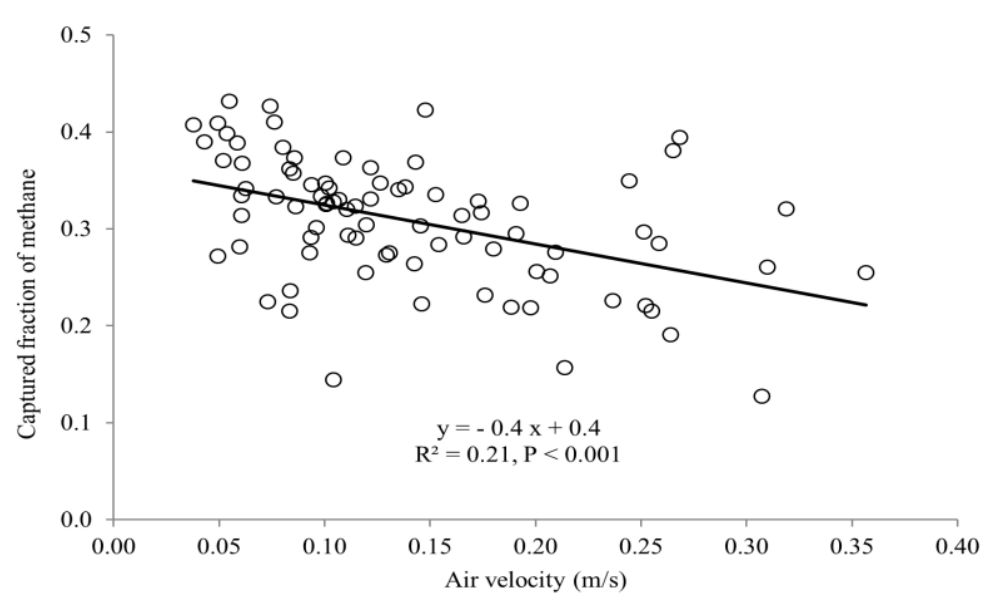

Figure 4. Relation between captured fraction of methane and air velocity near the feed bin in the barn for simulated flux levels ranging between $200-400 \mathrm{~g} / \mathrm{day}$.

\subsubsection{Methane concentration versus methane flux}

Measured methane concentrations were linearly related to controlled methane production under barn conditions $(\mathrm{P}<0.001)$, but with higher variations than under laboratory conditions (Figure 5a). The standard error of measurement increased from $75 \mathrm{ppm}$ at the 30 $\mathrm{cm}$ sample distances in the laboratory to $86 \mathrm{ppm}$ in the barn. The measurement $\mathrm{CV}$ of the mean measured methane concentration also increased to $21.8 \%$. Due to the disturbed aerial conditions, the mean CFM decreased from 0.62 at the $30 \mathrm{~cm}$ sample distances in the laboratory to 0.31 in the barn. Similar to the laboratory, CFMs were not influenced by controlled methane flux in the barn (Figure 5b). The slope of the regression lines did not 


\section{Chapter 5}

differ from zero $(\mathrm{P}>0.05)$. With a lower CFM and a higher measurement error, differences of measured methane concentrations under barn conditions were smaller and varied more between simulated cows than in the laboratory, which means more measurements are required to demonstrate differences between cows under barn conditions. To distinguish a $30 \mathrm{~g} /$ day between cows around $300 \mathrm{~g} /$ day, the minimum number of measurements must be increased from 7 in the laboratory to 38 in the barn. If we want to demonstrate a $5 \mathrm{~g} /$ day between cows around $300 \mathrm{~g} / \mathrm{day}$ in the barn, the minimum number of measurements must be increased to 1,250 (Table 1). Considering an average of two visits to the milking robot per cow per day, minimum measurement days are 19 for $30 \mathrm{~g} /$ day and 625 for $5 \mathrm{~g} /$ day methane production differences.
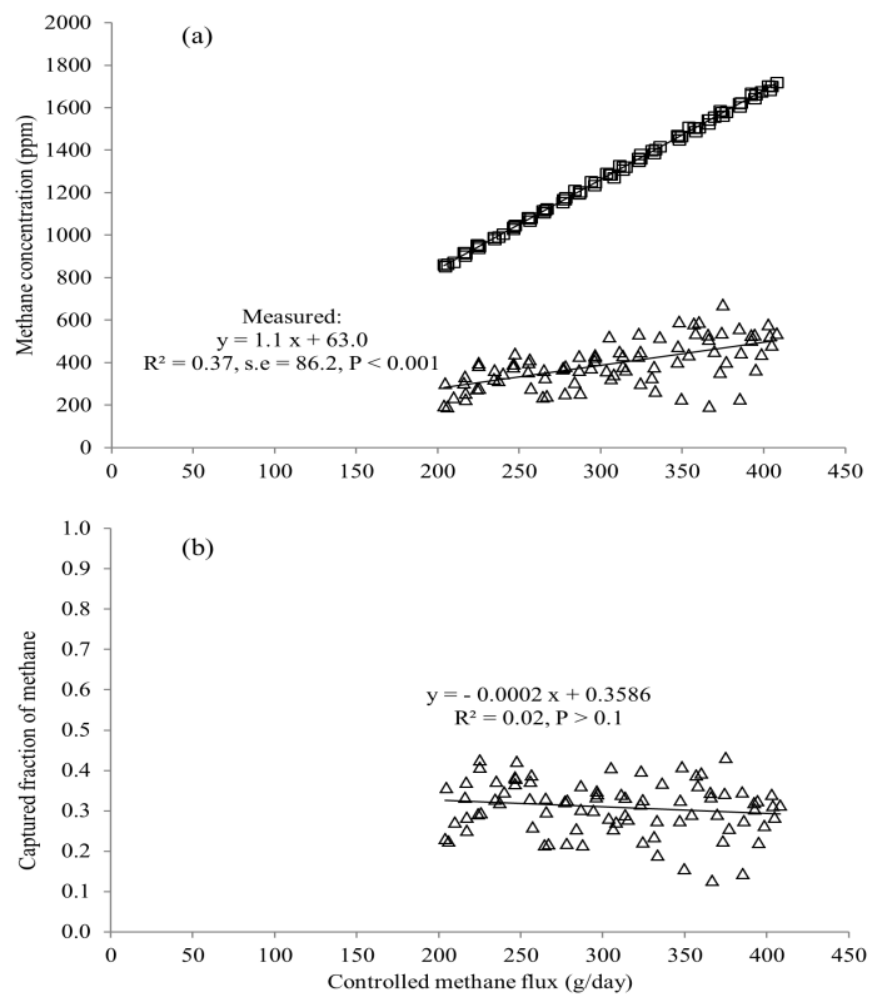

Figure 5. Measured methane concentrations at inlet of sampling line (a) and captured fraction of methane (b) at 30 $\mathrm{cm}$ sample distances versus controlled methane flux in the barn. Methane concentrations at exhalation point ( $\square$ ) are predicted mean methane concentrations of the ARC's emitted air. 
Uncertainty assessment of a breath methane concentration method

\subsubsection{Effects of a cow's head movement}

During the experiment in the barn, the ARC's nose was placed in the feed bin where a cow would normally place its mouth. However, cows are free to move their head in the bin during the visit to the milking robot, and consequently will create variability in sampling distance. According to the records of the 20 observed cows, cows spent 366 s (s.d. 84) in the milking robot during each visit. In each visit, the cow's head was located at the IN-C during $76 \%$ (s.d. 13), OUT during $16 \%$ (s.d. 10), and IN-SP during $8 \%$ (s.d. 10) of the total visit time. The CFM at the IN-C was estimated at 0.31 as measured from the ARC in the barn, at IN-SP assumed to be 0.41 as being closest to the sampling tube, and 0 in the area outside the feed bin (OUT area). Based on these values, the CFM's CV caused by head movement was estimated at $13 \%$ (Equation 6). Combining this estimated head movement with the measured CV in the barn with a fixed head position, the total CFM's CV increased to $25 \%$ (Equation 7). The total CFM's CV is not very sensitive to the assumed CFM at INSP. When the assumed CFM changes by $10 \%$, the total CFM's CV only varies $1.6 \%$. Therefore, the total CFM's CV of $25 \%$ is a relatively robust representation of the effects of a cow's head movement. With this $\mathrm{CV}$, the minimum measurement number is 13 to demonstrate a $30 \mathrm{~g} /$ day difference between cows around $300 \mathrm{~g} /$ day. Without head movement effects, the minimum number of measurements is only 7 (Table 1). To demonstrate a $5 \mathrm{~g} /$ day difference between cows around $300 \mathrm{~g} /$ day, minimum measurement number must be increased to 1,575 , which is equal to 787.5 measurement days.

\subsubsection{Effects of the air exhalation rate}

Different tidal volumes and breath frequencies may result in various air exhalation rates between cows. Predicted methane concentrations at the exhalation point $\left(\mathrm{MC}_{\mathrm{EP}}\right)$ with 4 different air exhalation rates (scenario 2-5) are compared with the mean air exhalation rate (scenario 1) in Figure 6. A higher air exhalation rate decreases $\mathrm{MC}_{\mathrm{EP}}$. Compared to scenario 1 , the emitted air's methane concentrations are $33 \%$ higher in scenario 2 with the lowest air exhalation rate, and $26 \%$ lower in scenario 3 with the highest air exhalation rate. When the air exhalation rates in scenario 4 and 5 are close to the mean level in scenario 1 , the differences to the mean level of the emitted air's methane concentrations are also smaller. The emitted air's methane concentrations are $12 \%$ higher in scenario 4 and $8 \%$ lower in 


\section{Chapter 5}

scenario 3 compared to scenario 1. Due to the variations in the air exhalation rate between cows, the relation between emitted air's methane concentration level $\left(\mathrm{MC}_{\mathrm{EP}}\right)$ and methane production rate is disturbed. For instance, an emitted air's methane concentration level of 1,200 ppm may indicate a methane production of $213 \mathrm{~g} /$ day in scenario 2, $255 \mathrm{~g} / \mathrm{day}$ in scenario 4, $285 \mathrm{~g} /$ day in scenario 1, $310 \mathrm{~g} /$ day in scenario 5, and $385 \mathrm{~g} /$ day in scenario 3 (Figure 6).

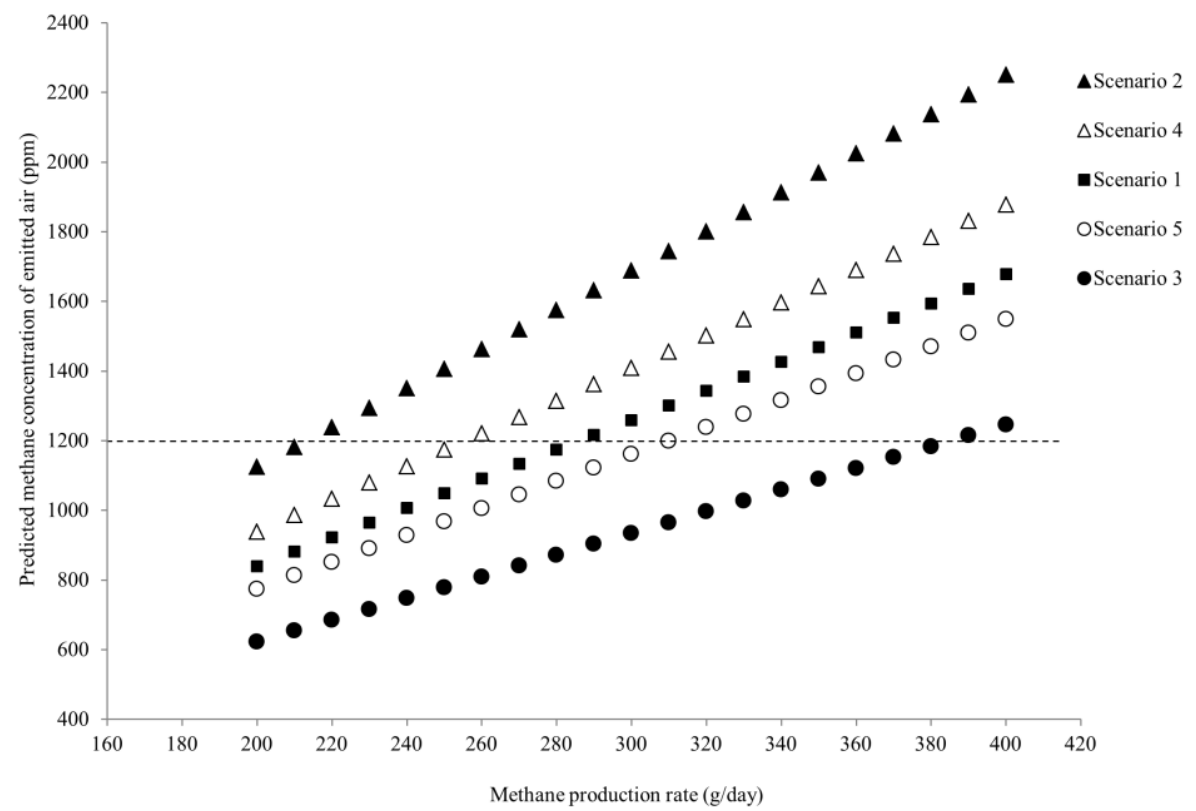

Figure 6. Predicted methane concentrations at exhalation point as a function of methane flux levels under 5 scenarios with different air exhalation rates. The air exhalation rate is $132 \mathrm{l} / \mathrm{min}$ in scenario 1 (匹), $951 / \mathrm{min}$ in scenario $2(\mathbf{\Delta}), 175$ 1/min in scenario $3(\bullet), 120$ l/min in scenario $4(\triangle)$, and 145 l/min in scenario $5(O)$.

\subsubsection{Measurement errors of the breath methane measurement}

Measurement errors of the breath methane measurement include (1) random errors caused by aerial conditions, and variable source-sampling distances by head movements; and (2) systematic errors at cow level caused by variations in the air exhalation rates between cows, and at barn level where air flow patterns around measurements points may vary as a result of differences in ventilation management and barn-layout. The standard random error of a measurement increased from $37 \mathrm{ppm}$ in the laboratory with the $5 \mathrm{~cm}$ sampling distance to 


\section{Uncertainty assessment of a breath methane concentration method}

$94 \mathrm{ppm}$ in the barn with the $30 \mathrm{~cm}$ sampling distance and head movements (Table 1). These random errors influence the precision of measured methane production while using the breath methane measurement. These random errors can be reduced by repeating measurements. To assess feeding effects on methane production, random errors should be reduced to demonstrate the difference between cows. If the feeding can achieve only a 5 $\mathrm{g} /$ day difference on methane production, 1,725 measurements are required to reduce the effects of random error under barn conditions (Table 1). However, for the purpose of breeding cows with lower methane production the positive correlation between measured methane concentrations and methane production rates will, if applied at sufficient numbers, support genetic progress.

Unlike random errors, systematic errors cannot be compensated by repeating measurements. Due to the variations in air exhalation rates between cows, a methane production rate could have systematically different methane concentration levels. Variability in air exhalation rate may be the result of genetic differences but also the result of their physiological status, like heat stress of high yielding animals. The risk exists that the efficiency of breeding on this proxy for methane production is undermined by selection on other physiological variables that are correlated with methane concentration in exhaled breath air. To which extent other animal linked variables are correlated with methane concentration is not clear from existing literature. The effects of systematic differences in ventilation management and barn-layout, will complicate as well interpretation of cow measurements carried out at different barn locations. Our results showed clear effects of air velocity around sampling location on the dilution of emitted methane from the ARC. Consistency in dilution levels between sampling locations in different barns have to be verified before they can be used together. Considering this, the capability of breath measurement methods is uncertain to assess feeding effects or to select cows for breeding, and requires further investigation into variation sources with a systematic nature. 


\section{Chapter 5}

\section{Conclusions}

The breath methane measurement method is a novel and low-cost on-farm technique. The present results show that measured methane concentrations are positively related to the controlled methane production rates by the ARC under both laboratory and barn conditions. However, disturbed barn condition and the head movements of cows increase measurement errors of measured methane concentrations. With these measurement errors, a large number of measurements are required to demonstrate differences in methane production rates between cows. Systematic errors, such as between-cow variation in air exhalation rates, ventilation management, and barn lay-out cannot be reduced by repeated sampling. We conclude that the capability of the breath measurement method to adequately evaluate and rank methane production rates among cows is highly uncertain and requires further investigation into variation sources with a systematic nature.

\section{Acknowledgments}

This study was funded by Wageningen UR Livestock Research, the Ministry of Economic Affairs of the Netherlands (Research Program Sustainable Agriculture, KB-12-006.03-002), and the China Scholarship Council. The authors are thankful to Johan Ploegaert of Wageningen UR Livestock Research, and Cornelis Cnossen of Wageningen UR Farm Technology Group for helping with the experiment in the dairy cow barn. 


\section{CHAPTER 6}

\section{Design and evaluation of a methane flux}

\section{measurement method for dairy cows in cubicles}

Liansun Wu, ${ }^{* 1}$ Peter W.G. Groot Koerkamp, ${ }^{*} \dagger$ Cornelis Cnossen, ${ }^{*}$ Coen Uijterlinde, ${ }^{*}$ and Nico Ogink $\dagger$

*Farm Technology Group, Wageningen University, P.O. Box 16, 6700 AA, Wageningen, The Netherlands

†Wageningen UR Livestock Research, P.O. Box 135, 6700 AC, Wageningen, The

Netherlands

${ }^{1}$ Corresponding author: Liansun.wu@wur.nl

This chapter is submitted to Journal of Dairy Science. 


\section{Chapter 6}

\section{Interpretive summary}

A cubicle hood sampler was designed and constructed to measure methane fluxes produced by cows lying in a cubicle. The recovery rate, being the measured flux by the hood sampler relative to a known release rate of a so-called artificial reference cow, was assessed under both laboratory and barn conditions. The sampler captured $97.2 \%$ of the methane released by the artificial reference cow under barn conditions. In the barn, the coefficient of variation was $8.0 \%$ at a methane release rate of $300 \mathrm{~g} / \mathrm{d}$. We concluded that this newly developed hood sampler is sufficiently accurate to measure methane production of individual cows in cubicles to assess the effect of various reduction measures.

\section{Abstract}

Greenhouse gas emissions can be mitigated by breeding dairy cows with low methane production. For that, a method is needed that measures the methane flux in the breath of a large number of cows under barn conditions. An oversized sample hood combined with air extraction, placed around the head of a cow when she is lying in a cubicle, could be used for this. The objective of this study was to design, construct, and evaluate two hood types, various air extraction rates, nose positions and layouts of a cubicle hood sampler (CHS) that can measure the methane flux produced by a cow in a cubicle under various aerial conditions. The methane recovery rate, being the measured flux by the hood sampler relative (\%) to a known release rate of a so-called artificial reference cow (ARC), was assessed under both laboratory and barn conditions. The ARC simulated the lungs, respiratory tract, and rumen of a cow and released a variable methane flux to generate a concentration pattern in the exhaled breath that closely resembled a real cow's pattern through exhalation and eructation; the released methane flux was controlled at pre-set values.

The results showed that the methane recovery rate of the CHS in the laboratory was significantly affected by the hood type, extraction flow rate, presence of a top curtain, induced airflow, and extended side panels. The highest recovery (99.6\%) was achieved with a fume sample hood with a top curtain and the highest flow rate. In the barn, the CHS with 


\section{Methane flux measurement in cubicles}

a fume sample hood, a flow rate of $200 \mathrm{~m}^{3} / \mathrm{h}$, a top curtain, and extended side panels captured $97.2 \%$ (s.d. 8.1) of the methane released by the ARC, regardless of the air velocity in the cubicle or the nose position of the cow. In the barn, standard errors of a single measurement were estimated to be $24.1 \mathrm{~g} /$ day at the flow rate of $200 \mathrm{~m}^{3} / \mathrm{h}$. This estimate corresponds to a coefficient of variation at a mean measured methane production of $8.0 \%$. We concluded that this newly developed method is sufficiently accurate to assess methane production of individual cows in cubicles.

Keywords: methane, dairy cow, cubicle hood sampler, methane recovery rate

\section{Introduction}

Enteric methane $\left(\mathrm{CH}_{4}\right)$ produced by dairy cows has become a global concern because it has 28 times the global warming potential of carbon dioxide $\left(\mathrm{CO}_{2}\right)$ and consequently more negatively influences global climate change than $\mathrm{CO}_{2}$ (Cottle et al., 2011; Myhre et al., 2013). In dairy farming, methane contributes about $50 \%$ of the total greenhouse gas emissions in the dairy production chain up to farm gate (FAO, 2010). A dairy cow produces 250 to $400 \mathrm{~g}$ methane per day (Bannink et al., 2011). This methane is mainly released through the nose and mouth by exhalation and eructation, and in small quantities by flatus (Murray et al., 1976).

Enteric methane from dairy cows can, amongst others, be mitigated through breeding animals with lower methane production (Cottle et al., 2011). Breeding has gained more research interest because of its inexpensive, cumulative, and permanent effects (De Haas et al., 2011). Several studies have reported variations of 7 to $15 \%$ in methane production between cows (Blaxter and Clapperton, 1965; Grainger et al., 2007; Johnson and Johnson, 1995; Yan et al., 2010). This variation and with the heritability of this trait provides the potential to select dairy cows with a lower methane production. This selection requires methane production data from a large number of individual cows, which have to be obtained from cows on commercial farms. However, this data is difficult to obtain at commercial farms because current methane-measuring techniques are limited either 


\section{Chapter 6}

because of technical complexity and costs, or because of short and non-representative sampling periods (Storm et al., 2012).

Methane production of individual cows on commercial farms is currently determined either by measuring methane concentrations or by measuring methane fluxes. Methane and in some cases also the $\mathrm{CO}_{2}$ concentration in the exhaled breath of a cow is measured when cows visit a milking robot or a feed station, and daily methane production is determined in two approaches (Bell et al., 2014; Garnsworthy et al., 2012; Hellwing et al., 2012; Madsen et al., 2010). The first approach uses the peak $\mathrm{CH}_{4}$ concentration to calculate a methane emission index. This index positively correlated with the daily methane production measured in a respiration chamber (Garnsworthy et al., 2012). In the second approach the $\mathrm{CH}_{4} / \mathrm{CO}_{2}$ concentration ratio is multiplied with the estimated daily $\mathrm{CO}_{2}$ production of cows to obtain the daily methane production (Madsen et al., 2010). After leaving the nose and mouth, further referred to as nose, the exhaled breath air with high concentrations of $\mathrm{CH}_{4}$ and $\mathrm{CO}_{2}$ is mixed with surrounding air with low gas concentrations, and dilution increases with distance to the nose. This dilution of breath air is affected by three factors: airflow pattern around the cow, the cow's head movement, and the cow's breath flow rate $(\mathrm{Wu}$, 2016). A variable airflow around the cow in a milking robot affects the dilution rate of the breath air. A cow's head movement changes the distance between the cow's nose and the air sampling point, and extent of dilution varies with the distance. Variability between cows in breath frequency and tidal volume will also lead to variability in the breath flow rates of cows, resulting in varying methane concentrations in exhaled air among cows with the same methane production. Consequently, the measured methane concentration in the air around a cow's head is a vulnerable index and therefor only a proxy for the methane production.

The other way to determine the methane production of individual cows on commercial farms is by measurement of the actual methane fluxes from dairy cows, e.g. by using the GreenFeed method (Dorich et al., 2015; Huhtanen et al., 2015). In this method, a cow visits a feed bin with an integrated measurement system that captures the cow's breath with a fangenerated airflow. The methane flux in the breath is then calculated by multiplying the 


\section{Methane flux measurement in cubicles}

measured methane concentration with the generated airflow rate. Although the GreenFeed measures methane the flux from individual cows, Hammond et al. (2015) reported that the method could not detect the difference in methane production between cows due to limited measurement numbers and a short sampling time for each cow. The sampling time is restricted by the duration of feed bin visits.

To overcome measurement limitations of the GreenFeed method other approaches are needed. In free stall barns, cows typically spend up to 14 hours lying, resting, and ruminating in their cubicles, while generally remaining in a stable position. This period could be used to measure the methane flux produced by the resting cows by placing a hood around their heads, called a cubicle hood sampler (CHS). The methane recovery rate is a critical success factor for such a hood sampler. The recovery rate is the measured flux by the hood sampler relative (\%) to a known release rate of an artificial source. The recovery rate will, like the breath concentration method, depend on the effect of variable airflow patterns in the barn, cow's nose position and distance to the hood, and variable background gas concentrations. Knowledge of these effects is needed to design and develop an effective CHS.

The objectives of the study were

(1) To design and construct a cubicle hood sampler (CHS) to measure the methane flux produced by individual cows in a cubicle;

(2) Evaluate the recovery rate of the CHS under controlled lab conditions: two aerial conditions, two hood types, a range of air extraction rates, various nose positions, and different layouts of the CHS;

(3) To evaluate the recovery rate of the CHS in a cubicle house under variable aerial conditions with a range of methane release rates;

(4) To investigate to what extent the CHS can detect the variation of methane production between cows under barn conditions. 


\section{Chapter 6}

\section{Materials and methods}

\subsection{CHS composition and layout}

The CHS (Figure 1) was designed and constructed to capture the methane that a cow emits when she is lying in a cubicle. The CHS consists of a sample hood, an airflow rectifier (PERROT, Ede, The Netherlands), a flow meter (1468J507; LAMBRECHT, Göttingen, Germany), an air sample point connected to a Fourier transform infrared spectroscopy (FTIR) gas analyzer (GASMET DX-4000; Gasmet Technologies Oy, Helsinki, Finland), a valve (PERROT, Ede, The Netherlands), and a fan (TD-250; S\&P Holland, Breda, The Netherlands). The sample hood is placed at the front of a cubicle where it creates an isolated area around the cow's head. The airflow generated by the fan captures the exhaled breath with methane, and is sucked into the sample hood and tube towards the rectifier, flow meter and sample point. Air from the sample point is continuously sampled in which the methane concentration is determined by a gas analyzer. A tube-integrated flow meter measures the flow rate through the system. The measured flow rate is then multiplied with the methane concentration of the capture flow rate to calculate the captured methane flux after the methane concentration has been corrected for the barn's background concentration. 


\section{Methane flux measurement in cubicles}

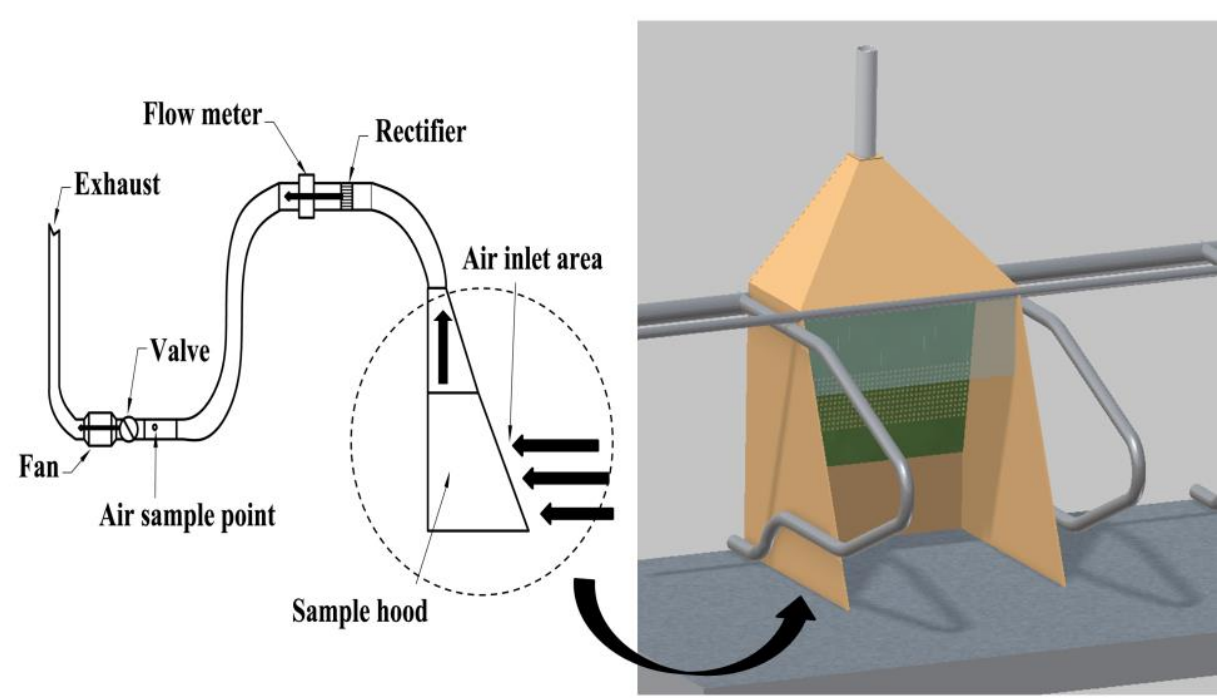

Figure 1. Schematic side view of the Cubicle Hood Sampler (left), with a fan to create a controllable airflow that creates a negative pressure at the air inlet area, and a tube with flow meter to transport extracted air to the exhaust, and the position of the Cubicle Hood Sampler in a cubicle (right). The arrows indicate the airflow direction.

We constructed 2 different sample hoods. The basic sample hood (Figure 2;1.2 $\mathrm{m} \times 0.6 \mathrm{~m}$ $\times 2.2 \mathrm{~m}$ ) consisted of a top sample hood $\left(\mathrm{A}_{1}\right)$ with an open inlet to the exhaust tube, a front panel $\left(\mathrm{A}_{2}, 1.2 \mathrm{~m} \times 1.2 \mathrm{~m}\right)$, and 2 side panels $\left(\mathrm{A}_{3}, 1.2 \mathrm{~m} \times 0.6 \mathrm{~m}\right)$. The second sample hood was a modification of the basic sample hood, and called fume sample hood (Figure 3 ). Here 2 inside panels were added to the front and top segments of the basic sample hood. The panels had three separate gas inlet areas: at the front $\left(\mathrm{B}_{1}, 1.2 \mathrm{~m} \times 0.28 \mathrm{~m}\right)$, at the middle top $\left(\mathrm{B}_{2}, 1.2 \mathrm{~m} \times 0.06 \mathrm{~m}\right)$, and at the upper top $\left(\mathrm{B}_{3}, 1.2 \mathrm{~m} \times 0.035 \mathrm{~m}\right)$. Each inlet consisted of a perforated panel with round holes $(\varnothing 0.54 \mathrm{~cm})$ that were evenly distributed over each gas inlet area. The total inlet surface in each of these areas was $120.9 \mathrm{~cm}^{2}$ at the front, $31.1 \mathrm{~cm}^{2}$ at the middle top, and $9.62 \mathrm{~cm}^{2}$ at the upper top. The fume sample hood was extended and tested with different auxiliaries to improve the system's performance. A top curtain $(\mathrm{C}, 1.2$ $\mathrm{m} \times 0.8 \mathrm{~m}$ ) could be mounted over the whole width of the front open area of the fume sample hood to decrease the sample hood's front open area from $1.44 \mathrm{~m}^{2}$ to $0.96 \mathrm{~m}^{2}$. Two extended panels (D) could be added to the side panels to increase the panel area from 0.72 to $1.08 \mathrm{~m}^{2}$. A panel could be placed in front of the fume sample hood to simulate a cow's body (Figure 2 and 3). 


\section{Chapter 6}
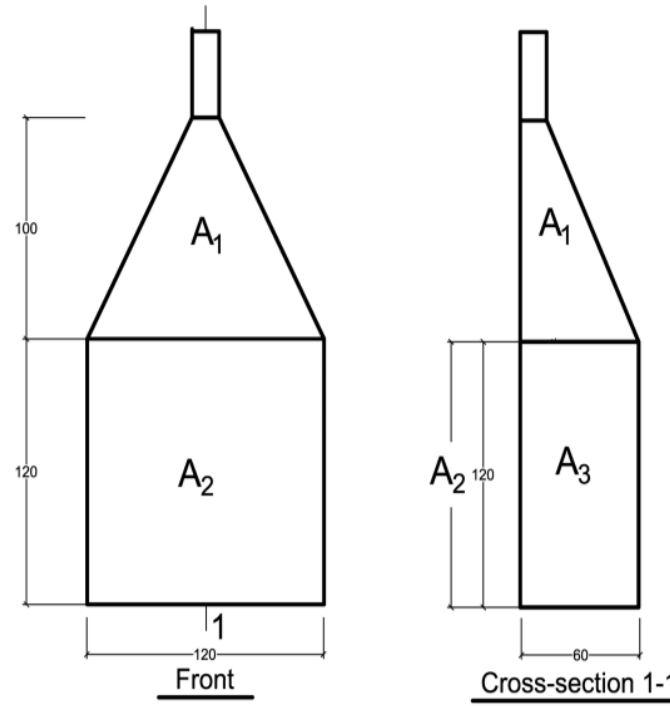

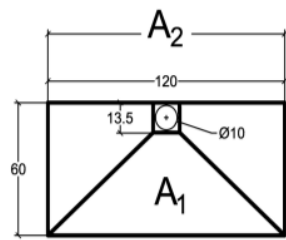

Top

Figure 2. The front (left), cross-section 1-1 (middle), and top (right) view of the basic sample hood. The basic sample hood consisted of a top hood $\left(A_{1}\right)$, a front panel $\left(A_{2}\right)$, and 2 side panels $\left(A_{3}\right)$.
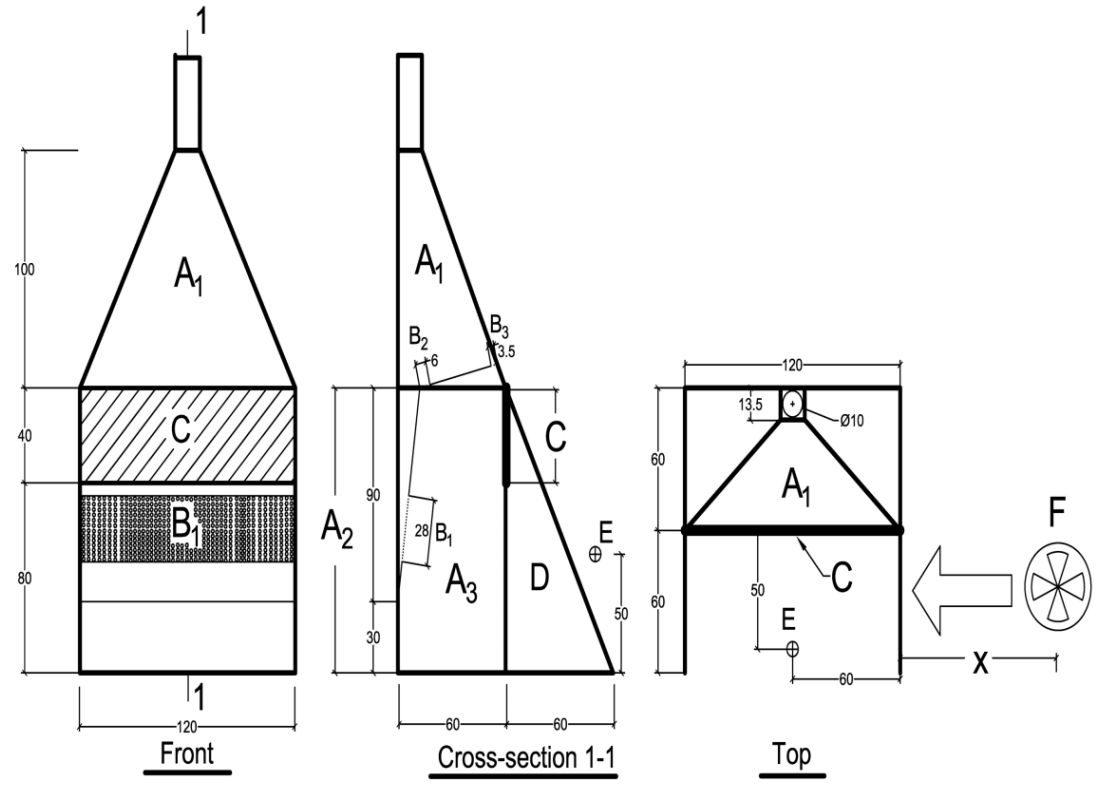

Figure 3. The front (left), cross-section 1-1 (middle), and top (right) view of the fume sample hood. The fume sample hood consisted of the basic sample hood in Figure 2 plus extensions. Two additional panels, one at the 
Methane flux measurement in cubicles

front and one at the top inside the hood were added. The panels contained three gas inlets: at the front $\left(\mathrm{B}_{1}\right)$, the middle top $\left(\mathrm{B}_{2}\right)$, and the upper top $\left(\mathrm{B}_{3}\right)$. Each gas inlet was made of a perforated panel with round holes. The fume sample hood was also extended with a top curtain (C) and 2 extended side panels (D). Below top curtain C, the front cow panel was placed to simulate a cow's body. An airflow with controllable velocity air was induced by a fan $(\mathrm{F})$ at a distance of $\mathrm{X}$, and was measured at location $\mathrm{E}$. The distance of $\mathrm{X}$ was $1.20 \mathrm{~m}$ for an air velocity of 1.0 $\mathrm{m} / \mathrm{s}$, and $1.44 \mathrm{~m}$ for $0.5 \mathrm{~m} / \mathrm{s}$.

\subsection{Reference methane source, methane recovery rate, and mass balance verification}

We used the ARC to evaluate the performance of the CHS in a laboratory and a barn. The ARC simulated the lungs, respiratory tract, and rumen of a cow and released a variable methane flux to generate a concentration pattern in the exhaled breath that closely resembled a real cow's pattern through exhalation and eructation (Wu et al., 2015); the released methane flux was controlled at pre-set values. In all tests, we controlled the ARC to release methane at a mean rate of $300 \mathrm{~g} / \mathrm{day}$. The performance of the CHS was evaluated by the methane recovery rate during a test, being the measured flux by the hood sampler relative to the known release rate of the $\mathrm{ARC}$, according the following equation:

Recovery rate $(\%)=\frac{m_{C H 4} \text { captured }}{m_{C H}{ }_{\text {released }}} \times 100$

Where $m_{C H 4}$ released is the methane mass controlled and released by the ARC during each test in $\mathrm{g}, m_{\mathrm{CH} 4}{ }_{\text {captured }}$ is methane mass captured by the CHS during the test in $\mathrm{g}$, which is calculated as

$m_{C H 4}$ captured $=Q_{\text {airflow }} \times T \times\left(C_{C H 4}-C_{b}\right) \times 10^{-6} \times \rho_{C H 4}$

Where $Q_{\text {airflow }}$ is the airflow rate through the hood system in $\mathrm{m}^{3} \mathrm{~s}^{-1} ; T$ is the measurement time in s; $C_{\mathrm{CH} 4}$ is the methane concentration in the sampled air measured by the FTIR gas analyzer, in ppm; $C_{b}$ is the mean background methane concentration, measured before and after each test, in ppm; $\rho_{\mathrm{CH} 4}$ is the methane density for the given measurement conditions, in $\mathrm{g} / \mathrm{m}^{3}$. 


\section{Chapter 6}

The reliability of the measurement system was verified under both laboratory and barn conditions by checking the methane mass balance under ideal sampling conditions, i.e. that no loss of methane, released by the ARC, from the hood was expected. In doing so, the released methane flux from the $\mathrm{ARC}$ should be equal to the measured methane flux through the measurement system of the sample hood. This implies a methane recovery rate of $100 \%$.

In the laboratory setting, the nose of the ARC was placed inside the basic hood sampler close to the tubing's air inlet. The flow rate through the hood was then increased from 20 to $200 \mathrm{~m}^{3} / \mathrm{h}$ in increments of $20 \mathrm{~m}^{3} / \mathrm{h}$. At the flow rates of 60 and $160 \mathrm{~m}^{3} / \mathrm{h}$, the tests were repeated 10 times to explore the measurement error.

In the barn setting where the fume hood sampler was used, the ARC's nose was placed in the center of the hood at $10 \mathrm{~cm}$ from the back panel at a height of $50 \mathrm{~cm}$. The sample hood's front open area was closed by a plastic cloth, leaving a small area $(0.1 \mathrm{~m} \times 1.2 \mathrm{~m})$ open at the bottom. The methane recovery rate was tested four times at the flow rates of 120 and $200 \mathrm{~m}^{3} / \mathrm{h}$

\subsection{Evaluation of the methane recovery rate in the laboratory}

Several factors may affect the CHS's methane recovery rate, including flow rate through the hood, sample hood type, the hood's open area, the cow's body size and its nose position. Variability in velocity of barn airflows that cross the sampling hood area may also affect the sampling performance. We performed an experiment in the air laboratory of Wageningen UR Livestock Research to assess the influence of these factors on the CHS's methane recovery rate.

\subsubsection{Flow rate and nose position in the basic sample hood}

Five flow rates $\left(40,80,120,160\right.$, and $\left.200 \mathrm{~m}^{3} / \mathrm{h}\right)$ were each tested once at three vertical $(10$, 50 and $100 \mathrm{~cm}$ ) $\times$ four horizontal nose positions (A-D in Figure 3) in the basic sample hood. The tests were repeated four times for nose position $\mathrm{B}$ at 10,50 , and $100 \mathrm{~cm}$. The direction of the exhaled air from the nose was always perpendicular to the back plate as indicated by the arrows in Figure 4. The selected horizontal positions were restricted to the sample 
hood's left side as it was assumed that the airflow pattern on both sides of the CHS was equal.

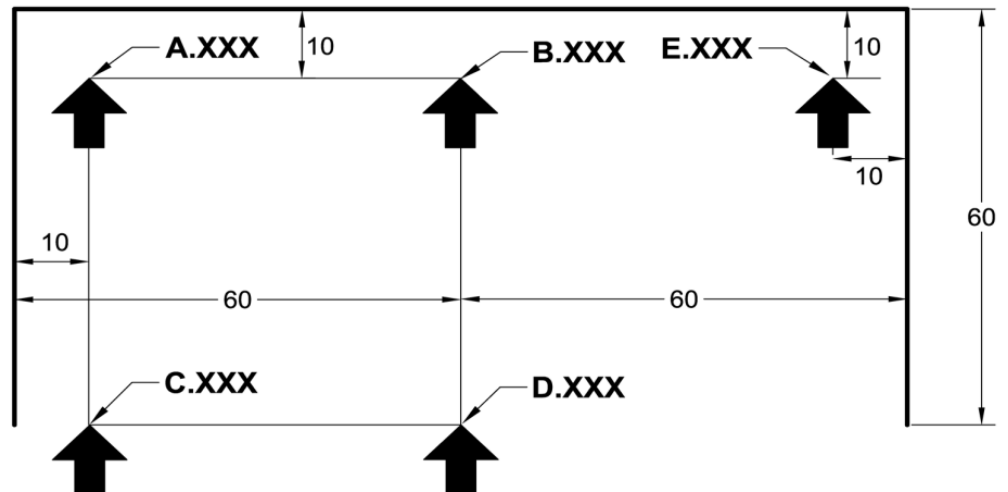

Figure 4. Top view of the sample hood with five nose positions (A-E). Nose positions A-D were used in the lab and $\mathrm{E}$ was only used in the barn. The arrows display the direction of the nose's exhalation flow. This layout was used for tests at a height of 10,50 , and $100 \mathrm{~cm}$ above floor level, indicated by ' XXX'. For instance, the position of B.050 means the position B at the height of $50 \mathrm{~cm}$.

\subsubsection{Fume sample hood tests in the laboratory}

After analyzing how the flow rate affected the methane recovery rate of the basic sample hood, we assessed the performance of the fume sample hood. The fume sample hood captured the released methane mainly through the front panel (Figure 3), while the basic sample hood sucked the air from the top only (Figure 2). All tests described below with the fume sample hood in the laboratory were repeated four times at two flow rates (120 and $\left.200 \mathrm{~m}^{3} / \mathrm{h}\right)$.

(1) Nose position

The fume sample hood was tested at three nose positions (B.010, B.050, and B.100).

(2) Top curtain

The hood's front open area was decreased by the top curtain C in Fig. 3. To analyze effects of the top curtain, the fume sample hood with the top curtain was tested at one nose position (B.050). 


\section{Chapter 6}

\section{(3) Cow panel}

When a cow was lying under the hood, the cow's body size would reduce the front open area. A cardboard obstacle $(0.6 \mathrm{~m} \times 0.3 \mathrm{~m} \times 0.85 \mathrm{~m})$ called the 'cow panel' was placed in front of the sample hood to simulate the effects of a cow's body, also see Figure 3. This, along with the top curtain, decreased the front open area to $0.48 \mathrm{~m}^{2}$ compared to $1.44 \mathrm{~m}^{2}$ without a cow panel and curtain. The fume sample hood with the cow panel and the top curtain was tested at one nose position (B.050).

(4) Nose position

The nose position was expected to vary when a cow was lying under the hood. We selected four nose positions to assess the effects on methane recovery rates. The four nose positions of A-D are shown in Figure 4 at a height of $50 \mathrm{~cm}$, where a cow's head is normally situated. Each nose position was tested in the fume sample hood with the top curtain and the cow panel.

(5) Induced airflow

After analyzing the factors related to the sampler and the cow, we introduced a horizontal airflow to analyze the effects of the environment. A fan was placed next to the sample hood at a height of $50 \mathrm{~cm}$. The fan blew air perpendicularly to the cow panel axis along the sample hood's inlet (Figure 3). The induced air velocity along the front side of the sample hood was adjusted by moving the fan further away from or closer to the hood. The induced air velocity was measured at location E (Figure 3). We tested the fume sample hood at one nose position (B.050) with an induced air velocity of 0.5 (s.d. 0.2) and 1.0 (s.d. 0.2) $\mathrm{m} / \mathrm{s}$. The fume sample hood included the top curtain and the cow panel.

(6) Extended side panels

To prevent loss of breath-air due to the induced horizontal airflow, we evaluated the performance of the fume sample hood with extended side panels (D, Figure 3). The fan was located next to the sample hood at a height of $50 \mathrm{~cm}$ to produce an induced air velocity of 


\section{Methane flux measurement in cubicles}

0.5 (s.d. 0.2) and 1.0 (s.d. 0.2) $\mathrm{m} / \mathrm{s}$. We tested one nose position (B.050). The fume sample hood also included the top curtain and cow panel.

\subsection{Evaluation of the methane recovery rate in the barn}

After the laboratory experiments, we evaluated the CHS with the ARC in a dairy cow house at Wageningen University. The house was equipped with a natural ventilation system, including large openings on the sidewalls combined with an open central ridge as air outlet, and slatted floors in the cow area with manure storage below. 25 cows were housed in the barn during the experiment and all cows received the same feeding management.

In the middle of the barn, we installed the CHS in a cordoned off cubicle, still allowing the cows to lie in the adjacent cubicles. The CHS consisted of the fume sample hood, a top curtain, a cow panel, and extended side panels. Due to the cubicle's limited space, we simulated the cow panel with a plastic cloth that had the same dimensions $(0.60 \mathrm{~m} \times 0.85 \mathrm{~m})$ as the cardboard obstacle used in the laboratory. The experimental set up is shown in Figure 5. The ARC and a data logger (CR10, Campbell Scientific, Shepshed, UK) were placed on a steel table in front of the CHS. A FTIR gas analyzer was placed under the table. The data logger recorded the values from 2 air velocity sensors (SS 20.01; SCHMIDT Technology, St. Georgen, Germany), and a temperature sensor (HygroClip S3; Rotronic, New York, USA). 2 air velocity sensors were placed at a height of $1 \mathrm{~m}$ : one was placed at the left side of the cubicle $\left(\mathrm{L}_{1}\right.$, Figure 5) and the other one was placed at the front of the cubicle $\left(\mathrm{L}_{2}\right.$, Figure 5). The temperature sensor was placed at a height of $2 \mathrm{~m}$ (K, Figure 5). In addition, a steel mesh box was installed around the measurement cubicle to prevent interference by cows and to protect the equipment. 


\section{Chapter 6}

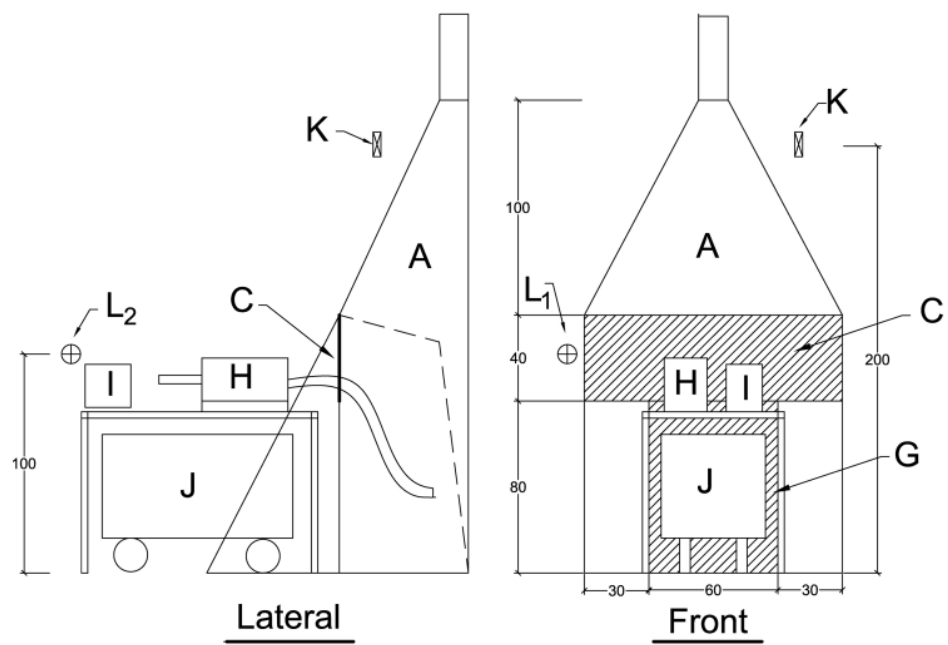

Figure 5. The lateral (left) and front (right) view of experimental set up in the barn: the CHS included the fume sample hood (A), a top curtain (C), a cow panel (G), and extended side panels (D); the artificial reference cow (H); a data logger (I); the FTIR gas analyzer $(\mathrm{J})$; a temperature sensor $(\mathrm{K})$; and 2 air velocity sensors $\left(\mathrm{L}_{1}\right.$ and $\left.\mathrm{L}_{2}\right)$. Letters A, C, and D correspond to elements in Figure 3.

The CHS's performance was evaluated at 11 different methane production rates, released by the ARC. Each rate was tested at three nose positions at flow rates of 120 and $200 \mathrm{~m}^{3} / \mathrm{h}$. The simulated cow's daily methane production rate was controlled from 200 to $400 \mathrm{~g} /$ day in increments of $20 \mathrm{~g} /$ day. Three nose positions (A.050, B.050, and E.050) were selected from the left to right (Figure 4). At each nose position, the 11 simulated methane production levels were applied in random order for 3 minutes each (called a trial), with a 3 minute break in-between to ensure methane emitted into the measurement system from the previous test had completely dissipated. In each trial, the CHS airflow rate was measured every minute and the methane concentration in the airflow was measured by the FTIR gas analyzer, one value per 2 or 3 seconds. We conducted the experiment twice in one week, selecting days with different weather conditions, and repeated the whole setup twice in another week. In total, we completed 264 trials $(4$ days $\times 11$ levels $\times 3$ nose positions $\times 2$ flow rates). During the experiment, the air velocity at the measurement points near the test cubicle and temperature in the barn were measured every minute. 
Methane flux measurement in cubicles

\subsection{Statistical analysis}

Data were analyzed with the GenStat 16 statistical system (VSN International Ltd., UK). In the mass balance experiment, the mean methane recovery rate measured at different flow rates was compared with $100 \%$ methane recovery rate by a one-sided t-test under the hypothesis (H0) as not different from 100\%. In the laboratory's factorial experiments, we used ANOVA to assess the effect of factors on the methane recovery rate. The difference of the methane recovery rate between the 2 sample hood types was analyzed for each nose position by one-way ANOVA. In the barn experiment, measurement data were analyzed with a general linear regression model (GLM):

$\mathrm{Y}_{\mathrm{ijk}}=\mu+\mathrm{F}_{\mathrm{i}}+\mathrm{N}_{\mathrm{j}}+\beta_{1, \mathrm{i}} \times \mathrm{V}+\beta_{2, \mathrm{i}} \times \mathrm{X}+(\mathrm{FN})_{\mathrm{ij}}+\mathrm{e}_{\mathrm{ijk}}$

Where $Y_{i j k}$ is the methane mass measured from the CHS; $\mu$ is the intercept; $F_{i}$ and $N_{j}$ are the effects of flow rate $i\left(120\right.$ and $\left.200 \mathrm{~m}^{3} / \mathrm{h}\right)$ and nose position $\mathrm{j}(\mathrm{A}, \mathrm{B}$, and $\mathrm{E}) ; \beta_{1, \mathrm{i}}$ is the regression coefficient of measured air velocity $\mathrm{V}$ around the cubicle, for each level i of $\mathrm{F}$, and $\beta_{2, \mathrm{i}}$ is regression coefficient of controlled daily methane production $\mathrm{X}$ of the ARC for each level $\mathrm{i}$ of $\mathrm{F}$; $\mathrm{FN}$ is the interaction between flow rates $\mathrm{i}$ and nose positions $\mathrm{j}$; $\mathrm{e}_{\mathrm{ijk}}$ is the random residual effect.

\section{Results and discussion}

\subsection{Methane recovery rate in the mass balance test}

In the laboratory setting the mean methane recovery rate was $99.4 \%$ (s.d. 1.4) for flow rates from 40 to $200 \mathrm{~m}^{3} / \mathrm{h}$. Only when a flow rate of $20 \mathrm{~m}^{3} / \mathrm{h}$ was applied a lower recovery rate (88.6\%) was measured. The mass balance experiment showed that the CHS system could measure the expected full recovery rate for flow rates between 40 and $200 \mathrm{~m}^{3} / \mathrm{h}$ that were not different from $100 \%(\mathrm{H} 0: \mathrm{P}=0.802)$. In contrast to the higher flow rates, a flow rate of $20 \mathrm{~m}^{3} / \mathrm{h}$ was probably too low to prevent part of the exhaled air from flowing out of the CHS, despite the nose's position deep in the hood. 


\section{Chapter 6}

Similarly, the full methane recovery rate was verified in the mass balance test in the barn setting. This test measured recovery four times under the flow rates of 120 and $200 \mathrm{~m}^{3} / \mathrm{h}$. Mean methane recovery rate was $98.7 \%$ (s.d. 2.5) at a flow rate of $120 \mathrm{~m}^{3} / \mathrm{h}$ and $99.9 \%$ (s.d. 0.9 ) at a flow rate of $200 \mathrm{~m}^{3} / \mathrm{h}$. These recovery rates were not different from $100 \%$ (H0: $\mathrm{P}=$ 0.385 at the flow rate of $120 \mathrm{~m}^{3} / \mathrm{h}$ and $\mathrm{P}=0.860$ at the flow rate of $200 \mathrm{~m}^{3} / \mathrm{h}$ ). The full recovery of $100 \%$ demonstrated that the controlled methane flux released by the ARC and the methane flux calculated from the measured concentration and airflow rate in the hood were in line with each other.

\subsection{Factors investigated in the laboratory setup}

The CHS's methane recovery rate is affected by the factors related to the hood sampler design, the cows, and the environment. By exploring the effects of these factors, we could improve the CHS's performance so that it captured all the released methane from the ARC under variable conditions.

The sampler system's factors that we tested in the laboratory experiments included the flow rate, the sample hood type, the top curtain, and cow panel. These factors were individually assessed on methane recovery rates. Results were used to determine the measurement system's optimal configuration to be tested under barn conditions.

\subsubsection{Flow rate and nose position for the basic sample hood}

Methane recovery rates of the basic sample hood were significantly affected by flow rates, and location and height of the nose positions $(\mathrm{P}<0.001)$. Mean methane recovery rates increased from $44.6 \%$ at the flow rate of $40 \mathrm{~m}^{3} / \mathrm{h}$ to $88.6 \%$ at the flow rate of $200 \mathrm{~m}^{3} / \mathrm{h}$. Higher flow rates increased methane recovery rates of the basic sample hood because the sample hood had a higher negative air pressure. Mean methane recovery rates increased by $4.7 \%$ when the nose height increased from $10 \mathrm{~cm}$ to $100 \mathrm{~cm}$. Increasing the height of the nose position had a positive effect on methane recovery rates because the nose outlet was closer to the air inlet. Methane recovery rates also varied at the different locations of nose position. Nose position $\mathrm{C}$ had the highest mean methane recovery rates $(81.2 \%)$ while nose position D had the lowest (65.6\%). Both findings indicate that the negative air pressure was 


\section{Methane flux measurement in cubicles}

not evenly distributed at the same height plane in the basic sample hood. Based on observations of lying behavior, we expect a lying cow's head to be mainly located in the middle of the cubicle, which is nose position B in this study. Figure 6 shows methane recovery rates of the basic sample hood at three heights of nose position B at five flow rates. Similarly, both nose position and flow rate significantly influenced the methane recovery rate of the basic sample hood $(\mathrm{P}<0.001)$. Mean methane recovery rates increased from $39.9 \%$ at the flow rate of $40 \mathrm{~m}^{3} / \mathrm{h}$ to $84.1 \%$ at the flow rate $200 \mathrm{~m}^{3} / \mathrm{h}$. However, mean methane recovery rates did not further increase between flow rates of 160 and $200 \mathrm{~m}^{3} / \mathrm{h}(\mathrm{P}>$ 0.05), indicating that the effect of flow rate is nearing its maximum at these levels. As nose position B.100 was nearest to the air inlet, it had higher methane recovery rates than the other 2 heights, especially at a high flow rate.

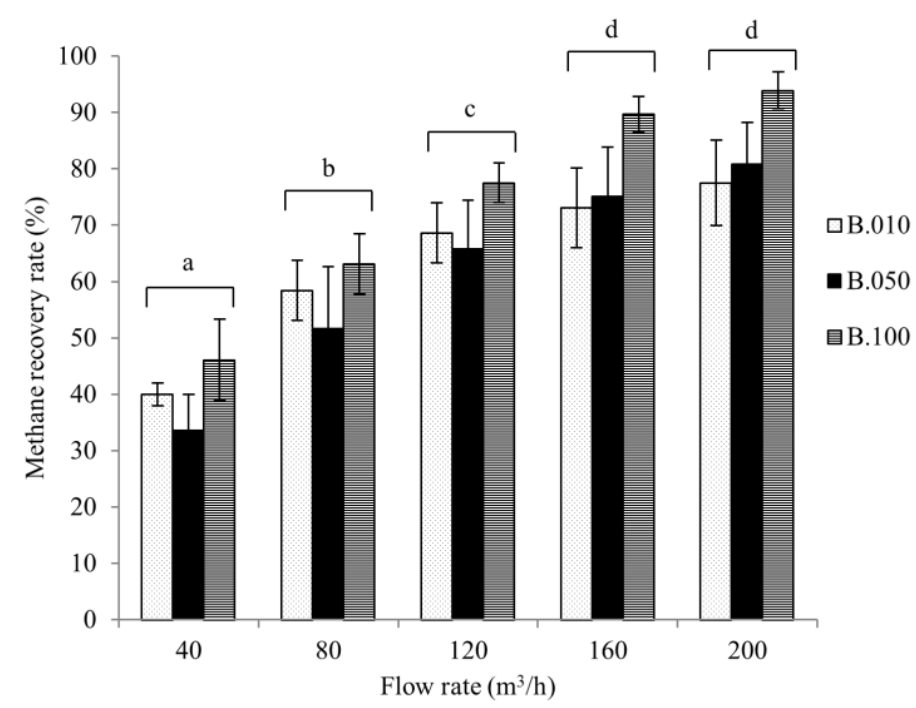

Figure 6. Methane recovery rates of the basic sample hood at three nose positions and five flow rates. The nose positions were at three heights: 10,50 , and $100 \mathrm{~cm}$ of nose position B. Error bars show the standard deviation of each test $(n=4)$. Different letters show significant difference of mean methane recovery rates at different flow rates $(\mathrm{P}<0.05)$.

\subsubsection{Fume sample hood}

Methane recovery rates of the fume sample hood were compared to those of the basic sample hood at three heights of nose position B at 2 flow rates (Figure 7). At the height of 


\section{Chapter 6}

$50 \mathrm{~cm}$, the fume sample hood performed significantly better at the imposed flow rates of $120(\mathrm{P}=0.015)$ and $200 \mathrm{~m}^{3} / \mathrm{h}(\mathrm{P}=0.004)$. This improvement can be attributed to the implementation of the front panel with gas inlets in the fume sample hood at this height (Figure 3). As a result, the nose position B.050 was much closer to the air inlet of the fume sample hood than it was in the basic sample hood. With a shorter distance to the air inlet, the negative air pressure was also expected to be higher. At the height of 10 and $100 \mathrm{~cm}$, methane recovery rates did not differ between these hood types $(\mathrm{P}>0.05)$. When a cow is lying in the cubicle, its head will mostly be positioned at the height of $50 \mathrm{~cm}$ and, to a lesser extent, positioned at the height of $10 \mathrm{~cm}$ and $100 \mathrm{~cm}$. Thus, it can be expected that the fume sample hood will capture more methane from a cow lying in a cubicle than the basic sample hood will.

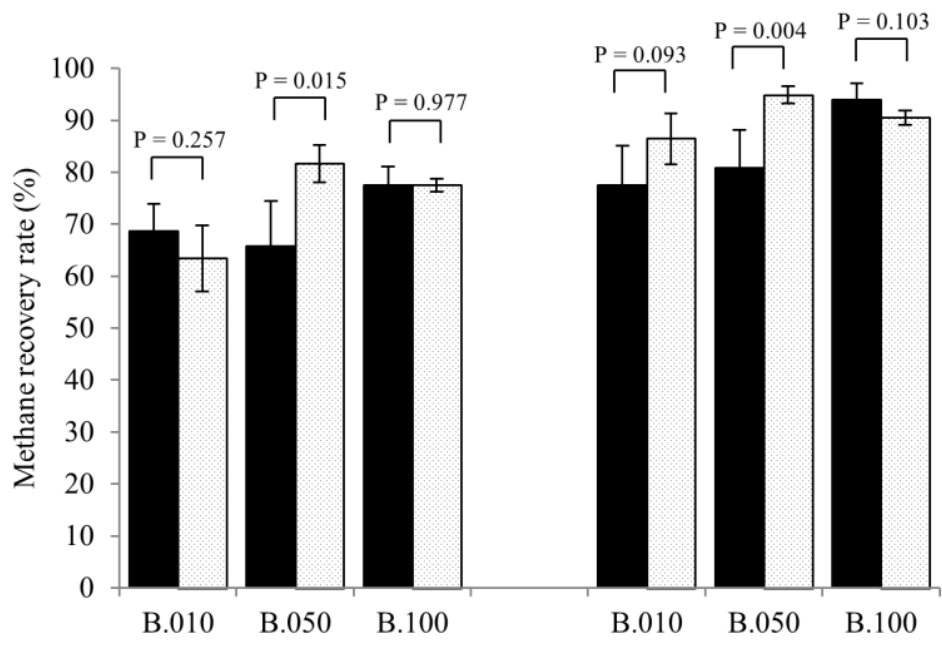
(a) $120 \mathrm{~m}^{3} / \mathrm{h}$
(b) $200 \mathrm{~m}^{3} / \mathrm{h}$

- Basic sample hood $\square$ Fume sample hood

Figure 7. Methane recovery rates of the basic and fume sample hood at three nose positions at the flow rates of 120 (a) and $200 \mathrm{~m}^{3} / \mathrm{h}$ (b). The three nose positions were at the height of 10,50 , and $100 \mathrm{~cm}$ of nose position B. Error bars show the standard deviation of each test $(n=4)$.

\subsubsection{Effects of top curtain}

A top curtain increased the methane recovery rates at the flow rates of 120 and $200 \mathrm{~m}^{3} / \mathrm{h}$

(Figure 8). At the flow rate of $120 \mathrm{~m}^{3} / \mathrm{h}$, the fume sample hood with a top curtain had a 


\section{Methane flux measurement in cubicles}

methane recovery rate that was $8.3 \%$ higher $(\mathrm{P}=0.002)$ than the fume hood without the top curtain. At the flow rate of $200 \mathrm{~m}^{3} / \mathrm{h}$, the additional top curtain increased the methane recovery rate by $2.0 \%(P=0.011)$, bringing the methane recovery rate close to $100 \%$. The improvement caused by the top curtain can be explained by the following two reasons: (1) the top curtain decreases the front open area from $1.44 \mathrm{~m}^{2}$ to $0.96 \mathrm{~m}^{2}$, resulting in higher air velocities near the nose position, and thus improving the CHS's recovery rate; (2) the top curtain may also prevent the released methane from leaving the sample hood.

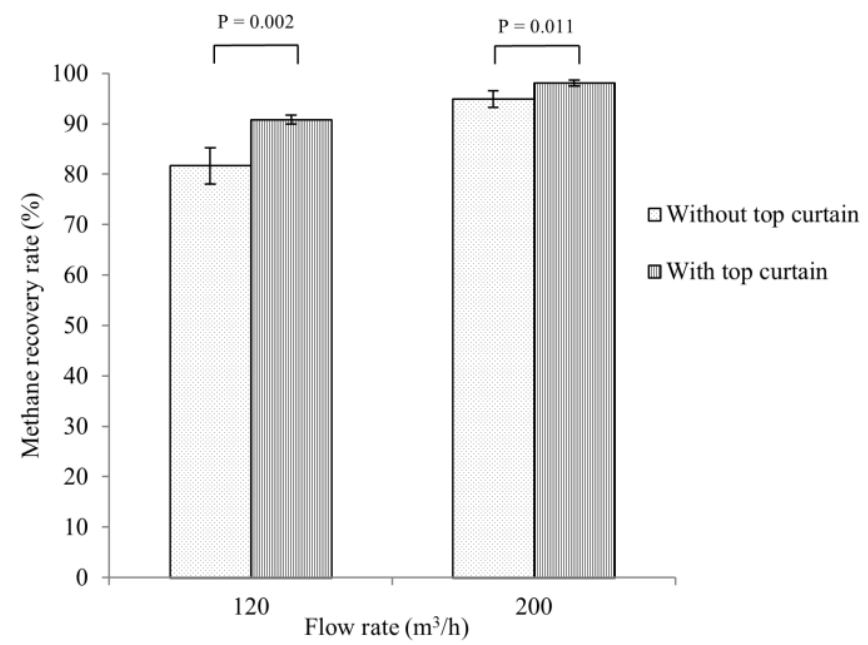

Figure 8. Methane recovery rates of the fume hood with and without a top curtain at the flow rates of 120 and 200 $\mathrm{m}^{3} / \mathrm{h}$. The measurement nose position was B.050. Error bars show the standard deviation of each test $(\mathrm{n}=4)$.

With these results, we concluded that the fume sample hood equipped with a top curtain was the best sample hood configuration for further laboratory testing. We assessed cow factors (cow panel and nose positions) and environmental effects (induced horizontal air) for this configuration.

\subsubsection{Effects of cow panel on the fume hood with top curtain}

The cow panel increased the methane recovery rates at flow rates of 120 and $200 \mathrm{~m}^{3} / \mathrm{h}$ (Figure 9). At the flow rate of $120 \mathrm{~m}^{3} / \mathrm{h}$, the cow panel increased the methane recovery rate by $7.4 \%(\mathrm{P}<0.001)$. At the flow rate of $200 \mathrm{~m}^{3} / \mathrm{h}$, the methane recovery rate increased by $1.8 \%(\mathrm{P}=0.001)$, reaching at a $99.8 \%$ methane recovery rate. This performance 


\section{Chapter 6}

improvement can be explained by the decreased size of the front open area; the cow panel reduced the inlet surface from $0.92 \mathrm{~m}^{2}$ to $0.48 \mathrm{~m}^{2}$, creating the same effect on air velocity in the hood as in the case of the top curtain. Moreover, the cow panel also prevented the released methane to escape from the sample hood. Consequently, a cow's body will naturally increase the CHS's methane recovery rate when the cow is lying under the sample hood.

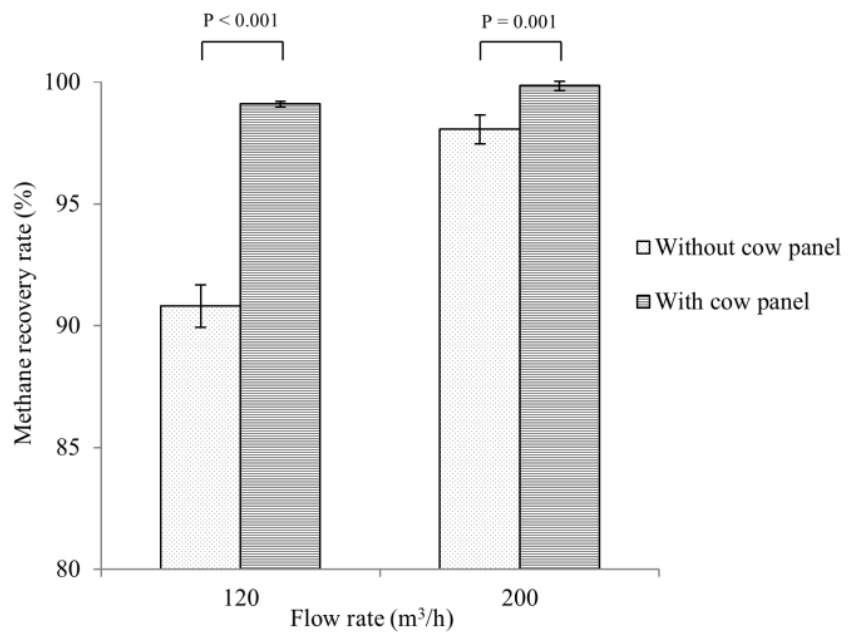

Figure 9. Methane recovery rates of the fume sample hood with and without the cow panel at the flow rates of 120 and $200 \mathrm{~m}^{3} / \mathrm{h}$. The measurement nose position was B.050. Error bars show the standard deviation of each test $(n=4)$.

\subsubsection{Effects of nose position on the fume hood with top curtain and cow panel}

Methane recovery rates did not differ between four nose positions at the flow rate of 200 $\mathrm{m}^{3} / \mathrm{h}(\mathrm{P}=0.454)$, but they were different at the flow rate of $120 \mathrm{~m}^{3} / \mathrm{h}(\mathrm{P}<0.001$; Figure 10$)$. At the flow rate of $200 \mathrm{~m}^{3} / \mathrm{h}$, the CHS had enough capacity to uniformly capture methane from different nose positions under the sample hood area. At the flow rate of $120 \mathrm{~m}^{3} / \mathrm{h}$, however, the capture capacity decreased and could not evenly cover the whole area under the sample hood. Thus, methane recovery rates varied in different locations under the sample hood at a lower flow rate. 
Methane flux measurement in cubicles

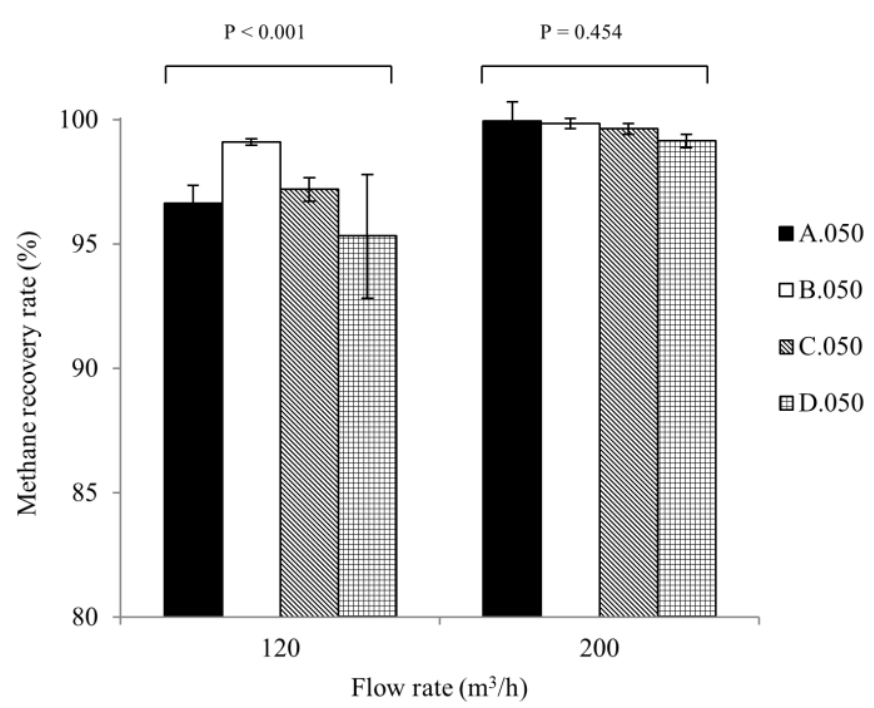

Figure 10. Methane recovery rates for the fume hood with a top curtain and a cow panel at four nose positions at the flow rates of 120 and $200 \mathrm{~m}^{3} / \mathrm{h}$. These four nose positions were at a height of $50 \mathrm{~cm}$. Error bars show the standard deviation of each test $(n=4)$.

\subsubsection{Effects of induced horizontal air velocity on the fume hood with top curtain and cow panel}

Induced horizontal air velocity significantly decreased the CHS's methane recovery rate at the flow rates of 120 and $200 \mathrm{~m}^{3} / \mathrm{h}(\mathrm{P}<0.001$; Figure 11). The induced horizontal air velocity disturbed the negative air pressure and airflow patterns in the inlet area of the CHS. Therefore, less released methane was captured and more escaped from the sample hood. At the flow rate of $120 \mathrm{~m}^{3} / \mathrm{h}$, the methane recovery rate decreased more at the air velocity of $1.0 \mathrm{~m} / \mathrm{s}$ than at $0.5 \mathrm{~m} / \mathrm{s}$ (10.1 vs. $12.9 \%$ ), apparently because a higher air velocity resulted in a higher disturbance in the sample hood. At the flow rate of $200 \mathrm{~m}^{3} / \mathrm{h}$, however, the methane recovery rate decreased much less at the air velocities of 0.5 and $1.0 \mathrm{~m} / \mathrm{s}(2.3 \mathrm{vs}$. $2.2 \%)$. These results show that the disturbing effects of the induced horizontal airflow can be largely compensated by increasing flow rates. 


\section{Chapter 6}

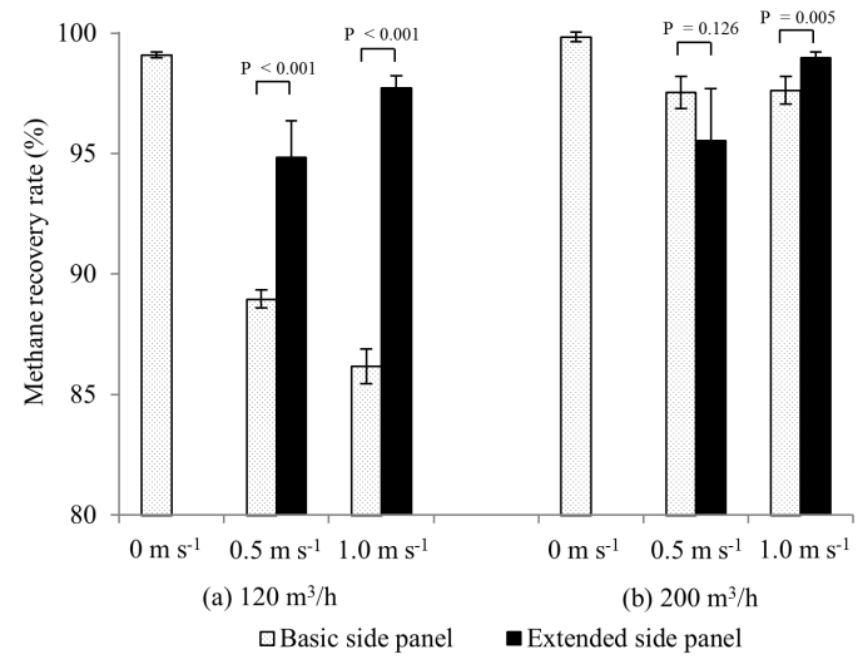

Figure 11. Methane recovery rates for the fume hood with a top curtain and a cow panel under induced horizontal air at the flow rates of (a) 120 and (b) $200 \mathrm{~m}^{3} / \mathrm{h}$. 2 levels of induced horizontal air $(0.5$ and $1.0 \mathrm{~m} / \mathrm{s})$ were tested with 2 types of side panels (basic and extended). The measurement nose position was B.050. Error bars show the standard deviation of each test $(n=4)$.

\subsubsection{Effects of extended side panels on the fume hood with top curtain and cow panel}

Extending the side panels reduced the negative effects of the induced horizontal air velocity (Figure 11). At the flow rate of $120 \mathrm{~m}^{3} / \mathrm{h}$, the extended side panels significantly increased the methane recovery rate for both levels of induced horizontal air velocity $(\mathrm{P}<0.001)$. At the flow rate of $200 \mathrm{~m}^{3} / \mathrm{h}$, the extended side panels also significantly increased the methane recovery rate at the air velocity of $1.0 \mathrm{~m} / \mathrm{s}(\mathrm{P}=0.005)$, but they made no difference at the air velocity of $0.5 \mathrm{~m} / \mathrm{s}(\mathrm{P}=0.126)$. Adding the extended side panels increased the total side panel surface by $50 \%$ as compared to the basic side panels. With larger side panels, part of the induced horizontal air could be prevented from entering the inlet area of the CHS and causing disturbances. At the flow rate of $200 \mathrm{~m}^{3} / \mathrm{h}$, the CHS already had the capacity to compensate for the disturbances from the induced horizontal air. Therefore, the extended panels showed improvements only at the air velocity of $1.0 \mathrm{~m} / \mathrm{s}$, but not at the air velocity of $0.5 \mathrm{~m} / \mathrm{s}$. 
Methane flux measurement in cubicles

\subsection{Evaluation of the CHS in the barn by the ARC}

\subsubsection{Factor and co-variable effects on measured methane production}

Flow rate, controlled methane flux, nose position, and air velocity significantly affected the measured methane production $\left(\mathrm{P}<=0.001\right.$ ). At the flow rate of $200 \mathrm{~m}^{3} / \mathrm{h}$, mean measured daily methane production was $302 \mathrm{~g} / \mathrm{day}$, which was $28.6 \mathrm{~g}$ more than the production measured at the flow rate of $120 \mathrm{~m}^{3} / \mathrm{h}$. The higher sampling performance at the higher flow rate corresponded with the laboratory results. However, under disturbed barn conditions, the CHS could capture only $88.0 \%$ (s.d. 8.3) of the controlled methane mass instead of $99.1 \%$ as it did in the laboratory at the flow rate of $120 \mathrm{~m}^{3} / \mathrm{h}$. At the flow rate of $200 \mathrm{~m}^{3} / \mathrm{h}$, the CHS could capture $97.2 \%$ (s.d. 8.1) of the released methane. This result was similar to the results measured in the laboratory, but with larger variation. The methane recovery rate was different from $100 \%$ (H0: P < 0.001), which means that the CHS underestimated the simulated methane production at the flow rates of 120 and $200 \mathrm{~m}^{3} / \mathrm{h}$. Measured methane production from the CHS was strongly linearly related to the controlled methane production by the ARC $(\mathrm{P}<0.001)$. Flow rate interacted with the regression coefficient in this relation $(P=0.015)$. Effects of nose position also interacted with flow rate $(P=0.005)$. At the flow rate of $120 \mathrm{~m}^{3} / \mathrm{h}$, nose position $\mathrm{B}$ had a significantly lower measured methane production than nose positions A and C. These differences may be caused by the released air's movement pattern. If released air first hits the front panel, uncaptured air may escape from the front open area at both sides. Since nose position B was in the middle, uncaptured air could escape from the 2 sides. While nose positions A and C were placed close to one side panel, uncaptured air could escape only from one side. Similar air movement patterns of nose positions $\mathrm{A}$ and $\mathrm{C}$ might explain that measured methane production did not differ between these 2 nose positions. However, the nose position had no significant effects at the flow rate of $200 \mathrm{~m}^{3} / \mathrm{h}$, demonstrating that at a higher flow rate and consequently at a higher negative pressure under the sample hood, the CHS could uniformly capture methane flux from different locations. Similar to the nose position effects, air velocity had negative effects only on measured methane production at the flow rate of $120 \mathrm{~m}^{3} / \mathrm{h}$. As earlier observed in the laboratory experiments, the higher sampling flow rate compensated the effects of air velocity around the CHS. 


\section{Chapter 6}

\subsubsection{Relation between controlled and measured methane production}

\section{at 2 flow rates}

Since the flow rate is a key operational parameter in the CHS, the relation between controlled methane release and measured methane flux was separately investigated with linear regression at the flow rates of 120 and $200 \mathrm{~m}^{3} / \mathrm{h}$ (Figure 12). The measured methane flux by the CHS was strongly linearly related to the controlled methane release by the ARC $(\mathrm{P}<0.001)$. Standardized residuals were distributed around zero under different controlled methane production rates at the flow rates of 120 and $200 \mathrm{~m}^{3} / \mathrm{h}$.
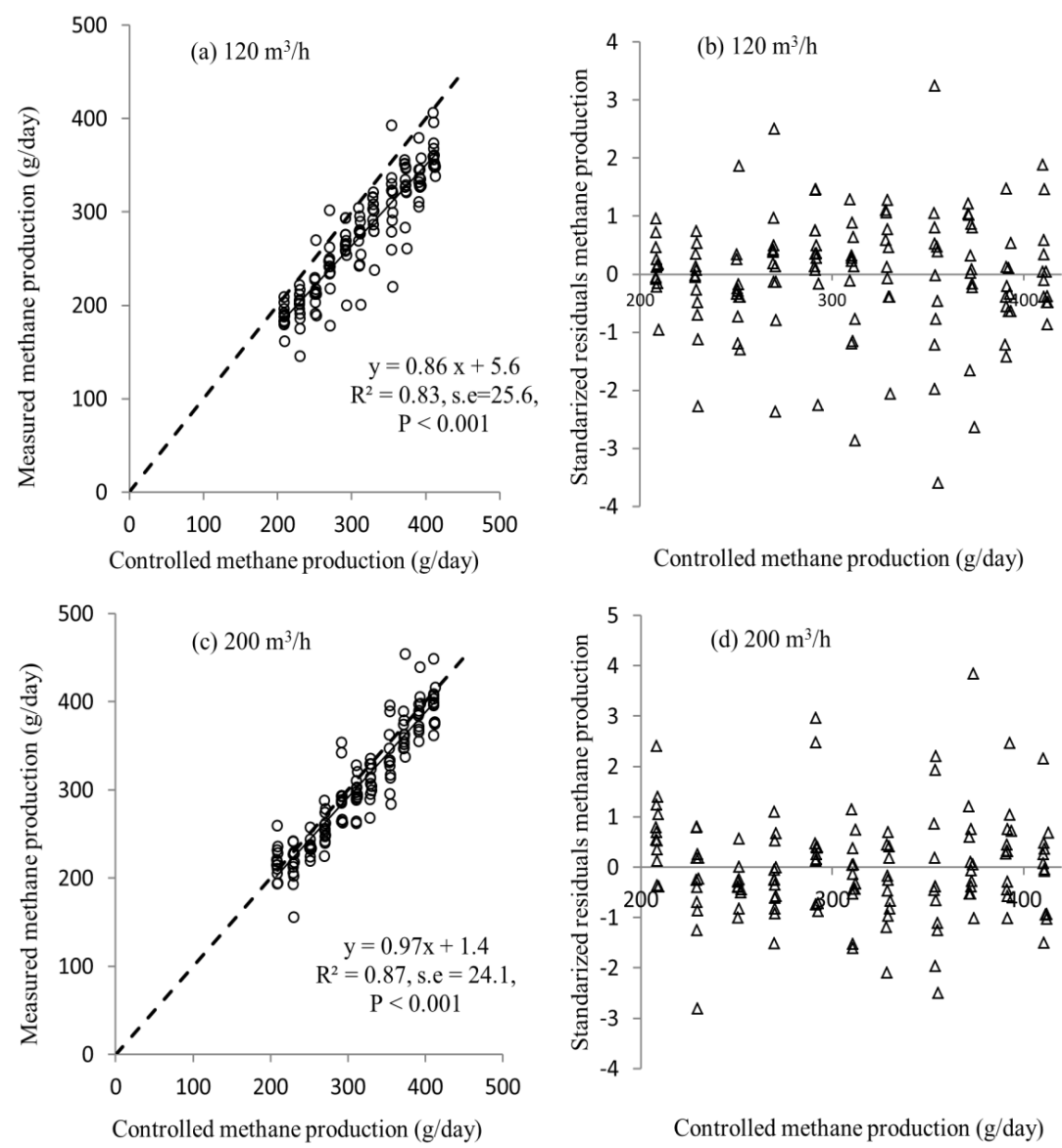

Figure 12. Methane release (g/day) controlled by the ARC versus measured by the CHS (left) and standardized residuals (right) versus controlled methane release (g/day) during each 3-minute experiment. The dotted line represents the line of equivalence. 


\section{Methane flux measurement in cubicles}

For the newly developed CHS, standard errors of a single measurement were estimated to be $25.6 \mathrm{~g} /$ day at the flow rate of $120 \mathrm{~m}^{3} / \mathrm{h}$ and $24.1 \mathrm{~g} /$ day at the flow rate of $200 \mathrm{~m}^{3} / \mathrm{h}$. These rates correspond to coefficient of variations $(\mathrm{CV})$ at mean measured methane productions of $9.4 \%$ at the flow rate of $120 \mathrm{~m}^{3} / \mathrm{h}$ and $8.0 \%$ at the flow rate of $200 \mathrm{~m}^{3} / \mathrm{h}$. This single measurement $\mathrm{CV}$, based on a 3-minute sampling duration, is already close to the smallest $\mathrm{CV}$ reported for variation in methane production between cows, which ranges from 7 to 17\% (Yan et al., 2010; Blaxter and Clapperton, 1965). With more measurement repetitions within and over days, standard errors and corresponding $\mathrm{CV}$ can be further decreased.

Although the CHS configuration with the flow rate of $200 \mathrm{~m}^{3} / \mathrm{h}$ showed higher methane recovery rates than with a flow rate of $120 \mathrm{~m}^{3} / \mathrm{h}$, the random measurement error was similar for these 2 flow rates (25.6 versus 24.1). This means that the capability of ranking cows on methane production does not significantly differ between these flow rates. In the case of a strong variable background concentration of methane in the barn, a sampling system with a lower flow rate might be more attractive because the released breath is less diluted by barn air, and, as such, less sensitive to background concentration. However, in this situation, the observed systematic underperformance in recovery needs to be constant under all practical circumstances. Therefore, the configuration with the higher flow rate might be preferred as more robust against the effects of variable barn conditions.

\section{Conclusions}

The CHS designed and constructed in this study can measure methane production from individual cows and detect differences between cows in methane production. The performance of the CHS was affected by the flow rate, hood type, presence of a top curtain, and extra side panels. With a flow rate of $200 \mathrm{~m}^{3} / \mathrm{h}$, the CHS with a fume sample hood, a top curtain, and extended side panels captured $97.2 \%$ (s.d. 8.1) of the methane released by the ARC, regardless of the air velocity or the cow's nose positions under barn conditions. Based on the CHS performance characteristics, we concluded that this newly developed method is sufficiently accurate to assess methane production of individual cows in cubicles. 


\section{Chapter 6}

\section{Acknowledgements}

This study was funded by Wageningen UR Livestock Research, the Ministry of Economic Affairs of the Netherlands (Research Program Sustainable Agriculture, KB-12-006.03-002), and the China Scholarship Council. The authors are thankful to Johan Ploegaert of Wageningen UR Livestock Research, Ries Verkerk and Willem van Ommeren of Wageningen UR Animal Science Group for helping with the experiment in Wageningen University's dairy barn. 
CHAPTER 7

General discussion and conclusions 


\section{Chapter 7}

\section{Introduction}

Mitigation of methane emission from dairy cows is critical to reduce the dairy industry's contribution to the production of greenhouse gases and subsequently to global warming (Gerber et al., 2013). Methane production from dairy cows contributes $4 \%( \pm 26 \%)$ of anthropogenic greenhouse gas emissions (FAO, 2010). On average, a typical Holstein Friesian dairy cow produces 250 to $400 \mathrm{~g}$ methane per day (Bannink et al., 2011), which is mainly emitted through the eructation and exhalation from the rumen and only in a small quantity through rectum as flatus (Lassey, 2007; Murray et al., 1976). As a product of rumen fermentation, methane released by dairy cows also accompanies with a loss of energy for the animal (Blaxter et al., 1972; Yan et al., 2010; Johnson and Johnson, 1995). Therefore, reduction of methane production from dairy cows will benefit not only the environment but may also improve production efficiency. Methane production can be reduced by feeding / nutrition measures or potentially permanently reduced by breeding. To assess the effects of any methane mitigation methods, we have to be capable of measuring the methane production from dairy cows. Measurement methods should meet requirements with regard to accuracy and precision, number of animals included, representativeness for conditions (animal behaviour and farm management) and time aspects (variations), practicalities (labour and technical aspects), and costs; requirements will differ for distinct goals and mitigation strategies (Chapter 2). Although there are already several methods to measure methane production from dairy cows, none of the methods are flawless. Methods are limited either because of technical complexity and costs or because of short sampling periods (Storm et al., 2012). Given this, new measurement techniques need to be developed to widen the options to measure the methane production from individual cows under farm conditions, and more insight is needed in the performance of existing measurement methods.

The main objective of this thesis was to design, test and validate methods to determine or rank the methane production of individual dairy cows at farm house level. This thesis was subdivided as follows: a review on existing knowledge and methods to measure $\mathrm{CH}_{4}$ production (Chapter 2), characterisation of aerial conditions around cubicles in dairy barns 


\section{General discussion and conclusions}

and implication of accuracy of methane measurement methods (Chapter 3), design and test of a gold standard or reference method (Chapter 4), assessment of the performance of an existing breath concentration method (Chapter 5), and design and test of a methane flux method to assess the $\mathrm{CH}_{4}$ production of individual cows (Chapter 6).

In Chapter 2, we first summarized 14 requirements of methane measurement methods to assess methane mitigation strategies. Then we reviewed existing measurement methods in three categories that differ in measurement principle. Merits and drawbacks of the methods were evaluated and discussed against the requirements. None of the existing methods fulfilled all the requirements. The GreenFeed method, being a farm implementation of a flux method, is currently the best available approach to measure methane production of individual cows in the farm. However, there is uncertainty about the representativeness of the results because methane production is only measured during short feed bin visits. To measure methane production rates of individual cows under farm conditions, sampling of breath air during the lying period of cows in cubicles could be a practical direction. To rank cows in methane production rates, the $\mathrm{CH}_{4} / \mathrm{CO}_{2}$ ratio method is a promising method, but requires further research to assess its accuracy, especially with respect to the representativeness of the short sampling periods.

In Chapter 3, mean methane concentrations around the cubicles in a dairy barn were measured, varying between 29-37 ppm in the summer period and 33-51 ppm in the winter period. Spatial variations $(\mathrm{CV})$ of methane concentration around the cubicle were $71 \%$ in the summer and $58 \%$ in the winter period. Temporal variations of methane concentration varied from 115 to $153 \%$ in the summer, and from 57 to $109 \%$ in the winter period among the sample locations around the cubicle. Variability of background methane concentration was then used to assess its potential impact on the accuracy of current methane measurement methods. Effects on accuracy were expressed in two theoretical equations. The measurement coefficient of variation $(\mathrm{CV})$ of assessed methane production of individual cows decreased exponentially with a higher captured fraction of the breath in a concentration method, and increased linearly with higher flow rates in a flux method. The measurement $\mathrm{CV}$ was strongly positively influenced by the level and the variability of the 


\section{Chapter 7}

measured background methane concentration, in both the methane flux and the concentration method.

In Chapter 4, we designed and constructed an artificial reference cow (ARC). Average methane concentration in exhaled gas released by the ARC had a mean difference of $2.8 \%$ between measured and controlled levels. The slopes of the regression lines between methane mass input and output of the ARC did not differ from unity $(\mathrm{P}>0.01)$ at a breath frequency of 30 times per minute and a tidal volume of $4.4 \mathrm{~L}$ and $6 \mathrm{~L}$. Besides precisely controlling methane production at pre-set levels, methane concentrations released by the ARC were controlled to fluctuate as sinusoidal cycles to mimic observed cow release patterns. Both time interval and methane concentration level of methane fluctuation cycles produced by the ARC are almost similar to the methane fluctuation cycles measured from the real cows.

In Chapter 5, we assessed the breath methane concentration method that measures methane concentrations of cows' breath air in a feed bin as an indicator of methane production. We investigated their relationship in a laboratory setup and in a barn setting with a milking robot, using the ARC as cow simulator. Measured methane concentrations of the simulated cows were positively related to pre-set methane production rates of the ARC. In the laboratory, source-sampling distances of 5 and $30 \mathrm{~cm}$ resulted in $\mathrm{R}^{2}$-values of 0.97 and 0.84 , and s.e. of $37 \mathrm{ppm}$ and $75 \mathrm{ppm}$ respectively. From the laboratory to the barn, at $30 \mathrm{~cm}$ sampling distance, $\mathrm{R}^{2}$-value decreased to 0.37 and s.e. increased to $86 \mathrm{ppm}$ as a result of barn air turbulence, the latter increasing to a theoretical $94 \mathrm{ppm}$ if the modeled variability of the cow's head movement was accounted for as well. This results in a measurement CV of $24.5 \%$. Besides this random error, cow variation in air exhalation rate and barn differences in air flow patterns around sampling locations, may disturb the relation between measured concentration and production rate. As a result, the methane concentrations of breath air will vary between cows with the same methane production rates.

In Chapter 6, we developed a cubicle hood sampler (CHS) that measures methane fluxes from lying cows in the cubicles. The CHS with a fume sample hood, a top curtain, extended 


\section{General discussion and conclusions}

side panels, and a hood flow of $200 \mathrm{~m}^{3} / \mathrm{h}$, captured $97.2 \%$ (s.d. 8.1) of the methane released by the ARC, regardless of the air velocity around the cubicle or the cow's nose position under barn conditions. In the barn, standard errors of a single measurement were estimated to be $24.1 \mathrm{~g} /$ day at a hood flow rate of $200 \mathrm{~m}^{3} / \mathrm{h}$. This corresponds with a measurement $\mathrm{CV}$ of $8 \%$ at mean methane production level, which is much smaller than the $24.5 \%$ measured in the breath concentration method (Chapter 5).

In this final chapter we discuss our main findings, as outlined above, in a broader context. Methane measurement methods can be developed for different purposes: (1) to determine the methane production level of individual cows; (2) to rank cows in methane production. To provide information for methane emission inventories or assess feed effects, we need to determine methane production levels. To breed low methane production cows, we need a breeding trait to rank cows in methane production. Therefore, adequate sampling and measurement strategies need to be defined for different applications. Current methane measurement methods can be categorized into three measurement principles: (1) breath methane concentration methods; (2) tracer gas methods; and (3) methane flux methods. This chapter focuses on discussing the fundamentals of these three methane measurement principles in subsequently section $2-4$, and assesses the measurement error (random and systematic) of each measurement variable. This information is used to discuss these methods in relation to the various applications. By understanding the pros and cons of the measurement principles, we can therefore apply the most adequate methods for assessing inventory of methane emission from dairy cows and effects of methane mitigation methods. Besides, this information can also be used to measure other gases released by cows for other applications, for instance, disease detection.

\section{Breath methane concentration method}

\subsection{Working principle and current application}

Breath methane concentration methods (sniffer and laser) only measure the methane concentration (ppm) in cows' breath. In the sniffer method, a sampling tube is placed closely to the cow' nose to continuously analyse the methane concentrations in the cow's breath. The measurement places are normally connected to a feed bin of a milking robot or 


\section{Chapter 7}

feed station where the cows' exhalation point remains more or less in the same position for some period of time. The laser method is not limited to a feed bin position as it measures the methane column density between the laser equipment and the target point, which is normally 3 meters (Chagunda et al., 2009). The working principle of the breath methane concentration method can be summarized as follows:

$\mathrm{MPR}=\mathrm{Q} \times\left(\mathrm{C}_{\mathrm{m}}-\mathrm{C}_{\mathrm{bg}}\right) \times \frac{1}{\delta} \times \rho \times 10^{-6}$

Where, MPR is the measured methane production in $\mathrm{g} / \mathrm{min}$; $\mathrm{Q}$ is the cow's breath air exchange rate in $1 / \mathrm{min} ; \mathrm{C}_{\mathrm{m}}$ is methane concentration of sampled breath air in ppm; $\mathrm{C}_{\mathrm{bg}}$ is the methane concentration of background air in ppm; $\delta$ (range $0-1$ ) is the fraction of exhaled breath air in the mixed air that is sampled, and $\rho$ is $0.668 \mathrm{~g} / \mathrm{l}$ under normal conditions.

\subsection{Accuracy of breath methane concentration methods}

From Equation 1, we can see that the accuracy (trueness and precision, as defined in ISO5725) of methane flux methods depends on four variables: $\mathrm{Q}, \mathrm{C}_{\mathrm{m}}, \mathrm{C}_{\mathrm{bg}}$, and $\delta$. The overall measurement $\mathrm{CV}$ of measured methane production (CV-MPR) as function of the measurement $\mathrm{CV}$ of each of these variables is shown in Table 1.

Table 1 Effects of variability of four measurement variables $\left(\mathrm{Q}, \mathrm{C}_{\mathrm{m}}, \mathrm{C}_{\mathrm{bg}}\right.$, and $\delta$ ) on measurement $\mathrm{CV}$ of the measured methane production (CV-MPR) in the breath methane concentration method

\begin{tabular}{|c|c|}
\hline Variable & CV-MPR $(\theta)$ \\
\hline $\mathrm{Q}$ & $\theta_{\mathrm{Q}}= \pm \alpha_{\mathrm{Q}}$ \\
\hline $\mathrm{C}_{\mathrm{m}}$ & $\theta_{\mathrm{C}_{m}}= \pm \alpha_{C_{m}} \times \frac{\mathrm{C}_{\mathrm{m}}}{\left(C_{m}-C_{b g}\right)} \times 10^{-6}$ \\
\hline $\mathrm{C}_{\mathrm{bg}}$ & $\theta_{\mathrm{C}_{b g}}= \pm \alpha_{C_{b g}} \times \frac{\mathrm{C}_{\mathrm{bg}} \times \mathrm{Q} \times \rho}{\mathrm{MPR} \times \delta} \times 10^{-6}$ \\
\hline$\delta$ & $\theta_{\delta}= \pm \frac{\alpha_{\delta} / 100}{1+\alpha_{\delta} / 100} \times 100 \%$ \\
\hline
\end{tabular}




\section{General discussion and conclusions}

\subsubsection{Cow's air exchange rate $(Q)$}

Since the breath methane concentration method does not incorporate the measurement of a flow rate, the cow's breath exchange rate is used in the equation to derive a methane flux from the measured methane concentration. The addition of this airflow component clarifies how methane concentrations in the breath air relate to the actual flux. The cow's breath exchange air is the driving force to emit the methane from dairy cows. The cow's air exchange rate can be calculated by multiplying the cows' tidal volume and breath frequency. However, variability of breath exchange air rate is unknown. The few existing studies in literature report that air exchange rate can vary from 95 to $174.51 / \mathrm{min}$ (Chapter 5). These variations can exist within and between cows. Within cow variation can be caused by physical factors. For instance, heat stress results in increased breathing frequency and a higher air exchange rate than at normal level. Genetic difference between cows, such as the volume of the lung, may also introduce variation in air exchange rate. However, there are no studies known that give insight into the level of genetic variability in this trait.

CV-MPR is linearly increased by the CV of a method to measure or predict the cow's air exchange rate (Table $1, \theta_{\mathrm{Q}}$ ). Normally in reported studies, the level of air exchange rate is implicitly taken to be constant, as there are no studies that pay attention to this source of variation. Literature data indicate that variability in air exchange rate between cows may be $15 \%$ and more, which would introduce at least a $15 \%$ uncertainty into measured methane production. In fact this is a much more serious problem than the measurement $\mathrm{CV}$ of the cow's air exchange rate. However, under practical conditions, it is not realistic to measure air breath exchange rates of each individual cow in dairy barns at a large scale. As a result this method is unable to correct for this error source. The most serious consequence is that it is subject to systematic variation in air exchange rate between cows. This will disturb the relationship between measured concentration $\mathrm{C}_{\mathrm{m}}$ and production rate, and undermine the capability of this method to accurately rank cows in methane production. Figure 6 in Chapter 5 clearly shows that a given emitted air's methane concentration level can be associated with a wide range of methane production rates, if variability in air exchange rate between animals is assumed. This systematic error cannot be reduced by repeating 


\section{Chapter 7}

measurements. If part of this effect is genetically based, this will lead to ranking cows on air exchange rate as well.

\subsubsection{Methane concentration of sampled breath air $\left(C_{m}\right)$}

Effects of measurement errors in the methane concentrations of sampled breath air $\left(\alpha_{\mathrm{C}_{m}}\right)$ on CV-MPR (Table $1, \theta_{\mathrm{Cm}}$ ) are influenced by three variables: $\alpha_{\mathrm{Cm}}, \mathrm{C}_{\mathrm{m}}$, and $\mathrm{C}_{\mathrm{bg}}$. The magnitude of parameter $\alpha_{\mathrm{Cm}}$ depends on the applied measurement device. The FTIR gas analyser used in this thesis has a $0.1 \%$ to $0.7 \%$ systematic difference compared to the known concentration of calibration gases, and the measurement CV $\left(\alpha_{\mathrm{Cm}}\right)$ of the FTIR is smaller than $0.5 \%$. Measurement errors in the gas analyser can be minimised by proper calibration. Because the methane concentration is measured near the mouth of the animal, the calibration range of the gas analyser in this method is $0-3000 \mathrm{ppm}$, which is much higher than concentration ranges in methane flux methods. The accuracy of the gas analyser may also be affected by its response time in case strongly fluctuating concentrations, such as the eructation gases, are measured. In breath methane concentration methods, the sampling interval is normally set as very short (20 s (Lassen et al., 2012) or even $1 \mathrm{~s}$ (Garnsworthy, 2005)) to measure methane concentration peaks due to the eructation process. For such short sampling intervals, effects of the response time of the gas analyser on measurement results are than more crucial than in methods that measure a mean concentration over a much longer sampling time.

The response time of the gas analyser is related to the working principle. In Chapter 3, we briefly discussed the meaning of the working principle of gas analyser on the measurement results. In this thesis, we used a Fourier transform infrared spectroscopy (FTIR) gas analyser to measure gas concentrations, which was also used in breath methane measurements (Lassen et al., 2012). The gas analyser continuously sampled the gas with $4.01 \mathrm{~min}^{-1}$ and analysed its concentration in the sample cell $(0.41)$. Because the gas is continuously sampled and flowing through the sample cell, the gas in the sample cell is continuously changing. It takes theoretically (in case of a constant flow) $6 \mathrm{~s}$ to completely refresh the sample cell. So, the measured concentration represents a moving average over the preceding $6 \mathrm{~s}$. Hence, variation between recorded values based on measurement 


\section{General discussion and conclusions}

intervals smaller than $6 \mathrm{~s}$ will be partly smoothed by preceding gas concentrations, meaning that short term variation within $6 \mathrm{~s}$ cannot be monitored in full detail. For measuring dynamic patterns in methane concentrations of eructation gases, short measurement intervals are required to depict actual variations. If the response time of the gas analyser and measurement interval are not short enough, measured methane concentrations will be smoothed. Therefore, characteristic of methane concentration patterns of cows' eructation, e.g. peak concentrations, eructation cycle time, will be different. Lassen et al. (2012) measured lower methane concentrations and longer eructation cycles with a FTIR gas analyser in 20 s measurement interval than Garnsworthy et al. (2012) who used an infrared methane analyser (Guardian Plus) with $1 \mathrm{~s}$ measurement interval. To compare the measurement results in different studies, the effects of the gas analyser should therefore be carefully considered. If the purpose is to measure methane concentrations patterns of eructation gases, the gas analyser should be carefully selected and examined according to the requirements of this application.

The equation relating $\alpha_{\mathrm{Cm}}$ to CV-MPR shows that the sampled fraction parameter $\delta$ has a strong impact. In fact parameter $\delta$ is controlling the concentration difference $\left(C_{m}-C_{b g}\right)$, where in case of a low sampling fraction $\mathrm{C}_{\mathrm{m}}$ will be lower as a result of a higher dilution of exhaled air. In case of a low concentration difference the measurement errors in both $\mathrm{C}_{\mathrm{m}}$ and $\mathrm{C}_{\mathrm{bg}}$ will increase the inaccuracy of $\left(\mathrm{C}_{\mathrm{m}}-\mathrm{C}_{\mathrm{bg}}\right)$. Thus a low value of $\delta$ amplifies the effects of measurement error in $\mathrm{C}_{\mathrm{m}}$. When $\delta$ nears 1 , consequently there will be no amplification effect on CV-MPR. Hence, effects of measurement CV $\left(\alpha_{\mathrm{Cm}}\right)$ on CV-MPR can be reduced by increasing the sampled fraction of methane concentration $(\delta)$ as much as possible. The sampled fraction of methane concentration can be increased with a shorter sampling distance and lower air turbulence in and around the feed bin, as outlined in section 2.2.4.

\subsubsection{Methane concentration of the background air $\left(C_{b g}\right)$}

Effects of the background methane concentration on CV-MPR expressed as CV $\left(\theta_{\mathrm{Cbg}}\right)$ are influenced by the measurement error of $C_{b g}\left(\alpha_{C_{b g}}\right)$, the level of $C_{b g}$, the air exchange rate $(\mathrm{Q})$, and the fraction of the breath air in the sampled air $(\delta)$. CV-MPR decreases linearly 


\section{Chapter 7}

with a decreasing level of background methane concentration levels and decreases linearly with decreasing measurement error in background concentration (Chapter 3). Similarly as for the effect of measurement errors in $\mathrm{C}_{\mathrm{m}}$, the concentration difference $\left(\mathrm{C}_{\mathrm{m}}-\mathrm{C}_{\mathrm{bg}}\right)$ has a strong impact. A small difference $\left(\mathrm{C}_{\mathrm{m}}-\mathrm{C}_{\mathrm{bg}}\right)$ amplifies the effects of measurement error in $\mathrm{C}_{\mathrm{bg}}$. The level of $\mathrm{C}_{\mathrm{m}}$ is positively related to the sampled fraction of the methane concentration ( $\delta$ ). Thus the difference between $\mathrm{C}_{\mathrm{m}}$ and $\mathrm{C}_{\mathrm{bg}}$ gets bigger when the $\delta$ increases. CV-MPR is estimated to be more than $15 \%$ in the cubicle with a $\delta$ of 0.05 and less than $5 \%$ in the feeder bin with a $\delta$ of 0.30 (Chapter 3).

Effects of measurement errors in $\mathrm{C}_{\mathrm{bg}}$ on CV-MPR can be reduced by (1) by continuous measurements and multiple sampling points to cover temporal and spatial variation, thus lowering $\alpha_{C_{b g}}$; and (2) increasing the sampled methane fraction ( $\delta$ ) of the measurement system. Measurement CV of measured methane production can be controlled below 5\% with a sampled fraction of 0.3 . A sampled fraction of 0.3 can be achieved in the feed bin of a milking robot or feed station if aerial turbulence is minimized. Considering a less than $5 \%$ measurement $\mathrm{CV}$ caused by variation of the background methane concentration, the measurement interval of the background methane concentration can be much longer and less frequent.

\subsubsection{Sampled fraction of methane concentration $(\delta)$}

The sampled faction of methane concentration ( $\delta$; range $0-1)$ is the sampled fraction of the exhaled breath air in the mixed air that is measured. Under the assumption of ideal mixing $\delta$ thus represents the relative part of the methane concentration in the breath air in the sampled and measured methane concentration. Effects of the measurement $\mathrm{CV}$ of the sampled fraction of methane concentration $\left(\alpha_{\delta}\right)$ on CV-MPR are only influenced by the level of $\alpha_{\delta}$. From the equation it can be seen that CV-MPR decreases exponentially with decreasing $\alpha_{\delta}$. The measurement $\mathrm{CV}$ of the sampled fraction increased from $14.3 \%$ in the laboratory to $21.1 \%$ in the barn (Chapter 5). These random variations can be reduced by repeating measurements, but it requires a large number of measurements with this level of measurement $\mathrm{CV}$. For each measurement location, it is necessary to explore these random 


\section{General discussion and conclusions}

errors first. So, we can determine how many measurements need to be to have accurate results.

Another issue to consider is systematic variation in $\delta$ between different sampling setups. The sample fraction of methane concentration is mainly influenced by sampling distance and turbulence of the ambient airflow, as outlined in Chapter 5. It decreased from 0.6 in the laboratory to 0.3 in the barn. The sampled fraction of methane concentration may vary between measurement setups in different dairy barns because airflow patterns, resulting from natural ventilation, around the sampling points in feed bins will differ as a result of different barn situations and variability in ventilation management. This variation can create systematic differences in measured methane concentrations between barns and even between setups in the same barn. In fact this means that the level of $\delta$ has to be determined at each barn location and data has to be calibrated to one level of $\delta$ to make comparison of data from different dairy barns possible.

\subsection{Application of breath methane concentration methods}

Breath methane concentration methods can be operated at a relatively low cost level. The measurement system is easily integrated in feed bins of milking robots or feed stations of dairy farms. It has the least intervention to cows' behaviours, and measurements can be continually performed for a long time. One measurement system can measure a large number of cows during one day, however only 1 to 3 times during a few minutes for each cow in case of systems that are connected to milking robots.

However, the simplicity of the measurement system is accompanied with a number of clear drawbacks. The breath concentration methods are only measuring methane concentrations, and not fluxes. As such, it strongly depends on a robust relation between methane concentration in the mixed air and methane production rate of a cow. Yet, as discussed before this relation can be weakened by systematic effects that are both cow and sampling location related. The cows' air exhalation rate (level and variability within and between cows) is a serious source of uncertainty that needs to be further investigated. Cow differences in exhalation rate weaken the relationship between the methane concentration 


\section{Chapter 7}

and methane production rate (Chapter 5). The sampled fraction of methane is affected by sampling distances and locations, airflow pattern around, and cows' head movement. The variability of dilution effects may cause systematic differences between measurements from measurement locations in different barns.

Effects of random measurement errors can be reduced by minimizing, as much as possible, the dilution of breath air during sampling, resulting in higher measured methane concentrations. Random errors can be further minimized by repeating measurements in the breath methane concentration method, but this is not the case for systematic errors. The presence of possible systematic errors is the fundamental flaw of methods using breath methane concentration only. Further investigation into the impact of variation sources with a systematic nature is needed before such methods are applied on a large scale in programs with the aim to breed cows with low methane production.

\section{Tracer gas method}

\subsection{Working principle and current application}

In this group of methods, both the methane concentration and a tracer gas concentration that are simultaneously released from dairy cows are measured. The method uses the $\mathrm{CH}_{4} /$ tracer gas concentration ratio to calculate a cow's daily methane production being the product of the concentration ratio and the predicted or measured daily tracer gas production. Both artificial $\left(\mathrm{SF}_{6}\right.$, injected in the rumen) and metabolic gases $\left(\mathrm{CO}_{2}\right)$ are used as tracer. In practice, some researchers use the $\mathrm{CH}_{4} / \mathrm{CO}_{2}$ ratio to directly express differences in methane production without calculating methane production from individual $\mathrm{CO}_{2}$ production. This approach is a simplification of the tracer gas method and is denoted in this thesis as the ratio method (Chapter 2). The discussion of the tracer gas method in this chapter is based on the tracer gas method without simplification.

The working principle of the tracer gas method can be summarized as follows:

MPR $=P_{t} \times\left(C_{m}-C_{b g}\right) \times \frac{1}{C_{t}-C_{t b g}} \times \rho$ 


\section{General discussion and conclusions}

Where, MPR is the measured methane production in $\mathrm{g} / \mathrm{min}$; $\mathrm{P}_{\mathrm{t}}$ is the calculated or measured tracer gases production of dairy cows in $1 \mathrm{~min}^{-1} ; \mathrm{C}_{\mathrm{m}}$ is the methane concentration of the sampled breath air in ppm; $C_{b g}$ is the background methane concentration in ppm; $C_{t}$ is the tracer gas concentration of the sampled breath air in ppm; $\mathrm{C}_{\mathrm{tbg}}$ is the background tracer gas concentration in ppm; $\rho$ is a conversion constant being $0.668 \mathrm{~g} / 1$ under normal conditions.

\subsection{Accuracy of tracer gas methods}

From Equation 2, we can see that the accuracy of the tracer gas method depends on five variables: $P_{t}, C_{m}, C_{b g}, C_{t}$, and $C_{t b g}$. The effects of these variables on CV-MPR are shown in Table 2. The equations of the first three variables are analogue to those of the breath concentration method (Table 1).

Table 2 Effects of variability of five measurement variables $\left(\mathrm{P}_{\mathrm{t}}, \mathrm{C}_{\mathrm{m}}, \mathrm{C}_{\mathrm{bg}}, \mathrm{C}_{\mathrm{t}}\right.$, and $\left.\mathrm{C}_{\mathrm{tbg}}\right)$ on measurement $\mathrm{CV}$ of measured methane production (CV-MPR) in tracer gas and concentration ratio method

\begin{tabular}{ccc}
\hline Variable & CV-MPR $(\theta)$ \\
\hline $\mathrm{P}_{\mathrm{t}}$ & $\theta_{P_{t}}= \pm \alpha_{P_{t}}$ \\
$\mathrm{C}_{\mathrm{C} m}= \pm \alpha_{C_{m}} \times \frac{\mathrm{C}_{\mathrm{m}}}{C_{m}-\mathrm{C}_{\mathrm{bg}}}$ & $\theta_{\mathrm{C}_{b g}}= \pm \alpha_{C_{b g}} \times \frac{\mathrm{C}_{\mathrm{bg}}}{C_{m}-\mathrm{C}_{\mathrm{bg}}}$ \\
$\mathrm{C}_{\mathrm{t} g}$ & $\theta_{C_{t}}= \pm \frac{\alpha_{C_{t}} / 100}{1+\frac{\alpha_{C_{t}}}{100}-\frac{C_{t b g}}{C_{t}} \times 100 \%}$ \\
$\mathrm{C}_{\mathrm{tbg}}$ & $\theta_{C_{t b g}}= \pm \frac{\alpha_{C_{t b g}} / 100}{1+\frac{\alpha_{C_{t b g}}}{100}-\frac{C_{t b g}}{C_{t}}}$
\end{tabular}

$\alpha_{P_{t}}$ is the measurement $\mathrm{CV}$ of $\mathrm{P}_{\mathrm{t}}$ in $\% ; \alpha_{C_{t}}$ is the measurement $\mathrm{CV}$ of $\mathrm{C}_{\mathrm{t}}$ in $\% ; \alpha_{C_{t b g}}$ is the measurement $\mathrm{CV}$ of $\mathrm{C}_{\mathrm{tbg}}$ in $\%$.

\subsubsection{Tracer gas production $\left(P_{t}\right)$}

The CV-MPR linearly increases with the measurement $\mathrm{CV}$ of the tracer gas production rate (Table $2, \theta_{\mathrm{Pt}}$ ). In case of the use of metabolic $\mathrm{CO}_{2}$ as tracer, its production can be derived from the known constant $\mathrm{CO}_{2}$ production per unit of heat production of cows, where heat 


\section{Chapter 7}

production is predicted from a number of cow specific variables: cow's weight, milk production, and pregnancy, as presented in CIGR-publications (CIGR, 1992, 1984). The measurement error of these production variables will be included into the uncertainty of the final prediction of $\mathrm{CO}_{2}$ production, although it is noted that in practice they can be collected with high accuracy on modern dairy farms. The $\mathrm{CO}_{2}$ prediction equations are based on analyses of several cow studies and represent general relationships, which still allow individual deviations from cow to cow. It is also noted that the underlying metabolic studies of the prediction equations represent 24 -h averages and as such do not account for diurnal patterns. To include diurnal patterns the 24-h average levels are normally related to diurnal patterns of an activity index, but this relation has an uncertain prediction quality and needs further research. Hence, using metabolic $\mathrm{CO}_{2}$ production as a tracer gas at an individual cow level is associated with a number of uncertainties in prediction that are difficult to quantify.

$\mathrm{SF}_{6}$ has been used in many physiological studies and has the advantage that there is technical control over its release rate. Although the $\mathrm{SF}_{6}$ release tubes can be controlled, the preparation and calibration in the laboratory is very laborious. It was shown that the release rates of the tubes in rumen fluid showed a 6-11\% difference with tubes in open air. This variability in release rate is an important source of error (Vlaming, 2008), and will be directly reflected in the measured methane production as shown by the first equation in Table 2.

\subsubsection{Methane concentration of sampled breath air $\left(C_{m}\right)$ and background $\left(C_{b g}\right)$}

The effect of errors in the methane concentration of sampled breath air $\left(\mathrm{C}_{\mathrm{m}}\right)$ on CV-MPR (Table $\left.2, \theta_{\mathrm{Cm}}\right)$ is determined by three variables $\left(\alpha_{\mathrm{Cm}}, \mathrm{C}_{\mathrm{m}}\right.$, and $\left.\mathrm{C}_{\mathrm{bg}}\right)$, which are the same as for $\mathrm{C}_{\mathrm{m}}$ in the breath methane concentration method (section 2.2.2). As already stated in section 2.2.2, the magnitude of parameter $\alpha_{\mathrm{Cm}}$ depends on the applied measurement device, which can be minimised by calibration and adequate sampling intervals. Small differences between $C_{m}$ and $C_{b g}$ amplify the effects of measurement error in $C_{m}$. In case $C_{b g}$ is negligible to $C_{m}$, the ratio of $C_{m} /\left(C_{m}-C_{b g}\right)$ will be 1 , and consequently there is no effect of 


\section{General discussion and conclusions}

$\mathrm{C}_{\mathrm{bg}}$ and $\mathrm{C}_{\mathrm{m}}$ on CV-MPR. The level of $\mathrm{C}_{\mathrm{m}}$ is positively related to the sampled fraction of methane concentration $(\delta)$, which depends on the sampling distance and surrounding airflow turbulence.

The effects of the background methane concentration on CV-MPR (Table 2, $\theta_{\mathrm{Cbg}}$ ) have a structure that is similar to the effects of the methane concentration of sampled breath air $\left(\theta_{\mathrm{Cm}}\right)$, both being influenced by three variables $\left(\alpha_{\mathrm{Cbg}}, \mathrm{C}_{\mathrm{m}}\right.$, and $\left.\mathrm{C}_{\mathrm{bg}}\right)$.

$\theta_{\mathrm{Cbg}}$ is influenced by the difference between $\mathrm{C}_{\mathrm{m}}$ and $\mathrm{C}_{\mathrm{bg}}$, and the variation of the background methane concentration $\left(\alpha_{\mathrm{Cbg}}\right)$. The effect of the difference between $\mathrm{C}_{\mathrm{m}}$ and $\mathrm{C}_{\mathrm{bg}}$ as in $\theta_{\mathrm{Cm}}$ can be minimized by a higher sampled fraction of methane concentration $(\delta)$. The effects of background methane concentration are very different between indoor (barn) and outdoor (pasture) conditions. The outdoor background methane concentration is about 2-3 ppm. The contribution of background methane concentration to CV-MPR is estimated to be $0.2 \%$ with a measurement $\mathrm{CV}$ of $20 \%$ for outdoor concentrations based on 5-minutes sampling intervals (Wu et al., 2012). In dairy barns, background methane concentration can vary between 20 to $50 \mathrm{ppm}$, and measurement $\mathrm{CV}$ can range from 50 to $150 \%$ indoor (Chapter 3). Consequently, the contribution of background methane concentration to CV-MPR can reach levels of 4-30\%. The effects of background methane concentration can be reduced by continuously measuring background concentration to deal with temporal variation, and more sampling points to cover spatial variation.

\subsubsection{Tracer gas concentration of sampled breath air $\left(C_{t}\right)$ and background $\left(\boldsymbol{C}_{t b g}\right)$}

The effect of tracer gas concentration of sampled breath air $\left(\mathrm{C}_{\mathrm{t}}\right)$ on CV-MPR (Table $\left.2, \theta_{\mathrm{Ct}}\right)$ is influenced by the measurement $\mathrm{CV}$ of tracer gas $\left(\alpha_{\mathrm{Ct}}\right)$ and the difference between $\mathrm{C}_{\mathrm{t}}$ and $\mathrm{C}_{\mathrm{tbg}}$. Difference between $\mathrm{C}_{\mathrm{t}}$ and $\mathrm{C}_{\mathrm{tbg}}$ depends on the dilution of the tracer gas, which can be influenced by the sampling distance and surrounding airflow turbulence. Similarly, the parameter $\alpha_{\mathrm{Ct}}$ is mainly determined by the performance of the gas analyser and differences in dilution rate of air. An assumed measurement $\mathrm{CV}$ of $0.5 \%\left(\alpha_{\mathrm{Ct}}\right)$ in the $\mathrm{SF}_{6}$ method and $25 \%$ in the $\mathrm{CO}_{2}$ method (Chapter 3) result in a measurement $\mathrm{CV}$ of $4.9 \%$ and $20 \%$ for the measured methane production, respectively. It is noted that little is known with regard to 


\section{Chapter 7}

the measurement $\mathrm{CV}$ of sampled $\mathrm{SF}_{6}$. The measurement $\mathrm{CV}$ could be minimised by appropriate calibration of the gas analyser, adequate lengths of sampling intervals, shortening the sampling distance, and taking measurements under lower turbulence conditions.

Effects of background tracer gas concentration on CV-MPR (Table 2, $\theta_{\text {Ctbg }}$ ) are influenced by the measurement $\mathrm{CV}$ of background tracer gas concentration $\left(\alpha_{\mathrm{Ctbg}}\right)$ and difference between $C_{t}$ and $C_{t b g}$. Similar as in $\theta_{C t}$, difference between $C_{t}$ and $C_{t b g}$ depends on the dilution of the tracer gas. The measurement $\mathrm{CV}$ of background tracer gas concentration $\left(\alpha_{\mathrm{Ctbg}}\right)$ varied in $\mathrm{SF}_{6}$ and $\mathrm{CO}_{2}$ tracer gas method. A background $\mathrm{SF}_{6}$ concentration of $6 \mathrm{ppt}$ resulted in a measurement $\mathrm{CV}$ of $25 \%$ in the $\mathrm{SF}_{6}$ method (Williams et al., 2011), which would result in a contribution of $20 \%$ on CV-MPR. In the $\mathrm{CO}_{2}$ method, effects of background $\mathrm{CO}_{2}$ concentration differ between indoor and outdoor conditions. A measurement $\mathrm{CV}$ of $3.0 \%$ of the background $\mathrm{CO}_{2}$ concentration outdoor would result in a CV-MPR of $2.9 \%$, and would increase up to $21.3 \%$ with a measurement $\mathrm{CV}$ of $27 \%$ of the background $\mathrm{CO}_{2}$ concentration indoor. To reduce the effects of background tracer gas concentration, especially in case of indoor measurements, continual measurement and more sampling points are required.

\subsection{Application of tracer gas method}

The tracer gas method only measures concentration of gases, but its performance is better than the breath methane concentration method. The major advantage of using tracer gas is that the methane production can be monitored by indirectly measuring the airflow that accompanies the methane release through a known release rate of a tracer gas. The effects of variation in the air exhalation rate of a cow as in the breath methane concentration method do not exist here. Effects of the background methane concentration are similar as in the breath methane concentration method. The accuracy of the measured methane production can be affected by the problem of the inadequacy of the prediction of the $\mathrm{CO}_{2}$ production for individual cows in using $\mathrm{CO}_{2}$ as tracer gas. Although the level of control in the $\mathrm{SF}_{6}$ method is higher, it has to be noted that cows' normal behaviour is disturbed by the measurement system and thus can influence the representative of the measurement data. 


\section{General discussion and conclusions}

In its most simple form the tracer gas approach could be applied as a $\mathrm{CH}_{4} / \mathrm{CO}$ ratio method and the ratio could be used as a ranking parameter. In fact in this case an equal $\mathrm{CO}_{2}$ production is assumed for all cows. However, it should be realized that appropriate ranking on this ratio is partly disturbed by cow differences in $\mathrm{CO}_{2}$ production.

\section{Methane flux method}

\subsection{Working principle and applications}

Methane flux methods measure the methane flux (mass or volume per unit of time) emitted from the rumen of dairy cows. In a methane flux method the breath air of a cow is fully captured by a controlled external airflow, and the capture flow rate and the methane concentration in the airflow is measured. The methane production rate of a cow is then calculated as the product of the measured methane concentration and airflow rate. The working principle of the methane flux method can be summarized as follows:

$\mathrm{MPR}=\mathrm{F} \times\left(\mathrm{C}_{\mathrm{m}}-\mathrm{C}_{\mathrm{bg}}\right) \times \frac{1}{\tau} \times \rho \times 10^{-6}$

Where, MPR is the measured methane production in $\mathrm{g} / \mathrm{min}$; $\mathrm{F}$ is the capture flow rate in $1 / \mathrm{min} ; \mathrm{C}_{\mathrm{m}}$ is the methane concentration of the airflow in ppm; $\mathrm{C}_{\mathrm{bg}}$ is the methane concentration of the background air in ppm; $\tau$ (range $0-1$ ) is the captured fraction of a cow's produced methane; $\rho$ is the methane density in $g / 1$. Currently, the respiration chamber, ventilated head hood or mask, and the GreenFeed are using this principle to determine the methane production of dairy cows (Chapter 2). The cubicle hood sampler (CHS, Chapter 5) also applies a methane flux method to measure methane production of dairy cows in the cubicle.

\subsection{Accuracy of methane flux methods}

From Equation 3, we can see that the accuracy of the methane flux method depends on four variables: $F, C_{m}, C_{b g}$, and $\tau$. The relation between CV-MPR and the measurement errors in these variables is shown in Table 3 . 


\section{Chapter 7}

Table 3 Effects of variability of four measurement variables $\left(F, C_{m}, C_{b g}\right.$, and $\left.\tau\right)$ on measurement $\mathrm{CV}$ of measured methane production (CV-MPR) in the methane flux method

\begin{tabular}{cc}
\hline Variable & CV-MPR $(\theta)$ \\
\hline $\mathrm{F}$ & $\theta_{\mathrm{F}}= \pm \alpha_{\mathrm{F}}$ \\
$\mathrm{C}_{\mathrm{m}}$ & $\theta_{\mathrm{C}_{m}}= \pm \alpha_{C_{m}} \times \frac{\mathrm{C}_{\mathrm{m}} \times \mathrm{F} \times \rho}{\mathrm{MPR} \times \tau} \times 10^{-6}$ \\
$\mathrm{C}_{\mathrm{bg}}$ & $\theta_{\mathrm{C}_{b g}}= \pm \alpha_{C_{b g}} \times \frac{\mathrm{C}_{\mathrm{bg}} \times \mathrm{F} \times \rho}{\mathrm{MPR} \times \tau} \times 10^{-6}$ \\
$\tau$ & $\theta_{\tau}= \pm \frac{\alpha_{\tau} / 100}{1+\alpha_{\tau} / 100} \times 100 \%$
\end{tabular}

$\alpha_{\mathrm{F}}$ is the measurement $\mathrm{CV}$ of $\mathrm{F}$ in $\% ; \alpha_{\tau}$ is the measurement $\mathrm{CV}$ of $\tau$ in $\%$.

\subsubsection{Capture flow rate $(F)$}

The capture airflow is the main driving force to collect the released methane from dairy cows. In measurement systems with an enclosed space, such as a respiration chamber and hood methods, the capture flow rate is normally controlled at $20-40 \mathrm{~m}^{3} / \mathrm{h}$. Note that the majority of air is re-circulated in these systems, and that the capture flow rate is only a small proportion of this. The capture flow rate increases in measurement system with a more open inlet. For example, the capture flow rate increases to $90-135 \mathrm{~m}^{3} / \mathrm{h}^{-}$for the GreedFeed system, with an open inlet above the feed bin. In the CHS (Chapter 5) with an even larger inlet opening, the capture flow rate increased to $100-200 \mathrm{~m}^{3} / \mathrm{h}$ to have sufficient capacity to collect all released methane. The capture flow rate is measured at the inlet in a positively pressurized system and at the outlet in a negatively pressurized system.

CV-MPR linearly increases with the measurement CV $\left(\alpha_{\mathrm{F}}\right)$ of capture flow rate (Table 3, $\left.\theta_{\mathrm{F}}\right)$. The measurement $\mathrm{CV}$ of the capture flow rate depends on the characteristics of the measurement method. In most cases a fan anemometer is used. Fan anemometer models applied in these applications typically may show a 2-3\% bias on measured results (Calvet et al., 2013), which can be minimised by calibration. With a good quality fan, the random error in the measured flow rate is very small. In the CHS system, the measurement CV of the flow rate was about $0.5 \%$. 


\section{General discussion and conclusions}

\subsubsection{Methane concentration of the airflow $\left(C_{m}\right)$}

Effects of the measurement error in the airflow's methane concentration $\left(\alpha_{\mathrm{Cm}}\right)$ on CV-MPR (Table $\left.3, \theta_{\mathrm{Cm}}\right)$ are influenced by five variables $\left(\alpha_{\mathrm{Cm}}, \mathrm{C}_{\mathrm{m}}, \mathrm{F}, \mathrm{MPR}\right.$, and $\left.\tau\right)$, with a structure similar to the methane concentration and tracer gas method. For a given measurement system and a cow, MPR and $\tau$ are normally fixed. Thus, measurement CV of measured methane concentration is mainly affected by $\alpha_{\mathrm{Cm}}, \mathrm{C}_{\mathrm{m}}$, and $\mathrm{F}$. Because the methane concentration level in the airflow is negatively related to the capture flow rate of the measurement system, the effect of $\mathrm{F}$ is compensated by the inversely lower $\mathrm{C}_{\mathrm{m}}$. Therefore, the measurement $\mathrm{CV}\left(\alpha_{\mathrm{Cm}}\right)$ of the airflow's methane concentration is the major contributor to the measurement $\mathrm{CV}$ of measured methane concentration. The accuracy of the airflow's methane concentration depends on the gas analyser used in the system. Measurement bias can be minimised by calibrating the gas analyser with span gas cylinders. Because of its dilution in the capture flow rate, the methane concentration level is decreased as compared to the original level in the exhaled breath. So, the calibration of the gas analyser in the methane flux method should focus on the range of 0-500 ppm. If the aim of the measurements is to monitor a large number of cows for breeding low methane emission cows, the goal of the measurements is to rank cows in methane production. In that case the bias of the analyser can be neglected since all measurements have the same bias and the ranking is not affected.

The measurement CV of the FTIR gas analyser used in this thesis is smaller than $0.5 \%$. Thus the measurement $\mathrm{CV}$ of $\mathrm{C}_{\mathrm{m}}$ has minor effects on CV-MPR. We used FTIR equipment to analyse the methane concentrations in our studies. This equipment is fast and accurate but also expensive. Measurement equipment with a lower accuracy could decrease the costs, and still fulfil the requirements for ranking. Cheaper measurement equipment might have higher random errors or more bias. However, higher random variation can be acceptable and solved by higher number of measurements, and bias can be accepted for ranking if it is constant and not drifting. To avoid effects of drifting frequent calibration is required. 


\section{Chapter 7}

\subsubsection{Methane concentration of the background air $\left(C_{b g}\right)$}

Effects of background methane concentration on CV-MPR (Table $3, \theta_{\mathrm{Cbg}}$ ) are influenced by the background variability $\left(\alpha_{\mathrm{Cbg}}\right)$, the background methane concentration level $\left(\mathrm{C}_{\mathrm{bg}}\right)$, the capture flow rate $(\mathrm{F})$, the methane production rate (MPR), and the captured fraction of methane production $(\tau)$. At a given level of background methane concentration, an increase in the variability in background methane concentration measurement, as expressed in its $\mathrm{CV}$, will result in a similar increase in CV-MPR. Similarly, at a constant measurement CV of background methane concentration, an increase in background methane concentration results in the same proportional increase in CV-MPR. The contribution to CV-MPR could amount more than 15\% with background methane concentration of $15 \mathrm{ppm}$ and a measurement CV of $150 \%$ (Chapter 3).

The effect of measurement errors in $\mathrm{C}_{\mathrm{bg}}$ on CV-MPR is amplified by the capture flow rate, which can reach $15 \%$ at a flow rate of $200 \mathrm{~m}^{3} / \mathrm{h}$ (Chapter 3). If we compare this $15 \%$ to the $5 \%$ in breath methane concentration methods, it becomes clear that the variability of the background methane concentration has stronger effects in methane flux methods. In the respiration chamber the internal circulation of airflow is relatively high, the capture flow rate is the lowest, and background methane concentration is continuously measured. So, in that flux method the background methane concentration has only small effects on the measured methane production. However, other flux methods, such as GreenFeed or CHS, are measuring in the barn with a large open inlet for access of the exhaled breath with methane. In these methods much higher capture flow rates are used to capture the emitted methane, which will increase the CV-MPR because the concentration difference $\left(\mathrm{C}_{\mathrm{m}}-\mathrm{C}_{\mathrm{bg}}\right)$ is reduced and the measurement errors in both methane concentrations will become more important. Thus the CV-MPR caused by background methane variation can reach $15 \%$ at a flow rate of $50 \mathrm{~m}^{3} / \mathrm{h}$ and even reach $60 \%$ at $200 \mathrm{~m}^{3} / \mathrm{h}$ (Chapter 3). The respiration chamber and hood/mask systems are less prone to spatial variability of background methane concentration than the GreenFeed and CHS, due to a smaller inlet pipe, which reduces spatial variability and enables complete mixing. 


\section{General discussion and conclusions}

Given this, the background methane measurement is very crucial in case of the application of methane flux methods with relatively open inlets in the barns, like the GreenFeed and CHS. This type of measurement uncertainty can be reduced in two ways: (1) continually measurement and more sampling points to cover temporal and spatial variation in the inlet, and (2) decrease the capture flow rate as much as possible. Background methane concentration in the barn clearly revealed spatial and temporal variation, which is mainly affected by airflow patterns and barn management (Chapter 3). Ideally, it would be better to have multiple sampling points to simultaneously measure background methane concentration at the inlet. Another way to reduce the effects of background methane concentration is to decrease the capture flow rate. CV-MPR decreased below $15 \%$ when the capture flow rate decreased from 200 to $50 \mathrm{~m}^{3} / \mathrm{h}$ (Chapter 3). With a low capture flow rate, the measured methane concentration $\left(\mathrm{C}_{\mathrm{m}}\right)$ will be much higher than the background methane concentration, and thus lower the effect on the measured methane production. However, a decrease of the capture flow rate can reduce the captured fraction of the measurement system ( $\tau$; Chapter 6 ), and might introduce a systematic error.

\subsubsection{Captured fraction of methane production $(\tau)$}

The captured fraction is the methane flux measured by the system as compared to the actual methane production rate of a dairy cow. The captured fraction of a methane flux method mainly depends on the capture flow rate of the system. With a closed system like the respiration chamber all the released methane can be captured with a very low flow rate. Much higher flow rates are needed in the GreenFeed or CHS to capture most or all of the released methane because of the open inlet system. Besides, design of the CHS and different auxiliaries can also increase the captured fraction of the system (Chapter 6).

The captured fraction of a methane flux method can be higher than $95 \%$ and even close to $100 \%$. The CV of the captured fraction of methane production can be expected to be small in case of a high capture flow rate (F), depending on the dynamics of the barn airflow patterns around the sampling location. The CHS designed in Chapter 6 can capture $97.2 \%$ of released methane with a $\mathrm{CV}$ of $8.0 \%$ at a flow rate of $200 \mathrm{~m}^{3} \mathrm{~h}^{-1}$. This measurement $\mathrm{CV}$ of the captured fraction would results in a measurement $\mathrm{CV}$ of $7.4 \%$ for the measured 


\section{Chapter 7}

methane production (Table $3, \theta_{\tau}$ ). Because this measurement $\mathrm{CV}$ was based on a 3-mins sampling duration, such variations can be reduced by more repetitions.

An adequate calibration procedure is required to determine the captured fraction of the system. Respiration chambers, which are considered as the reference method with a captured fraction of $100 \%$, showed a big variation (55 - 115\%) between different chambers (Gardiner et al., 2015). Even more calibration care is needed for methods with large opening inlets. In some studies this calibration is based on releasing a known gas flux at a fixed point (GreenFeed; Huhtanen et al., 2015). In this way the variation in aerial turbulence can probably be covered, but not the head movement of the cows. Besides, a constant release does not simulate the cows' inhaling and exhaling process, neither the eructation pattern, which could influence the captured fraction of measurement systems with a large opening inlet. The artificial reference cow (ARC) designed in Chapter 3 can precisely control methane production and release methane concentration patterns as real cows. Moreover, the ARC can also be used to assess effects of possible systematic errors on the captured fraction, e.g. the effect of the capture flow rate.

\subsection{Application of the flux method}

To determine methane production of individual dairy cows, the methane flux method is currently the most accurate method. Compared to the methane concentration and ratio method, methane flux methods have very low measurement errors and no bias risks when the measurement system is well controlled and calibrated. The 'closed' respiration chamber method can provide more accurate measurement values than the 'open' GreenFeed and CHS method that are developed for barn application. These open methods do not interfere with normal housing conditions and have lower operational cost. There are clear drawbacks connected to the open system, i.e. risks of bias due to a low and variable captured fraction on the one hand and large measurement CVs (mainly background) that are increased at higher capture flow rates on the other hand.

The GreenFeed method only measures one or two times a period of 6 minutes per day per cow. Such short-term measurement may not precisely present daily methane production due 


\section{General discussion and conclusions}

to daily variations of methane production. This could possibly be overcome if measurement results of many cows are combined. The methane production rate at any given moment depends on feed type, feeding time, or variations of methanogenic bacteria in the rumen (Hegarty, 2013). It therefor remains uncertain to what extent the methane production measured during intake of concentrates is representative for a certain daily average level of methane production. The CHS method can measure the methane production from lying cows in the cubicles. So, the CHS can measure longer periods, and cover eventually up to $14 \mathrm{~h}$ per cow per day, and under representative conditions. The drawback of short measurements in the GreenFeed can thus be overcome with the CHS.

\section{General conclusions}

In this final chapter, we evaluated methane measurement methods along the lines of three working principles and explored the measurement error of the measurement variables. Measurement errors in sampled methane concentration exist in all three working principles but their bias can be reduced by calibration of the gas analyser. Besides the errors in measurement of sampled concentration, the capture flow rate and the background methane concentration are the main contributors to the measurement error in the methane flux methods with large open inlets. The breath methane concentration methods do not have these problems, but are prone to random errors caused by cow behaviour and air turbulence, and probably to systematic errors caused by the cows' physiological variation in air exchange rate. These systematic errors play no role in the tracer gas method, but here problems in assessing the tracer gas production $\left(\mathrm{CO}_{2}\right)$ contribute to the measurement uncertainty.

The main conclusions from chapter 2-6 and this general discussion are:

- None of existing methods meet all requirements to evaluate the effects of methane mitigation methods. New measurement methods are still needed to measure a large number of individual dairy cows under farm conditions. The GreenFeed method, being a farm implementation of a flux method, is currently the best available approach to measure methane production of individual cows in the farm. To 


\section{Chapter 7}

measure methane production rates of individual cows under farm conditions, sampling of breath air during the lying period of cows in cubicles could be a practical direction. To rank cows in methane production rates, the $\mathrm{CH}_{4} / \mathrm{CO}_{2}$ ratio method is a promising method, but requires further research to assess its accuracy, especially with respect to the representativeness of the short sampling periods.

- Methane concentration around cubicles in a dairy barn showed clear spatial and temporal variations. The variation was affected by the management, climate data (air temperature), and airflow patterns. This study provided essential information to apply both methane concentration and flux methods in dairy barns to assess methane production of individual cows in such a way that measurement $\mathrm{CV}$ of the assessed methane production can be limited.

- Based on the performance characteristics of the ARC, this system is a suitable and reliable reference source that can be helpful in developing and improving practical methane measurement methods, both under laboratory and experimental conditions as well as under practical conditions.

- The breath methane concentration measurement method is a novel and low-cost on-farm technique. However, the capability of the breath measurement method to adequately rank methane production rates among cows is highly uncertain. Cow variation in air exhalation rate and barn differences in air flow patterns around sampling locations, may disturb the relation between measured concentration and production rate. Further insight in these variation sources with a systematic nature is required.

- Tracer gas methods are not subject to the systematic errors that are associated with the breath methane concentration method, and are more reliable in ranking cows on methane production than methane concentrations alone. The $\mathrm{CO}_{2}$-based tracer gas method is easier to operate and has lower costs than methane flux methods. However the prediction uncertainty of individual cow $\mathrm{CO}_{2}$ production restricts its reliability.

- The methane flux method is currently the most accurate method to determine the methane production rate. The closed system versions can easily be calibrated and 


\section{General discussion and conclusions}

have limited risk of bias. The cost of closed systems limits its application for being applied to large numbers of cows. Open versions of the flux method (GreenFeed, CHS) are to be preferred for on farm application. Due to the open inlet of these constructions and the dilution of the exhaled rumen in the capture flow, they are very sensitive for variability in background methane concentration.

- The CHS that was designed and constructed in this study can measure the methane production from individual cows and detect the difference between cows in methane production under farm conditions. The CHS captured $97 \%$ of the methane released by the ARC with a measurement $\mathrm{CV}$ of $8.0 \%$. Further evaluation of the CHS is needed to assess the cow's behaviour with the CHS installed in front of the cubicles.

\section{Recommendations}

The main error sources of current methane measurement principles were systematically analysed in this thesis, and needs for further improvement of methods identified. The following aspects are recommended with regard to improvement of measurement methods for individual methane production of cows under barn conditions.

- The breath methane concentration measurement method needs further insight in variation sources with a systematic nature that are related to the cow's exhalation rate. It is difficult to measure the cow's exhalation rate but a related factor (e.g. breath frequency that is measurable) could be used to indicate the effects of the cow's exhalation rate. Thus measured methane concentration together with the related factor would better reveal the relation between methane concentration and flux. Systematic errors caused by airflow characteristic that vary between sampling locations and fluctuate in time could be decreased by frequent determination of dilution level at sampling points, and calibration of records to a constant dilution level.

- In the tracer gas method, closer sampling distances will decrease dilution of sampled air and reduce most of the random error. Prediction accuracy of individual cow $\mathrm{CO}_{2}$ production in $\mathrm{CO}_{2}$ based tracer gas method could be further 


\section{Chapter 7}

improved by making use of information from measurement systems based on flux measurements of both $\mathrm{CO}_{2}$ and $\mathrm{CH}_{4}$ production.

- For the methane flux method, improvement in accuracy can be reached by carefully analysing the background methane concentration and adequate spatial sampling, and decreasing the capture flow rate. However, reducing the capture flow rate would make the measurement system (especially the system with a more open inlet) vulnerable to factors that reduce methane capture rates, for instance the airflow disturbance. Possible solutions could exist in modifying the design of the system with auxiliaries to maintain full methane capture at a low capture flow rate.

- The presence of diurnal patterns in methane production is an important issue in the uncertainty of the results from short-term measurement performed in the feed bin. Diurnal patterns could be derived from its relation with an activity index, but this relation has an uncertain prediction quality and needs further research.

- The measurement systems developed for sampling the breath air of cows in dairy barns, such as CHS, GreenFeed or sniffer method, provide a promising platform for analysing other gases and volatiles released by cows. The cows' breath air could give information on the physiological status of cows and detect for example diseases. It should be realized that the technical challenges here are not only related to analysing volatile compounds but also to proper sampling systems of the cow's breath that deal with dilution and background problems. The insights and knowledge derived from developing sampling methods in methane measurement systems can be used for this purpose. 
Summary

\section{Summary}

There is an increasing interest in mitigation of methane $\left(\mathrm{CH}_{4}\right)$ production of ruminants due to the strong relation between methane emission and the greenhouse effect that links to global climate change (Steinfeld et al., 2006). Methane production from dairy cows contributes $4 \%$ ( $\pm 26 \%$, margin error) of anthropogenic greenhouse gas emissions (FAO, 2010). On average, a typical Holstein Friesian dairy cow produces 250 to $400 \mathrm{~g}$ methane per day (Bannink et al., 2011), which is mainly released through the eructation from the rumen and only in a small quantity through the rectum as flatus (Lassey, 2007; Murray et al., 1976). As a product of rumen fermentation, methane released by dairy cows also accompanies with a loss of energy for the animal (Blaxter et al., 1972; Yan et al., 2010; Johnson and Johnson, 1995). Therefore, reduction of methane production from dairy cows will benefit not only the environment, but may also improve the production efficiency.

Methane production can be reduced by feeding / nutrition measures or potentially permanently by breeding. Changes in diet composition may reduce methane production per unit feed by well over 60\% (McGinn et al., 2006). Cattle ingesting a highly digestible grass produced relatively less $\mathrm{CH}_{4}$ than those ingesting more fibrous forage (Blaxter and Clapperton, 1965; Benchaar et al., 2001). Through breeding the genetic variation in methane production between individuals is used to reduce methane emissions (Hegarty, 2004; Bell et al., 2010; De Haas et al., 2011). Animal selection with this individual variation could achieve 10-20\% reduction in the methane losses from dry matter during digestion (Waghorn et al., 2006). While nutritional manipulation and farm management can immediately reduce methane production, breeding has gained more research interests because of its inexpensive, cumulative, and permanent effects (De Haas et al., 2011).

To assess the effect of any methane mitigation method, including those related to breeding, we have to be capable of measuring methane production from dairy cows. Measurement methods should be convenient, practical, and economically feasible for a large number of individual cows under farm conditions. Although there are already several methods to 


\section{Summary}

measure methane production from dairy cows, none of the methods are flawless and application of the methods are limited either because of technical complexity and costs, or because of short sampling periods (Storm et al., 2012). New measurement techniques need to be developed to widen the options to measure the methane production from individual cows under farm conditions, and more insight is needed in the performance in terms of measurement uncertainty of existing measurement methods.

Given this, the main objective of this thesis is to design, test, and validate methods to determine or rank the methane production of individual dairy cows at farm house level. This thesis is subdivided as follows: a review on existing knowledge, measurement requirements, and methods to measure methane production of dairy cows (Chapter 2), characterisation of aerial conditions around cubicles in dairy barns and the implication of the accuracy of methane measurement methods (Chapter 3), design and test of a reference method that simulates the methane production of cows (Chapter 4), assessment of the performance of an existing breath concentration method (Chapter 5), and design and test of a methane flux method to assess the methane production of individual cows (Chapter 6). In the end, Chapter 7 summarizes the findings of Chapter 2 to 6 and discusses them a broader perspective. Recommendations are made for the future research.

In Chapter 2, we first summarized 14 requirements methane measurement methods should meet to assess effects of methane mitigation strategies. Then we reviewed existing measurement methods in three categories that differ in measurement principle: 1) flux 2) breath methane concentration 3) tracer gas ratio. Merits and drawbacks of the methods were evaluated and discussed against the requirements. Breath methane concentration methods are easy and low cost, but physiological differences between cows (e.g. variations of tidal volume between cows) and air flow patterns around sampling locations that differ between barns may introduce a systematic error on the measured methane concentration. The methane tracer gas method is not affected by these systematic sources, but has problems in determining tracer gas production (predicted $\mathrm{CO}_{2}$ production or controlled $\mathrm{SF}_{6}$ production). The GreenFeed method, being a farm implementation of a flux method, is currently the best available approach to measure methane production of individual cows in the farm. 
However, there is uncertainty about the representativeness of the results because methane production is measured only during short feed bin visits. This review study revealed that none of existing methods meet all requirements to evaluate the effects of methane mitigation methods. To measure methane production rates of individual cows under farm conditions, sampling of breath air during the lying period of cows in cubicles could be a practical direction. To rank cows in methane production rates, the $\mathrm{CH}_{4} / \mathrm{CO}_{2}$ ratio method is a promising method, but requires further research to assess its accuracy, especially with respect to the representativeness of the short sampling periods.

In Chapter 3, we assessed methane concentration levels and variations in time, and around cubicles, explored effects of barn and management factors on them, and assessed the effect of the variation of the background methane concentrations on assessing methane production of individual dairy cows in cubicles. Mean methane concentrations around the cubicle in a dairy barn varied between 29-37 ppm in the summer period and 33-51 ppm in the winter period. Spatial variations (CV) of methane concentration around the cubicle were $71 \%$ in the summer and $58 \%$ in the winter period. Temporal variations of methane concentration varied from 115 to $153 \%$ in the summer, and from 57 to $109 \%$ in the winter period among the sample locations around the cubicle. Variability of background methane concentration was then used to assess its potential impact on the accuracy of current methane measurement methods. Effects on accuracy were expressed in two theoretical equations. The measurement coefficient of variation (CV) of assessed methane production of individual cows decreased exponentially with a higher captured fraction of the breath in a concentration method, and increased linearly with higher flow rates in a flux method. The measurement $\mathrm{CV}$ was strongly positively influenced by the level and the variability of the measured background methane concentration in both the methane flux and the concentration method. This study provided essential information to apply both methane concentration and flux methods in dairy barns to assess methane production of individual cows in such a way that measurement $\mathrm{CV}$ of the assessed methane production can be limited. 


\section{Summary}

In Chapter 4, we designed and constructed an artificial reference cow (ARC). We built a device that simulated exhaling and inhaling cycles and eructation. The ARC consisted of a cylinder in which methane was injected by mass flow controllers and ejected by a piston in the cylinder. Average methane concentration in exhaled gas released by the ARC had a mean difference of $2.8 \%$ between measured and controlled levels. The slopes of the regression lines between methane mass input and output of the ARC did not differ from unity $(\mathrm{P}>0.01)$ at a breath frequency of 30 times per minute and tidal volume of $4.4 \mathrm{~L}$ and 6 L. Besides precisely controlling methane production at pre-set values, methane concentrations released by the ARC were controlled to fluctuate as sinusoidal cycles to mimic observed cow release patterns. Both time interval and methane concentration level of methane fluctuation cycles produced by the ARC were comparable to the methane fluctuation cycles measured from the real cows. Based on the ARC's performance characteristics, the ARC properly represented the methane production release, and that the system precisely controlled methane concentration and production. The ARC can be used as a known reference source to develop practical methane measurement methods.

In Chapter 5, we assessed assess the uncertainty of a breath methane concentration method in a feeder bin and its capability to measure and rank cows' methane production. We investigated their relation in a laboratory setup and in a barn setting with a milking robot, using the ARC as cow simulator. Measured methane concentrations of the simulated cows were positively related to pre-set methane production rates of the ARC. In the laboratory, source-sampling distances of 5 and $30 \mathrm{~cm}$ resulted in $\mathrm{R}^{2}$-values of 0.97 and 0.84 , and s.e. of $37 \mathrm{ppm}$ and $75 \mathrm{ppm}$ respectively. From the laboratory to the barn, at $30 \mathrm{~cm}$ sampling distance, $\mathrm{R}^{2}$-value decreased to 0.37 and s.e. increased to $86 \mathrm{ppm}$ as a result of barn air turbulence, the latter increasing to a theoretical $94 \mathrm{ppm}$ if the modeled variability of the cow's head movement was accounted for as well. In practice the effect of these random errors can be compensated by sampling strategies including repeated measurements on each cow over time, thus increasing the distinctive power between cows. However, systematic errors that may disturb the relation between concentration and production rate, like cow variation in air exhalation rate and air flow patterns around sampling locations that differ between barns, cannot be compensated by such repeated measurements. As a result, the 
methane concentrations of breath air will vary between cows with the same methane production rate. Given this, the capability of the breath concentration measurement method to adequately measure and rank methane production rates among cows is uncertain and requires further investigation into variation sources with a systematic nature.

In Chapter 6, we developed a cubicle hood sampler (CHS) that measures methane fluxes from lying cows in the cubicles. The methane recovery rate of the CHS was assessed under both laboratory and barn conditions with an artificial reference cow (ARC). The results showed that the methane recovery rate of the CHS in the laboratory was significantly affected by the hood type, extraction flow rate, presence of a top curtain, induced airflow, and extended side panels. The highest recovery (99.6\%) was achieved with a fume sample hood with a top curtain and the highest flow rates. In the barn, the CHS with a fume sample hood, a top curtain, extended side panels, and a hood flow of $200 \mathrm{~m}^{3} / \mathrm{h}$, captured $97.2 \%$ (s.d. 8.1) of the methane released by the ARC, regardless of the air velocity or the cow's nose positions. In the barn, standard errors of a single measurement were estimated to be 24.1 $\mathrm{g} /$ day at a hood flow rate of $200 \mathrm{~m}^{3} / \mathrm{h}$ with a measurement $\mathrm{CV}$ of $8.0 \%$, which is much smaller than measured in the breath concentration method (Chapter 5). Based on the CHS's performance characteristics, we concluded that this newly developed method is sufficiently accurate to measure methane production of individual cows in cubicles.

In Chapter 7, we discussed our main findings from Chapter 2 to 6 in a broader context. Current methane measurement methods were categorized into three measurement principles: (1) breath methane concentration methods; (2) tracer gas methods; and (3) methane flux methods. For each measurement principle, we formulated a general equation based on the working principle, and assessed the measurement error (random and systematic) of each measurement variable. The methane concentration method is simple and low cost, but cows' air exhalation rates may introduce systematic errors on measured methane concentration, which are the fundamental flaw of only using the methane concentration. Tracer gas methods are not subject to the systematic errors that are associated with the breath methane concentration method, and are more reliable in ranking cows on methane production than methane concentrations alone. The $\mathrm{CO}_{2}$-based tracer gas method is easier to operate than 


\section{Summary}

$\mathrm{SF}_{6}$-based methods and has lower costs than methane flux methods. However, the prediction uncertainty of individual cow $\mathrm{CO}_{2}$ production restricts its reliability. The methane flux method is currently the most accurate method to determine methane production rates. Most of the random error comes from the temporal and spatial variations of background methane concentration, but the system has no risk of bias. Directly ranking cows with the $\mathrm{CH}_{4} / \mathrm{CO}_{2}$ ratio could also be a promising direction. Besides, to mitigate methane production of dairy cows, methane measurement systems can also be used to sample and measure other gases released by cows for other applications, for instance, disease detection. 
References

\section{References}

\section{A}

Alford, a. R., R.S. Hegarty, P.F. Parnell, O.J. Cacho, R.M. Herd, and G.R. Griffith. 2006.

The impact of breeding to reduce residual feed intake on enteric methane emissions from the Australian beef industry. Aust. J. Exp. Agric. 46:813-820.

Arthur, P.F., J. a. Archer, D.J. Johnston, R.M. Herd, E.C. Richardson, and P.F. Parnell. 2001. Genetic and phenotypic variance and covariance components for feed intake, feed efficiency, and other postweaning traits in Angus cattle. J. Anim. Sci. 79:28052811.

Arthur, P.F., and R.M. Herd. 2005. Efficiency of feed utilisation by livestock Implications and benefits of genetic improvement. Can. J. Anim. Sci. 85:281-290.

Aulick, L.H., H. Arnhold, E.H. Hander, and a D. Mason. 1983. A new open and closed respiration chamber. Q. J. Exp. Physiol. 68:351-357.

\section{B}

Bannink, A., M.W. van Schijndel, and J. Dijkstra. 2011. A model of enteric fermentation in dairy cows to estimate methane emission for the Dutch National Inventory Report using the IPCC Tier 3 approach. Anim. Feed Sci. Technol. 166-167:603-618.

Beauchemin, K. a., M. Kreuzer, F. O’Mara, and T. a. McAllister. 2008. Nutritional management for enteric methane abatement: A review. Aust. J. Exp. Agric. 48:21-27.

Bell, M.J., N. Saunders, R.H. Wilcox, E.M. Homer, J.R. Goodman, J. Craigon, and P.C. Garnsworthy. 2014. Methane emissions among individual dairy cows during milking quantified by eructation peaks or ratio with carbon dioxide. J. Dairy Sci. 97:65366546.

Bell, M.J., E. Wall, G. Russell, C. Morgan, and G. Simm. 2010. Effect of breeding for milk yield, diet and management on enteric methane emissions from dairy cows. Anim. Prod. Sci. 50:817-826.

Benchaar, C., C. Pomar, and J. Chiquette. 2001. Evaluation of dietary strategies to reduce methane production in ruminants: A modelling approach. Can. J. Anim. Sci. 81:563574.

Bjerg, B., G. Zhang, J. Madsen, and H.B. Rom. 2012. Methane emission from naturally ventilated livestock buildings can be determined from gas concentration measurements. Environ. Monit. Assess. 184:5989-6000.

Blaxter, K.L., J.M. Brockway, and A.W. Boyne. 1972. A new method for estimating the heat production of animals. Q. J. Exp. Physiol. 57:60-72.

Blaxter, K.L., and J.L. Clapperton. 1965. Prediction of the amount of methane produced by 


\section{References}

ruminants. Br. J. Nutr. 19:511-522.

Boadi, D. a., K.M. Wittenberg, and a. D. Kennedy. 2002. Validaton of the sulphur hexafluoride (SF6) Tracer Gas Technique for Measurement of Methane and Carbon Dioxide Production By Cattle. Can. J. Anim. Sci. 82:125-131.

Boadi, D., C. Benchaar, J. Chiquette, and D. Massé. 2004. Mitigation strategies to reduce enteric methane emissions from dairy cows: Update review. Can. J. Anim. Sci. 84:319-335.

C

Calvet, S., R. Gates, and G. Zhang. 2013. Measuring gas emissions from livestock buildings: a review on uncertainty analysis and error sources. Biosyst. Eng. 116:221231.

Chagunda, M.G.G., D. Ross, and D.J. Roberts. 2009. On the use of a laser methane detector in dairy cows. Comput. Electron. Agric. 68:157-160.

Chagunda, M.G.G., and T. Yan. 2011. Do methane measurements from a laser detector and an indirect open-circuit respiration calorimetric chamber agree sufficiently closely? Anim. Feed Sci. Technol. 165:8-14.

CIGR. 1984. Climatization of animal houses. CIGR. Scottish Farm Building Investigation Unit, Craibston, Scotland.

CIGR. 1992. Climatization of animal houses. CIGR. Faculty of Agricultural Sciences, State University of Ghent, Belgium.

CIGR. 2002. Climatization of Animal Houses. Forth report of working group. Danish Institute of Agricultural Sciences, Research Centre Bygholm.

C-lock. 2014. Greenfeed system. C-lock inc. Retrieved October 22, 2014, from http://clockinc.com/introduction.php.

Cottle, D.J., J. V. Nolan, and S.G. Wiedemann. 2011. Ruminant enteric methane mitigation: A review. Anim. Prod. Sci. 51:491-514.

Cross, N. 2008. Engineering Design Methods: Strategies for Product Design. 4th ed. WILEY, New Jersey, USA.

D

De Haas, Y., J.J. Windig, M.P.L. Calus, J. Dijkstra, M. De Haan, A. Bannink, and R.F. Veerkamp. 2011. Genetic parameters for predicted methane production and potential for reducing enteric emissions through genomic selection. J. Dairy Sci. 94:6122-34.

DeRamus, H.A., T.C. Clement, D.D. Giampola, and P.C. Dickison. 2003. Methane emissions of beef cattle on forages: efficiency of grazing management systems. $J$. Environ. Qual. 32:269-277.

Derno, M., H.-G. Elsner, E. Paetow, H. Scholze, and M. Schweigel. 2009. Technical note: a new facility for continuous respiration measurements in lactating cows. J. Dairy Sci. 
References

92:2804-2808.

Dorich, C.D., R.K. Varner, a. B.D. Pereira, R. Martineau, K.J. Soder, and a. F. Brito. 2015. Short communication: Use of a portable, automated, open-circuit gas quantification system and the sulfur hexafluoride tracer technique for measuring enteric methane emissions in Holstein cows fed ad libitum or restricted. J. Dairy Sci. 98:2676-2681.

$\mathbf{E}$

Eckard, R.J., C. Grainger, and C. a M. de Klein. 2010. Options for the abatement of methane and nitrous oxide from ruminant production: A review. Livest. Sci. 130:4756.

Ellis, J., A. Bannink, and I. Hindrichsen. 2016. The effect of lactic acid bacteria included as a probiotic or silage inoculant on in vitro rumen digestibility, total gas and methane production. Anim. Feed Sci. Technol. 211:61-74.

Ellis, J.L., J. Dijkstra, E. Kebreab, a. Bannink, N.E. Odongo, B.W. McBRIDE, and J. France. 2008. Aspects of rumen microbiology central to mechanistic modelling of methane production in cattle. J. Agric. Sci. 146:213-233.

Even, P.C., A. Mokhtarian, and A. Pele. 1994. Practical aspects of indirect calorimetry in laboratory animals. Neurosci. Biobehav. Rev. 18:435-447.

F

FAO. 2010. Greenhouse gas emissions from the dairy sector. Rome, Italy.

\section{G}

Gallivan, G.J., W.N. McDonell, and J.B. Forrest. 1989a. Comparative ventilation and gas exchange in the horse and the cow. Res. Vet. Sci. 46:331-336.

Gallivan, G.J., W.N. McDonell, and J.B. Forrest. 1989b. Comparative pulmonary mechanics in the horse and the cow. Res. Vet. Sci. 46:322-330.

Gallivan, G.J., L. Viel, J.D. Baird, and W.N. McDonell. 1991. Pulmonary structure and function in adult dairy cows with an expanded lung field. Can. J. Vet. Res. 55:15-20.

Gardiner, T.D., M.D. Coleman, F. Innocenti, J. Tompkins, a. Connor, P.C. Garnsworthy, J.M. Moorby, C.K. Reynolds, a. Waterhouse, and D. Wills. 2015. Determination of the absolute accuracy of UK chamber facilities used in measuring methane emissions from livestock. Measurement. 66:272-279.

Garnsworthy, P.C. 2005. Methane emissions by individual dairy cows under commercial conditions. 5. 1-21 pp.

Garnsworthy, P.C., J. Craigon, J.H. Hernandez-Medrano, and N. Saunders. 2012a. On-farm methane measurements during milking correlate with total methane production by individual dairy cows. J. Dairy Sci. 95:3166-80.

Garnsworthy, P.C., J. Craigon, J.H. Hernandez-Medrano, and N. Saunders. 2012b. Variation among individual dairy cows in methane measurements made on farm 


\section{References}

during milking. J. Dairy Sci. 95:3181-9.

Gerber, P., T. Vellinga, C. Opio, B. Henderson, and H. Steinfeld. 2010. Greenhouse Gas Emissions from the Dairy Sector a Life Cycle Assessment. Food and Agriculture Organization Of The United Nations, Animal Production and Health Division, Rome, Italy. 32-33 pp.

Gerber, P.J., H. Steinfeld, B. Henderson, A. Mottet, C. Opio, J. Dijkman, A. Falcucci, and G. Tempio. 2013. Tackling climate change through livestock - A global assessment of emissions and mitigation opportunities. Rome, Italy.

Grainger, C., T. Clarke, S.M. McGinn, M.J. Auldist, K. a Beauchemin, M.C. Hannah, G.C. Waghorn, H. Clark, and R.J. Eckard. 2007. Methane emissions from dairy cows measured using the sulfur hexafluoride (SF6) tracer and chamber techniques. J. Dairy Sci. 90:2755-2766.

Groot Koerkamp, P.W.G., J.H.M. Metz, G.H. Uenk, V.R. Phillips, M.R. Holden, R.W. Sneath, J.L. Short, R.P.P. White, J. Hartung, J. Seedorf, M. Schröder, K.H. Linkert, S. Pedersen, H. Takai, J.O. Johnsen, and C.M. Wathes. 1998. Concentrations and Emissions of Ammonia in Livestock Buildings in Northern Europe. J. Agric. Eng. Res. 70:79-95.

Guan, L.L., J.D. Nkrumah, J. a. Basarab, and S.S. Moore. 2008. Linkage of microbial ecology to phenotype: Correlation of rumen microbial ecology to cattle's feed efficiency. FEMS Microbiol. Lett. 288:85-91.

\section{$\mathbf{H}$}

Hafez, E.S.E., and M.F. Bouissou. 1975. The behaviour of cattle. 3rd ed. Bailliere Tindall, London.

Hammond, K.J., D.J. Humphries, L. a. Crompton, C. Green, and C.K. Reynolds. 2015. Methane emissions from cattle: Estimates from short-term measurements using a GreenFeed system compared with measurements obtained using respiration chambers or sulphur hexafluoride tracer. Anim. Feed Sci. Technol. 203:41-52.

Haque, M.N., C. Cornou, and J. Madsen. 2014. Estimation of methane emission using the $\mathrm{CO} 2$ method from dairy cows fed concentrate with different carbohydrate compositions in automatic milking system. Livest. Sci. 164:57-66.

Hegarty, R.S. 2004. Genotype differences and their impact on digestive tract function of ruminants: a review. Aust. J. Exp. Agric. 44:459.

Hegarty, R.S. 2013. Applicability of short-term emission measurements for on-farm quantification of enteric methane. Animal. 7 Suppl 2:401-8.

Hegarty, R.S., J.P. Goopy, R.M. Herd, and B. McCorkell. 2007. Cattle selected for lower residual feed intake have reduced daily methane production. J. Anim. Sci. 85:14791486.

Hegarty, R.S., and J.C. McEwan. 2010. Genetic Opportunities to Reduce Enteric Methane 


\section{References}

Emissions from Ruminant Livestock. Proc. 9th World Congr. Genet. Appl. to Livest. Prod.

Hellwing, a L.F., P. Lund, M.R. Weisbjerg, M. Brask, and T. Hvelplund. 2012. Technical note: test of a low-cost and animal-friendly system for measuring methane emissions from dairy cows. J. Dairy Sci. 95:6077-85.

Hellwing, A., and P. Lund. 2013. Comparison of enteric methane production predicted from the $\mathrm{CH} 4 / \mathrm{CO} 2$ ratio and measured in respiration chambers. Adv. Anim. Biosci. 4:557.

Henderson, G., F. Cox, and S. Ganesh. 2015. Rumen microbial community composition varies with diet and host, but a core microbiome is found across a wide geographical range. Sci. Rep.

Holter, J., and A. Young. 1992. Methane prediction in dry and lactating Holstein cows. J. Dairy Sci.

Hristov, A., J. Oh, and J. Firkins. 2013a. Special Topics-mitigation of methane and nitrous oxide emissions from animal operations: I. A review of enteric methane mitigation options. J. Anim. Sci. 91:5045-5069.

Hristov, A., T. Ott, and J. Tricarico. 2013b. SPECIAL TOPICS-Mitigation of methane and nitrous oxide emissions from animal operations: III. A review of animal management mitigation options. J. Anim. Sci. 91:5059-5113.

Huhtanen, P., E.H. Cabezas-Garcia, S. Utsumi, and S. Zimmerman. 2015. Comparison of methods to determine methane emissions from dairy cows in farm conditions. $J$. Dairy Sci. 98:3394-3409.

Huhtanen, P., S. Krizsan, and E. Garcia. 2013. Repeatability and between cow variability of enteric $\mathrm{CH} 4$ and total $\mathrm{CO} 2$ emissions. Adv. Anim. Biosci.

\section{$\mathbf{J}$}

Johnson, D., P. HW, and A. Seidl. 2002. Methane, nitrous oxide and carbon dioxide emissions from ruminant livestock production systems. Greenh. gases Anim. Agric.

Johnson, K. a, and D.E. Johnson. 1995. Methane emissions from cattle. J. Anim. Sci. 2483 2492.

Johnson, K., M. Huyler, H. Westberg, B. Lamb, and P. Zimmerman. 1994. Measurement of methane emissions from ruminant livestock using a sulfur hexafluoride tracer technique. Environ. Sci. Technol. 28:359-362.

Joo, H.S.S., P.M.M. Ndegwa, a. J.J. Heber, J.-Q. Ni, B.W.W. Bogan, J.C.C. RamirezDorronsoro, and E. Cortus. 2015. Greenhouse gas emissions from naturally ventilated freestall dairy barns. Atmos. Environ. 102:384-392.

Jordan, E., D.K. Lovett, M. Hawkins, J.J. Callan, and F.P. O’Mara. 2006. The effect of varying levels of coconut oil on intake, digestibility and methane output from continental cross beef heifers. Anim. Sci. 82:859. 


\section{References}

Jungbluth, T., E. Hartung, and G. Brose. 2001. Greenhouse gas emissions from animal houses and manure stores. Nutr. Cycl. Agroecosystems. 60:133-145.

$\mathbf{K}$

Kaharabata, S.K., P.H. Schuepp, and R.L. Desjardins. 2000. Estimating methane emissions from dairy cattle housed in a barn and feedlot using an atmospheric tracer. Environ. Sci. Technol. 34:3296-3302.

Knapp, J., G. Laur, and P. Vadas. 2014. Invited review: Enteric methane in dairy cattle production: Quantifying the opportunities and impact of reducing emissions. $J$. dairy ....

Kurihara, M., T. Magner, R. a Hunter, and G.J. McCrabb. 1999. Methane production and energy partition of cattle in the tropics. Br. J. Nutr. 81:227-234.

$\mathbf{L}$

Lassen, J., P. Løvendahl, and J. Madsen. 2012. Accuracy of noninvasive breath methane measurements using Fourier transform infrared methods on individual cows. J. Dairy Sci. 95:890-8.

Lassey, K.R. 2007. Livestock methane emission: From the individual grazing animal through national inventories to the global methane cycle. Agric. For. Meteorol. 142:120-132.

Lassey, K.R., C.S. Pinares-Patiño, R.J. Martin, G. Molano, and a. M.S. McMillan. 2011. Enteric methane emission rates determined by the SF6 tracer technique: Temporal patterns and averaging periods. Anim. Feed Sci. Technol. 166-167:183-191.

Lassey, K.R., M.J. Ulyatt, R.J. Martin, C.F. Walker, and I.D. Shelton. 1997. Methane emissions measured directly from grazing livestock in New Zealand. Atmos. Environ. 31:2905-2914.

\section{M}

Madsen, J., B.S. Bjerg, T. Hvelplund, M.R. Weisbjerg, and P. Lund. 2010. Methane and carbon dioxide ratio in excreted air for quantification of the methane production from ruminants. Livest. Sci. 129:223-227.

Maia, G.D.N., B.C. Ramirez, A.R. Green, L.F. Rodriguez, J.R. Segers, D.W. Shike, and R.S. Gates. 2015. A Novel Ruminant Emission Measurement System: Part I. Design Evaluation and Description. Trans. ASABE. 58:749-762.

Marik, T., and I. Levin. 1996. A new tracer experiment to estimate the methane emissions from a dairy cow shed using sulfur hexafiuoride (SF6). Glob. Biogeochem. CYCLES 10:413-418.

Martin, C., D.P. Morgavi, and M. Doreau. 2010. Methane mitigation in ruminants: from microbe to the farm scale. Animal. 4:351.

Mc Court, a., T. Yan, C.S. Mayne, and M.G. Porter. 2006. Prediction of methane output in 
beef cattle from indirect respiration calorimetry data. Int. Congr. Ser. 1293:46-49.

McGinn, S.M., K. a Beauchemin, a D. Iwaasa, and T. a McAllister. 2006a. Assessment of the sulfur hexafluoride (SF6) tracer technique for measuring enteric methane emissions from cattle. J. Environ. Qual. 35:1686-1691.

McGinn, S.M., T.K. Flesch, L. a Harper, and K. a Beauchemin. 2006b. An approach for measuring methane emissions from whole farms. J. Environ. Qual. 35:14-20.

Middelaar, C. Van, and J. Dijkstra. 2014. Cost-effectiveness of feeding strategies to reduce greenhouse gas emissions from dairy farming. J. Dairy Sci. 97:2427-2439.

Miller, W.H., and R.M. Koes. 1988. Construction and operation of an open-circut indirect calorimetry system for small ruminants. J. Anim. Sci. 66:1042-1047.

Moss, A.R., J. Jouany, and J. Newbold. 2000. Methane production by ruminants: its contribution to global warming (Review article). Ann. Zootech. 49:231-253.

Münger, a., and M. Kreuzer. 2008. Absence of persistent methane emission differences in three breeds of dairy cows. Aust. J. Exp. Agric. 48:77-82.

Murray, P.J., a. Moss, D.R. Lockyer, and S.C. Jarvis. 1999. A comparison of systems for measuring methane emissions from sheep. J. Agric. Sci. 133:439-444.

Murray, R.M., a M. Bryant, and R. a Leng. 1976. Rates of production of methane in the rumen and large intestine of sheep. Br. J. Nutr. 36:1-14.

Myhre, G., D. Shindell, F.-M. Bréon, W. Collins, J. Fuglestvedt, J. Huang, D. Koch, J.-F. Lamarque, D. Lee, B. Mendoza, T. Nakajima, A. Robock, G. Stephens, T. Takemura, and H. Zhang. 2013. Anthropogenic and natural radiative forcing. In Climate Change 2013: The Physical Science Basis. Contribution of Working Group I to the Fifth Assessment Report of the Intergovernmental Panel on Climate Change. Cambridge University Press, Cambridge, United Kingdom and New York, NY, USA.

$\mathbf{N}$

Ngwabie, N.M., K.H. Jeppsson, G. Gustafsson, and S. Nimmermark. 2011. Effects of animal activity and air temperature on methane and ammonia emissions from a naturally ventilated building for dairy cows. Atmos. Environ. 45:6760-6768.

Ngwabie, N.M., K.H. Jeppsson, S. Nimmermark, C. Swensson, and G. Gustafsson. 2009. Multi-location measurements of greenhouse gases and emission rates of methane and ammonia from a naturally-ventilated barn for dairy cows. Biosyst. Eng. 103:68-77.

Ngwabie, N.M., A. Vanderzaag, S. Jayasundara, and C. Wagner-Riddle. 2014. Measurements of emission factors from a naturally ventilated commercial barn for dairy cows in a cold climate. Biosyst. Eng. 127:103-114.

\section{$\mathbf{O}$}

Ogink, N.W.M., R.E. Crump, Y. De Haas, J. Mosquera Losada, A. Bannink, and J. Dijkstra. 2012. Individual methane recordings in dairy cattle. Lelystad. 24 pp. 


\section{References}

Okine, E., J. Basarab, V. Baron, and M. Price. 2001. Net feed efficiency in young growing cattle: III. Relationships to methane and manure production. Can. J. Anim. Sci.

$\mathbf{P}$

Pedersen, S., V. Blanes-Vidal, H. Joergensen, A. Chwalibog, A. Haeussermann, M.J.W. Heetkamp, and A.J.A. Aarnink. 2008. Carbon Dioxide Production in Animal Houses: A literature review. Agric. Eng. Int. CIGR Ejournal. X:1-19.

Pedersen, S., H. Takai, J.O. Johnsen, J.H.M. Metz, P.W.G. Groot Koerkamp, G.H. Uenk, V.R. Phillips, M.R. Holden, R.W. Sneath, J.L. Short, R.P. White, J. Hartung, J. Seedorf, M. Schröder, K.H.H. Linkert, and C.M. Wathes. 1998. A Comparison of Three Balance Methods for Calculating Ventilation Rates in Livestock Buildings. $J$. Agric. Eng. Res. 70:25-37.

Pereira, J., D. Fangueiro, T.H. Misselbrook, D.R. Chadwick, J. Coutinho, and H. Trindade. 2011. Ammonia and greenhouse gas emissions from slatted and solid floors in dairy cattle houses: A scale model study. Biosyst. Eng. 109:148-157.

Pinares-Patiño, C.S., and H. Clark. 2008. Reliability of the sulfur hexafluoride tracer technique for methane emission measurement from individual animals: An overview. Aust. J. Exp. Agric. 48:223-229.

Pinares-Patiño, C.S., and S. Hickey. 2013. Heritability estimates of methane emissions from sheep. Animal. 7:316-321.

Pinares-Patiño, C.S., a. Machmüller, G. Molano, a. Smith, J.B. Vlaming, and H. Clark. 2008. The SF6 tracer technique for measurements of methane emission from cattleeffect of tracer permeation rate. Can. J. Anim. Sci. 88:309-320.

Pinares-Patiño, C.S., and G.C. Waghorn. 2012. Evaluation of the greenfeed methane measurement system.

Place, S.E., Y. Pan, Y. Zhao, and F.M. Mitloehner. 2011. Construction and operation of a ventilated hood system for measuring greenhouse gas and volatile organic compound emissions from cattle. Animals. 1:433-446.

$\mathbf{R}$

Rosenbaum, B.J., D.L. Makoff, and L.J. Mills. 1969. A metabolic-environmental chamber for the study of unusual breathing atmospheres. J. Appl. Physiol. 27:892-894.

$\mathbf{S}$

Saha, C.K., C. Ammon, W. Berg, M. Fiedler, C. Loebsin, P. Sanftleben, R. Brunsch, and T. Amon. 2014. Seasonal and diel variations of ammonia and methane emissions from a naturally ventilated dairy building and the associated factors influencing emissions. Sci. Total Environ. 468-469:53-62.

Sejian, V., R. Lal, J. Lakritz, and T. Ezeji. 2011. Measurement and prediction of enteric methane emission. Int. J. Biometeorol. 55:1-16. 
Steinfeld, H., P. Gerber, T. Wassenaar, V. Castel, M. Rosales, and C. De Haan. 2006. Livestock's long shadow: environmental issues and options. Rome, Italy.

Stevens, D.G. 1981. A Model of Respiratory Vapor Loss in Holstein Dairy Cattle. Trans. ASABE. 24:151-154.

Storm, I.M.L.D., A.L.F. Hellwing, N.I. Nielsen, and J. Madsen. 2012. Methods for measuring and estimating methane emission from ruminants. Animals. 2:160-183.

Suzuki, T., I. Phaowphaisal, P. Pholsen, R. Narmsilee, S. Indramanee, P. Nitipot, A. Chaokaur, K. Sommart, N. Khotprom, V. Panichpol, and T. Nishida. 2008. In vivo nutritive value of Pangola grass (Digitaria eriantha) hay by a novel indirect calorimeter with a ventilated hood in Thailand. Japan Agric. Res. Q. 42:123-129.

$\mathbf{U}$

Ulyatt, M.J., S.K. Baker, G.J. McCrabb, and K.R. Lassey. 1999. Accuracy of SF6 tracer technology and alternatives for field measurements. Aust. J. Agric. Res. 50:13291334.

UNFCC. 1997. Kyoto Protocol. In United Nations Framework Convention on Climate Change. Kyoto, Japan.

UNFCC. 2016. Paris Agreement. Eur. Comm. Retrieved January 25, 2016, from http://ec.europa.eu/clima/policies/international/negotiations/future/index_en.htm.

V

van Zijderveld, S.M., B. Fonken, J. Dijkstra, W.J.J. Gerrits, H.B. Perdok, W. Fokkink, and J.R. Newbold. 2011. Effects of a combination of feed additives on methane production, diet digestibility, and animal performance in lactating dairy cows. $J$. Dairy Sci. 94:1445-1454.

Vlaming, J.B. 2008. Quantifying variation in estimated methane emission from ruminants using the SF6 tracer technique. Thesis.

Vlaming, J.B., N. Lopez-Villalobos, I.M. Brookes, S.O. Hoskin, and H. Clark. 2008. Within- and between-animal variance in methane emissions in non-lactating dairy cows. Aust. J. Exp. Agric. 48:124-127.

W

Waghorn, G.C., and R.S. Hegarty. 2011a. Lowering ruminant methane emissions through improved feed conversion efficiency. Anim. Feed Sci. Technol. 166-167:291-301.

Waghorn, G.C., and R.S. Hegarty. 2011b. Lowering ruminant methane emissions through improved feed conversion efficiency. Anim. Feed Sci. Technol. 166-167:291-301.

Waghorn, G.C., S.L. Woodward, M. Tavendale, and D. a. Clark. 2006. Inconsistencies in rumen methane production-effects of forage composition and animal genotype. Int. Congr. Ser. 1293:115-118.

Williams, S.R.O., P.J. Moate, M.C. Hannah, B.E. Ribaux, W.J. Wales, and R.J. Eckard. 


\section{References}

2011a. Background matters with the SF6 tracer method for estimating enteric methane emissions from dairy cows: A critical evaluation of the SF6 procedure. Anim. Feed Sci. Technol. 170:265-276.

Williams, Y.J., J.E. Pryce, C. Grainger, W.J. Wales, N. Linden, M. Porker, and B.J. Hayes. 2011b. Variation in residual feed intake in Holstein-Friesian dairy heifers in southern Australia. J. Dairy Sci. 94:4715-4725.

Wu, L., P.W.G. Groot Koerkamp, and N.W.M. Ogink. 2015. Design and test of an artificial reference cow to simulate methane release through exhalation. Biosyst. Eng. 136:3950.

Wu, L., P. W. G. G. Koerkamp, and N. W. M. Ogink. 2016a. Design and performance evaluation of a methane flux measurement method for dairy cows in cubicles. Unpublished.

Wu, L., P. W. G. G. Koerkamp, and N. W. M. Ogink. 2016b. Uncertainty assessment of a breath methane concentration method to determine methane production of dairy cows. Unpublished.

Wu, W., G. Zhang, and P. Kai. 2012. Ammonia and methane emissions from two naturally ventilated dairy cattle buildings and the influence of climatic factors on ammonia emissions. Atmos. Environ. 61:232-243.

\section{Y}

Yan, T., C.S. Mayne, F.G. Gordon, M.G. Porter, R.E. Agnew, D.C. Patterson, C.P. Ferris, and D.J. Kilpatrick. 2010. Mitigation of enteric methane emissions through improving efficiency of energy utilization and productivity in lactating dairy cows. $J$. Dairy Sci. 93:2630-2638.

Young, B. a., B. Kerrigan, and R.J. Christopherson. 1975. a Versatile Respiratory Pattern Analyzer for Studies of Energy Metabolism of Livestock. Can. J. Anim. Sci. 55:1722.

$\mathbf{Z}$

Zhang, G., J.S. Strøm, B. Li, H.B. Rom, S. Morsing, P. Dahl, and C. Wang. 2005. Emission of ammonia and other contaminant gases from naturally ventilated dairy cattle buildings. Biosyst. Eng. 92:355-364. 
Acknowledgements

\section{Acknowledgements}

First and foremost, I am very grateful to my promoter, Prof. Peter W.G. Groot Koerkamp, for bringing me to Wageningen and training me as an independent researcher. Normally, the promoter only partly joins discussion with PhDs, but Peter always managed to join almost all meetings with me. It is always fruitful to discuss with him every time. His constructive thoughts and creative ideas inspire me to explore different possibilities in the project. His critical comments significantly improved the quality of the manuscript. Peter is not only my scientific mentor feeding my academic knowledge, but also my friend caring for my life in Wageningen. I have talked this story many times to my friends, but I would like to say it here again. Peter picked me up from the airport, prepared food, and arranged my living when I arrived the Netherlands. Peter also remembers my birthday and sends greeting to me every year. For everything he has done makes me feel at home and makes life much easier in Wageningen.

I am deeply grateful to my daily supervisor, Dr Nico Ogink, for his wholeheartedly supports in my $\mathrm{PhD}$ study. I still feel very lucky to choose this $\mathrm{PhD}$ topic so I could be guided by Nico. He gives freedom to try my ideas and respects to any of my thoughts. I can always directly go to his office once I have problems, and he always discussed and solved problems together with me. His expertise and wide knowledge greatly helped me to successfully finish this PhD thesis. Nico did not only teach me how to do science, but he also influences my living style. I learned to be always optimistic because of all the time smiles on his face and his sense of humour. Thanks to Nico, I started to run and enjoy classic music. Thanks for inviting me to your concerts in OBK. I also would like to thank his wife for the warmly invitations and hospitality.

I wish to express my profound appreciation to my colleagues at the Farm Technology Group. They are Eldert van Henten, Sam Blaauw, Fran Helderman, Jan Willem Hofstee, Willem Hoogmoed, Joris IJsselmuiden, Simon van mourik, Bert van 't Ooster, Hanneke Pome, Peter van Beveren, Monique Mul, Dennis Snoek, Hyun Suh, Bastiaan Vroegindeweij, Wouter Bac, Xiangyu Song, Shuo Yin, Phuong Vu, Ellen van Weeghel, 


\section{Acknowledgements}

Andres Schlageter, Miranda Tap, and Myriam Zwartkruis-Klaassen. It is been a great experience to work with them in this solidarity group. I would never forget every talk, discussion, and debating with them in group meetings, coffee breaks lunch, $\mathrm{PhD}$ dinners, and Friday afternoon drinks. Special thanks to Dennis Snoek for being my travel companion in our trips in Denmark and China, his selfless help, and invitation and hospitality in my first bachelor party and your wedding party, Bastiaan Vroegindeweij for his dedicated support for my $\mathrm{PhD}$ research, Peter van Beveren for his help on the evaluation model, enjoying drinks and movies, and working together on Sunday, Hyun Suh for your selfless help and inspiring talks, Sam Blaauw for helping me to solve all my computer problems, Willem Hoogmoed and his wife for the warmly invitations and hospitality.

To the Livestoch Research group: I also would like to express my gratitude to the people in Wageningen Livestock Research institute because I have done most of my experiment there. I am deeply indebted to Johan Ploegaert. Johan has worked together with me in most of my experiments. He always patiently explained all details to me about the measurement sensors and was willing to share all his experience with me. I really enjoyed working with him in the lab and my research could not be done without his help. Thanks also to Johan's girlfriend for the warmly invitations and hospitality. Besides Johan, the other technicians Annemieke Hol, Jos Huis in 't Veld, Eef Lovink, and Guus Nijeboer also contributed a lot to my experiments. I also wish to thank other people from Livestock Research Centre. They are Andre Aarnink, Hendrik Jan van Dooren, Karin Groenestein, Roland Melse, Julio Mosquera Losada, and Dick Starmans.

I would like to give special thanks to Yvette de Haas and Jan Dijkstra for their help in editing and review the second Chapter of the thesis. Also I like to thank two of my students: Cornelis Cnossen and Coen Uijterlinde for their contribution to my research. Cornelis Cnossen did his master thesis with me. His hard work and creative thoughts made the cubicle hood sampler (CHS) to successfully capture the released methane from dairy cows. Coen Uijterlinde did his bachelor thesis with me on the barn testing of the CHS. It was quite intensive work and he successfully helped me to collect sufficient data. 


\section{Acknowledgements}

Friends make life much easier, especially when you live in a foreign country. I would like to thank all my friends for the company in my PhD life. Special thanks to Junqi Zhu, Junfei Gu, Yang Yu, Fang Gou, Wenfeng Cong, Yingying Jing, Xinxin Wang, Guohua Li, Tao Li, Chuchu, Liu, Jingmeng Wang, Qian Liu, Bin Chen, Ou Xiang, Yunyu, Pan, Junyu Xu, Zhaohai Bai, Weijie Guo, Linlin Qin, Zhixiong Lu, Mingtian Yao, Vivi He, Chidu Huang, Yong Hou, Qin Wei, Kailei Tang, Tian Zeng, Lin Ma, Xin Jin, Luciano Mendes, Nadège Edouard, Michael Bischoff, Bart Knol, Nadia Vendrig, Xander Zaaiman, Kit Tang, Nick Heijmink, Giorgos Ntinas, Andrea Lehotayová, Jorge LLoru, Marieke Vroegindeweij, Eveline Hooft van Huysduynen, Ries Verkerk, Willem van Ommeren, and many others that I might forget to mention here. Thanks for your company that made my $\mathrm{PhD}$ journey colourful and joyful.

This study would not have possible without the financial support of Wageningen UR Livestock Research, the Ministry of Economic Affairs of the Netherlands (Research Programme Sustainable Agriculture), and the China Scholarship Council. I gratefully acknowledge the support from these funds to cover my research and living expenses.

Last but not least, I would like to thanks my parents. Thanks for their continuous love and support. Unlike other most Chinese parents, they supported every decision I have made and always encouraged me once I was frustrated. I could not smoothly study and live in the Netherlands without every week talk with them. Thanks, mom and dad! 



\section{Publication list}

\section{Peer-reviewed paper}

Wu, L., Groot Koerkamp, P. W. G., \& Ogink, N. W. M. (2015). Design and test of an artificial reference cow to simulate methane release through exhalation. Biosystems Engineering, 136, 39-50.

Wu, L., Groot Koerkamp, P. W. G., \& Ogink, N. W. M. (2015). Performance assessment of breath methane measurements with an artificial reference cow. Submitted to Journal of Dairy Science.

Wu, L., Groot Koerkamp, P. W. G., \& Ogink, N. W. M. (2016). Temporal and spatial variation of methane concentrations around lying cubicles in dairy barns. Submitted to Biosystems Engineering.

\section{Coference paper}

Wu, L., ZhengXiang, S., ChaoYuan, W., XiaoYan, Y., JiFeng, Z., \& others. (2012). Experimental study on a partial cooling system using underground water for open dairy bull barns. The Ninth International Livestock Environment Symposium (ILES IX). International Conference of Agricultural Engineering-CIGR-AgEng 2012: Agriculture and Engineering for a Healthier Life, Valencia, Spain, 8-12 July 2012, $\mathrm{P}-0767$.

Wu, L., \& Groot Koerkamp, P. (2013). Temporal and spatial variation of $\mathrm{CH}_{4}$ and $\mathrm{CO}_{2}$ concentrations in and around lying cubicles of dairy barns. Advances in Animal Biosciences, 4, 378.

Wu, L., Groot Koerkamp, P. W. G., \& Ogink, N.W.M. (2014). Design and test of an artificial reference cow to simulate methane production. In Proceedings International Conference of Agricultural Engineering. Zurich, Switzerland, 2014, 370, pp. 1-8.

Wu, L., Groot Koerkamp, P.W.G., \& Ogink, N.W.M. (2014). Assessment of the relation between methane concentrations and the methane flux of an artificial reference cow. In Book of Abstracts18th World Congress of CIGR.

Groot Koerkamp, P. W. G., Snoek, J. W., \& Wu, L. (2014). Design and evaluation of strategies for integrated manure management to reduce environmental impact. In Book of Abstracts18th World Congress of CIGR.

Wu, L., Groot Koerkamp, P. W. G., \& Ogink, N.W.M. (2015). Design and validation of an artificial reference cow for breath measurements of cows in the cubicles. International Symposium on Animal Environment \& Welfare. Oct. 23-26, 2015, Chongqing, China. 



\section{Training and Supervision Plan}

\section{The Basic Package (3 credits)}

- WIAS Introduction Course (2011)

- $\quad$ Course on philosophy of science and/or ethics (2012)

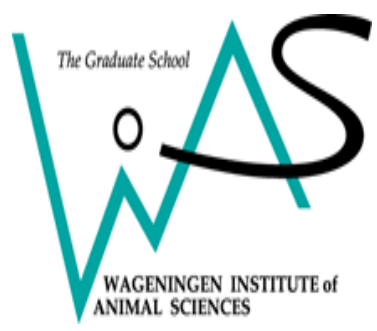

\section{Scientific Exposure (10 credits)}

\section{International conferences}

- International conference of Agricultural Engineering, Zurich, Switzerland, July 610 (2014)

- The XVIII CIGR World Congress 2014 on Agricultural \& Biosystems Engineering, Beijing, China, Sep 16-19 (2014)

- International Symposium on Animal Environment and Welfare, ISAEW, Chongqiang, China, Oct 23-25 (2015)

Seminars and workshops

- Solutions for climate change from animal production, Zodiac, Wageningen, 13 June (2014)

- $\quad$ WIAS Science Day, Wageningen, April 30 (2014)

- $\quad$ COST-Methagene workshop, Wageningen, Oct 7-8 (2015)

\section{Presentations}

- Temporal and spatial variation of $\mathrm{CH}_{4}$ and $\mathrm{CO}_{2}$ concentrations in and around lying cubicles of dairy barns, Dublin, June 24, poster (2012)

- Experimental study on a partial cooling system using underground water for open dairy bull barns, Valencia, July 8, poster (2013)

- Design and test of an artificial reference cow to simulate methane production, Zurich, July 6, poster (2014) 
Training and Supervision Plan

- Assessment of the relation between methane concentrations and the methane fluxes of an artificial reference cow, Beijing, Sep 17, oral (2014)

- Design and validation of an artificial reference cow for breath measurements of cows in cubicles, Chongqiang, 25 Oct, oral (2015)

\section{In-Depth Studies (10 credits)}

- Fundamentals of Ventilation, Indoor Air Quality, Air Motion and Emissions (2012)

\section{Professional Skills Support Courses (4 credits)}

- $\quad$ Techniques for Writing and presenting a scientific paper (TWP) (2014)

- Information Literacy including EndNote introduction (ILP) (2011)

- $\quad$ Scientific writing (2014)

- $\quad$ A tailor made English writing course (2014)

\section{Research Skills Training (6 credits)}

- $\quad$ Preparing own $\mathrm{PhD}$ research proposal

\section{Didactic Skills Training (3 credits)}

Supervising theses

- $\quad$ MSc major thesis (2014)

- $\quad$ BSc thesis (2015)

\section{Education and Training Total (36 credits)}

* one ECTS credit equals a study load of approximately 28 hours 


\section{Curriculum vitae}

\section{Curriculum vitae}

Liansun Wu (吴联笋) was born on $19^{\text {th }}$ March, 1986 in WenZhou, ZheJiang Province, China. In 2004, he graduated from Cangnan Senior High School. After that, he left his hometown and studied Bioenvironmental and Bioenergy Engineering at China Agricultural University in Beijing. In 2008, he continued to pursue his master degree at China Agricultural University. During his MSc studies, he worked on a thesis entitled 'Development of a cooling unit using underground water for dairy bull pen in summer'. After he received his master degree in 2010, he successfully received a scholarship from the China Scholarship Council. In March 2011, he moved to the Netherlands and started his $\mathrm{PhD}$ research in Wageningen University. During his PhD study, he worked on the thesis 'Measurement methods to assess methane production of individual dairy cows in a barn' in Farm Technology Group and the Wageningen Livestock Research institute. 
Colophon

\section{Colophon}

Funding This study was funded by Wageningen UR Livestock Research, the Ministry of Economic Affairs of the Netherlands (Research Programme Sustainable Agriculture, KB-12-006.03-002), and the China Scholarship Council.

\section{Cover design Liansun $\mathrm{Wu}$}

Printing GVO drukkers \& vormgevers B. V., Ede, the Netherlands 


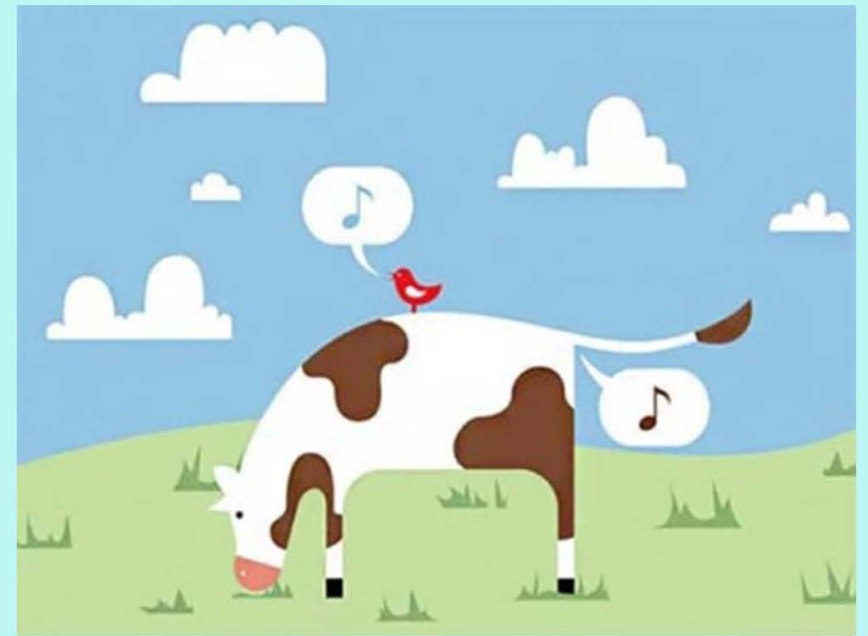

